*ak RMIS View/Frint Document Cover Sheet tow

This document was retrieved from the Documentation and Records Manaqement (DRM) ISEARCH System. It is intended for Information only and may not be the most recent or updated version. Contact a Document Service Center (see Hanford Info for locations) if you need additional retrieval information.

Accession \#: D196054094

Document \#: SD-MP-SRID-002

Title/Desc:

WHC STANDARDS REQUIREMENTS IDENTIFICATION DOCUMENT

Pages: 383 


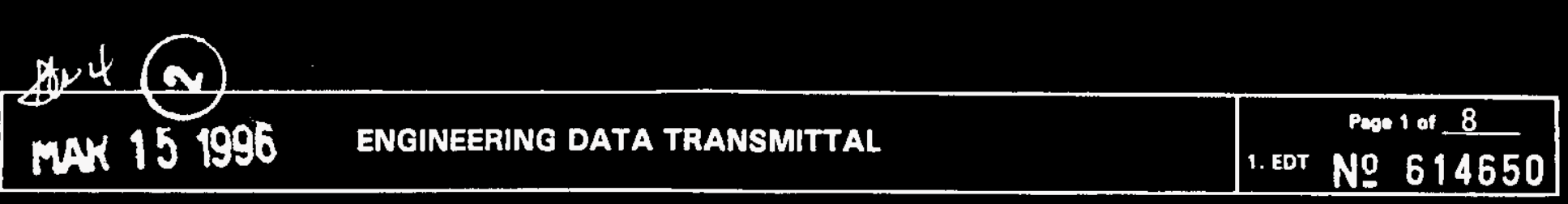

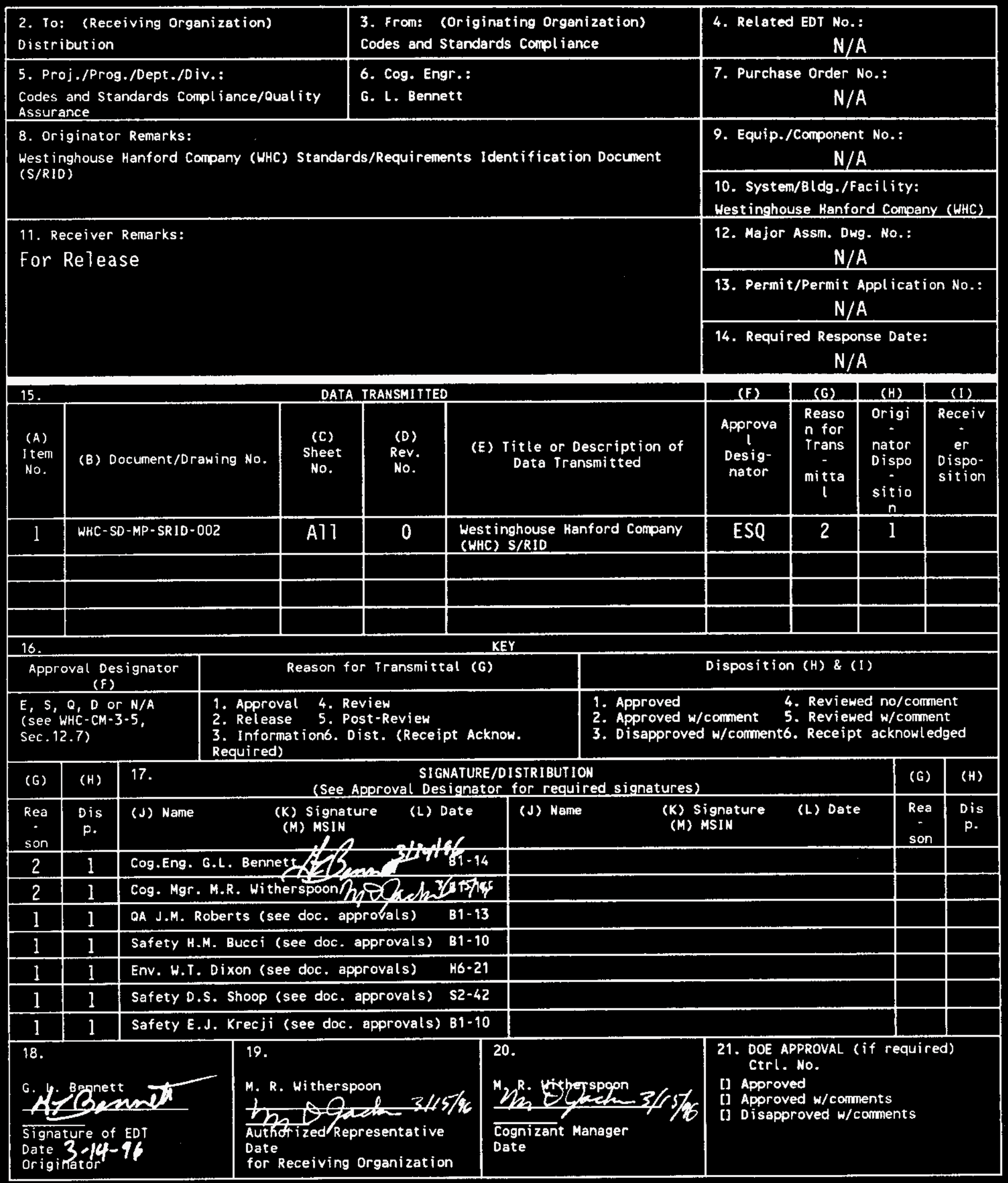

BD-7400-172-2 (04/94) GEF097 
INSTRUCTIONS FOR COMPLETION OF THE ENGINEERING DATA TRANSMITTAL. (USE BLACK INK OR TYPE)

\begin{tabular}{|c|c|}
\hline$\frac{\text { BLOCK }}{(11)}$ & $\frac{\text { THTLE }}{\text { EDT }}$ \\
\hline (2) & To: (Receiving Organization) \\
\hline (3) & From: OOriginating Organization \\
\hline (4) & Related EDT No. \\
\hline$(5)^{*}$ & Proj./Prog./Dept./Div. \\
\hline$(6)^{*}$ & Cosnizant Engineor \\
\hline$(7)$ & Rurchase Order No. \\
\hline$(8)^{*}$ & Oripinator Ramarks \\
\hline (9) & Equipment/Component No. \\
\hline (10) & Syatem/BIdg./Facility \\
\hline (11) & Receiver Remarke \\
\hline (12) & Mojor Assm. Dwo. No. \\
\hline (13) & Permit/Permit Application No. \\
\hline$(14)$ & Required Response Date \\
\hline
\end{tabular}

(15) * Data Transmitted

$(A)^{*}$ Item Number

(B) - Document/Drawing No.

(C) ${ }^{-}$Sheet No.

(D). Rev. No.
(E) Title or Description of Data Transmittod

(F)• Approval Designator

(G) Reason for Transmittal

(H) Originator Disposition

(I) Receiver Disposition

(16) Koy

(17)

\section{Signsture/Distribution}

(G) Reason
(H) Disposition
(J) Name
$(K)^{\circ}$ Signature
(L) Date
(M) MSIN

Signature of EDT Originator tor Peceiving Organization

(201 ${ }^{\circ}$ Cognizant Manager

(21) DOE Approval
- Pro-assigned EDT number.

- Enter the individual's name, title of the organization, or entity (0.8., Distribution) that the EDT is being transmitted to.

- Enter the titlo of the organization originating and transmitting the EDT.

- Enter EDT numbere which relate to the data being tranemittod.

- Enter the Project/Program/Department/Division titie or Project/Program acronym or Project Number, Work Order Number or Organization Code.

- Enter the name of the individual identified as being responsible for coordinating diaportion of the EDT.

- Enter relatod Purchase Order (P. O.) Number, if availablo.

- Enter special or additional comments concerning tranemittal, or "Key" retrieval words may be entered.

- Enter equipment/component number of affected item, if appropriate.

- Enter applicable system, building or facility number, if appropriato.

- Enter special or additional comments concerning transmittal.

- Enter applicable drawing number of major assembly, if appropriate.

- Enter applicable permit or permit application number, if appropriate.

- Enter the date a response is required from individuals identified in Block 17 (Signature/Distribution).

- Enter sequential number, beginning with 1, of the information listed on EDT.

- Enter the unique identification number assigned to the document or drawing being tranemitted.

- Enter the sheet number of the information being transmitted. If no sheet number, leave blank.

- Enter the revision number of the information being transmitted. If no revision number, loavo blank.

- Enter the titile of the document or drawing or a brief description of the subject if no titlo in identified.

- Enter the appropriate Approval Designator (Block 15). Also, indicate the appropriato approvals for each item listed, i.e.. SO, ESO, otc.

- Enter the appropriate code to identify the purpose of the data transmittal (see Block 16 ).

- Enter the sppropriate disposition code (see Block 16 ).

- Enter the appropriate disposition code (see Block 16).

- Number codes used in completion of Blocks 15 (G). (H), and (I), and 17 (G), (H) (Signature/Distribution).

- Enter the code of the reason for transmittal (Block 16 ).

- Enter the code for the disposition (Block 16).

- Enter the signature of the individual completing the Disposition $17(\mathrm{H})$ and the Transmittel.

- Obtain appropriate signature(s).

- Enter date signature is obtained.

- Enter MSIN. Note: If Distribution Sheet it used, show entire distribution fincluding that indicated on Page 1 of the EDT) on the Distribution Sheet.

- Enter the signature and date of the individual originating the EDT Contered prior to tranamittal to Receiving Organization). If the EDT originator is the cognizant engineer, sign both Blocks 17 and 18

- Enter the signature and dote of the individual identified by the Receiving Organization as authorized to approve disposition of the EDT and acceptance of the dats transmitted, as applicable.

- Enter the signature and date of the cognizant manager. (This signature is authorization for release.1

- Enter DOE approval (if required) by signature or control number that tracks the approval to a signature, and indicate DOE action. 


\section{WESTINGHOUSE HANFORD COMPANY}

\section{STANDARDS}

\section{REQUIREMENTS}

IDENTIFICATION

DOCUMENT

FUNCTIONAL AREA

Management Systems

\section{SIGNATURES}

Interpretive Authority:

Mn $\theta$ yackesm for $3 / 4 / 96$

J. M. Roberts 


\section{WESTINGHOUSE HANFORD COMPANY}

\section{STANDARDS}

\section{REQUIREMENTS}

\section{IDENTIFICATION}

\section{DOCUMENT}

FUNCTIONAL AREA

Quality Assurance

SIGNATURES

Interpretive Authority:

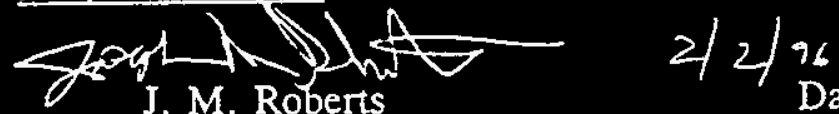




\section{WESTINGHOUSE HANFORD COMPANY}

\section{STANDARDS}

\section{REQUIREMENTS}

\section{IDENTIFICATION}

DOCUMENT

\section{FUNCTIONAL AREA}

Fire Protection

\section{SIGNATURES}

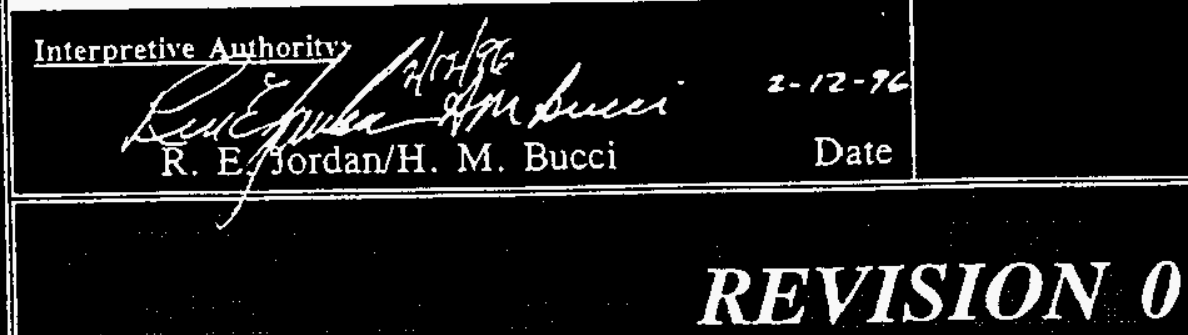




\section{WESTINGHOUSE HANFORD COMPANY}

STANDARDS

\section{REQUIREMENTS}

\section{IDENTIFICATION}

DOCUMENT

FUNCTIONAL AREA

Nuclear Safety

\section{SIGNATURES}

Interpretive Authority:
$E 2$ Xrgei
E. J. Krejć
$2-1-96$
Date

\section{REVISION 0}




\section{WESTINGHOUSE HANFORD COMPANY}

\section{STANDARDS}

\section{REQUIREMENTS}

\section{IDENTIFICATION}

DOCUMENT

\section{FUNCTIONAL AREA}

Occupational Safety \& Health

\section{SIGNATURES}

hterpretivg Aughoritv:

D.S.Shoop/J. R. Bell 2/12/96 Date

\section{REVISION 0}




\section{WESTINGHOUSE HANFORD COMPANY}

\section{SYANDARDS}

\section{REQUIREMENTS}

\section{IDENTIFICATION}

\section{DOCUMENT}

\section{FUNCTIONAL AREA: \\ Environmental Protection}

\section{SIGNATURES}

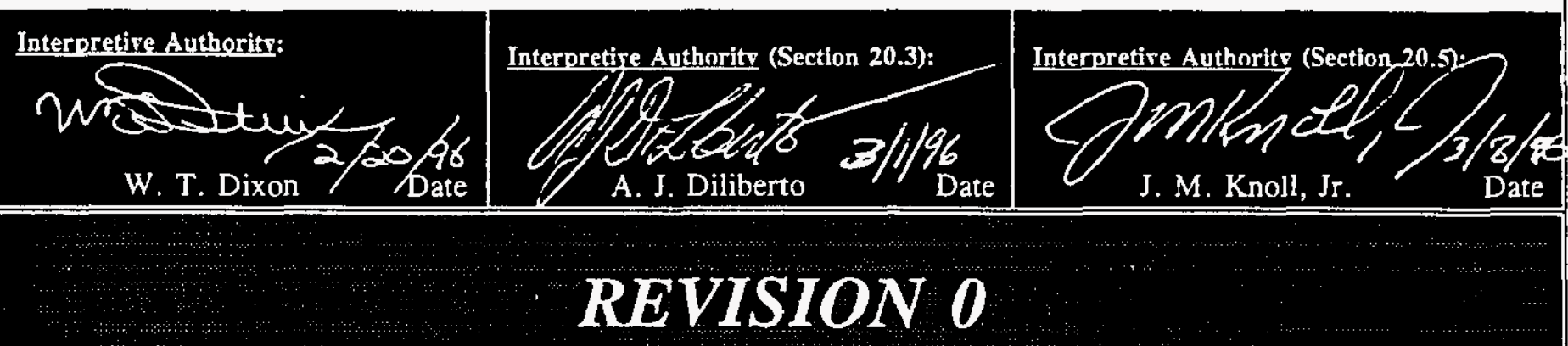




\title{
Westinghouse Hanford Company (WHC) Standards/Requirements Identification Document (S/RID)
}

\author{
Greg L. Bennett \\ West inghouse Hanford Company, Richland, WA 99352 \\ U.S. Department of Energy Contract DE-AC06-87RL10930
EDT/ECN: $614650 \quad$ UC: 630
Org Code: 38700 Charge Code: MDMCD
B\&R Code: YN0100000 Total Pages:s\%? \\ Key Words: Westinghouse Hanford Company (WHC), S/RID, \\ Standards/Requirements Identification Document
}

Abstract: This Standards/Requirements Identification Document (S/RID) sets forth the Environmental Safety and Health (ES\&H)

standards/requirements for Westinghouse Hanford Company Level Programs, where implementation and compliance is the responsibility of these organizations. These standards/requirements are adequate to ensure the protection of the health and safety of workers, the public, and the environment.

TRADEMARK DISCLAIMER. Reference herein to any specific commercial product, process, or service by trade name, trademark, manufacturer, or otherwise, does not necessarily constitute or imply its endorsenent, recomendation, or favoring by the United States Government or any agency thereof or its contractors or subcontractors.

Printed in the United States of Anerica. To obtain copies of this document, contact: uHC/Bcs Docunent Control Services, P.O. Box 1970, Mailstop 16-08, Richlagd un 0935 ? Phone (509) 372-2620. Fax (509) 376-4989.
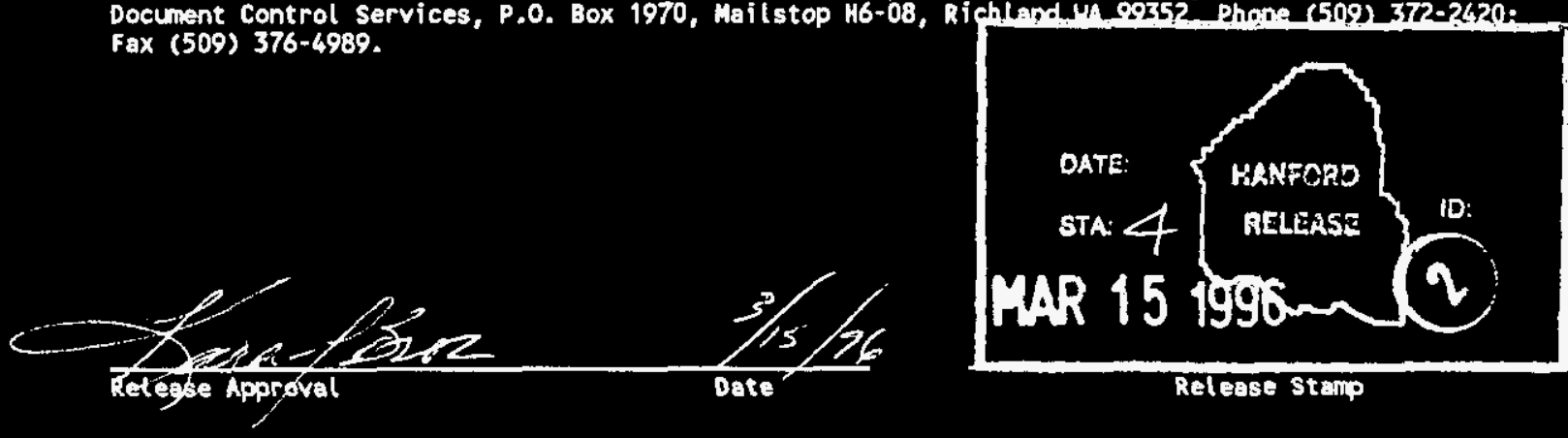

Release Stamp

\section{Approved for Public Release}


THIS PAGE INTENTIONALLY

IHFT BLANK

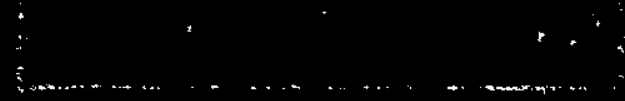


Westinghouse Hanford Company (WHC)

Standards/Requirements Identification Document

1.0 Management Systems
WHC-SD-MP-SRID-002

January 10, 1996

Rev. 0

Page i of $i$

\section{TABLE OF CONTENTS}

1.0 MANAGEMENT SYSTEMS

1.1

1.1 .1

1.1 .2

1.1 .3

1.1 .4

1.2

1.3

1.4

1.5

1.6

1.6.1

1.6 .2

1.6 .3

1.6 .4

1.7

1.8

1.8.1

1.8 .2

1.8 .3

1.9

1.10
MANAGEMENT AND ADMINISTRATION

Policies, Plans, and Procedures

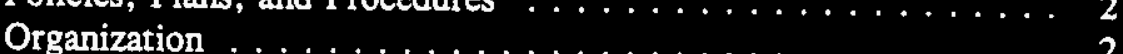

Staffing $\ldots \ldots \ldots \ldots \ldots \ldots \ldots \ldots 2_{2}$

Training and Qualification $\ldots \ldots \ldots \ldots \ldots \ldots, 2$

POLICY AND PROCEDURES $\ldots \ldots \ldots \ldots \ldots \ldots \ldots \ldots \ldots$

ISSUE MANAGEMENT $\ldots \ldots \ldots \ldots \ldots \ldots \ldots \ldots \ldots$

COMPLIANCE MANAGEMENT $\ldots \ldots \ldots \ldots \ldots \ldots \ldots 6$

MANAGEMENT EVALUATIONS $\ldots \ldots \ldots \ldots \ldots \ldots \ldots$

OCCURRENCE REPORTING $\ldots \ldots \ldots \ldots \ldots \ldots \ldots \ldots$

Identification and Categorization $\ldots \ldots \ldots \ldots \ldots \ldots \ldots$

Notification and Reporting $\ldots 1511 \mathrm{X} \ldots \ldots \ldots \ldots \ldots \ldots 7$

Investigation $\ldots \ldots \ldots \ldots \ldots \ldots \ldots \ldots \ldots \ldots$

Tracking

OPERATIONAL READINESS REVIEWS

10

DOCUMENT AND DATABASE CONTROL - RECORDS

MANAGEMENT $\ldots \ldots \ldots \ldots \ldots \ldots \ldots \ldots \ldots \ldots \ldots$

Control $\ldots \ldots \ldots \ldots \ldots \ldots \ldots \ldots \ldots \ldots \ldots \ldots$

Storage $\ldots \ldots \ldots \ldots \ldots \ldots \ldots \ldots \ldots \ldots \ldots \ldots 43$

Retention and Disposal $\ldots \ldots \ldots \ldots \ldots \ldots \ldots \ldots . \ldots 49$

KEY INTERFACES $\ldots \ldots \ldots \ldots \ldots \ldots \ldots \ldots \ldots \ldots$

REFERENCES $\ldots \ldots \ldots \ldots \ldots \ldots \ldots \ldots \ldots \ldots \ldots \ldots$

1.10 .1

1.10 .2

Requirement Source Documents . . . . . . . . . . . . . . . 61

Reviewed Documents Not Used as Requirement Sources . . . . 61 
This page intentionally leit blenk. 


\subsection{MANAGEMENT SYSTEMS}

\section{INTRODUCTION}

A Standards/Requirements Identification Document (S/RID) sets forth the Environmental Safety and Health (ES\&H) standards/requirements. This S/RID is applicable to the appropriate life cycle phases of design, construction, operation, and decommissioning for each of the categories of facilities addressed in Revision 5 of the Department of Energy Implementation Plan for the Defense Nuclear Facilities Safety Board (DNFSB) Recommendation 90-2. This Recommendation calls for the strengthening of DOE weapons complex activities through the identification and application of relevant DOE Orders, regulations, industry codes/standards, industry guidance documents and, as appropriate, good industry practices. These standards/requirements are adequate to ensure protection of the health and safety of workers, the public, and the environment.

The Westinghouse Hanford Company S/RID, as defined in Revision 5 of the Department of Energy Implementation Plan for DNFSB Recommendation 90-2, contains standards/requirements applicable company-wide that are necessary for safe operation of the site and its associated facilities, and that are not the direct responsibility of a specific facility manager (e.g., a company-wide fire department). Facility S/RIDs contain standards/requirements applicable to a specific facility that are the direct responsibility of the facility manager.

\section{SCOPE}

The requirements of the Management Systems Functional Area are selected to ensure adequate protection for the health and safety of the worker and public, and protection of the environment for nuclear facilities. Company-level requirements are those requirements which are implemented by a central organization for the entire company. Examples include Fire Department, General Employee Training and Dosimetry. Therefore, some requirements contained in this document may be intentionally duplicated in facility S/RIDs. This was necessary to capture shared implementation responsibilities occurring at both the company and facility level. 


\section{Policies, Plans, and Procedures}

See section 1.2 for requirements.

1.1 .2

$\underline{1.1 .3}$

\section{1 .4}

\section{2}

1.3

\section{Orcanization}

The requirements for this subelement are included in the Quality Assurance Functional Area.

\section{Stafiing}

General and detailed requirements applicable to personnel selection and staffing are identified in the Training and Qualification (T\&Q) Functional Area.

\section{Training and Oualification}

\section{POLICY AND PROCEDURES}

Westinghouse Hanford Company level organizations are responsible for maintaining and updating site manuals which are used as implementing documents by WHC facilities.

\section{REQUIREMENT SOURCE: 10CFR830 Part 120(c)(1)(iv)}

"Documents and Records. Documents shall be prepared, reviewed, approved, issued, used, and revised to prescribe processes, specify requirements, or establish design. Records shall be specified, prepared, reviewed, approved, and maintained."

\section{REQUIREMENT SOURCE: 10CFR830 Part 120(c)(2)(i)}

"Work Processes. Work shall be performed to established technical standards and administrative controls using approved instructions, procedures, or other appropriate means. Items shall be identified and controlled to ensure their proper use. Items shall be maintained to prevent their damage, loss, or deterioration. Equipment used for process monitoring or data collection shall be calibrated and maintained."

\section{ISSUE MANAGEMENT}

\section{REQUIREMENT SOURCE: 10CFR708 Part 3}

"It is the policy of DOE that employees of contractors at DOE facilities should be able to provide information to DOE, to Congress, or to their contractors concerning violations of law, danger to health and safety, or matters involving mismanagement, gross waste of funds, or abuse of authority, to participate in proceedings conducted before Congress or pursuant to this part, and to refuse to engage in illegal or dangerous activities without fear of employer reprisal. Contractor employees who believe they have been subject to such reprisal may submit their complaints to DOE for review and appropriate administrative remedy as provided in $\$ \$ 708.6$ through 708.11 of this part." 


\section{REQURREMENT SOURCE: 10CFR830 Part 120(c)(1)(iii)}

"Quality Improvement. Processes to detect and preveat quality problems shall be established and implemented. Items, services, and processes that do not meet established requirements shall be identified, controlled, and corrected according to the importance of the problem and the work affected. Correction shall include ideatifying the causes of problems and working to prevent recurrence. Item characteristics, process implementation, and other quality-related information shall be reviewed and the data analyzed to identify items, services, and processes needing improvement."

\section{REQUIREMONT SOURCE: DOE5480.29 Preamble, Section 5.b}

"Employee concern reports shall be managed in a manner that assures prompt identification, prioritization, evaluation, corrective and protective response, and resolution of employee concerns raised by DOE, contractor, and subcontractor employees;"

\section{REQUIREMIENT SOURCE: DOE5480.29 Preamble, Section 9.f(1) and (2)}

"Employee concerns shall be processed within the following timeframes:

(1) Acknowledgement regarding priority determination and the established resolution schedule will be available to the originator within 5 working days of receipt of the concern;

(2) All evaluations shall be completed within 30 working days of assignment;"

\section{REQUIREMENT SOURCE: RLID5480.29 Attachment 1, Section 8.b(1)}

"The RL Contractor ECM:

Submits program documentation (such as written procedures and forms), and any subsequent modifications of its ECP, to the RL ECM for review."

\section{REQUIREMENT SOURCE: RLID5480.29 Attachment 1, Section 8.b(2)}

"The RL Contractor ECM:

Assigns each new employee concern a unique number, enters the employee concern report in a formal tracking system, and generates an Employee Concerns Record."

\section{REQUREMENT SOURCE: RUID5480.29 Attachment 1, Section 8.b(3)}

"The RL Contractor ECM:

Reviews and approves its subcontractor's ECP documentation (such as written procedures and forms) and any subsequent modifications."

\section{REQUREMENT SOURCE: RLID5430.29 Attachment 1, Section 8.b(4)}

"The RL Contractor ECM:

Based upon review of the content of the employee concern, determines its significance and the need for an independent investigation. If such an investigation is needed: 
(a) Assigns an organization, deparment, division, or special investigator the responsibility to investigate the employee concern.

(b) Assures that the organizational element named in the employee concern is not directly involved in the investigation.

(c) Reviews investigation findings and concurs with recommended corrective actions and resolution schedules.

Otherwise arranges for an appropriate response to the concern and approves the adequacy of the response."

\section{REQURREMENT SOURCE: RLID5480.29 Attachment 1, Section 8.b(5)}

\section{"The RL Contractor ECM:}

Structures the resolution process according to the following criteria:

(a) The resolution of each employee concern at the lowest level of management possible is encouraged.

(b) Employees consider reporting employee concerns within their organization's ECP first.

(c) When compelling reasons exist for going outside their organization's ECP (such as fear of reprisal), Hanford contractor employees may report employee concerns directly to the RL ECP.

(d) If an employee feels that he/she has experienced a reprisal that is protected under 10 CFR 708, a complaint may be made directly to the RL ECP."

\section{REQUIREMINT SOURCE: RLID5480.29 Attachment 1, Section 8.b(6)}

"The RL Contractor ECM:

Obtains monthly status reports from subcontractor ECMs/Coordinators, which provide a status of employee concerns initiated, closed, or unresolved during the past month."

\section{REQUIREMINNT SOURCE: RUID5480.29 Attachment 1, Section 8.b(7)}

"The RL Contractor ECM:

Issues by the 5th of each month, to the RL ECP Manager, a status report of all employee concerns initiated, closed, or remaining unresolved (including subcontractors) during the past month. The monthly status reports should include:

(a) Employee Concern Report Number

(b) Priority (based on the potential "significance" of the employee concern)

(c) Title

(d) An evaluation of the employee concern

(e) Current resolution status (open or closed)

(f) Name of the individual responsible for investigating the employee concern

(g) Statistical summaries of the employee concerns (for trending)

(h) Significant issues or improvements and/or enhancement." 


\section{REQUIREMENT SOURCE: RLID5480.29 Attachment 1, Section 8.b(8)}

"The RL Contractor ECM:

Process employee concerns within the time period indicated by the following criteria:

(a) Acknowledgements regarding priority determinations and the established schedule for resolution of the employee concern are available within five working days.

(b) A status report is provided to the Contractor ECM by the assigned investigator within 15 working days.

(c) All investigations are normally completed within 30 working days from the receipt of the employee concern.

(d) Exceptions to the 30-day investigation requirement are documented by a written action plan (sent to the Contractor ECM) that explains why the employee concern is unresolved and provides a list of actions required to resolve the employee concern satisfactorily.

(e) "Significant" employee concerns that are not fully investigated within 30 days, or that are not documented by written action plans, are forwarded to the RL ECP Manager for follow-up."

\section{REQUIREMENT SOURCE: RUD5480.29 Attachment 1, Section 8.b(9)}

\section{"The RL Contractor ECM:}

Notifies the RL ECP Manager, within 24 hours of the determination, of all employee concerns that are not resolved within the specified time periods that meet one or more of the criteria, such as an employee concern involving an alleged reprisal, or that cannot be resolved to the Originator's satisfaction."

\section{REQUREMENT SOURCE: RUID5480.29 Attachment 1, Section 8.b(10)}

"The RL Contractor ECM:

Documents the resolution of employee concerns in monthly status reports and initiate remedial and corrective actions (such as design changes, personnel training, material changes, maintenance, or procedure revisions). In addition, document actions already taken to preclude, prevent, or mitigate future recurrences."

\section{REQULREMENT SOURCE: RLIDS480.29 Attachment 1, Section 8.b(11)}

"The RL Contractor ECM:

Ensures that every departing employee (due to reassignment, termination, retirement) has an opportunity to complete an Exit Interview Form. All completed Exit Interview Forms are transmitted to the ECM for review." 
Author's Note: This S/RID is being developed as part of the implementation of the requirements management process. It provides a primary tool of the compliance management program.

\section{MANAGEMINTT EVALUATIONS}

\section{REQUREMENT SOURCE: DOE5480.26 Section 7.a.(2)}

"Deparmental elements not included in the formal DOE PI Program shall internally establish and track operations using PIs appropriate to their organizations but are excluded from formal reporting requirements defined in DOE-STD-1048-92."

\section{OCCURRENCE REPORTING}

A Westinghouse Hanford Company level organization provides information to the facilities for implementation of lessons learned requirements at the facility level.

Emergency classification requirements are found in the WHC Emergency Management Functional Area.

\section{REQUTREMENT SOURCE: DOE-0-232.1 Part 4}

Author's Note: DOE Manual 232.1-1 provides detailed information for categorizing and reporting occurrences at DOE facilities. It complements DOE $O 232.1$ and its use is required by that Order.

"REQUIREMENTS.

DOE M 232.1-1, OCCURRENCE REPORTING AND PROCESSING OF OPERATIONS

INFORMATION, is required to implement this Order."

\section{REQUREMENT SOURCE: DOE-0-232.1 Part 4.c., and 4.c.(1)}

"Departmental Elements and contractors at facilities shall do the following:

(1) Develop or revise implementing procedures for the Occurrence Reporting Program at their facility to ensure appropriate categorization, notification, reporting, and investigating of events and/or conditions.

(a) On the effective date of this Order, all reporting requirements of this Order shall be implemented except for the submittal and approval of the site implementing procedures.

(b) Implementation procedures shall be submitted for approval to the respective DOE Secretarial Office within 4 months after approval of this Order.

(c) Implementation procedures submitted by the contractor or facility operator shail be considered automatically approved 2 months atter submittal, if they are not deliberately approved or rejected by DOE prior to the automatic approval.

(d) Pending approval of new or modified implementing procedures, the procedures approved and in effect as of the effective date of this Order may be used." 
Identification and Cateqorization

\section{REQUTRMENT SOURCE: DOE-0-232.1 Part 4.a.}

Author's Note: Only item (2) is applicable at the site level. Item (1) is the responsibility of the respective facility.

"Immediately following an occurrence, DOE-owned or -operated facility staff and operators shall:

(1) ensure that appropriate immediate response(s) are taken to stabilize or return the facility/operation to a safe condition; and

(2) identify and promptly notify the Facility Manager of abnormal events and conditions and record and archive appropriate information pertaining to such occurrences."

REQUTREMENT SOURCE: DOE-0-232.1 Part 4.b, and 4.b.(1)

Author's Note: Only item (b) is applicable at the site level. All other items which involve event categorizations are the responsibility of the respective facility.

"b. Departmental Elements and contractors responsible for DOE-owned or -operated facilities shall ensure a Facility Manager or Facility Manager Designee is available at all times to carry out the following requirements.

(1) Perform categorization of the event.

(a) If the event is categorized as an Emergency in accordance with the DOE 5500 series Orders, then make the notification of the Emergency as required in the DOE 5500 series Orders and prepare the written Occurrence Reports in accordance with this Order.

(b) If the event is not categorized as an Emergency, then categorize the event as an Unusual or Off-Normal Occurrence as soon as practical but, in all cases, within 2 hours of identification.

(c) If the category is not clear or the occurrence exceeds the threshold of more than one criteria, the occurrence shall be categorized at the higher level being considered. As an example, discovery of a defective item, material, or service, normally reportable as an Off Normal Occurrence, that caused the reduction of safety margin below that prescribed in the authorization basis, would be reported as an Unusual Occurrence.

(d) The occurrence category shall either be elevated, maintained, or lowered as information is made available."

1.6.2 Notirication and Reporting

Author's Note: Occurrence reporting and submittal is the responsibility of the respective facility.

\section{REQUIREMIENT SOURCE: 10CFR835 Part 1301(e)}

"Occurrence reports to DOE regarding emergencies and/or accidents shall be prepared and submitted in accordance with Departmental requirements for occurrence reporting and processing." 


\section{REQUIREMDNT SOURCE: 40CFR355 Part 40(b)(1)}

Author's Note: Although a site level organization is responsible for making initial offsite notifications of releases, the facility has the responsibility for supplying this organization with the pertinent information.

"Notice Requirements. The owner or operator of a facility subject to this section shall immediately notify the community emergency coordinator for the local emergency planning committee of any area likely to be affected by the release and the State emergency response commission of any State likely to be affected by the release. If there is no local emergency planning committee, notification shall be provided under this section to relevant local emergency response personnel."

\section{REQUTEMENT SOURCE: 40CFR355 Part 40(b)(2)}

"Emergency release notification. Notice requirements. The notice required under this section shall include the following to the extent known at the time of notice and so long as no delay in notice or emergency response results:

(i) The chemical name or identity of any substance involved in the release.

(ii) An indication of whether the substance is an extremely hazardous substance.

(iii) An estimate of the quantity of any such substance that was released into the environment.

(iv) The time and duration of the release.

(v) The medium or media into which the release occurred.

(vi) Any known or anticipated acute or chronic health risks associated with the emergency and, where appropriate, advice regarding medical attention necessary for exposed individuals.

(vii) Proper precautions to take as a result of the release, including evacuation (unless such information is readily available to the community emergency coordination pursuant to the emergency plan).

(viii) The names and telephone number of the person or persons to be contacted for further information."

\section{REQUIREMENT SOURCE: 40CFR355 Part 40(b)(3)}

"As soon as practicable after a release which requires notice under (b)(1) of this section, such owner or operator shall provide a written follow-up emergency notice setting forth and updating the information required under paragraph (b)(2) of this section, and including additional information with respect to:

(i) Actions taken to respond to and contain the release,

(ii) Any known or anticipated acute or chronic health risks associated with the release, and,

(iii) Where appropriate, advice regarding medical attention necessary for exposed individuals." 
REQURTMINNT SOURCE: DOE-0-232.1 Part 4.b.(2) Introduction

"Notify the DOE Facility Representative and the HQ Emergency Operations Center (HQ EOC) of an Unusual Occurrence as soon as practical but, in all cases, within 2 hours of categorization."

\section{REQUIREMENT SOURCE: DOE-0-232.1 Part 4.b.(3)}

"Prepare and submit a Notification Report as soon as practical but, in all cases, before the close of the next business day from the time of categorization (not to exceed 80 hours)."

REQULREMINT SOURCE: DOE-0-232.1 Part 4.b.(4)

"Prepare and submit an Update Report when significant and new information is available or upon request of DOE."

\section{REQUREMENT SOURCE: DOE-0-232.1 Part 4.b.(5)}

"Document any changes in categorization in an Update Report and submit before the close of the next business day from the time of recategorization (not to exceed 80 hours)."

\section{REQULREMINT SOURCE: DOE-0-232.1 Part 4.b.(6)}

"Prepare and submit a Final Report to the DOE Facility Representative when the root cause of the occurreace has been analyzed, corrective actions determined and scheduled, and lessons learned identified. Submit the Final Report as soon as possible, but no later than $\mathbf{4 5}$ calendar days after initial categorization."

\subsubsection{Investipation}

Investigation requirements are contained in the facility specific S/RIDs.

\section{$\underline{1.6 .4}$}

\section{Tracking}

\section{REQUREMENT SOURCE: DOE-0-232.1 Part 4.b.(7)}

Author's Note: Submittal of an Update Repon including a detailed explanation of the delay and estimated date for submittal of the Final Report is the responsibility of the respective facility.

"If the required analysis cannot be completed within 45 calendar days, submit an Update Report within the $\mathbf{4 5}$ days and include a detailed explanation of the delay and an estimated date for submittal of the Final Report."

\section{REQUREMIENT SOURCE: DOE-0-232.1 Part 4.b.(8)}

"If the Final Report was rejected by either the Facility Representative or Program Manager, prepare and resubmit the revised Final Report within 21 calendar days of disapproval." 


\section{REQUIREMIENT SOURCE: RLID5480.31 Section 6.e and 6.e(1)}

"RL contractors with responsibilities for performance of ORRs and RAs shall be required to:

(1) Prepare an implementing procedure for use in performing startup and restart activities in accordance with this Implementing Directive."

\section{REQUREMENT SOURCE: RLID5480.31 Section 6.e(4) thru (9)}

"(4) Notify RL of planned start-ups or restarts and proposed AA in accordance with this Implementing Directive.

(5) Conduct ORRs and RAs in accordance with the provisions of this Implementing Directive.

(6) Notify RL of readiness of the facility to startup or restart, after completion of the contractor ORR and RAs.

(7) Designate the Contractor ORR Team Leader assuring the Team Leader's independence from the facility.

(8) Designate the Contractor RA Team Leader assuring the team Leader's independence from the facility for new starts, or as specified in MOU for restarts.

(9) Provide a MOU for review and approval to the Assistant Manager RL when restarts of a facility do not require either an ORR or RA."

\section{DOCUMENT AND DATABASE CONTROL - RECORDS MANAGEMENT}

Author's Note: Additional records requirements are located in Section 1.2.

\section{REQURRMINT SOURCE: 36CFR1220 Part 30}

"Authority. Section 3101 of Title 44 of the U.S.C. requires the head of each Federal agency to make and preserve records containing adequate and proper documentation of the organization, functions, policies, decisions, procedures and essential transactions of the agency and designed to furnish the information necessary to protect the legal and financial rights of the Government and of persons directly affected by the agency's activities."

\section{REQUIREMINT SOURCE: 36CFR1220 Part 32(a)}

"Program content. Agency programs shall, among other things, provide for:

Cooperation with NARA in developing and applying standards, procedures, and techniques designed to improve the management of records, promote the maintenance and security of records deemed appropriate for permanent preservation, and facilitate the segregation and disposal of temporary records." 


\section{REQUREMENT SOURCE: 36CFR1220(950828) Part 42}

"Agency Internal evaluations. Each agency shall periodically evaluate its records management programs relating to records creation and recordkeeping requirements, maintenance and use of records, and records disposition. These evaluations shall include periodic monitoring of staff determinations of the record status of documentary materials, including electronic mail, and implementation of these decisions. These evaluations should determine compliance with NARA regulations in subchapter B of this chapter and assess the effectiveness of the agency's records management program."

\section{REQUIREMENT SOURCE: 36CFR1222 Part 10}

"Authority.

(a) 44 U.S.C. 2904, vests in the Archivist of the United States responsibility for providing guidance and assistance to Federal agencies with respect to ensuring adequate and proper documentation of the policies and transactions of the Federal Government, including developing and issuing standards to improve the management of records.

(b) 44 U.S.C. 3101, requires that the head of each Federal agency shall make and preserve records containing adequate and proper documentation of the organization, functions, policies, decisions, procedures, and essential transactions of the agency and designed to furnish the information necessary to protect the legal and financial rights of the Government and of persons directly affected by the agency's activities.

(c) 44 U.S.C. 3102, requires that the head of each Federal agency shall establish and maintain an active, continuing program for the economical and efficient management of the records of the agency. The program, among other things, shall provide for -

(1) Effective controls over the creation, and over the maintenance and use of records in the conduct of current business;

(2) Cooperation with the Administrator of General Services and the Archivist in applying standards, procedures, and techniques designed to improve the management of records, promote the maintenance and security of records deemed appropriate for preservation, and facilitate the segregation and disposal of records of temporary value."

\section{REQULREMINT SOURCD: 36CFR1222 Part 40}

"Removal of records. Agencies shall develop procedures to ensure that departing officials do not remove Federal records from agency custody."

\section{REQUIREMINT SOURCE: 36CFR1222 Part 42(a)}

"Removal of nonrecord materials. Nonrecord materials, including extra copies of agency records kept only for convenience of reference, may be removed from Government agencies only with the approval of the head of the agency of the individual authorized to act for the agency on matters pertaining to agency records." 


\section{REQUIREMINT SOURCE: 36CFR1222 Part 42(b) and (c)}

"(b) Agencies shail ensure that when nonrecord material containing classified information is removed from the executive branch, it is protected under conditions equivalent to those required of executive branch agencies. The originating agency or its successor in function retains control over access to such classified information, even after it is properly removed from the agency.

(c) Agencies shall ensure the appropriate protection of nonrecord material containing information which is restricted from release under the Privacy Act or other statutes, when such restricted nonrecord material is removed from Government agencies."

\section{REQUREMIENT SOURCE: 36CFR1222 Part 46}

"Recordkeeping requirements of other agencies. When statutes, regulations, directives or authoritative issuances of other agencies prescribe an agency's recordkeeping requirements, the agency so affected shall include these in appropriate directives or other authoritative issuances prescribing its organization, functions, or activities."

\section{REQUIREMENT SOURCE: 36CFR1222 Part 48}

"Data created or received and maintained for the Government by contractors.

(a) Contractors performing Congressionally-mandated program functions are likely to create or receive data necessary to provide adequate and proper documentation of these programs and to manage them effectively. Agencies shall specify the delivery to the Government of all data needed for the adequate and proper documentation of contractor-operated programs in accordance with requirements of the Federal Acquisition Regulation (FAR) and, where applicable, the Defense Federal Acquisition Regulation Supplement (DFARS).

(b) When contracts involve the creation of data for the Government's use, in addition to specifying a final product, agency officials may need to specify the delivery of background data that may have reuse value to the Government. Before specifying the background data that contractors must deliver to the agency, program and contracting officials shall consult with agency records and information managers and historians and, when appropriate, with other Government agencies to ensure that all agency and Government needs are met, especially when the data deliverables support a new agency mission or a new Government program.

(c) Deferred ordering and delivery-of-data clauses and rights-in-data clauses shall be included in contracts whenever necessary to ensure adequate and proper documentation or because the data have reuse value to the Government.

(d) When data deliverables include electronic records, the agency shall require the contractor to deliver sufficient technical documentation to permit the agency or other Government agencies to use the data.

(e) All data created for Government use and delivered to, or falling under the legal control of, the Government are Federal records and shall be managed in accordance with records management legislation as codified at 44 U.S.C. chapters 21, 29, 31, and 33, the Freedom of Information Act (5 U.S.C. 552), and the Privacy Act (5 U.S.C. 552a), and shall be scheduled for disposition in accordance with 36 CFR part 1228." 


\section{REQURJMENT SOURCE: 36CFR1222(950828) Part 50}

\section{"Records Maintenance}

(a) Agencies shall prescribe an appropriate records maintenance program so that complete records are filed or otherwise identified and preserved, records can be found when needed, the identification and retention of permanent records are facilitated, and permanent and temporary records are physically segregated or, for electronic records, segregable.

(b) Each Federal agency, in providing for effective controls over the maintenance of records, shall:

(1) Establish and implement standards and procedures for classifying, indexing, and filing records as set forth in GSA and NARA handbooks;

(2) Formally specify official file locations for records in all media and prohibit the maintenance of records at unauthorized locations;

(3) Formally specify which officials are responsible for maintenance and disposition of electronic records and which computer systems are used for recordkeeping;

(4) Standardize reference service procedures to facilitate the finding, charging out, and refiling of paper, audiovisual, and cartographic and architectural records, and to ensure that reference to electronic records minimizes the risk of unauthorized additions, deletions, or alterations;

(5) Make available to all agency employees published standards, guides, and instructions designed for easy reference and revision;

(6) Review its records maintenance program periodically to determine its adequacy; audit a representative sample of its paper, audiovisual, electronic, cartographic, and architectural files for duplication, misclassification, or misfiles;

(7) Maintain microform, audiovisual, and electronic records in accordance with 36 CFR parts 1230,1232 , and 1234 , respectively;

(8) Establish and implement procedures for maintaining records all nonrecord materials separately; ensure that record materials generated electronically are clearly identified as records and protected from unauthorized change or deletion for the length of their scheduled retention period; and

(9) Establish and implement procedures for the separate maintenance of any personal papers in accordance with \$1222.36."

\section{REQUIREMINT SOURCE: 36CFR1228 Part 72}

"Approval. No permanent or unscheduled records shall be loaned to non-Federal recipients without prior written approval from NARA. This authorization is not required for temporary loan of permanent and unscheduled records between Federal agencies." 


\section{REQUIREMENT SOURCE: 36CFR1228 Part 104}

"Reporting.

(a) The head of a Federal agency shall report any unlawful or accidental destruction, defacing, alteration, or removal of records in the custody of that agency to NARA (NIR) Washington, DC 20408. The report shall include:

(1) A complete description of the records with volume and dates if known;

(2) The office of origin;

(3) A statement of the exact circumstances surrounding the alienation, defacing, or destruction of the records;

(4) A statement of the safeguards established to prevent further loss of documentation; and

(5) When appropriate, details of the actions taken to salvage, retrieve, or reconstruct the records.

(b) This report has been cleared in accordance with 41 CFR Part 201-45 and assigned Interagency Report Control Number 0285-NAR-AR.

(c) The Archivist of the United States will assist the head of the agency in contacting the Attorney General for the recovery of any unlawfully removed records."

\section{REQUIREMENT SOURCE: 41CER201 Part 9, Section 103(a) thru (e)}

"Procedures.

(a) Assign specific responsibility for the development and implementation of agencywide records management programs to an office of the agency and to a qualified records manager.

(b) Consider the guidance contained in GSA and NARA handbooks and bulletins when establishing and implementing agency records management programs.

(c) Issue a directive establishing program objectives, responsibilities, authorities, standards, guidelines, and instructions for its records management program.

(d) Apply appropriate records management practices to all records, irrespective of the medium (e.g., paper, electronic, or other) on which the record resides.

(e) Control the creation, maintenance, and use of agency records and the collection and dissemination of information to ensure that the agency -

(1) Does not accumulate unnecessary records;

(2) Does not create forms and reports that collect information inefficiently or unnecessarily;

(3) Periodically reviews all existing forms and reports (both those originated by the agency and those responded to by the agency but originated by another agency or branch of Government) to determine if they need to be improved or canceled; 
(4) Maintains its records cost effectively and in a manner that allows them to be retrieved quickly and reliably; and

(5) Keeps its mailing and copying costs to a minimum."

\section{RELATED REFERENCES}

1. 41CFR201 Part 9, Section 101

2. 36CFR1220 Part 34

3. 36CFR1220 Part 36

4. 36CFR1222 Part 44

5. 44USC3102 All

6. 36CFR1222(950828) Part 32

\section{REQUIREMINNT SOURCE: 44USC3101 All}

"The head of each Federal agency shall make and preserve records containing adequate and proper documentation of the organization, functions, policies, decisions, procedures, and essential transactions of the agency and designed to furnish the information necessary to protect the legal and financial rights of the Government and of persons directly affected by the agency's activities."

\section{RELATED REFERENCES}

1. 36CFR1228 Part 20

2. 36CFR1222 Part 10

\section{REQUIREMENT SOURCE: 44USC3105 All}

"The head of each Federal agency shall establish safeguards against the removal or loss of records he determines to be necessary and required by regulations of the Archivist. Safeguards shall include making it known to officials and employees of the agency -

(1) that records in the custody of the agency are not to be alienated or destroyed except in accordance with sections $3301-3314$ of this title, and

(2) the penalties provided by law for the unlawful removal or destruction of records."

\section{REQUREMENT SOURCE: 44USC3312 AII}

"Photographs or microphotographs of records made in compliance with regulations under section 3302 of this title shall have the same effect as the originals and shall be treated as originals for the purpose of their admissibility in evidence. Certified or authenticated reproductions of the photographs or microphotographs shall be admitted in evidence equally with the original photographs or microphotographs."

\section{REQUTREMENT SOURCD: 44USC3506 All}

"(a) Each agency shall be responsible for carrying out its information management activities in an efficient, effective, and economical manner, and for complying with the information policies, principles, standards, and guidelines prescribed by the Director. 
(b) The head of each agency shall designate, within three months after the effective date of this Act, a senior official or, in the case of military departments, and the Office of the Secretary of Defense, officials who report directly to such agency head to carry out the responsibilities of the agency under this chapter. If more than one official is appointed for the military departments the respective duties of the officials shall be clearly delineated.

(c) Each agency shall -

(1) systematically inventory its major information systems and periodically review its information resources management activities;

(2) ensure its information systems do not overlap each other or duplicate the systems of other agencies;

(3) develop procedures for assessing the paperwork and reporting burden of proposed legislation affecting such agency;

(4) assign to the official designated under subsection (b) the responsibility for the conduct of and accountability for any acquisitions made pursuant to a delegation of authority under section 111 of the Federal Property and Administrative Services Act of 1949 (40 U.S.C. 759);

(5) ensure that information collection requests required by law or to obtain a benefit, and submitted to nine or fewer persons, contain a statement to inform the person receiving the request that the request is not subject to the requirements of section 3507 of this chapter; and (FOOTNOTE 1)

FOOTNOTE 1) So in original. The word "and" probably should not appear.

(6) implement applicable Government-wide and agency information policies, principles, standards, and guidelines with respect to information collection, paperwork reduction, statistical activities, records management activities, privacy and security of records, sharing and dissemination of information, acquisition and use of information technology, and other information resource management functions;

(7) periodically evaluate and, as needed, improve, the accuracy, completeness, and reliability of data and records contained within Federal information systems; and

(8) develop and annually revise a 5-year plan, in accordance with appropriate guidance provided by the Director, for meeting the agency's information technology needs.

(d) The head of each agency shall establish such procedures as necessary to ensure the compliance of the agency with the requirements of the Federal Information Locator System, including necessary screening and compliance activities."

\section{REQUIREMINT SOURCE: DOE1324.5B Preamble, Section 8.c(1) and (2)}

"(1) Develop and implement a records management program consistent with the requirements of Federal law, Code of Federal Regulations, DOE directives, DOE guidelines, and Departmentally established or accepted referenced standards.

(2) Ensure that all records management program requirements are kept current and available for review." 


\subsubsection{Control}

\section{REQUREMENT SOURCE: 36CFR1228 Part 184}

"Audiovisual records. Audiovisual records appraised as permanent should be transferred to the National Archives as soon as they become inactive or whenever the agency cannot provide proper care and handling of the materials (see part 1232 of this chapter) to guarantee their preservation. Additionally, the following policies shall govern the transfer of audiovisual records to the National Archives:

(a) Motion pictures. The following copies shall be considered necessary for the preservation, duplication, and reference service of motion pictures transferred to the National Archives of the United States. Agencies shall transfer all specified copies, if they exist.

(1) Agency-sponsored motion picture films for distribution (informational films):

(i) Original negative or color original plus separate optical sound track; and

(ii) Intermediate master positive or duplicate negative plus optical sound track; and

(iii) Sound projection print.

(2) Agency motion picture films made for internal use (program films):

(i) Original negative or color original plus sound, and

(ii) Projection print.

(3) Agency acquired motion picture films: Two projection prints.

(4) Unedited outtakes and trims (the discards of film productions) may be considered for deposit in the National Archives if they are properly arranged, labeled, and described and show unstaged, unrehearsed events of historical interest or historically significant phenomena. The following elements should be included:

(i) Original negative or color original; and

(ii) Work print.

(b) Still pictures. The following elements are necessary for the preservation, duplication, and reference service of each pictorial image transferred to the National Archives of the United States. Agencies shall transfer all specified copies, if they exist.

(1) For black and white photographs, an original negative and a captioned print. If the original negative is unstable safety, acetate, nitrate, or glass, a duplicate negative is also needed.

(2) For color photographs, the original color transparency or color negative, a captioned print, and an internegative if one exists.

(3) For slide sets, the original and a reference set, and the related audio recording and script if one exists. 
(4) For other pictorial records such as posters, original artwork, and filmstrips, the original and a reference print.

(c) Sound recordings. The following types of audio documents are necessary for the preservation, duplication, and reference service of sound recordings transferred to the National Archives of the United States. Agencies shall transfer all specified copies, if they exist.

(1) For conventional, mass-produced, or multiple-copy disc recordings, the master tape, the matrix or stamper of each sound recording, and a disc pressing of each recording.

(2) For magnetic sound recordings usually on audio tape (reel-to-reel, cassette, or cartridge), the original tape or the earliest generation of the recording available and a "dubbing" if one has been made.

(d) Video recordings. The original or the earliest generation of the video recording is necessary for the preservation, duplication, and reference service of this medium. A kinescope of the recording may be substituted.

(e) Finding aids and production documentation. The following records shall be transferred to the National Archives with the audiovisual records to which they pertain:

(1) Existing finding aids such as data sheets, shot lists, continuities, review sheets, catalogs, indexes, lists of captions, and other textual documentation that are necessary or helpful for the proper identification, retrieval, and use of the audiovisual records; and

(2) Production case files or similar files that include copies of production contracts, scripts, transcripts, and appropriate documentation bearing on the origin, acquisition, release, and ownership of the production."

\section{REQUIREMENT SOURCE: 36CFR1228 Part 186}

"The following classes of cartographic and architectural records appraised as permanent should be transferred to the National Archives as soon as they become inactive or whenever the agency cannot provide the proper care and handling of the materials to guarantee their preservation.

(a) Maps and charts.

(1) Manuscript maps; printed and processed maps on which manuscript changes, additions, or annotations have been made for record purposes or which bear manuscript signatures to indicate official approval; and single printed or processed maps that have been attached to or interfiled with other documents of a record character or in any way made an integral part of a record.

(2) Master sets of printed or processed maps in the custody of the agency by which they were issued. Such master sets should be kept segregated from the stock of maps heid for distribution and from maps received from other agencies. A master set should include one copy of each edition of a printed or processed map issued.

(3) Computer-related and computer-plotted maps that cannot be reproduced by the National Archives because of destruction of the magnetic tapes or other stored data or because of the unavailability of ADP equipment. 
(4) Index maps, card indexes, lists, catalogs, or other finding aids that may be helpful in using the maps transferred.

(5) Records related to preparing, compiling, editing, or printing maps, such as manuscript field notebooks of surveys, triangulation and other geodetic computations, and project folders containing specifications to be followed and appraisals of source materials to be used.

(b) Aerial photography and remote sensing innagery.

(1) Vertical and oblique negative aerial film, conventional aircraft.

(2) Annotated copy negatives, internegatives, rectified negatives, and glass plate negatives from vertical and oblique aerial film, conventional aircraft.

(3) Annotated prints from aerial film, conventional aircraft.

(4) Infrared, ultraviolet, multispectral (multiband), video, imagery radar, and related tapes, converted to a film base.

(5) Indexes and other finding aids in the form of photo mosaics, flight line indexes, coded grids, and coordinate grids.

(c) Architectural and related engineering drawings.

(1) Design drawings, preliminary and presentation drawings, and models which document the evolution of the design of a building or structure.

(2) Master sets of drawings which document the condition of a building or structure in terms of its initial construction and subsequent alterations. This category includes final working drawings, "as-built" drawings, shop drawings, and repair and alteration drawings.

(3) Drawings of repetitive or standard details of one or more buildings or structures.

(4) "Measured" drawings of existing buildings and original or photocopies of drawings reviewed for approval.

(5) Related finding aids and specifications to be followed."

\section{REQUTREMENT SOURCD: 36CFR1228 Part 188(a)}

"Electronic records.

Magnetic tape.

(1) Computer magnetic tape is a fragile medium, highly susceptible to the generation of error by improper care and handling. To ensure that permanently valuable information stored on magnetic tape is preserved, Federal agencies should schedule files for disposition as soon as possible after the tapes are written. When NARA has determined that a file is worthy of preservation, the agency should transfer the file to the National Archives as soon as it becomes inactive or whenever the agency cannot provide proper care and handling of the tapes (see part 1234 of this chapter) to guarantee the preservation of the information they contain.

(2) Agencies shall transfer electronic records to the National Archives either on open reel magnetic tape or on tape cartridges. Open reel magnetic tape shall be on one-half inch 7 or 9 
track tape reels recorded at 800,1600 , or 6250 bpi. Tape cartridges shall be 18 track 3480 -class cartridges recorded at 37,871 bpi. The data shall be written in ASCII or EBCDIC with all extraneous control characters removed from the data (except record length indicators for variable length records, or marks designating a datum, word, field, block or file), blocked at not higher than 32,760 bytes per block. The open reel magnetic tapes or the tape cartridges on which the data are recorded shall be new or recertified tapes (see part 1234 of this chapter) which have been passed over a tape cleaner before writing and shall be rewound under controlled tension."

\section{REQUIREMIENT SOURCE: 36CFR1228 Part 188(b)}

"Other magnetic media. When an electronic file that has been designated for preservation by NARA is maintained on a direct access storage device, the file shall be written on an open ree! magnetic tape or on a magnetic tape cartridge that meets the specifications in paragraph (a)(2) of this section. This tape copy shall be transferred to the National Archives."

\section{REQUIREMENT SOURCE: 36CFR1228 Part 188(c)}

"Documentation. Documentation adequate for servicing and interpreting electronic records that have been designated for preservation by NARA shall be transferred with them. This documentation shall include, but not necessarily be limited to completed NARA Form 14097, Technical Description for Transfer of Electronic Records, or its equivalent. Where it has been necessary to strip data of extraneous control characters (see paragraphs (a) and (b) of this section), the codebook specifications defining the data elements and their values must match the new format of the data. Guidelines for determining adequate documentation may be obtained from the Office of Records Administration (NI), National Archives and Records Administration, Washington, DC 20408."

\section{REQUIREMENT SOURCE: 36CFR1228(950828) Part 1(e)}

"The material was created or received on an electronic mail system and it meets the definition of record. For specific instructions on the disposition of records created or received on electronic mail systems, see 36 CFR 1234.32."

\section{REQUTREMENT SOURCE: 36CFR1230 Part 7}

"Agency responsibilities. The head of each Federal agency must ensure that the management of microform records incorporates the following elements:

(a) Assigning responsibility to develop and implement an agencywide program for managing all records on microform media and notifying the National Archives and Records Administration (N1), Washington, DC 20408 of the name and title of the person assigned the responsibility.

(b) Integrating the management of microform records with other records and information resources management programs of the agency.

(c) Incorporating microform records management objectives, responsibilities, and authorities in pertinent agency directives and disseminating them throughout the agency as appropriate.

(d) Establishing procedures for addressing records management concerns, including recordkeeping and disposition requirements, before approving new microform records systems or enhancements to existing systems. 
(e) Ensuring that adequate training is provided for the managers and users of microform records.

(f) Developing and securing NARA approval of records schedules covering microform records, and ensuring proper implementation of the schedule provisions.

(g) Ensuring that computerized indexes associated with microform records, such as in a computer-assisted retrieval(CAR) system, are scheduled in accordance with part 1234 of this chapter.

(h) Reviewing the agency's program periodically to ensure compliance with NARA standards in this part for the creation, storage, use, inspection, and disposition of microform records."

\section{REQURTMINT SOURCE: 36CFR1230 Part 10}

"Disposition authorization.

(a) Permanent or unscheduled records. Agencies must schedule the disposition of both source documents (originals) and microforms by submitting Standard Form (SF) 115, Request for Records Disposition Authority, to NARA in accordance with part 1228 of this chapter. Source documents may not be disposed of before NARA authorization is received. The original records shall not be destroyed after microfilming when NARA determines that the original records have intrinsic value or when NARA concludes that the microforms present reference problems because of the access restrictions, including security classification, or other characteristics of the original records.

(1) Agencies using microfilming methods and procedures meeting the standards in $\$ 1230.14$ shall include on the SF 115 the following certification: "This certifies that the records described on this form were (or will be) microfilmed in accordance with the standards set forth in 36 CFR part 1230."

(2) Agencies using microfilming methods, materials and procedures that do not meet the standards in \$1230.14(a) shall include on the SF 115 a description of the system and standards used.

(3) Agencies proposing to retain and store the silver original microforms of permanent records after disposal of the original records shall include on the SF 115 a statement that the agency's storage conditions shall comply with the standards of $\$ 1230.20$ and that the inspections required by $\$ 1230.22$ will be performed.

(b) Temporary records. Agencies do not need to obtain further NARA approval before disposing of scheduled temporary records that have been microfilmed. The approved retention period for temporary records shall be applied to microform copies of such records; the original records shall be destroyed upon verification of the microfilm, unless legal requirements preclude early destruction of the originals."

\section{REQUTREMTNT SOURCE: 36CFR1230 Part 12}

"Preparatory steps prior to filming.

(a) The integrity of the original records authorized for disposal shall be maintained by ensuring that the microforms are adequate substitutes for the original records and serve the purpose for 
which such records were created or maintained. Copies shall be complete and contain all information shown on the originals.

(b) The records shall be arranged, identified, and indexed so that any particular document or component of the records can be located. Each microform roll or fiche shall include accurate titling information on a titling target or header. At a minimum, titling information shall include the name of the agency and organization; the title of the records; the number or identifier for each unit of film; the security classification, if any; and the inclusive dates, names, or other data identifying the records to be included on a unit of film. For fiche, complete titling information may be placed as a microimage in frame 1 if the information will not fit on the header.

(c) Each microform shall contain an identification target showing the date of filming. When necessary to give the film copy better legal standing, the target shail also identify the person authorizing the microfilming. See ANSI/AIIM MS19-1987 for standards for identification targets.

(d) The following formats are mandatory standards for microforms.

(1) Roll film •

(i) Source documents. The formats described in ANSI/AIIM MS14-1988 must be used for microfilming source documents on $16 \mathrm{~mm}$ and $35 \mathrm{~mm}$ roll film. A reduction ratio of no greater than 1:24 is recommended for typewritten or correspondence type of documents. See ANSI/AIIM MS23-1991 for determining the appropriate reduction ratio and format for meeting the image quality requirements. When microfilming on $35 \mathrm{~mm}$ film for aperture card applications, the format dimensions in AIIM/MS32-1987, Table 1 are mandatory, the aperture card format "D Aperture" shown in ANSI/AIIM MS41-1988, Figure 1 must be used. The components of the aperture card, including the paper and adhesive, must conform to the requirements of ANSI IT9.2-1991. The 35mm film used in the aperture card application must conform to film designated as LES00 in ANSI/NAPM IT9.1-1992.

(ii) COM. Computer output microfilm (COM) generated images shall be the simplex mode described in ANSI/AIIM MS14-1988 at an effective ratio of 1:24 or 1:48 depending upon the application.

(2) Microfiche. For microfilming source documents or computer generated information (COM) on microfiche, the appropriate formats and reduction ratios prescribed in ANSI/AIIM MS5-1990 must be used as specified for the size and quality of the documents being filmed. See ANSI/AIIM MS23-1991 for determining the appropriate reduction ratio and format for meeting the image quality requirements.

(e) Index placement. -

(1) Source documents. When filming original (source) documents, all indexes, registers, or other finding aids, if microfilmed, shall be placed either in the first frames of the first roll of film or in the last frames of the last roll of film of a series or in the last frames of the last microfiche or microfilm jacket of a series.

(2) COM. Computer-generated microforms shall have the indexes following the data on a roll of film or in the last frames of a single microfiche, or the last frames of the last fiche in a series. Other index locations may be used only if dictated by special system constraints." 


\section{REQUIREMENT SOURCE: 36CFR1230 Part 14}

"Film and image requirements for permanent records or unscheduled records.

(a) Application. The following standards shall apply to the microfilming of permanent records where the original paper record will be destroyed or otherwise disposed of. Systems that produce original permanent records on microfilm with no paper originals, such as computer output microfilm (COM), must be designed so that they produce microfilm which meets the standards of this section. Unscheduled records from systems such as COM must also meet the standards of this section. Prior NARA approval of a SF 115 is required before unscheduled paper records are disposed of after microfilming.

(b) Film stock standards. Only polyester-based silver gelatin type film that conforms to ANSI/NAPM IT9.1-1992 for LE 500 film must be used in all applications.

(c) Processing standards. Microforms shall be processed so that the residual thiosulfate ion concentration will not exceed 0.014 grams per square meter in accordance with ANSU/NAPM IT9.1-1992. Processing shall be in accordance with processing procedures in ANSI/AIIM MS1-1988 and MS23-1991.

(d) Quality standards -

(1) Resolution -

(i) Source documents. The method for determining minimum resolution on microforms of source documents shall conform to the Quality Index Method for determining resolution and anticipated losses when duplicating as described in ANSI/AIIM MS23-1991 and MS43-1988. Resolution tests shall be performed using a NIST-SRM 1010a, Microcopy Resolution Test Chart (a calibrated and certified photographic reproduction) as specified in ISO 3334-1991 (the standard practice for using the test chart), and the patterns will be read following the instructions of ISO 3334-1991. The character used to determine the height used in the Quality Index formula shall be the smallest character used to display information. A Quality Index of five is required at the third generation level.

(ii) COM. Computer output microforms (COM) shall meet the requirements of ANSI/AIM MS1-1988.

(2) Background density of images. The background ISO standard visual diffuse transmission density on microforms shall be appropriate to the type of documents being filmed. The procedure for density measurement is described in ANSI/AIIM MS23-1991 and the densitometer shall be in accordance with ANSI/ISO 5/3-1984, for spectral conditions and ANSI IT2.19-1990, for geometric conditions for transmission density. Recommended visual diffuse transmission background densities for images of documents are as follows:

\begin{tabular}{lll}
\hline Classification & $\begin{array}{l}\text { Description of } \\
\text { document }\end{array}$ & Background density \\
\hline Group 1 & $\begin{array}{l}\text { High-quality, high- } \\
\text { contrast printed } \\
\text { books, periodicals, } \\
\text { and black typing }\end{array}$ & $1.3-1.5$ \\
\hline
\end{tabular}


Group 2

Group 3

Group 4

Group 5
Fine-line originals, black opaque pencil writing, and documents with small high-contrast printing

Pencil and ink drawings, faded printing, and very small printing, such as footnotes at the bottom of a printed page

Low-contrast manuscripts and drawings, graph paper with pale, fine-colored lines; letters typed with a worn ribbon; and poorly printed, faint documents

Poor-contrast documents (special exception) $0.7-0.85$

1.15-1.4

$1.0-1.2$

$0.8-1.0$$$
0.7-0.85
$$

Recommended visual diffuse transmission densities for computer generated images are as follows:

Film type

Silver gelatin

Process: Conventional

Density measurement method: Printing or diffuse

Min. Dmax*: 0.75

Max. Dmin*: 0.15

Minimum density difference: 0.60

Silver gelatin

Process: Full reversal

Density measurement method: Printing

Min. Dmax*: 1.50

Max. Dmin*: 0.20

Minimum density difference: 1.30

*Character or line density, measured with a microdensitometer or by comparing the film under a microscope with an image of a known density.

(3) Base plus fog density of films. The base plus fog density of unexposed, processed films should not exceed 0.10 . When a tinted base film is used, the density will be increased. The difference must be added to the values given in the tables in paragraph (d)(2) of this section. 
(4) Line or Stroke Width. Due to optical limitations in most photographic systems, film images of thin lines appearing in the original document will tend to fill in as a function of their width and density. Therefore, as the reduction ratio of a given system is increased, the background density shall be reduced as needed to easure that the copies produced will contain legible characters. "

\section{REQUREMIENT SOURCE: 36CFR1230 Part 16}

"Film and image requirements for temporary records, duplicates, and user copies.

(a) Temporary records with a retention period over 99 years. Agencies must follow the film and image requirements in $\$ 1230.14$.

(b) Other temporary records. Agencies must select an appropriate film stock that meets agency needs for temporary microforms to be kept for less than 100 years and ensures the preservation of the microforms for their full retention period. NARA does not require use of particular standards for processing microfilm of such temporary records; agencies may consult appropriate ANSI standards or manufacturer's instructions."

\section{REQUIREMENT SOURCE: 36CFR1230 Part 20}

"Storage.

(a) Permanent records. The conditions specified in ANSI PH1.43-1985 and ANSI IT9.2-1988, are required for storing permanent microform records.

(b) Temporary records. Temporary microform records can be stored under the same conditions as temporary paper records."

REQUTREMENT SOURCE: 36CFR1230 Part 22(a)(1) thru (4)

"Inspection.

(a) Permanent and unscheduled records.

(1) Master films of permanent records microfilmed in order to dispose of the original record, master films of permanent records originally created on microfilm, and other master films scheduled for transfer to the National Archives, must be inspected by the agency creating the film when the films are 2 years old and, until they are transferred to a Federal records center or to the National Archives, every 2 years thereafter. The inspection must be made in accordance with ANSI/AIIM MD45-1990.

(2) Microforms cannot be accepted for deposit with the National Archives of the United States until the first inspection (occurring after the microforms are 2 years old) has been performed. Permanent microforms may be transferred to a Federal records center only after the agency has performed the first inspection or has certified that the microforms will be inspected by the agency, an agency contractor, or the Federal records center (on a reimbursable basis) when they become 2 years old.

(3) To facilitate inspection, an inventory of microfilm must be maintained, listing each microform series/publication by production date, producer, processor, format, and results of previous inspections. 
(4) The elements of the inspection shall consist of:

(i) An inspection for aging blemishes following the guidelines in the ANSI/AIIMMS45-1990;

(ii) A rereading of resolution targets;

(iii) A remeasurement of density; and

(iv) A certification of the environmental conditions under which the microforms are stored, as specified in $\$ 1230.20(a)$. .

\section{REQUIREMENT SOURCE: 36CFR1230 Part 22(a)(5)}

"An inspection report must be prepared, and a copy must be furnished to NARA in accordance with $\$ 1230.26(b)$. The inspection report must contain:

(i) A summary of the inspection findings, including:

(A) A list of batches by year that includes the identification numbers of microfilm rolls and microfiche in each batch;

(B) The quantity of microforms inspected;

(C) An assessment of the overall condition of the microforms;

(D) A summary of any defects discovered, e.g., redox blemishes or base deformation; and

(E) A summary of corrective action taken.

(ii) A detailed inspection log created during the inspection that contains the following information:

(A) A complete description of all records inspected (title; roll or fiche number or other unique identifier for each unit of film inspected; security classification, if any; and inclusive dates, names, or other data identifying the records on the unit of film);

(B) The date of inspection;

(C) The elements of inspection (see subparagraph (a)(4) of this section);

(D) Any defects uncovered; and

(E) The corrective action taken."

\section{REQUTRMIENT SOURCE: 36CFR1230 Part 22(a)(0) and (7)}

"(6) An agency having in its custody a master microform that is deteriorating, as shown by the inspection, shall prepare a silver duplicate in accordance with $\$ 1230.14$ to replace the deteriorating master. The duplicate film will be subject to the 2-year inspection requirement before transfer to a Federal Record Center or the National Archives.

(7) Inspection must be performed in an environmentally controlled area in accordance with ANSI/AIIM MS45-1990." 


\section{REQUTREMIONT SOURCE: 36CFR1230 Part 22(b)}

"Temporary records. Inspection by sampling procedures described in $\$ 1230.22(a)$ is recommended but not required."

\section{REQUREMENT SOURCE: 36CFR1230 Part 24}

"Use of microform records.

(a) The silver gelatin original microform or duplicate silver gelatin microform created in accordance with $\$ 1230.14$ of this part (archival microform) must not be used for reference purposes. Duplicates must be used for reference and for further duplication on a recurring basis or for large-scale duplication, as well as for distribution of records on microform. Agency procedures must ensure that the archival microform remains clean and undamaged during the process of making a duplicating master.

(b) Agencies retaining the original record in accordance with an approved records disposition schedule may apply agency standards for the use of microform records."

\section{REQUIREMENT SOURCE: 36CFR1230 Part 26}

"Disposition of microform records. The disposition of microform records shall be carried out in the same manner prescribed for other types of records in part 1228 of this chapter with the following additional requirements:

(a) The silver gelatin original (or a silver gelatin duplicate negative microform record created in accordance with \$1230.14) plus one microform copy of each permanent record microfilmed by an agency, must be transferred to an approved agency records center, the National Archives of the United States, or to a Federal records center, at the time that the records are to be transferred in accordance with the approved records disposition schedule, SF 258, or other authorization for transfer. Non-silver copies must be packaged separately from the silver gelatin original or silver duplicate microform copy and labeled clearly as non-silver copies.

(b) The microforms shall be accompanied by:

(1) Information identifying the agency and organization; the title of the records; the number or identifier for each unit of film; the security classification, if any; the inclusive dates, names, or other data identifying the records to be included on a unit of film;

(2) Any finding aids relevant to the microform that are not contained in the microform; and

(3) The inspection $\log$ forms and inspection reports required by $\$ 1230.22(a)(5)$ and (6).

(c) The information required in this paragraph (b) shall be attached to the SF 135 when records are being transferred to a Federal records center and to the SF 258 when records are being transferred to the legal custody of the National Archives."

\section{REQUIREMINT SOURCE: 36CFR1232 Part 4(a)}

"Each Federal agency, in providing for effective controls over the creation of records, shall establish an appropriate program for the management of audiovisual records which program shall be governed by the following guidelines: 
(1) Prescribe the types of records to be created and maintained so that audiovisual operations and their products are properly documented (guidelines describing the appropriate types of records are in $\$ 1228.184$ of this chapter).

(2) For contractor-produced audiovisual records, establish contract specifications which will protect the Government's legal title and control over all such audiovisual media and related documentation.

(3) Keep inventories indicating the location of all generations of audiovisual records, whether in agency storage, a Federal records center, or in a commercial facility such as a laboratory or library distribution center.

(4) Schedule disposition of all audiovisual records as soon as practicable after creation, following the instruction in GRS 21, Audiovisual Records, or a specific agency records schedule approved by the Archivist of the United States. The scheduling of permanent records must take into account the different record elements identified in $\$ 1228.184$, and must always include related finding aids.

(5) Review agency audiovisual recordkeeping practices for possible improvement."

\section{REQULREMENT SOURCE: 36CFR1234(950828) Part 10}

"Agency responsibilities. The head of each Federal agency shall ensure that the management of electronic records incorporates the following elements:

(a) Assigning responsibility to develop and implement an agency-wide program for the management of all records created, received, maintained, used, or stored on electronic media; and notifying the National Archives and Records Administration, Office of Records Administration (NI), Washington, DC 20408 and the General Services Administration, Regulations Branch (KMPR), Washington, DC 20405, of the name and title of the person assigned the responsibility.

(b) Integrating the management of electronic records with other records and information resources management programs of the agency.

(c) Incorporating electronic records management objectives, responsibilities, and authorities in pertinent agency directives and disseminating them throughout the agency as appropriate.

(d) Establishing procedures for addressing records management requirements, including recordkeeping requirements and disposition, before approving new electronic information system or enhancements to existing systems.

(e) Ensuring that adequate training is provided for users of electronic mail systems on recordkeeping requirements, the distinction between Federal records and nonrecord materials, procedures for designating Federal records, and moving or copying records for inclusion in an agency recordkeeping system.

(f) Ensuring that adequate training is provided for users of electronic information system in the operation, care, and handling of the equipment, software, and media used in the system.

(g) Developing and maintaining up-to-date documentation about all electronic information system that is adequate to: Specify all technical characteristics necessary for reading or processing the records; identify all defined inputs and outputs of the system; define the contents of the files and records; determine restrictions on access and use; understand the 
purpose(s) and function(s) of the system; describe update cycles or conditions and rules for adding information to the system, changing information in it, or deleting information; and ensure the timely, authorized disposition of the records.

(h) Specifying the location, manner, and media in which electronic records will be maintained to meet operational and archival requirements, and maintaining inventories of electronic information system to facilitate disposition.

(i) Developing and securing NARA approval of records disposition schedules, and ensuring implementation of their provisions.

(j) Specifying the methods of implementing controls over national security-classified, sensitive, proprietary, and Privacy Act records stored and used electronically.

(k) Establishing procedures to ensure that the requirements of this part are applied to those electronic records that are created or maintained by contractors.

(l) Ensuring compliance with applicable Government-wide policies, procedures, and standards such as those issued by the Office of Management and Budget, the General Accounting Office, the General Services Administration, the National Archives and Records Administration, and the National Institute of Standards and Technology.

(m) Reviewing electroaic information system periodically for conformance to established agency procedures, standards, and policies as part of the periodic reviews required by 44 U.S.C. 3506. The review should determine if the records have been properly identified and described, and whether the schedule descriptions and retention periods reflect the current informational content and use. If not, or if substantive changes have been made in the structure, design, codes, purposes, or uses of the system, submit an SF 115, Request for Records Disposition Authority, to NARA."

\section{RELATED REFERENCES}

$\begin{array}{ll}\text { 1. } & \text { 36CFR1234(950828) Part 30(a) } \\ \text { 2. } & \text { 36CFR1234(950828) Part 30(b) } \\ \text { 3. } & \text { 36CFR1234(950828) Part 30(c) } \\ \text { 4. } & \text { 36CFR1234(950828) Part 30(d) } \\ \text { 5. } & \text { 36CFR1234(950828) Part 30(e) } \\ \text { 6. } & \text { 36CFR1234(950828) Part 30(f) } \\ \text { 7. } & \text { 36CFR1234(950828) Part 30(g) } \\ \text { 8. } & \text { 36CFR1234(950828) Part 30(h) } \\ \text { 9. } & \text { 36CFR1234(950828) Part 32 }\end{array}$

\section{REQUIREMENT SOURCE: 36CFR1234(950828) Part 20}

"Creation and use of data files.

(a) For electronic information system that produce, use, or store data files, disposition instructions for the data shall be incorporated into the system's design.

(b) Agencies shall maintain adequate and up-to-date technical documentation for each eiectronic information system that produces, uses, or stores data files. Minimum documentation required is a narrative description of the system; physical and technical characteristics of the records, including a record layout that describes each field including its name, size, starting or relative 
position, and a description of the form of the data (such as alphabetic, zoned decimal, packed decimal, or numeric), or a data dictionary or the equivalent information associated with a data base management system including a description of the relationship between data elements in data bases; and any other technical information needed to read or process the records."

\section{REQUIREMITNT SOURCE: 36CFR1234(950828) Part 22}

"Creation and use of text documents.

(a) Electronic recordkeeping system that maintain the official file copy of text documents on electronic media shall meet the following minimum requirements:

(1) Provide a method for all authorized users of the system to retrieve desired documents, such as an indexing or text search system;

(2) Provide an appropriate level of security to ensure integrity of the documents;

(3) Provide a standard interchange format when necessary to permit the exchange of documents on electronic media between agency computers using different software/operating systems and the conversion or migration of documents on electronic media from one system to another; and

(4) Provide for the disposition of the documents including, when necessary, the requirements for transferring permanent records to NARA (see $\$ 1228.188$ of this chapter).

(b) Before a document is created electronically on electronic recordkeeping system that will maintain the official file copy on electronic media, each document shall be identified sufficiently to enable authorized personnel to retrieve, protect, and carry out the disposition of documents in the system. Appropriate identifying information for each document maintained on the electronic media may include: office of origin, file code, key words for retrieval, addressee (if any), signator, author, date, authorized disposition (coded or otherwise), and security classification (if applicable). Agencies shall ensure that records maintained in such systems can be correlated with related records on paper, microform, or other media. "

\section{REQUIREMENT SOURCE: 36CFR1234(950828) Part 24 Introduction}

"Agencies shall manage records created or received on electronic mail systems in accordance with the provisions of this chapter pertaining to adequacy of documentation, recordkeeping requirements, agency records management responsibilities, and records disposition (36 CFR parts 1120,1222 , and 1228)."

\section{REQUIREMINT SOURCE: 36CFR1234(950828) Part 24(a)}

"Agency instructions on identifying and preserving electronic mail messages will address the following unique aspects of electronic mail:

(1) Some transmission data (names of sender and addressee(s) and date the message was sent) must be preserved for each electronic mail record in order for the context of the message to be understood. Agencies shall determine if any other transmission data is aeeded for purposed of context.

(2) Agencies that use an electronic mail system that identifies users by codes or nicknames or identifies addressees only by the name of a distribution list shall instruct staff on how to retain 
names on directories or distributions lists to ensure identification of the sender and addressee(s) of messages that are records.

(3) Agencies that use an electronic mail system that allows users to request acknowledgments or receipts showing that a message reached the mailbox or inbox of each addressee, or that an addressee opened the message, shall issue instructions to e-mail users specifying when to request such receipts or acknowledgments for recordkeeping purposes and how to preserve them.

(4) Agencies with access to external electronic mail systems shall ensure that Federal records sent or received on these systems are preserved in the appropriate recordkeeping system and that reasonable steps are taken to capture available transmission and receipt data as needed by the agency for recordkeeping purposes.

(5) Some e-mail systems provide calendars and task lists for users. These may meet the definition of Federal record. Calendars that meet the definition of Federal records are to be managed in accordance with the provisions of General Records Schedule 23, Item 5.

(6) Draft documents that are circulated on electronic mail systems may be records if they meet the criteria specified in 36 CFR 1222.34."

\section{REQUIREMENT SOURCE: 36CFR1234(950828) Part 24(b)}

"Agencies shall consider the following criteria when developing procedures for the maintenance of electronic mail records in appropriate recordkeeping systems, regardless of format.

(1) Recordkeeping systems that include electronic mail message must:

(i) Provide for the grouping of related records into classifications according to the nature of the business purposes the records serve;

(ii) Permit easy and timely retrieval of both individual records and files or other groupings of related records;

(iii) Retain the records in a usable format for their required retention period as specified by a NARA-approved records schedule;

(iv) Be accessible by individuals who have a business need for information if the system;

(v) Preserve the transmission and receipt data specified in agency instructions; and

(vi) Permit transfer of permanent records to the National Archives and Records Administration (see 36 CFR 1228.198 and 36 CFR 1234.32(a)).

(2) Agencies shall not store the recordkeeping copy of electronic mail messages that are Federal records only on the electronic mail system, unless the system has all of the features specified in paragraph (b)(1) of this section. If the electronic mail system is not designed to be a recordkeeping system, agencies shall instruct staff on how to copy Federal records from the electronic mail system to a recordkeeping system." 
REQULAMENT SOURCE: 36CFR1234(950828) Part 24(c)

"Agencies that maintain their electronic mail records electronically shall move or copy them to a separate electronic recordkeeping system uniess their system has the features specified in paragraph $(b)(1)$ of this section. Because they do not have the features specified in paragraph (b)(1) of the section, backup tapes should not be used for recordkeeping purposes. Agencies may retain records from electronic mail systems in an off-line electronic storage format (such as optical disk or magnetic tape) that meets the requirements described at 36 CFR 1234.30(a). Agencies that retain permanent electronic mail records scheduled for transfer to the National Archives shall either store them in a format and on a medium that conforms to the requirements conceming transfer at 36 CFR 1228.188 or shall maintain the ability to convert the records to the required format and medium at the time transfer is scheduled."

REQUIREMIENT SOURCE: 36CFR1234(950828) Part 24(d)

"Agencies that maintain paper files as their record keeping systems shall print the electronic mail records and the related transmission and receipt data specified by the agency."

\section{REQUIREMENT SOURCE: 36CFR1234(950828) Part 26}

"Judicial use of electronic records. Electronic records may be admitted in evidence to Federal courts for use in court proceedings (Federal Rules of Evidence 803(8)) if trustworthiness is established by thoroughly documenting the recordkeeping system's operation and the controls imposed upon it. Agencies should implement the following procedures to exhance the legal admissibility of electronic records.

(a) Document that similar kinds of records generated and stored electronically are created by the same processes each time and have a standardized retrieval approach.

(b) Substantiate that security procedures prevent unauthorized addition, modification or deletion of a record and ensure system protection against such problems as power interruptions.

(c) Identify the electronic media on which records are stored throughout their life cycle, the maximum time span that records remain on each storage medium, and the NARA-approved disposition of all records.

(d) Coordinate all of the above with legal counsel and senior IRM and records management staff."

\section{REQUTREMENT SOURCE: 36CFR1234(950828) Part 28}

"Security of electronic records. Agencies shall implement and maintain an effective records security program that incorporates the following:

(a) Ensures that only authorized personnel have access to electronic records.

(b) Provides for backup and recovery of records to protect against information loss.

(c) Ensures that appropriate agency personnel are trained to safeguard sensitive or classified electronic records.

(d) Minimizes the risk of unauthorized alteration or erasure of electronic records. 
(e) Ensures that electronic records security is included in computer systems security plans prepared pursuant to the Computer Security Act of 1987 (40 USC 759 note). "

\section{REQUIREMENT SOURCE: 36CFR1234(950828) Part 32}

"Retention of electronic records. Agencies shail establish policies and procedures to ensure that electronic records and their documentation are retained as long as needed by the Government. These retention procedures shall include provisions for:

(a) Scheduling the disposition of all electronic records, as well as related documentation and indexes, by applying General Records Schedules (particularly GRS 20 or GRS 23) as appropriate or submitting an SF 115, Request for Records Disposition Authority, to NARA (see part 1228 of this chapter). The information in electronic information system, including those operated for the Government by a contractor, shall be scheduled as soon as possible but no later than one year after implementation of the system.

(b) Transferring a copy of the electronic records and any related documentation and indexes to the National Archives at the time specified in the records disposition schedule in accordance with instructions found in $\$ 1228.188$ of this chapter. Transfer may take place at an earlier date if convenient for both the agency and the National Archives and Records Administration.

(c) Establishing procedures for regular recopying, reformatting, and other necessary maintenance to ensure the retention and usability of electronic records throughout their authorized life cycle (see \$1234.28).

(d) Electronic mail records may not be deleted or otherwise disposed of without prior disposition authority from NARA (44 USC 3303a). This applies to the original version of the record that is sent or received on the electronic mail system and any copies that have been transferred to a recordkeeping system. See 36 CFR 1228 for records disposition requirements.

(1) Disposition of records on the electronic mail system. When an agency has taken the necessary steps to retain the record in a recordkeeping system, the identical version that remains on the user's screen or in the user's mailbox has no continuing value. Therefore, NARA has authorized deletion of the version of the record on the electronic mail system under General Records Schedule 20, Item 14, after the record has been preserved in a recordkeeping system along with all appropriate transmission data.

(2) Records in recordkeeping systems. The disposition of electronic mail records that have been transferred to an appropriate recordkeeping system is governed by the records schedule or schedules that control the records in that system. If the records in the system are not scheduled, the agency shall follow the procedure at 36 CFR part 1228."

\section{REQUIREMENT SOURCE: 36CFR1234(950828) Part 34}

"Destruction of electronic records. Electronic records may be destroyed only in accordance with a records disposition schedule approved by the Archivist of the United States, including General Records Schedules. At a minimum each agency shall ensure that:

(a) Electronic records scheduled for destruction are disposed of in a manner that ensures protection of any sensitive, proprietary, or national security information. 
(b) Magnetic recording media previously used for electronic records containing sensitive, proprietary, or national security information are not reused if the previously recorded information can be compromised by reuse in any way.

(c) Agencies shall establish and implement procedures that specifically address the destruction of electronic records generated by individuals employing electronic mail."

\section{REQUTRMIENT SOURCE: 36CFR1236 Part 10, Sentence 2 and 3}

"The records may be maintained on a variety of media including paper, magnetic tape or disk, photographic film, and microfilm. The management of vital records is part of an agency's continuity of operations plan designed to meet emergency management responsibilities."

\section{REQUIREMINT SOURCE: 36CFR1236 Part 12}

"Heads of agencies are responsible for the vital records program under the following authorities:

(a) To make and preserve records containing adequate and proper documentation of the agency's organization, functions, policies, procedures, decisions, and essential transactions, and to furnish information to protect the legal and financial rights of the Government and of persons directly affected by the agency's activities ( 44 U.S.C. 3101).

(b) To perform national security emergency preparedness functions and activities (Executive Order 12656)."

\section{REQUIREMENT SOURCE: 36CFR1236 Part 20, Sentence 3}

"In carrying out the vital records program agencies shall:

(a) Specify agency staff responsibilities;

(b) Ensure that all concerned staff are appropriately informed about vital records;

(c) Ensure that the designation of vital records is current and complete; and

(d) Ensure that vital records and copies of vital records are adequately protected, accessible, and immediately usable."

\section{REQUTREMENT SOURCE: 36CFR1236 Part 22, Sentence 1 and 3}

"Vital records include emergency plans and related records that specify how an agency is to respond to an emergency as well as those records that would be needed to continue operations and protect legal and financial rights. Only the most recent and complete source of the vital information needs to be treated as vital records."

\section{REQUTRIMIENT SOURCE: 36CFR1236 Part 24}

"Agencies shall ensure that retrieval procedures for vital records require only routine effort to locate needed information, especially since individuals unfamiliar with the records may need to use them during an emergency or disaster. Agencies also shall ensure that all equipment needed to read vital records or copies of vital records will be available in case of emergency or disaster. For electronic records systems, agencies also shall ensure that system 
documentation adequate to operate the system and access the records will be available in case of emergency or disaster."

\section{REQUIREMENT SOURCE: 36CFR1236 Part 26 Introduction}

"Agencies shall take appropriate measures to ensure the survival of the vital records or copies of vital records in case of emergency or disaster. In the case of electronic records, this requirement is met if the information needed in the event of emergency or disaster is available in a copy made for general security purposes, even when the copy contains other information."

\section{REQUIREMENT SOURCE: 36CFR1236 Part 26(a), Sentence 1 thu 3}

"Duplication. Computer backup tapes created in the normal course of system maintenance or other electronic copies that may be routinely created in the normal course of business may be used as the vital record copy. For hard copy records, agencies may choose to make microform copies. Standards for the creation, preservation and use of microforms are found in 36 CFR part 1230, Micrographic Records Management."

\section{REQUIREMENT SOURCE: 36CFR1236 Part 26(b)}

"Storage. When agencies choose duplication as a protection method, the copy of the vital record stored off-site is normally a duplicate of the original record.... original vital records must be retained for the period specified in the agency records disposition schedule. The agency may store the original records off-site if protection of original signatures is necessary, or if it does not need to keep the original record at its normal place of business."

\section{REQUIREMENT SOURCE: 36CER1236 Part 26(c)(1), Sentence 1 and 3}

"Under certain circumstances, Federal records centers (FRC's) may store copies of emergency operating vital records. Prior to preparing the records for shipment, the agency must contact the FRC to determine if the center can accommodate the storage requirements and return copies in an acceptable period of time."

\section{REQUIREMENT SOURCE: 36CFR1236 Part 26(c)(2)}

"The off-site copy of legal and financial rights vital records may be stored at an off-site agency location or, in accordance with $\$ 1228.156$ of this chapter, at an FRC."

\section{REQUREMENT SOURCE: 36CFR1236 Part 26(c)(3)}

"... the agency must specify on the SF 135, Records Transmittal and Receipt, that they are vital records (duplicate copies) and the medium on which they are maintained. The agency shall also periodically cycle (update) them by removing obsolete items and replacing them with the most recent version, when necessary."

\section{REQUREMINT SOURCE: 36CFR1236 Part 26(c), Sentence 2 and 4}

"Copies of emergency operating vital records need to be accessible in a very short period of time for use in the event of an emergency or a disaster. In deciding where to store vital records copies, agencies shall treat records that have the properties of both categories, that is, emergency operating and legal and financial rights records, as emergency operating records." 


\section{REQUIREMIENT SOURCE: 36CFR1236 Part 28}

"The disposition of original vital records is governed by records schedules approved by NARA (see part 1228, Disposition of Federal Records). Original records that are not scheduled may not be destroyed or deleted."

\section{REQUIREMENT SOURCE: SUSC552 Section (a)(2)}

"Each agency, in accordance with published rules, shall make available for public inspection and copying -

(A) final opinions, including concurring and dissenting opinions, as well as orders, made in the adjudication of cases;

(B) those statements of policy and interpretations which have been adopted by the agency and are not published in the Federal Register; and

(C) administrative staff manuals and instructions to staff that affect a member of the public;

unless the materials are promptly published and copies offered for sale. To the extent required to prevent a clearly unwarranted invasion of personal privacy, an agency may delete identifying details when it makes available or publishes an opinion, statement of policy, interpretation, or staff manual or instruction. However, in each case the justification for the deletion shall be explained fully in writing. Each agency shall also maintain and make available for public inspection and copying current indexes providing identifying information for the public as to any matter issued, adopted, or promulgated after July 4,1967, and required by this paragraph to be made available or published. Each agency shail promptly publish, quarterly or more frequently, and distribute (by sale or otherwise) copies of each index or supplements thereto unless it determines by order published in the Federal Register that the publication would be unnecessary and impracticable, in which case the agency shall nonetheless provide copies of such index on request at a cost not to exceed the direct cost of duplication. A final order, opinion, statement of policy, interpretation, or staff manual or instruction that affects a member of the public may be relied on, used, or cited as precedent by an agency against a party other than an agency only if -

(i) it has been indexed and either made available or published as provided by this paragraph; or

(ii) the party has actual and timely notice of the terms thereof."

\section{REQUREMENT SOURCE: SUSC552 Section (a)(3)}

"Except with respect to the records made available under paragraphs (1) and (2) of this subsection, each agency, upon any request for records which (A) reasonably describes such records and (B) is made in accordance with published rules stating the time, place, fees (if any), and procedures to be followed, shall make the records promptly available to any person."

\section{REQUIREMINT SOURCE: SUSC552 Section (a)(4)(A)(i) thru (v)}

"(i) In order to carry out the provisions of this section, each agency shall promulgate regulations, pursuant to notice and receipt of public comment, specifying the schedule of fees applicable to the processing of requests under this section and establishing procedures and 
guidelines for determining when such fees should be waived or reduced. Such schedule shall conform to the guidelines which shall be promulgated, pursuant to notice and receipt of public comment, by the Director of the Office of Management and Budget and which shall provide for a uniform schedule of fees for all agencies.

(ii) Such agency regulations shall provide that -

(I) fees shall be limited to reasonable standard charges for document search, duplication, and review, when records are requested for commercial use;

(II) fees shall be limited to reasonable standard charges for document duplication when records are not sought for commercial use and the request is made by an educational or noncommercial scientific institution, whose purpose is scholariy or scientific research; or a representative of the news media; and

(III) for any request not described in (I) or (II), fees shall be limited to reasonable standard charges for document search and duplication.

(iii) Documents shall be furnished without any charge or at a charge reduced below the fees established under clause (ii) if disclosure of the information is in the public interest because it is likely to contribute significantly to public understanding of the operations or activities of the government and is not primarily in the commercial interest of the requester.

(iv) Fee schedules shall provide for the recovery of only the direct costs of search, duplication, or review. Review costs shall include only the direct costs incurred during the initial examination of a document for the purposes of determining whether the documents must be disclosed under this section and for the purposes of withholding any portions exempt from disclosure under this section. Review costs may not include any costs incurred in resolving issues of law or policy that may be raised in the course of processing a request under this section. No fee may be charged by any agency under this section -

(I) if the costs of routine collection and processing of the fee are likely to equal or exceed the amount of the fee; or

(II) for any request described in clause (ii) (II) or (III) of this subparagraph for the first two hours of search time or for the first one hundred pages of duplication.

(v) No agency may require advance payment of any fee unless the requester has previously failed to pay fees in a timely fashion, or the agency has determined that the fee will exceed $\$ 250 . "$

\section{REQURDMENT SOURCE: SUSC552A Section (b)}

"Conditions of Disclosure. - No agency shall disclose any record which is contained in a system of records by any means of communication to any person, or to another agency, except pursuant to a written request by, or with the prior written consent of, the individual to whom the record pertains, unless disclosure of the record would be -

(1) to those officers and employees of the agency which maintains the record who have a need for the record in the performance of their duties;

(2) required under section 552 of this title; 
(3) for a routine use as defined in subsection (a)(7) of this section and described under subsection (e)(4)(D) of this section;

(4) to the Bureau of the Census for purposes of planning or carrying out a census or survey or related activity pursuant to the provisions of title 13;

(5) to a recipient who has provided the agency with advance adequate writien assurance that the record will be used solely as a statistical research or reporting record, and the record is to be transferred in a form that is not individually identifiable;

(6) to the National Archives and Records Administration as a record which has sufficient historical or other value to warrant its continued preservation by the United States Government, or for evaluation by the Archivist of the United Stares or the designee of the Archivist to determine whether the record has such value;

(7) to another agency or to an instrumentality of any governmental jurisdiction within or under the control of the United States for a civil or criminal law enforcement activity if the activity is authorized by law, and if the head of the agency or instrumentality has made a written request to the agency which maintains the record specifying the particular portion desired and the law enforcement activity for which the record is sought;

(8) to a person pursuant to a showing of compelling circumstances affecting the health or safety of an individual if upon such disclosure notification is transmitted to the last known address of such individual;

(9) to either House of Congress, or, to the extent of matter within its jurisdiction, any committee or subcommittee thereof, any joint committee of Congress or subcommittee of any such joint committee;

(10) to the Comptroller General, or any of his authorized representatives, in the course of the performance of the duties of the General Accounting Office;

(11) pursuant to the order of a court of competent jurisdiction; or

(12) to a consumer reporting agency in accordance with section $3711(\mathrm{f})$ of title 31 ."

\section{REQUREMENT SOURCE: SUSC552A Section (c)}

"Accounting of Certain Disclosures. - Each agency, with respect to each system of records under its control, shall -

(1) except for disclosures made under subsections (b)(1) or (b)(2) of this section, keep an accurate accounting of -

(A) the date, nature, and purpose of each disclosure of a record to any person or to another agency made under subsection (b) of this section; and

(B) the name and address of the person or agency to whom the disclosure is made;

(2) retain the accounting made under paragraph (1) of this subsection for at least five years or the life of the record, whichever is longer, after the disclosure for which the accounting is made; 
(3) except for disclosures made under subsection (b)(7) of this section, make the accounting made under paragraph (1) of this subsection available to the individual named in the record at his request; and

(4) inform any person or other agency about any correction or notation of dispute made by the agency in accordance with subsection (d) of this section of any record that has been disclosed to the person or agency if an accounting of the disclosure was made."

\section{REQUREMINT SOURCE: 5USC552A Section (d)}

"Access to Records. - Each agency that maintains a system of records shall -

(1) upon request by any individual to gain access to his record or to any information pertaining to him which is contained in the system, permit him and upon his request, a person of his own choosing to accompany him, to review the record and have a copy made of all or any portion thereof in a form comprehensible to him, except that the agency may require the individual to furnish a written statement authorizing discussion of that individual's record in the accompanying person's presence;

(2) permit the individual to request amendment of a record pertaining to him and -

(A) not later than 10 days (excluding Saturdays, Sundays, and legal public holidays) after the date of receipt of such request, acknowledge in writing such receipt; and

(B) promptly, either -

(i) make any correction of any portion thereof which the individual believes is not accurate, relevant, timely, or complete; or

(ii) inform the individual of its refusal to amend the record in accordance with his request, the reason for the refusal, the procedures established by the agency for the individual to request a review of that refusal by the head of the agency or an officer designated by the head of the agency, and the name and business address of that official;

(3) permit the individual who disagrees with the refusal of the agency to amend his record to request a review of such refusal, and not later than 30 days (excluding Saturdays, Sundays, and legal public holidays) from the date on which the individual requests such review, complete such review and make a final determination unless, for good cause shown, the head of the agency extends such 30-day period; and if, after his review, the reviewing official also refuses to amend the record in accordance with the request, permit the individual to file with the agency a concise statement setting forth the reasons for his disagreement with the refusal of the agency, and notify the individual of the provisions for judicial review of the reviewing official's determination under subsection $(\mathrm{g})(1)(\mathrm{A})$ of this section;

(4) in any disclosure, containing information about which the individual has filed a statement of disagreement, occurring after the filing of the statement under paragraph (3) of this subsection, clearly note any portion of the record which is disputed and provide copies of the statement and, if the agency deems it appropriate, copies of a concise statement of the reasons of the agency for not making the amendments requested, to persons or other agencies to whom the disputed record has been disclosed; and

(5) nothing in this section shall allow an individual access to any information compiled in reasonable anticipation of a civil action or proceeding." 


\section{REQURTMIINT SOURCE: SUSC552A Section (e)}

"Agency Requirements. - Each agency that maintains a system of records shail -

(1) maintain in its records only such information about an individual as is relevant and necessary to accomplish a purpose of the agency required to be accomplished by statute or by executive order of the President;

(2) collect information to the greatest extent practicable directly from the subject individual when the information may result in adverse determinations about an individual's rights, benefits, and privileges under Federal programs;

(3) inform each individual whom it asks to supply information, on the form which it uses to collect the information or on a separate form that can be retained by the individual -

(A) the authority (whether granted by statute, or by executive order of the President) which authorizes the solicitation of the information and whether disclosure of such information is mandatory or voluntary;

(B) the principal purpose or purposes for which the information is intended to be used;

(C) the routine uses which may be made of the information, as published pursuant to paragraph (4)(D) of this subsection; and

(D) the effects on him, if any, of not providing all or any part of the requested information;

(4) subject to the provisions of paragraph (11) of this subsection, publish in the Federal Register upon establishment or revision a notice of the existence and character of the system of records, which notice shail include -

(A) the name and location of the system;

(B) the categories of individuals on whom records are maintained in the system;

(C) the categories of records maintained in the system;

(D) each routine use of the records contained in the system, including the categories of users and the purpose of such use;

(E) the policies and practices of the agency regarding storage, retrievability, access controls, retention, and disposal of the records;

(F) the title and business address of the agency official who is responsible for the system of records;

(G) the agency procedures whereby an individual can be notified at his request if the system of records contains a record pertaining to him;

(H) the agency procedures whereby an individual can be notified at his request how he can gain access to any record pertaining to him contained in the system of records, and how he can contest its content; and

(I) the categories of sources of records in the system; 
(5) maintain all records which are used by the agency in making any determination about any individual with such accuracy, relevance, timeliness, and completeness as is reasonably necessary to assure faimess to the individual in the determination;

(6) prior to disseminating any record about an individual to any person other than an agency, uniess the dissemination is made pursuant to subsection (b)(2) of this section, make reasonable efforts to assure that such records are accurate, complete, timely, and relevant for agency purposes;

(7) maintain no record describing how any individual exercises rights guaranteed by the First Amendment unless expressly authorized by statute or by the individual about whom the record is maintained or unless pertinent to and withis the scope of an authorized law enforcement activity;

(8) make reasonable efforts to serve notice on an individual when any record on such individual is made availabie to any person under compulsory legal process when such process becomes a matter of public record;

(9) establish rules of conduct for persons involved in the design, development, operation, or maintenance of any system of records, or in maintaining any record, and instruct each such person with respect to such rules and the requirements of this section, including any other rules and procedures adopted pursuant to this section and the penaities for noncompliance;

(10) establish appropriate administrative, technical, and physical safeguards to insure the security and confidentiality of records and to protect against any anticipated threats or hazards to their security or integrity which could result in substantial harm, embarrassment, inconvenience, or unfaimess to any individual on whom information is maintained;

(11) at least 30 days prior to publication of information under paragraph (4)(D) of this subsection, publish in the Federal Register notice of any new use or intended use of the information in the system, and provide an opportunity for interested persons to submit written data, views, or arguments to the agency; and

(12) if such agency is a recipient agency or a source agency in a matching program with a non-Federal agency, with respect to any establishment or revision of a matching program, at least 30 days prior to conducting such program, publish in the Federal Register notice of such establishment or revision."

\section{REQUIREMENT SOURCE: SUSC552A Section (f)}

"Agency Rules. - In order to carry out the provisions of this section, each agency that maintains a system of records shall promulgate rules, in accordance with the requirements (including general notice) of section 553 of this title, which shall -

(1) establish procedures whereby an individual can be notified in response to his request if any system of records named by the individual contains a record pertaining to him;

(2) define reasonable times, places, and requirements for identifying an individual who requests his record or information pertaining to him before the agency shall make the record or information available to the individual;

(3) establish procedures for the disclosure to an individual upon his request of his record or information pertaining to him, including special procedure, if deemed necessary, for the 
Westinghouse Hanford Company (WHC) Standards/Requirements Identification Document
WHC-SD-MP-SRID-002

January 10, 1996

Rev. 0

Page 42 of 64

disclosure to an individual of medical records, including psychological records, pertaining to him;

(4) establish procedures for reviewing a request from an individual concerning the amendment of any record or information pertaining to the individual, for making a determination on the request, for an appeal within the agency of an initial adverse agency determination, and for whatever additional means may be necessary for each individual to be able to exercise fully his rights under this section; and

(5) establish fees to be charged, if any, to any individual for making copies of his record, excluding the cost of any search for and review of the record."

\section{REQUIREMENT SOURCE: SUSC552A Section (n)}

"Mailing Lists. - An individual's name and address may not be sold or rented by an agency unless such action is specifically authorized by law. This provision shall not be construed to require the withbolding of names and addresses otherwise permitted to be made public."

\section{REQURRMENT SOURCE: SUSC552A Section (q)}

"Sanctions. -

(1) Notwithstanding any other provision of law, no source agency may disclose any record which is contained in a system of records to a recipient agency or non-Federal agency for a matching program if such source agency has reason to believe that the requirements of subsection (p), or any matching agreement entered into pursuant to subsection (o), or both, are not being met by such recipient agency.

(2) No source agency may renew a matching agreement unless -

(A) the recipient agency or non-Federal agency has certified that it has complied with the provisions of that agreement; and

(B) the source agency has no reason to believe that the certification is inaccurate. "

\section{REQUIREMINT SOURCE: EO12516 Section I.A, Paragraph 7}

"The following principles should be applied in establishing administrative records:

- The record should be compiled as documents reiating to the selection of the response action are generated or received by the lead agency;

- The record should inciude documents that form the basis for the decision, whether or not they support the response selection; and

- The record should be a contemporaneous explanation of the basis for the selection of a response action."

\section{REQUIREMENT SOURCE: TPA Part Nine, Section 9.4, Paragraph 3 and 4}

"An administrative record will be established for each operabie unit and TSD group and will contain all of the documents containing information considered in arriving at a record of decision or permit. When the investigation process begins at each operable unit or when a 
permit action for a TSD unit (or group of units) is initiated, the administrative record file will be available to the public for review during normal business hours at the following location:

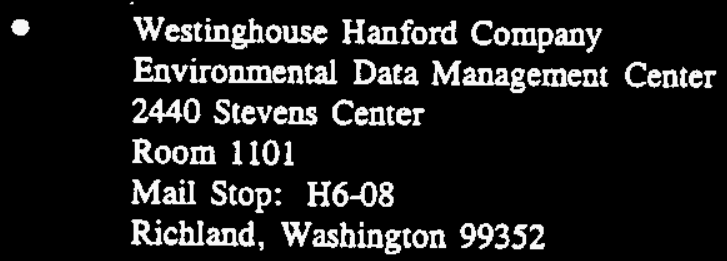

Two additional copies of the file will also be available to the public, during normal business hours, located as follows:

- $\quad$ EPA Region 10

Superfund Administrative Record Center

1200 Sixth Avenue

Park Place Building

Mail Stop: HW-113

Seattle, Washington 98101

- Washington State Department of Ecology

300 Desmond Drive

P.O. Box 47600

Lacey, Washington $98503^{\prime \prime}$

\section{REQUREMENT SOURCE: TPA Part Nine, Section 9.4, Paragraph 15}

"The DOE will maintain an index of all documents entered into the administrative record. A current copy of the index will be distributed at least quarterly to each administrative record file, each public information repository, and each project manager."

\section{Storage}

\section{REQUREMENT SOURCE: 36CFR1228 Part 183(a)}

"Permanent records shall be transferred to the National Archives of the United States when the records have been in existence for more than 30 years unless the head of the agency which has custody of the records certifies in writing to the Archivist that the records must be retained in agency custody for use in the conduct of the regular current business of the agency. Records that are scheduled in a NARA-approved records schedule to be transferred to the National Archives of the United States after a specified period of time are subject to the certification requirement only if the records are not transferred as scheduled."

\section{REQURTMITNT SOURCE: 36CFR1228 Part 194}

"Records subject to the Privacy Act of 1974. Transfers of records constituting systems of records subject to the Privacy Act of 1974 (5 U.S.C. 552a) shall be accompanied by the most recent agency privacy notice covering the records." 


\section{REQUIREMENT SOURCE: 36CFR1228 Part 220}

"Authority. Federal agencies are authorized to maintain and operate records centers for the storage, servicing, and disposal of their own noncurrent records when these centers are approved by the Archivist (44 U.S.C. 3103). Centers operated by Federal agencies are referred to in this Subchapter B as "agency records centers. " "

\section{REQUREMENT SOURCE: 36CFR1228 Part 222 Introduction and (a)}

"Facility standards for agency records centers. Inspection of agency records centers by NARA shail include an evaluation of the agency's compliance with the facility standards for records centers specified below:

(a) General.

(1) The facility should be a single-story building, at or above grade level, constructed with noncombustible materials.

(2) A floor load limit shall be established for the records storage area by a structural engineer. The allowable load limit shall be posted in a conspicuous place and shall not be exceeded.

(3) Steel shelving or other open-shelf records storage equipment shall be braced to prevent collapse under full load in accordance with Federal Specifications AS-S-271 or AA-S-1047. The records storage height shall not exceed 15 feet. Agencies operating records centers which have storage heights in excess of 15 feet may apply in writing to the National Archives (NC), Washington, DC 20408, for an exemption to this requirement. If a request for exemption is deaied, agencies will be required to remodel existing centers to meet the 15 -foot requirement.

(4) The area occupied by the center shall be equipped with an anti-intrusion alarm system, or equivalent, to protect against unlawful entry after hours."

\section{REQUIREMENT SOURCE: 36CFR1228 Part 222(b)}

"Fire safety.

(1) All walls separating records areas from each other and from other storage areas in the building shail be 4-hour fire resistant. The records areas shall not exceed 40,000 square feet each. Two-hour-rated firewalls shall be provided between the records storage areas and other auxiliary spaces. Penetrations in the walls shall not reduce the specified fire resistance ratings.

(2) Openings in firewalls separating records storage areas shall be avoided as far as possible but if openings are necessary they shall be protected by self-closing or automatic Class $\mathrm{A}$ firedoors, or equivalent, on each side of the wall openings.

(3) Roof support structures that cross or penetrate firewalls shall be cut and supported independently on each side of the firewall.

(4) If firewalls are erected with expansion joints, the joints shall be protected to their full height with No. 10 iron astragals lapping the opening on each side of the firewall.

(5) Building columns in the records storage areas shall be 2-hour fire resistant from the floor to the point where they meet the ceiling or roof framing system. 
(6) Automatic roof vents shall not be designed into new or existing buildings.

(7) Where lightweight steel roof or floor supporting members (e.g., bar joists having top chords with angles 2 by 1 1/2 inches or smaller, 1/4-inch thick or smaller, and 13/16-inch or smaller web diameters) are present, they shall be protected either by applying a 10 minute fire resistive coating to the top chords of the joists, or by retrofitting the sprinkler system with large drop sprinkler heads. Retrofitting may require modifications to the piping system to ensure that adequate water capacity and pressure are provided in the areas to be protected with these large drop sprinkler heads.

(8) Furnace or boiler rooms shall be separated from records storage areas by 4-hour-rated firewalls, with no openings directly from these rooms to the records storage areas. No open flame (oil or gas) equipment or unit heaters shall be installed or used in any records storage area.

(9) The arrangement of the records storage equipment shall be such that there shall be no dead-end aisles. Equipment rows running perpendicular to the wall shall terminate at least 18 inches from the wall.

(10) No oil-type electrical transformers, regardless of size, except thermally protected devices included in fluorescent light ballasts, shall be installed in the records storage areas. All electrical wiring shall be in metal conduit, except that armored cable may be used where flexible connections to light fixtures are required.

(11) All records storage and adjoining areas shall be protected by automatic wetpipe sprinklers. Automatic sprinklers are specified herein because they provide the most effective fire protection for high-piled storage of paper records on open-type shelving.

Note: Other automatic extinguishing systems or protective measures may provide an acceptable level of fire-loss risk depending upon specific conditions, such as type or importance of the records, the type and stacking height of the storage equipment used; or how the space is designed, controlled, and operated (as well as its value). Agencies may elect to use alternate standards, as appropriate to their needs, such as those issued by the National Fire Protection Association (see NFPA 13, NFPA 231, NFPA 231C, NFPA 232, and NFPA 232AM). Also, agencies may consult the Chief of the Accident and Fire Prevention Branch in the GSA regional office about these or other systems and protective measures.

(12) The sprinkler system shall be rated at 286 degrees Fahrenheit and designed to provide $0.30 \mathrm{gpm}$ per square foot for the most remote 1,500 square feet of floor area with a minimum flowing pressure of 7.0 psi at the most remote sprinkler head. Installation shall be in accordance with Standard Number 13 of the National Fire Protection Association.

(13) Maximum spacing of the sprinkler heads shall be on a 10-foot grid and the positioning of the heads shall provide complete, unobstructed coverage, with a clearance of not less than 18 inches from the top of the highest stored materials.

(14) The sprinkler system shall be equipped with a water-flow alarm connected to a continuously staffed fire department or central station, with responsibility for immediate response.

(15) A manual fire alarm system shail be provided with central station service or other automatic means of notifying the municipal fire department. A manual alarm pull station shall be located adjacent to each exit. Supplemental manual alarm stations are permitted within the records storage areas. 
(16) All water cutoff valves in the sprinkler system shall be equipped with automatic closure alarm connected to a continuously staffed station, with responsibility for immediate response.

(17) A dependable water supply free of internuption shall be provided. This normally requires a backup supply system having sufficient pressure and capacity to meet both firehose and sprinkler requirements for 2 hours.

(18) Interior firehose stations equipped with a $11 / 2$-inch diameter hose shall be provided in the records storage areas, enabling any point in the records storage area to be reached by a 50 -foot hose stream from a 100-foot hose lay. The fire hoses shall not be provided, however, unless training in the handling and use of small hoses, protective gear, and breathing equipment has been given, and these protective items are available for brigade members.

(19) In addition to the designed sprinkler flow demand, $500 \mathrm{gpm}$ shall be provided for hose stream demand. The hose stream demand shall be calculated into the system at the base of the main sprinkler riser.

(20) Fire hydrants should be located within 250 feet of each exterior entrance or other access to the records center that could be used by firefighters. All hydrants should be at least 50 feet away from the building walls and adjacent to a roadway usable by fire apparatus.

(21) Portable water-type fire extinguishers (2 1/2-gallon stored pressure-type) shall be provided at each fire alarm striking station.

(22) Catwalks may be provided in the aisles between the metal stacks in high-activity records storage areas without provision of sprinklers under the walkway. Where provided, the walking surface of the catwalks shall be of expanded metal at least 0.09-inch thickness with a 2-inch mesh length. The surface opening ratio shall be equal to or greater than that outlined in Military Specification (MIL-M-17194C) of March 8, 1955. The sprinkler water demand for protection over bays with catwalks where records are not oriented perpendicular to the aisles shall be calculated hydraulically to give $0.3 \mathrm{gpm}$ per square foot for the most remote 2,000 square feet.

(23) Storage of hazardous cellulose nitrate film requires special facilities not covered by the above standards. (See NFPA 40 and NFPA 232.)"

\section{REQUIREMENT SOURCE: 36CFR1228 Part 222(c)}

"Archives.

(1) Archival materials, whether on paper, plastic, or other media, generally require a much higher level of protection than temporary records, such as environmentally controlled and filtered storage space, and other safety measures not included in this section on agency records centers.

(2) Firesafety criteria for archives shall be the same as that for records centers, except that fire detection shall be incorporated into the archival storage areas in accordance with NFPA Standard 72E, and fire divisions in the archival storage areas may be reduced in size to reflect a management decision on the maximum amount of archives subject to damage or loss from fire." 


\section{REQULRMENT SOURCE: 44USC3103 All}

"When the head of a Federal agency determines that such action may affect substantial economies or increased operating efficiency, he shall provide for the transfer of records to a records center maintained and operated by the Archivist, or, when approved by the Archivist, to a center maintained and operated by the head of the Federal agency."

\section{REQUIREMTNT SOURCE: TPA Part Nine, Section 9.4, Paragraph 5}

"The DOE will compile and maintain the administrative record file at Richland, Washington, and provide copies to the EPA and Ecology for their respective files. At the time when the decisional document is signed, all documents forming the basis for selection of the final action(s) must have been placed in the administrative record file. Microfilm copies will be regularly provided to the EPA and Ecology for use in their files. This will include microfilm for all documents included since the last set of microfilm was provided. Microfilm readers will be made available for use at these locations."

\section{REQUIREMENT SOURCE: TPA Part Nine, Section 9.4, Paragraph 6, Sentence 1}

"A microfilm copy and one hard copy of the administrative records will be maintained in the Richland administrative record file."

\section{REQUIREMENT SOURCE: TPA Part Nine, Section 9.4, Paragraph 6, Sentence 2 thru 5}

"After one year following the CERCLA record of decision or RCRA permit determination, the hard copies of administrative record documents issued up to those decision points may be removed from the administrative record file. The microfilm copies will be kept on file for a minimum of 10 years. The final decision documentation (i.e., CERCLA proposed plan and record of decision, and RCRA permit) will be maintained in hard copy through completion of all remedial actions or the term of the permit. Current versions of all general documents (e.g., guidance and applicable procedures) will be maintained in hard copy throughout the RI/FS process or through the term of the permit."

\section{REQUIREMENT SOURCE: TPA Part Nine, Section 9.4, Paragraph 8}

"For those which are designated as primary documents (see Table 9-1) the administrative record will include:

- All drafts submitted to the regulatory agencies for review and/or approval

- Written comments from the support regulatory agency to the lead regulatory agency

- Written comments from the lead regulatory agency to DOE (to include Notice of Deficiency on a Permit Application)

- DOE written responses to comments received from the lead regulatory agency

- Final document and any subsequent revisions

- Drafts which are submitted for public comment. 
- For public comment documents, the public comments and lead regulatory agency responses (if no comments are received, a letter from the lead regulatory agency shall be included documenting that fact)."

\section{REQUTREMINT SOURCE: TPA Part Nine, Section 9.4, Paragraph 9}

"For those which are designated as secondary documents (see Table 9-2), the administrative record will include:

- Final document and any subsequent revisions

- Written comments from the support regulatory agency to the lead regulatory agency, if provided

- Written comments from the lead regulatory agency to DOE, if provided

- DOE written responses to comments received from the lead regulatory agency."

\section{REQURREMENT SOURCE: TPA Part Nine, Section 9.4, Paragraph 14}

"Any documents that the regulatory agency has determined to be subject to an applicable privilege, and that are part of the administrative record, shail be maintained exclusively in files of the appropriate parties until such time as enforcement action has been taken or the privilege has been waived."

\section{REQUIREMENT SOURCE: TPA Part Ten, Section 10.2, Paragraph 1 and 2}

"Information will be readily available to the public to ensure meaningful participation. One mechanism for accomplishing this goal is the establishment of public information repositories at major population centers. The locations of the repositories are as follows:

- University of Washington - Suzzalo Library

Mailstop FM-25 - Government Publications

Seattle, Washington 98915

(206) $543-4664$

- DOE-RL Public Reading Room

Washington State University/Tri-Cities

100 Sprout Road

Room 130

Richland, Washington 99352

(509) 376-8583

- Portland State University

Branford Price Millar Library

SW Harrison and Park

P.O. Box 1151

Portland, Oregon 97207

(503) $725-3690$ 


\section{- Gonzaga University}

Foley Center

E. 502 Boone

Spokane, Washington 99258

(509) 328-4220, extension 3125

All documents (with exception of drafts) listed on Table 2 of the CRP will be sent to the repositories. In addition, copies of drafts when submitted for public comment will be placed in the repositories. Any additional information or documents will be placed in the repositories as deemed necessary by the project managers."

\section{REQUIREMIENT SOURCE: TPA Part Ten, Section 10.5.2, Paragraph 2, Sentence 4}

"All public comments received on these documents, along with the lead regulatory agency's response to comments, will be placed in the administrative record and will be sent to the public information repositories."

\section{REQUIREMINT SOURCE: TPA Part Ten, Section 10.6, Paragraph 2, Sentence 1}

"Copies of all public comments received and the agencies' responses to comments will become part of the administrative record and will be sent to the public information repositories."

\section{REQUREMANT SOURCE: TPA Part Twelve, Section 12.5, Paragraph 2}

"Appendices B, C, E, and F will be reissued annually in conjunction with the annual update of Appendix D. Appendices may be updated separately from the action plan at any time to incorporate approved changes. If done, the revised version of the applicable appendix will be dated and transmitted to the project managers and the public information repositories. The transmittal will reference what changes have been incorporated. The DOE project manager will be responsible for maintaining the appendices up-to-date as necessary and distributing the revised appendices."

\section{$\underline{1.8 .3}$}

\section{Retention and Disposal}

\section{REQUIREMINNT SOURCE: 36CFR1220 Part 38}

"Provision shall be made to ensure that permanent records are preserved but that records no longer of current use to an agency are promptly disposed of or retired. Effective techniques for the accomplishment of these ends are the development of records disposition schedules; the transfer of records to records centers and the National Archives of the United States; the conversion of the information to other media; and the disposal of valueless records.

Disposition of any records requires the approval of the Archivist of the United States (see Part 1228 of this chapter)."

\section{REQUIREMENT SOURCE: 36CFR1222 Part 20(b)(6)}

"Develop and implement records schedules for all records created and received by the agency and obtain NARA approval of the schedules in accordance with 36 CFR part 1228;" 


\section{REQUREMINT SOURCE: 36CFR1222 Part 34(a) thru (c)}

"Identifying Federal records.

(a) General. To ensure that complete and accurate records are made and retained in the Federal Government, it is essential that agencies distinguish between records and nonrecord materials by the appropriate application of the definition of records (see 44 U.S.C. 3301 and 36 CFR 1220.14) to agency documentary materials. Applying the definition of records to most documentary materials created or received by agencies presents few problems when agencies have established and periodically updated recordkeeping requirements covering all media and all agency activities at all levels and locations.

(b) Record status. Documentary materiais are records when they meet both of the following conditions:

(1) They are made or received by an agency of the United States Government under Federal law or in connection with the transaction of agency business; and

(2) They are preserved or are appropriate for preservation as evidence of agency organization and activities or because of the value of the information they contain.

(c) Working files and similar materials. Working files, such as preliminary drafts and rough notes, and other similar materials shall be maintained for purposes of adequate and proper documentation if:

(1) They were circulated or made available to employees, other than the creator, for official purposes such as approval, comment, action, recommendation, follow-up, or to communicate with agency staff about agency business; and

(2) They contain unique information, such as substantive annotations or comments included therein, that adds to a proper understanding of the agency's formulation and execution of basic policies, decisions, actions, or responsibilities."

\section{REQUREMENT SOURCE: 36CFR1222 Part 36}

"(a).Personal papers are documentary materials, or any reasonably segregable portion thereof, of a private or nonpublic character that do not relate to or have an effect upon the conduct of agency business. Personal papers are excluded from the definition of Federal records and are not owned by the Government. Examples of personal papers include:

(1) Materials accumulated by an official before joining Government service that are not used subsequently in the transaction of Government business;

(2) Materials relating solely to an individual's private affairs, such as outside business pursuits, professional affiliations, or private political associations that do not relate to agency business; and

(3) Diaries, journals, personal correspondence, or other personal notes that are prepared or used for, or circulated or communicated in the course of, transacting Government business.

(b) Personal papers shall be clearly designated as such and shall at all times be maintained separately from the office's records. 
(c) If information about private matters and agency business appears in the same document, the document shall be copied at the time of receipt, with the personal information deleted, and treated as a Federal record.

(d) Materiais labeled "personal", "confidential", or "private", or similarly designated, and used in the transaction of public business, are Federal records subject to the provisions of pertinent laws and regulations. The use of a label such as "personal" is not sufficient to determine the status of documentary materials in a Federal office."

\section{REQUIRFMINT SOURCE: 36CFR1222 Part 38}

"Agency recordkeeping requirements shall prescribe the creation and maintenance of records of the transaction of agency business that are sufficient to:

(a) Document the persons, places, things, or matters dealt with by the agency.

(b) Facilitate action by agency officials and their successors in office.

(c) Make possible a proper scrutiny by the Congress or other duly authorized agencies of the Government.

(d) Protect the financial, legal, and other rights of the Government and of persons directly affected by the Government's actions.

(e) Document the formulation and execution of basic policies and decisions and the taking of necessary actions, including all significant decisions and commitments reached orally (person to person, by telecommunications, or in conference).

(f) Document important board, committee, or staff meetings."

\section{REQUIREMENT SOURCE: 36CFR1222(950828) Part 34(d)}

"Record status of copies. The determination as to whether a particular document is a record does not depend upon whether it contains unique information. Multiple copies of the same document and documents containing duplicative information, including messages created or received on electronic mail systems, may each have record status depending on how they are used to transact agency business. See paragraph $(f)(2)$ of this section concerning the nonrecord status of extra copies."

\section{REQUTREMENT SOURCE: 36CFR1222(950828) Part 34(f)}

"Nonrecord materials. Nonrecord materiais are Government-owned documentary materials that do not meet the conditions of record status (see \$1222.34(b)) or that are specifically excluded from status as records by statute (see 44 U.S.C. 3301):

(1) Library and museum material (but only if such material is made or acquired and preserved solely for reference or exhibition purposes);

(2) Extra copies of documents (but only if the sole reason such copies are preserved is for convenience of reference); and

(3) Stocks of publications and of processed documents. (Each agency shall create and maintain serial or record sets of its publications and processed documents, as evidence of agency 
activities and for the information they contain, including annual reports, brochures, pamphlets, books, handbooks, posters and maps.)"

\section{REQUIREMINT SOURCE: 36CFR1228 Part 22}

"The primary steps in developing agency records schedules are given below. Details in each step are contained in the NARA records management handbook, Disposition of Federal Records (NSN 7610-01-055-8704). Ultimately, all records of an agency must be scheduled, but they need not all be scheduled at the same time. An agency may schedule the records of one function, program or organizational element at a time.

(a) Determine the functions and activities documented by the records to be scheduled.

(b) Prepare an inventory of the records including a description of their medium, location, volume, inclusive dates, informational content and use.

(c) Evaluate the period of time the agency needs each records series or system by reference to its uses and value to agency operations or legal obligations.

(d) Based on agency need, formulate specific recommended disposition instructions for each records series or each part of an automated information system, including file breaks, retention periods for temporary records, transfer periods for permanent records, and instructions for the retirement of records to Federal records centers, when appropriate. Recommended retention periods take into account the rights of the Government and the rights of those directly affected by agency actions.

(e) Assemble into a draft schedule the descriptions and recommended disposition instructions for logical blocks of records, i.e., entire agency, organizational component, or functional area.

(f) Obtain approval of the records schedules from NARA (and from the General Accounting Office, when so required under Title 8 of the GAO "Policy and Procedures Manual for the Guidance of Federal Agencies")."

\section{REQUIREMINNT SOURCE: 36CFR1228 Part 24}

"(a) General. Agency records schedules approved by the Archivist of the United States specify the disposition for agency records. Records of continuing (permanent) value will be scheduled for retention and immediate or eventual transfer to the legal custody of NARA. All other records will be scheduled for destruction or donation after a specific period of time based on administrative, fiscal, and legal values.

(b) Characteristics of schedules. Though records disposition authority may be requested from NARA on a program-by-program, function-by-function, or office-by-office basis, all agency records must be scheduled. Schedules must follow the guidelines provided below:

(1) Schedules shall identify and describe clearly each series or system and shall contain disposition instruction that can be readily applied. (Additional information is required for permanent records as specified in $\$ 1228.28(b)$.) Schedules must be prepared so that each office will have standing instructions detailing the disposal, transfer, or retention of records.

(2) SF 115s shall include only new records not covered by the General Records Schedules (GRS) (see subpart C), deviations from the GRS (see \$1228.42), or previously scheduled records requiring changes in retention periods or substantive changes in description. 
(3) All schedules shall take into account the physical organization of records or the filing system so that disposal or transfer can be handled in blocks.

(4) The disposition of noarecord materials is controlled by instructions in the agency's printed or published records disposition manual. These instructions do not require NARA approval. Such items shall not be included on SF 115s. Non-record materials, such as extra copies of documents preserved solely for reference, and stocks of processed documents, and personal materials shall be maintained separately from official agency files to aid in records disposition.

(c) Provisions of schedules. Records schedules shall provide for:

(1) The destruction of records that have served their statutory, fiscal, or administrative uses and no longer have sufficient value to justify further retention. Procedures for obtaining disposal authorizations are prescribed in $\$ 1228.30$;

(2) The removal to a Federal records center (or to an agency records center approved under subpart K) of records not eligible for immediate destruction or other disposition but which are no longer needed in office space. These records are maintained by the records center until they are eligible for further disposition action;

(3) The retention of the minimum volume of current records in office space consistent with effective and efficient operations; and

(4) The identification of records of permanent value in accordance with $\$ 1228.28$, and the establishment of cutoff periods and dates when such records will be transferred to the legal custody of NARA."

\section{REQUTREMINT SOURCE: 36CFR1228 Part 26}

"(a) Submission. Requests for records disposition authority shall be initiated by Federal agencies by submitting Standard Form 115, Request for Records Disposition Authority, to NARA (NIR). An SF 115 is used for requesting authority to schedule (or establish the disposition for) permanent and temporary records, either on a recurring or one-time basis.

(1) New Federal agencies shall apply General Records Schedules to eligible records and shall submit to NARA SF 115 s covering all remaining records within 2 years of their establishment.

(2) Agencies shall submit to NARA schedules for the records of new programs and of programs that are reorganized or otherwise changed in a way that results in the creation of new or different records within 1 year of the implementation of the change.

(b) Certification. The signature of the authorized agency representative on the SF 115 shall constirute certification that the records recommended for disposal do not or will not have sufficient administrative, legal, or fiscal value to the agency to warrant retention beyond the expiration of the specified period and that records described as having permanent value will be transferred to the National Archives upon expiration of the stated period.

(c) Disapproval of requests for disposition authority. Requests for records disposition authority may be returned to the agency if the SF 115 is improperiy prepared. The agency shall make the necessary corrections and resubmit the form to NARA (NIR). NARA may disapprove the disposition request for an item if, after appraisal of the records, NARA determines that the proposed disposition is not consistent with the value of the records. In such cases, NARA will notify the agency in writing." 


\section{REQUTREMINT SOURCE: 36CFR1228 Part 28}

"Scheduling permanent records.

(a) Initiation. Federal agencies propose permanent retention of records in accordance with guidelines contained in the NARA records management handbook, Disposition of Federal Records (NSN 7610-01-055-8704).

(b) Requirements. Each item proposed for permanent retention on an SF 115 shall include the following:

(1) Records series title used by agency personnel to identify the records;

(2) Complete description of the records including physical type and information contents;

(3) Inciusive dates;

(4) An arrangement statement;

(5) Statement of restrictions on access which NARA should impose in conformity with the Freedom of Information Act if the records are proposed for immediate transfer;

(6) An estimate of the volume of records accumulated annually if the records are current and continuing;

(7) The total volume to date; and

(8) Disposition instructions, developed using the following guidelines:

(i) If the records series or system is current and continuing, the SF 115 will inciude a disposition instruction specifying the period of time after which the records will be transferred to the National Archives, normally within 30 years for paper records, 5-10 years for audiovisual or microform records, and as soon as the records become inactive or the agency cannot meet the maintenance requirements found in $\$ 1228.188$ of this part for electronic records.

(ii) If the records series or system is nonrecurring, i.e., no additional records will be created or acquired, the agency may propose either immediate or future transfer to the National Archives.

(c) Determination. NARA will determine whether or not records of permanent value and when the transfer of the permanent records will take place.

(1) If NARA determines that records are not permanent, it will notify the agency and negotiate an appropriate disposition. The disposition instruction on the SF 115 will be modified prior to NARA approval.

(2) If NARA determines that records are permanent, but that the transfer instructions are not appropriate, it will negotiate appropriate transfer terms with the agency. The disposition instruction on the SF 115 will be modified prior to NARA approval." 


\section{REQUREMENT SOURCE: 36CFR1228 Part 30}

"(a) Initiation. Federal agencies request authority to dispose of records, either immediately or on a recurring basis. Requests for immediate disposal are limited to records already in existence which no longer accumulate. For recurring records, approved schedules provide continuing authority to destroy the records. The retention periods approved by NARA are mandatory, and the agency shall dispose of the records after expiration of the retention period, except as provided in \$1228.54.

(b) Requirements. Each item on an SF 115 proposed for eventual destruction shall include the following:

(1) Records series title used by agency personnel to identify the records;

(2) Description of the records including physical type and informational content;

(3) If the records are contained in a Privacy Act system of records, a citation to the agency's alpha-numeric or numeric code designation for the system of records. If the system of records was added or deleted since the publication of the current Office of the Federal Register compilation of Privacy Act Issuances, the agency shall also cite the date and page of the Federal Register on which the new system notice appears or the deleted system is announced.

(4) Disposition instructions, developed using the following guidelines:

(i) If the records series or system is current and continuing, the SF 115 will include a disposition instruction specifying the period of time after which the records will be destroyed.

(ii) If the records series or system is nonrecurring, i.e., no additional records will be created or acquired, the agency may propose either immediate destruction or destruction on a future date.

(c) Determination. NARA may determine that records proposed as temporary merit permanent retention and transfer to the National Archives. In such cases, NARA arranges with the agency to change the disposition instruction prior to approval of the SF 115.

(d) General Accounting Office concurrence. Each Federal agency shall obtain the approval of the Comptroiler General for the disposal of program records less than 3 years old and for certain classes of records relating to claims and demands by or against the Government, and to accounts in which the Government is concerned in accordance with the GAO "Policy and Procedures Manual for Guidance of Federal Agencies", Title 8 - Records Management (44 U.S.C. 3309). This approval must be obtained before the approval of the disposal request by NARA, but the request may be submitted concurrently to GAO and NARA.

(e) Withdrawn items. Agencies may request that items listed on the SF 115 be withdrawn in order to aid in NARA's processing (appraisal) of the remaining items on the schedule.

(1) If, during the course of the appraisal process, NARA determines that records described by an item(s) on the proposed schedule do not exist or are not arranged as stated on the SF 115, NARA may request the agency to withdraw the item(s) from consideration, if the agency is unable to offer sufficient clarification.

(2) If NARA and the agency cannot agree on the retention period for an item(s), the items(s) may be withdrawn. In these cases, the agency will submit an SF 115 with a revised proposal for disposition within 6 months of the date of the approval of the original SF 115." 


\section{REQURREMENT SOURCE: 36CFR1228 Part 32}

"Request to change disposition authority. Agencies desiring to change the approved disposition of a series or system of records shall submit an SF 115. Disposition authorities contained in approved SF 115s are automatically superseded by approval of a later SF 115 applicable to the same records unless the later SF 115 specified an effective date. Agencies submitting revised schedules shall indicate on the SF 115 the relevant schedule and item numbers to be superseded, the citation to the current printed records disposition schedule, if any, and/or the General Records Schedules and item numbers which cover the records."

\section{REQUREMIENT SOURCE: 36CFR1228 Part 42}

"Applicability.

(a) New items or changes in the disposition of GRS records supersede approved agency schedules for the same series or system of records, unless the agency schedule provides for a shorter retention period, or unless NARA indicates that the GRS standard must be applied without exception. Agencies shall not request authority to apply GRS authorizations (see $\$ 1228.24(\mathrm{~b})(2))$.

(b) Agencies may request exceptions to disposition instructions in the GRS by submitting an SF 115 in accordance with $\$ 1228.30$ accompanied by a written justification explaining why the agency needs the records for a different period of time from other agencies.

(c) Provisions of the General Records Scheduies may be applied to records in the custody of the National Archives at NARA's discretion subject to the provisions of $\$ 1228.200$."

\section{REQUIREMENT SOURCE: 36CFR1228 Part 50}

"The application of approved schedules is mandatory (44 U.S.C. 3303a). The Archivist of the United States will determine whether or not records may be destroyed or transferred to the National Archives. If the Archivist approves the request for disposition authority, NARA will notify the agency by returning one copy of the completed SF 115 . This shall constitute mandatory authority for the final disposition of the records (for withdrawal of disposal authority or the extension of retention periods, see Sec.228.52 and 1228.54). The authorized destruction shall be accomplished as prescribed in $\$ 1228.58$. The head of each Federal agency shall direct the application of records schedules to ensure the agency maintains recorded information necessary to conduct Government business, avoid waste, and preserve permanent records for transfer to the National Archives. The agency head shall take the following steps to ensure proper dissemination and application of approved schedules:

(a) Issue an agency directive incorporating the disposition authorities approved by NARA, i.e., SF 115 s (except for one-time authorities covering nonrecurring records) and the General Records Schedules. Also include nonrecord materials with disposition instructions developed by the agency. Once all records and nonrecord materials are included, this document is the agency's comprehensive schedule. Agencies may also issue other directives containing instructions relating to agency records disposition procedures.

(1) Published schedules do not include nonrecurring records for which NARA has granted authority for immediate disposal or transfer to the National Archives. They do include general instructions for retirement of records to the Federal records centers, transfer of records to the National Archives, and other records disposition procedures. 
(2) Comprehensive schedules are formally published manuals or directives that provide for the disposition of all recurring records and nonrecord materials created by an agency. These schedules must cite the GRS or SF 115 and item numbers that provide the legal disposition authority for items covering record material.

(3) Prior to issuance, agencies may consult with NARA concerning directives or other issuances containing approved schedules, instructions for use of the Federal records centers, transfer of records to the National Archives, or other matters covered by NARA procedures or regulations.

(4) Agencies shall forward to the National Archives and Records Administration (NIR) three copies of each final directive or other issuance relating to records disposition and 20 copies of all published records schedules (printed agency manuals) and changes.

(b) Establish intemal training programs to acquaint appropriate personnel with the requirements and procedures of the records disposition program.

(c) Apply the approved records disposition schedules to the agency's records.

(1) Records described by items marked "disposition not approved" or "withdrawn" may not be destroyed until a specific disposition has been approved by NARA.

(2) Disposition authorities for items on approved SF 115s that specify an organizational component of the department or independent agency as the creator or custodian of the records may be applied to the same records after internal reorganization, but only if the nature, content, and functional importance of the records remain the same. Authority approved for items described in a functional format may be applied to any organizational component within the department or independent agency that is responsible for the relevant function.

(3) Disposition authorities approved for one department or independent agency may not be applied by another. Departments or agencies that acquire records from another department or agency, and/or continue creating the same series of records previously created by another department or agency through interagency reorganization must submit an SF 115 to NARA for disposition authorization for the records within one year of the reorganization.

(4) Unless otherwise specified, disposition authorities apply retroactively to all existing records as described in the schedule, including records acquired by transfer of function within or between agencies, as long as the nature, content, and functional importance of the records series is unchanged.

(d) Review approved schedules, and, if necessary, update them annually. Additions and changes to the GRS shall be incorporated or otherwise disseminated within 6 months of issuance from NARA."

\section{REQURDMISNT SOURCE: 36CFR1228 Part 54}

"(a) Approved agency records schedules and the General Records Schedules are mandatory (44 U.S.C. 3303a). Except as specified in paragraph (g) of this section, records series or systems approved for destruction shall not be maintained longer without the prior written approval of the National Archives and Records Administration (NIR). However, extended retention of individual shipments of records to a Federal records center are governed by procedures in $\$ 1228.164$ (c). 
(b) Upon submission of adequate justification, NARA may authorize a Federal agency to extend the retention period of a series or system of records (44 U.S.C. 2909). These extensions of retention periods will be granted for records which are required to conduct Government operations because of special circumstances which alter the normal administrative, legal, or fiscal value of the records.

(c) The head of a Federal agency may request approval of a temporary extension of a retention period by sending a letter to NARA (NIR), Washington DC 20408. The request shall include:

(1) A concise description of the records series for which the extension is requested.

(2) A complete citation of the specific provisions of the agency records schedule or the General Records Schedule currently governing disposition of the records;

(3) A statement of the estimated period of time that the records will be required; and

(4) A statement of the current and proposed physical location of the records including information on whether the records have been or will be transferred to one or more Federal records centers.

(d) Approval of a request for extension of retention periods may apply to records in the custody of one Federal agency or records common to several or all Federal agencies. If approval of a request is applicable to records in the custody of one agency, that agency will be notified by letter. If approval is applicable to records common to several agencies, notification may be made by NARA bulletin.

(e) Upon approval of a request for a change in retention periods applicable to records that have been or will be transferred to one or more Federal records centers, centers will be notified of the change and agencies will be furnished a copy of the notification. Agencies shall forward to the National Archives and Records Administration (NIR) 20 copies of all formally issued instructions which extend retention periods.

(f) Upon expiration of an approved extension of retention period, NARA will notify all affected agencies to apply normal retention requirements.

(g) Prior written approval of the National Archives and Records Administration is not required when records must be retained longer than their scheduled retention period because of court order. In such cases, agencies shall submit a report transmitting a copy of the court order to the National Archives and Records Administration (NIR) of the extension within 30 days after issuance of the court order. The notification shall include the information specified in paragraph (c) of this section."

\section{REQUIRDMENT SOURCE: 36CFR1228 Part 56}

"All records scheduled as permanent shall be transferred to the National Archives after the period specified on the SF 115 in accordance with procedures specified under subpart J."

\section{REQUREMDNT SOURCE: 36CFR1228 Part 58}

"(a) Authority. Federal agencies are required to follow regulations issued by the Archivist of the United States governing the methods of destroying records (44 U.S.C. 3302). Only the methods described in this section shall be used. 
(b) Sale or salvage. Paper records to be disposed of normally must be sold as wastepaper. If the records are restricted because they are national security classified or exempted from disclosure by statute, including the Privacy Act, or regulation, the wastepaper contractor must be required to pulp, macerate, shred, or otherwise definitively destroy the information contained in the records, and their destruction must be witnessed either by a Federal employee or, if authorized by the agency that created the records, by a contractor employee. The contract for sale must prohibit the resale of all other paper records for use as records or documents. Records other than paper records (audio, visual, and data tapes, disks, and diskettes) may be salvaged and sold in the same manner and under the same conditions as paper records. All sales must be in accordance with the established procedures for the sale of surplus personal property. (See 41 CFR part 101-45, Sale, Abandonment, or Destruction of Personal Property.)

(c) Destruction. If the records cannot be sold advantageously or otherwise salvaged, the records may be destroyed by burning, pulping, shredding, macerating, or other suitable means."

\section{REQUIREMINT SOURCE: 36CFR1228 Part 92}

"Menaces to human life or health or to property.

(a) Agencies may destroy records that constitute a continuing menace to human health or life or to property (44 U.S.C. 3310 ). When such records are identified, the agency head shall notify NARA (NIR), specifying the nature of the records, their location and quantity, and the nature of the menace. If NARA concurs in the determination, the Archivist will direct the immediate destruction of the records or other appropriate means of destroying the recorded information. However, if the records are still or motion picture film on nitrocellulose base that has deteriorated to the extent described in paragraph (b) of this section, the head of the agency may follow the procedure therein provided.

(b) Whenever any radarscope, aerial, or other still or motion picture film on nitrocellulose base has deteriorated to the extent that it is soft and sticky, is emitting a noxious odor, contains gas bubbles, or has retrograded into acrid powder, and the head of the agency having custody of it shall determine that it constitutes a menace to human health or life or to property, then the agency shall without prior authorization of the Archivist:

(1) Arrange for its destruction in a manner that will salvage its silver content if the silver content is of sufficient quantity and market value per troy ounce to warrant such salvage;

(2) Authorize burial in approved landfills, in the event the quantity is not sufficiently large to justify the salvaging of its silver content; or

(3) Effect other appropriate methods in the event that the methods provided in paragraph (b)(1) or (2) of this section are not feasible.

(c) These films should be removed from inhabited buildings as soon as possible.

(d) Within 30 days after the destruction of the film as provided in this section, the head of the agency who directed its destruction shall submit a written statement to NARA (NIR), Washington, DC 20408, describing the film and showing when, where, and how the destruction was accomplished." 


\section{REQUIREMIENT SOURCE: 36CFR1228 Part 100}

"Responsibilities.

(a) The Archivist of the United States and the heads of Federal agencies are responsible for preventing the alienation or unauthorized destruction of records, including all forms of mutilation. Records may not be removed from Federal custody or destroyed without regard to the provisions of agency records schedules (SF 115) approved by NARA or the General Records Schedules issued by NARA (44 U.S.C. 2905, 3106, and 3303a).

(b) The heads of Federal agencies are responsible for ensuring that all employees are aware of the provisions of the law relating to unauthorized destruction, alienation, or mutilation of records, and should direct that any such action be reported to them."

\section{REQUIREMENT SOURCE: 44USC3309 All}

"Records pertaining to claims and demands by or against the Government of the United States or to accounts in which the Government of the United States is concerned, either as debtor or creditor, may not be disposed of by the head of an agency under authorization granted under this chapter, until the claims, demands, and accounts have been settled and adjusted in the General Accounting Office, except upon the written approval of the Comptroller General of the United States."

\section{REQURRMENT SOURCE: TPA Part Nine, Section 9.4, Paragraph 12}

"The unit managers will meet at least monthly, as described in Section 8.2. During these meetings, the unit managers will decide which documents are appropriate for inclusion in the record. The DOE unit manager will then notify the administrative record staff of these documents to be added to the record."

\section{KEY INTERFACES}

The Management Systems Functional Area is a collection of systems and processes which service all other functional areas. Interfaces with the various Management Systems elements are identified by the other functional areas.

All the other functional areas interface with Management Systems for requirements/standards related to:

- Policy and procedure preparation, review, approval, control, and maintenance

- Issue management systems for the identification, evaluation, and prioritization of issues, determination of root causes, and the development, tracking, and completion of appropriate corrective action;

- Notification, reporting, investigation, and tracking of occurrences;

- Operational readiness reviews and readiness assessments;

- Records storage provisions to ensure records generated are available for future reference; 
Westinghouse Hanford Company (WHC)

Standards/Requirements Identification Document

WHC-SD-MP-SRID-002

January 10, 1996

Rev. 0

1.0 Management Systems

Page 61 of 64

- Records disposition measures to ensure records generated are retained only until their specified retention period has expired.

REFERENCES

1.10 .1

Requirement Source Documents

The following documents were used as requirement sources in the development of this S/RID:

5 U.S.C. 552, Public Information; Agency Rules; Opinions, Orders, Records, and Proceedings, 11/30/90.

5 U.S.C. 552a, Records Maintained on Individuals, 11/30/90.

10 CFR 830, Nuclear Safety Management, Part 120, Quality Assurance Requirements, 5/5/94.

10 CFR 835, Occupational Radiation Protection, 12/14/93.

10 CFR 708, DOE Contractor Employee Protection Program, 03/01/92.

36CFR, Federal Records Management, 07/01/95.

40 CFR 355, Emergency Planning and Notification; EPA/Superfund, Emergency Planning, and Community Right-to-Know Programs, 07/01/93 Edition.

41 CFR 201, Rules of Practice and Procedure, 01/04/93.

44 U.S.C., Public Printing and Documents, 10/22/85.

DOE 0 232.1, Occurrence Reporting and Processing of Operations Information, 10/30/95.

DOE 1324.5B, Records Management Program, 01/12/95.

DOE 5480.26, Trending and Analysis of Operations Information Using Performance Indicators, $1 / 15 / 93$.

DOE 5480.29, Employee Concerns Management System, 1/15/93.

Executive Order 12516, Final Guidance on Administrative Records for Selecting CERCLA Response Actions, 12/03/90.

RLID 5480.31, Startup and Restart of Facilities Operational Readiness Review and Readiness Assessments, 09/26/94.

Tri-Party Agreement, Hanford Federal Facility and Consent Order (FFACO), 03/01/94.

\section{Revieved Documents Not Used as Requirement Sources}

The following documents were reviewed as requirement sources but were not used in the development of this S/RID:

10 CFR 50 Appendix B, Quality Assurance Criteria for Nuclear Power Plants and Fuel Reprocessing Plants, 3/25/94. 
DOE 1300.2A, DOE Technical Standards Program, 5/19/92.

DOE 1324.2A, Records Disposition, 9/13/88; Change 1, 4/9/92.

DOE 1324.3, Files Management, 3/2/81; Change 1, 4/9/92.

DOE 1324.4A, Micrographics Management, 5/18/92.

DOE 1324.5A, Records Management Program, 4/30/92.

DOE 1324.6, Automated Office Electronic Recordkeeping, 7/8/87; Change 1, 6/12/92.

DOE 1330.1D, Computer Software Management, 5/18/92.

DOE 1340.1B, Management of Public Communications Publications and Scientific, Technical, and Engineering Publications, 1/7/93.

DOE 1360.1B, Acquisition and Management of Computing Resources, 1/7/93.

DOE 1360.6A, ADP Equipment/Data Systems, 11/12/92.

DOE 1430.1D, Scientific and Technical Information Management, 6/30/94.

DOE 1430.2B, Scientific and Technical Information Management Program, 2/25/93.

DOE 1430.4 A, Library Services, 5/18/92.

DOE 2300.1B, Audit Resolution and Followup, 6/8/92.

DOE 2320.1C, Cooperation with the Inspector General, 5/18/92.

DOE 2320.2B, Establishment of Departmental Position on Inspector General Reports, 5/18/92.

DOE 3220.1A, Management of Contractor Personnel Policies and Programs, 5/14/92.

DOE 3220.3A, Human Resource Development for M\&O Contractors, 5/18/92.

DOE 3410.1B, Training Management Plan; Change 2, 5/18/92.

DOE 4320.2A, Capital Assessment Management Process, 2/10/94

DOE 4330.4B, Maintenance Management Program, 2/10/94.

DOE 4700.1, Project Management System, 3/6/87; Change 1, 6/2/92.

DOE 5000.3B, Occurrence Reporting and Processing of Operations Information, 1/19/93; Change 1, 7/2/93.

DOE 5480.19, Conduct of Operations Requirements for DOE Facilities, 7/9/90; Change 1, $5 / 18 / 92$.

DOE 5480.20A, Personnel Selection, Qualification, Training, and Staffing Requirements at DOE Reactor and Non-Reactor Nuclear Facilities; Change 1, 11/15/94. 
Westinghouse Hanford Company (WHC)

Standards/Requirements Identification Document

1.0 Management Systems
WHC-SD-MP-SRID-002

January 10, 1996

Rev. 0

Page 63 of 64

DOE 5480.21, Unreviewed Safety Questions, 12/24/91.

DOE 5480.22, Technical Safety Requirements, 2/25/92; Change 1, 9/15/92.

DOE 5480.23, Nuclear Safety Analysis Reports, 4/03/92; Change 1, 3/10/94.

DOE 5480.26, Trending and Analysis of Operations Information Using Performance Indicators, $1 / 15 / 93$.

DOE 5480.29, Employee Concerns Management System, 1/15/93.

DOE 5480.31, Startup and Restart of Nuclear Facilities, 9/15/93.

DOE 5482.1B, Environmental, Safety, and Health Appraisal Program, 9/23/86; Change 1, $11 / 18 / 91$.

DOE 5484.1, Environmental Protection, Safety, and Health Protection Information Reporting Requirements, 2/24/81; Change 7, 10/17/90.

DOE 5500.1B, Emergency Management System, 4/30/91; Change 1, 2/27/92.

DOE 5500.2B, Emergency Categories, Classes, and Notification and Reporting Requirements, 4/30/91; Change 1, 2/27/92.

DOE 5500.3A, Planning and Preparedness for Operational Emergencies, 4/30/91; Change 1, 2/27/92.

DOE 5632.5, Physical Protection of Classified Matter, 12/3/88; Change 1, 7/30/93.

DOE 5635.1A, Control of Classified Documents and Information, 2/12/88.

DOE 5639.1, Information Security Program, 10/19/92.

DOE 5650.2B, Identification of Classified Information, 12/31/90; Change 2, 4/28/93.

DOE 5650.3A, Identification of Unclassified Controlled Nuclear Information, 6/8/92.

DOE/EH 0135, Criteria for Technical Safety Appraisals, 4/90.

DOE-STD-3006-93, Planning and Conduct of Operational Readiness Reviews, 11/93.

DOE NE/SP-000IT, Writer's Guide for Technical Procedures, $9 / 91$.

DOE-SAGD, Self Assessment Guidance Document, 12/92.

RL 5482.1B, ES8H QA Appraisal and Surveillance Program, 3/4/87.

NUREG-0899, Guidelines for Preparation of Emergency Operating Procedures, 8/82.

ASME-NQA-1-1994, Quality Assurance Program Requirements for Nuclear Facility Applications, 1994.

BMP-86-024, Software Controls for Plant Computers, 12/91. 
BMP-85-026, Writing Guidelines for Maintenance, Test, and Calibration Procedures, 6/85.

BMP-90-015, Performance Objectives and Criteria for Operating and Near Term Operating License Plants, 8/90. 
Westinghouse Hanford Company (WHC)

Standards/Requirements Identification Document

2.0 Quality Assurance
WHC-SD-MP-SRID-002

January 10, 1996

Rev. 0

Page $i$ of $i$

\section{TABLE OF CONTENTS}

2.0 QUALITY ASSURANCE

2.1

2.2

2.3

2.4

2.5

2.6

2.7

2.8

2.9 .1

2.10

2.11

2.12

2.12.1

2.12 .2

2.12 .3

2.13

2.13.1

2.13 .2

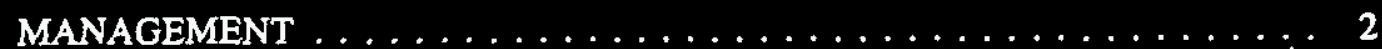

QUALITY ASSURANCE PROGRAM $\ldots \ldots \ldots \ldots \ldots \ldots \ldots \ldots, 2$

TRAINING AND QUALIFICATION OF PERSONNEL $\ldots \ldots \ldots \ldots \ldots, 2$

QUALITY IMPROVEMENT $\ldots \ldots \ldots \ldots \ldots \ldots \ldots \ldots \ldots \ldots$

DOCUMENTS AND RECORDS $\ldots \ldots \ldots \ldots \ldots \ldots \ldots \ldots \ldots$

WORK PROCESSES $\ldots \ldots \ldots \ldots \ldots \ldots \ldots \ldots \ldots \ldots \ldots \ldots$

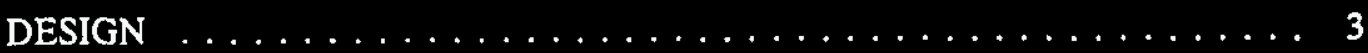

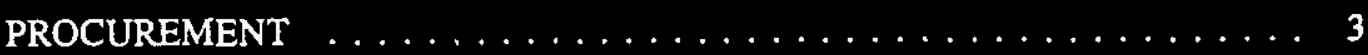

INSPECTION AND ACCEPTANCE TESTING $\ldots \ldots \ldots \ldots \ldots \ldots, 3$

Calibration Standards Lab . . . . . . . . . . . . . . 3

MANAGEMENT ASSESSMENT $\ldots \ldots \ldots \ldots \ldots \ldots \ldots \ldots$

INDEPENDENT ASSESSMENT $\ldots \ldots \ldots \ldots \ldots \ldots \ldots \ldots$

KEY INTERFACES $\ldots \ldots \ldots \ldots \ldots \ldots \ldots \ldots \ldots \ldots \ldots$

Training and Qualification $\ldots \ldots \ldots \ldots \ldots \ldots \ldots \ldots$

Maintenance .................... 5

Packaging and Transportation $\ldots \ldots \ldots \ldots \ldots \ldots \ldots \ldots$

REFERENCES $\ldots \ldots \ldots \ldots \ldots \ldots \ldots \ldots \ldots \ldots \ldots \ldots$

Requirement Source Documents ............... 5

Reviewed Documents Not Used as Requirement Sources $\ldots \ldots \ldots \ldots$. 5 
This page intentionally left blank. 


\subsection{QUALITY ASSURANCE}

\section{NTRODUCTION}

A Standards/Requirements Identification Document (S/RID) sets forth the Environmental Safety and Health (ES\&H) standards/requirements. This S/RID is applicable to the appropriate life cycle phases of design, construction, operation, and decommissioning for each of the categories of facilities addressed in Revision $\mathbf{5}$ of the Department of Energy Implementation Plan for the Defense Nuclear Facilities Safety Board (DNFSB) Recommendation 90-2. This Recommendation calls for the strengthening of DOE weapons complex activities through the identification and application of relevant DOE Orders, regulations, industry codes/standards, industry guidance documents and, as appropriate, good industry practices. These standards/requirements are adequate to ensure protection of the health and safety of workers, the public, and the environment.

The Westinghouse Hanford Company S/RID, as defined in Revision 5 of the Department of Energy Implementation Plan for DNFSB Recommendation 90-2, contains standards/requirements applicable company-wide that are necessary for safe operation of the site and its associated facilities, and that are not the direct responsibility of a specific facility manager (e.g., a company-wide fire department). Facility S/RIDs contain standards/requirements applicable to a specific facility that are the direct responsibility of the facility manager.

This S/RID defines the Westinghouse Hanford Company (WHC) Quality Assurance program in place at Hanford. The Quality Assurance program defined in this document is described in general accordance with the Environmental, Safety, and Health (ES\&H) Configuration Guide, Revision 0, dated July 30,1993 , and is presented in the form of program elements and subelements. The specific DOE Orders and regulations which serve as the basis for each element/subelement are identified and aligned with each subelement.

It is intended that this document be used as a baseline from which to compare the existing Quality Assurance Program at WHC. Additionally, this S/RID may be used as the basis against which future program definition and improvement efforts, including procedures development and/or revisions, can be compared to ensure consistency, completeness, and proper integration with other functional area programs.

\section{SCOPE}

The requirements of the QA Functional Area are applicable to company-wide quality programs and are adequate to ensure health and safety of the worker and public, and protection of environment for nuclear facilities. Some requirements contained in this document may be intentionally duplicated in facility S/RIDs. This was necessary to capture implementation responsibilities occurring at both the company and facility level.

NOTE: QA/QC programs/requirements specific to environmental sampling, analysis, and monitoring activities are contained in applicable facility-specific documents whose applicable regulations mandate those programs/requirements. 


\section{MANAGEMENT}

\section{REQUIREMENT SOURCE: 10CFR830 Part 120(a)(1)}

\section{"General Rule}

A contractor responsible for a DOE nuclear facility shall:

(i) Conduct its work in accordance with the criteria of paragraph (c) of this section;

(ii) Develop and submit for approval by DOE a Quality Assurance Program (QAP) for the work; and

(iii) Implement the QAP, as approved and modified by DOE."

\section{REQUIREMENT SOURCE: 10CFR830 Part 120(b)}

Author's Note: Item No. 2 no longer applies.

"Quality Assurance Program.

(1) A contractor shall develop a QAP by applying the quality assurance criteria specified in paragraph (c) of this section. A QAP shall include a discussion of how the criteria of paragraph (c) of this section will be satisfied. The criteria of paragraph (c) of this section shall be applied using a graded approach. The contractor shall use appropriate standards, wherever applicable, to develop and implement its QAP.

(2) Within 180 days after May 5, 1994, a contractor shall submit to DOE for approval a current QAP and an implementation plan.

(3) A contractor may, at any time, make changes to an approved QAP. Changes made over the previous year shall be submitted annually to DOE for review. A submittal shall identify the changes, the pages affected, the reason for the changes, and the basis for concluding that the revised QAP continues to satisfy the requirements of this section. Changes made to correct spelling, punctuation, or other editorial items do not require explanation.

(4) Implementation plans and QAPs shall be regarded as approved by DOE 90 days after submittal, unless approved or rejected by DOE at an earlier date, and shall include any modification made or directed by DOE."

\section{QUALITY ASSURANCE PROGRAM}

For requirements, refer to facility-specific S/RIDs.

\section{TRAINING AND QUALIFICATION OF PERSONNEL}

For requirements, refer to the WHC Training and Qualification Functional Area and facility-specific S/RIDs.

\section{QUALITY IMPROVEMENT}

Author's Note: This element refers to the company corrective action management system [Hanford Action Tracking System (HATS)]. 


\section{REQUREMINTT SOURCE: 10CFR830 Part 120(c)(1)(iii), Sentences 2 and 3}

2.5

2.6

2.7

2.8

2.9

\section{$\underline{2.9 .1}$}

"Items, services, and processes that do not meet established requirements shall be identifica, controlled, and corrected according to the importance of the problem and the work affectal. Correction shall include identifying the causes of problems and working to prevent recurrence."

\section{DOCUMENTS AND RECORDS}

\section{REQUIREMENT SOURCE: 10CFR830 Part 120(c)(1)(iv)}

"Documents and Records.

Documents shall be prepared, reviewed, approved, issued, used, and revised to prescribe processes, specify requirements, or establish design. Records shall be specified, prepared, reviewed, approved, and maintained."

WORK PROCESSES

For requirements, refer to facility-specific S/RIDs.

\section{DESIGN}

For requirements, refer to facility-specific S/RIDs.

\section{PROCUREMENT}

For requirements, refer to facility-specific S/RIDs.

INSPECTION AND ACCEPTANCE TESTING

REQUIREMENT SOURCE: 10CFR830 Part 120(c)(2)(iv)

Author's Note: Only sentence 2 applies.

"Inspection and Acceptance Testing. Inspection and testing of specified items, services, and processes shall be conducted using established acceptance and performance criteria. Equipment used for inspections and tests shall be calibrated and maintained."

\section{Calibration Standards Lab}

\section{REQUREMENT SOURCE: DOE4330.4B Chapter II, Section 12.3.1, Sentence 1 thru 4}

"Each piece of M\&TE should be assigned a unique identification number that is permanenty marked on or attached to the M\&TE (the identification number may consist of the manufacturer's serial number). These numbers assist in identifying, tracing, and positively controlling M\&TE. A master list of all controlled M\&TE should be maintained. If separte organizations control their own M\&TE, each organization should maintain or have access to a list of its own equipment." 

and 2

"Only calibration standards that are traceable to the National Institute of Standards and Technology or other nationally recognized standards should be used for calibration of M\&TE. If repair or calibration of a standard is necessary, the recalibration must be traceable to the National lnstitute of Standards and Technology or to the standard of record for the M\&TE."

\section{REQUIREMENT SOURCE: DOEA330.4B Chapter II, Section 12.3.2.b, Sentence 1 and 2}

"Calibration of equipment should be performed by qualitied technicians using approved procedures. (NOTE: The "ratio of accuracy" of the standard to the M\&TE being calibrated should be as high as reasonably achievable and consistent with national standards.)"

REQUIREMENT SOURCE: DOEA330.4B Chapter II, Section 12.3.2.c, Sentence 1

"Calibration frequency should be determined based on the manufacturer's recommendations, M\&TE usage, and M\&TE historical reliability."

REQUTREMENT SOURCE: DOEA330.4B Chapter II, Section 12.3.3.a, Sentence 1 thru 4

"As discussed in Paragraph 4, proper facilities are needed to help ensure that equipment is protected from damage in storage, is properly maintained, and is readily retrievable. M\&TE devices that are relatively easy to damage when transporting and handling should be provided more protection by boxing or special mounting rigs (e.g., test gauges mounted in portable frames). M\&TE in the issue area should be segregated from defective, out-of-calibration, or other M\&TE requiring investigation so that only calibrated M\&TE is available for issue. This should be a physically and distinctively marked separation."

\section{REQUIREMENT SOURCE: DOEA330.4B Chapter II, Section 12.3.3.c, Sentence 1}

"M\&TE devices that have special uses, limitations, or restrictions should be clearly labeled to describe their applications or limitations. "

\section{REQUIREMENT SOURCE: DOEA330.4B Chapter II, Section 12.3.3.d, Paragraph} 1 , Sentence 2

"Traceability of M\&TE should be provided to support a timely evaluation of instruments, systems, and other equipment associated with M\&TE found to be deficient."

MANAGEMENT ASSESSMENT

For requirements, refer to facility-specific S/RIDs. 
and freedom form the line to carry out its responsibilities. Persons conducting independent assessments shall be technically qualified and knowledgeable in the areas assessed."

\section{$\underline{2.12 .1}$}

\section{KEY INTERFACES}

\section{Training and Oualification}

Implementation of training requirements, as identified in 10 CFR 830.120 , are located in the WHC Training and Qualification chapter.

2.12 .2

2.12 .3

2.13

$\underline{2.13 .1}$

$\underline{2.13 .2}$

\section{Maintenance}

Requirements for M\&TE calibration labs are addressed in the WHC QA Functional Area chapter.

\section{Packaging and Transportation}

The QA/QC department interfaces with Packaging and Transportation personnel regarding the shipment of radioactive materials, specifically the manufacture and use of packagings.

\section{REFERENCES}

\section{Requirement Source Documents}

Title 10 Code of Federal Regulations Part 830, Nuclear Safety Management, 04/05/94

DOE 4330.4B, Maintenance Management Program, 02/10/94

\section{Reviewed Documents Not Used as Requirement Sources}

10 CFR 50 Appendix A, General Design Criteria for Nuclear Power Plants

10 CFR 50 Appendix B, Quality Assurance Criteria for Nuclear Power Plants and Fuel Reprocessing Plants

ASME NQA-1-1994, Quality Assurance Requirements for Nuclear Facilities, 07/29/94

American Society for Nondestructive Testing, SNT-TC-1A, Personnel Qualification and Certification in Nondestructive Testing, 1992 edition

ASME-NQA-3-1989, Quality Assurance program Requirements for the Collection of Scientific and Technical Information for Site Characterization of High-Level Nuclear Waste Repositories

International Organization for Standardization (ISO) 9000 , Quality Management and Quality Assurance Standards-Guidelines for Selection and Use

International Organization for Standardization (ISO) 9004, Quality Management and Quality System Elements-Guidelines

International Atomic Energy Agency (IAEA) International Nuclear Safety Advisory Group's Safety Series No. 75-INSAG-3, Basic Safety Principles for Nuclear Power Plants Use

DOE1324.5A, Records Management Program, 4/30/92 
DOE 4700.1, Project Management System, 06/02/92

DOE5700.6C, Quality Assurance, 08/21/91

NUREG 1293 Rev. 1, Quality Assurance Guidance for a Low-Level Radioactive Waste Disposal Facility

U.S. EPA, Interim Guidelines and Specifications for Preparing Quality Assurance Project Plans (QAMS-005/80), 12/29/80

ANSI/ASQC E4-1994, Specification and Guidelines for Quality Systems for Environmental Data Collection and Environmental Technology Programs 
Westinghouse Hanford Company (WHC)

Standards/Requirements Identification Document

3.0 Configuration Management
WHC-SD-MP-SRID-002

January 10, 1996

Rev. 0

Page i of $\mathrm{i}$

\section{TABLE OF CONTENTS}

3.0 CONFIGURATION MANAGEMENT $\ldots \ldots \ldots \ldots \ldots \ldots \ldots \ldots \ldots \ldots \ldots \ldots \ldots \ldots$ 
This page intentionally left blank. 
Westinghouse Hanford Company (WHC)

Standards/Requirements Identification Document

3.0 Configuration Management
WHC-SD-MP-SRID-002

January 10, 1996

Rev. 0

Page 1 of 2

\subsection{CONFIGURATION MANAGEMENT}

\section{INTRODUCTION}

A Standards/Requirements Identification Document (S/RID) set forth the Environmental Safety and Health (ES\&H) standards/requirements. This S/RID is applicable to the appropriate life cycle phases of design, construction, operation, and decommissioning for each of the categories of facilities addressed in Revision 5 of the Department of Energy Implementation Plan for the Defense Nuclear Facilities Safety Board (DNFSB) Recommendation 90-2. This Recommendation calls for the strengthening of DOE weapons complex activities through the identification and application of relevant DOE Orders, regulations, industry codes/standards, industry guidance documents and, as appropriate, good industry practices. These standards/requirements are adequate to ensure protection of the health and safety of workers, the public, and the environment.

The Westinghouse Hanford Company S/RID, as defined in Revision 5 of the Department of Energy Implementation Plan for DNFSB Recommendation 90-2, contains standards/requirements applicable company-wide that are necessary for safe operation of the site and its associated facilities, and that are not the direct responsibility of a specific facility manager (e.g., a company-wide fire department). Facility S/RIDs contain standards/requirements applicable to a specific facility that are the direct responsibility of the facility manager.

\section{SCOPE}

The Westinghouse Hanford Company (WHC) S/RID contains standards/requirements applicable to WHC that are adequate to ensure protection of the health and safety of workers, the public, and the environment, and that are not the direct responsibility of a specific facility manager (e.g., a company fire department).

\section{JUSTIFICATION OF FUNCTIONAL AREA NONAPPLICABILITY}

The Functional Areas listed below have been determined to be nonapplicable, for purposes of Westinghouse Hanford Company S/RID development, for one or more of the following reasons:

1. The Functional Area is outside the Scope statement above in that the applicable requirements/standards are the direct responsibility of a specific facility manager and identified in facility level S/RIDs;

2. Responsibility for implementation of the Functional Area lies within an organization other than Westinghouse Hanford Company; or 
Westinghouse Hanford Company (WHC)

Standards/Requirements Identification Document

3.0 Configuration Management
WHC-SD-MP-SRID-002

January 10, 1996

Rev. 0

Page 2 of 2

3. Applicable requirements/standards are appropriately identified within other WHC Functional Areas.

Maintenance

Management Systems

Configuration Management

Construction

Decontamination \& Decommissioning

Engineering Programs

Environmental Restoration

Nuclear Safety

Operations

Research \& Development

Waste Management 


\section{TABLE OF CONTENTS}

4.1

4.2

4.2.1

4.2 .2

4.2 .3

4.2 .4

4.2 .5

4.2 .6

4.2 .7

4.2 .8

4.2 .9
MANAGEMENT AND ADMINISTRATION $\ldots \ldots \ldots \ldots \ldots \ldots \ldots$

ADMINISTRATION OF TRAINING $\ldots \ldots \ldots \ldots \ldots \ldots \ldots$

Selection and Qualification $\ldots \ldots \ldots \ldots \ldots \ldots \ldots$

Training Needs Assessment $\ldots \ldots \ldots \ldots \ldots \ldots \ldots \ldots$

Design and Development $\ldots \ldots \ldots \ldots \ldots \ldots \ldots \ldots$

Implementation $\ldots \ldots \ldots \ldots \ldots \ldots \ldots \ldots \ldots$

Evaluation $\ldots \ldots \ldots \ldots \ldots \ldots \ldots \ldots \ldots \ldots \ldots$

Facilities and Equipment $\ldots \ldots \ldots \ldots \ldots \ldots \ldots$

Training Schedules $\ldots \ldots \ldots \ldots \ldots \ldots \ldots \ldots$

Testing, Qualification, Certification $\ldots \ldots \ldots \ldots \ldots \ldots$

Revision and Update of Training $\ldots \ldots \ldots \ldots \ldots$

TRAINING CATEGORIES AND SUBJECTS $\ldots \ldots \ldots \ldots \ldots \ldots \ldots \ldots$

TRAINING RECORDS AND DOCUMENTATION . . . . . . . . . 8

ACCREDITATION $\ldots \ldots \ldots \ldots \ldots \ldots \ldots \ldots \ldots \ldots$

KEY INTERFACES $\ldots \ldots \ldots \ldots \ldots \ldots \ldots \ldots \ldots \ldots$

Quality Assurance $\ldots \ldots \ldots \ldots \ldots \ldots \ldots \ldots \ldots \ldots$

Emergency Management $\ldots \ldots \ldots \ldots \ldots \ldots \ldots \ldots \ldots$

Safeguards and Security $\ldots \ldots \ldots \ldots \ldots \ldots \ldots \ldots \ldots$

Construction Program $\ldots \ldots \ldots \ldots \ldots \ldots \ldots \ldots$

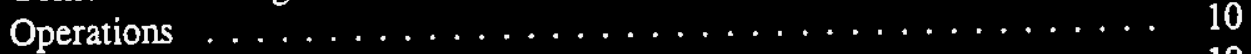

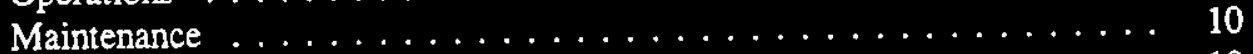

Radiation Protection .............................. 10

Fire Protection ............................ 10

Packaging and Transportation $\ldots \ldots \ldots \ldots \ldots \ldots \ldots \ldots$

Waste Management ...................... 11

Occupational Safety and Health $\ldots \ldots \ldots \ldots \ldots \ldots \ldots \ldots \ldots$

Environmental Protection .................... 11

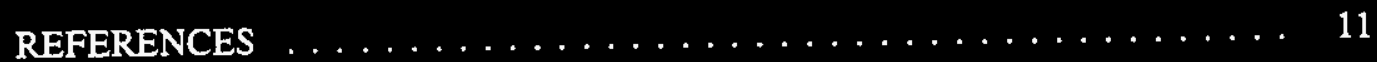

Requirement Source Documents . . . . . . . . . . . . . . . . 11

Reviewed Documents Not Used as Requirement Sources . . . . . . . 12 
This page intentionally left blank. 


\subsection{TRAINING AND QUALIFICATION}

\section{INTRODUCTION}

A Standards/Requirements Identification Document (S/RID) set forth the Environmental Safety and Health (ES\&H) standards/requirements. This S/RID is applicable to the appropriate life cycle phases of design, construction, operation, and decommissioning for each of the categories of facilities addressed in Revision 5 of the Department of Energy Implementation Plan for the Defense Nuclear Facilities Safety Board (DNFSB) Recommendation 90-2. This Recommendation calls for the strengthening of DOE weapons complex activities through the identification and application of relevant DOE Orders, regulations, industry codes/standards, industry guidance documents and, as appropriate, good industry practices. These standards/requirements are adequate to ensure protection of the health and safety of workers, the public, and the environment.

The Westinghouse Hanford Company S/RID, as defined in Revision 5 of the Department of Energy Implementation Plan for DNFSB Recommendation 90-2, contains standards/requirements applicable companywide that are necessary for safe operation of the site and its associated facilities, and that are not the direct responsibility of a specific facility manager (e.g., a companywide fire department). Facility S/RIDs contain standards/requirements applicable to a specific facility that are the direct responsibility of the facility manager.

This Standards/Requirements Identification Document (S/RID) defines the Westinghouse Hanford Company (WHC) Training and Qualification program in place at Hanford. The Training and Qualification program defined in this document is described in general accordance with the (ES\&H) Configuration Guidelines, Revision 0, dated July 30,1993, and is presented in the form of program elements and subelements. The specific DOE Orders, regulations, industry codes/standards, guidance documents and good industry practices which serve as the basis for each element/subelement are identified and aligned with each subelement.

It is intended that this document be used as a baseline from which to compare the existing Training and Qualification Program at WHC for determination of the level of program definition and maturity including the existence of an overall site infrastructure and clearly defined interfaces with other relevant functional areas. Additionally, this S/RID may be used as the basis against which future program definition and improvement efforts, including procedures development and/or revisions, can be compared to ensure consistency, completeness and proper integration with other functional programs. As described in the Key Interface section of this document, Training and Qualification interacts with multiple organizations within WHC.

\section{SCOPE}

This S/RID applies to the programmatic controls, activities, personnel, and programs involved in executing the mission of the Hanford Site. Each of the functional areas provides interpretive authority to the WHC Training Organization concerning the adequate set of requirements for Training and Qualification in that area. Requirements for training which are implemented by a Westinghouse Hanford Company level organization are included in this document. Additionally, some of the requirements cited in this document are intentionally duplicated in corresponding facility S/RIDs. This was necessary to address required implementation responsibilities occurring at both the company and 
Westinghouse Hanford Company (WHC)

Standards/Requirements Identification Document

WHC-SD-MP-SRID-002

January 10, 1996

Rev. 0

4.0 Training and Qualification

Page 2 of 13

facility levels. Facility specific training will be included in each facility's Training and Qualification Functional Area. The WHC Training Organization will assure verification of the content of training classes which implement 29 CFR 1910 and 29 CFR 1926 by the appropriate WHC Interpretive Authority. 
Westinghouse Hanford Company (WHC)

Standards/Requirements Identification Document

4.0 Training and Qualification
WHC-SD-MP-SRID-002

January 10, 1996

Rev. 0

Page 3 of 13
4.1

4.2

$\underline{4.2 .1}$

$\underline{4.2 .2}$

$\underline{4.2 .3}$

$\underline{4.2 .4}$
MANAGEMENT AND ADMINISTRATION

\section{REQUIREMENT SOURCE: 10CFR830 Part 120(c)(1)(ii)}

"Personnel Training and Qualifications. Personnel shall be trained and qualified to ensure they are capable of performing their assigned work. Personnel shall be provided continuing training to ensure that job proficiency is maintained."

\section{ADMINISTRATION OF TRAINING}

\section{Selection and Qualification}

\section{REQUIREMENT SOURCE: 29CFR1910 Part 120(e)(5)}

"Qualifications for trainers. Trainers shall be qualified to instruct employees about the subject matter that is being presented in training. Such trainers shall bave satisfactorily completed a training program for teaching the subjects they are expected to teach, or they shall have the academic credentials and instructional experience necessary for teaching the subjects.

Instructors shall demonstrate competent instructional skills and knowledge of the applicable subject matter."

\section{REQUREMENT SOURCE: 29CFR1910 Part 120(p)(7)(iii)}

"Trainers. Trainers who teach initial training shall have satisfactorily completed a training course for teaching the subjects they are expected to teach or they shall bave the academic credentials and instruction experience necessary to demonstrate a good command of the subject matter of the courses and comperent instructional skills."

\section{REQUIREMENT SOURCE: 29CFR1910 Part 120(q)(7)}

"Trainers. Trainers who teach any of the above training subjects shall have satisfactorily completed a training course for teaching the subjects they are expected to teach, such as the courses offered by the U.S. National Fire Acaderny, or they shall have the training and/or academic credentials and instructional experience necessary to demonstrate competent instructional skills and a good command of the subject matter of the courses they are to teach."

\section{Training Needs Assessment}

\section{REQUIREMINT SOURCE: DOE5430.20A Chapter I, Section 7.b Introduction,} Sentences 1 and 2

"Training Process. Initial and continuing training programs shall be established to ensure that operating organization personnel are qualified to perform job requirements. This shall be achieved by using a systematic approach to training."

\section{Desien and Development}

Requirements relative to design and development are addressed in subelement 4.2.2.

\section{Implementation}

Requirements relative to a training implementation matrix may be found in the facility Training and Qualification functional area. 


\section{REQUREMENT SOURCE: DOE5500.3A Section 11.c.(11)(a)}

$\underline{4.2 .5}$

$\underline{4.2 .6}$

$\underline{4.2 .7}$

$\underline{4.2 .8}$
"Training must be provided annually to workers who may have to take protective actions (e.g., assembly, evacuation) in the event of an emergency."

Evaluation

Evaluation requirements are addressed in subelement 4.2.2.

Facilities and Equipment.

Requirements for this subelement are implemented at the facility level.

Training Schedules

Requirements for this subelement are implemented at the facility level.

Texting, Qualification, Certification

REQUIREMENT SOURCE: DOE5480.20A Chapter I, Section 7 Introduction, Sentence 1 and 2

"TRAINING REQUIREMENTS. Training to support qualification and certification programs shall be based on a systematic approach to training. A graded approach shall be used to establish the systematic approach to training for operations personnel, maintenance personnel, technicians, and the technical staff."

\section{Revision and Update of Training}

Element 4.1 addresses requirements associated with the revision and update of training.

\section{TRAINING CATEGORIES AND SUBJECTS}

Identification and establishment of training categories and specific subjects should meet the collective needs of Hanford Site personnel, subcontractors and visitors. Other organizational elements at the Hanford Site should identify their particular training needs and requirements to the Training and Qualification Program staff.

\section{REQUIREMENT SOURCE: 10CFR835 Part 901(a)}

"All general employees shall be trained in radiation safety prior to receiving occupational exposure during access to controlled areas at a DOE site or facility. Allowance may be made for previous DOE training on generic radiation safety topics (i.e., those not specific to a site or facility), provided the training was received at another DOE site or facility within the past 2 years. Documentation of the previous training shall clearly identify the individual's name, date of training, topics covered, and name of the certifying individual. The knowledge of radiation safety possessed by general employees shall be verified by examination."

\section{REQUREMENT SOURCE: 10CFR835 Part 901(b)}

"Retraining shall be provided when there is a significant change to radiation protection policies and procedures that affect general employees and shall be conducted at intervals not to exceed 2 years." 


\section{REQUIREMIENT SOURCE: 10CFR835 Part 902}

"Radiological worker training programs and retraining shall be established and conducted at intervals not to exceed 2 years to familiarize the worker with the fundamentals of radiation protection and the ALARA process. Training shall include both classroom and applied training. Training shall either precede assignment as a radiological worker or be concurrent with assignment as a radiological worker if the worker is accompanied by and under the direct supervision of a trained radiological worker. Radiological worker training not specific to a given site or facility may be waived provided that: this training has been received at another DOE site or facility within the past 2 years; there is provision of proof-of-training in the form of a certification document containing the individual's name, date of training, and specific topics covered; and an appropriate official has certified the training of the individual. The knowledge of radiation safety possessed by radiological workers shall be verified by examination prior to an unsupervised assignment. The training shall include procedures specific to an individual's job assignment. The level of training is to be commensurate with each worker's assignment."

\section{REQUIREMENT SOURCE: 10CFR835 Part 903}

"Training and retraining programs for radiological control technicians shall be established and conducted at intervals not to exceed 2 years to familiarize technicians with the fundamentals of radiation protection and the proper procedures for maintaining exposures ALARA. This program shall include both classroom and applied training. The training shall either precede performance of tasks assigned to radiological control technicians or be concurrent with such task assignments if the individual is accompanied by and under the direct supervision of a trained individual. The required level of knowledge of radiation safety possessed by radiological control technicians shall be verified by examination to include demonstration prior to any unsupervised work assignment. The training program shall include procedures specific to the site or facility where the technician is assigned. The level of training shall be commensurate with the technician's assignment. Allowance may be made for previous DOE training on generic radiation safety topics (i.e., those not specific to a site or facility), provided the training was received within the past 2 years. Documentation of the previous training shall clearly identify the individual's name, date of training, topics covered, and name of the certifying individual."

\section{REQUIREMENT SOURCE: 10CFR835 Part 1302(e)}

Author's Note: "Individuals" refers to personnel involved in rescue and recovery operations.

"Each individual selected shall be trained in accordance with $\$ 835.902$ and briefed beforehand of the known or anticipated hazards to which the individual will be subjected."

\section{REQUIREMENT SOURCE: 29CFR1910 Part 120(e)(6)}

"Training certification. Employees and supervisors that have received and successfully completed the training and field experience specified in paragraphs (e)(1) through (e)(4) of this section shall be certified by their instructor or the head instructor and trained supervisor as having successfully completed the necessary training. A written certificate shall be given to each person so certified. Any person who has not been so certified or who does not meet the requirements of paragraph $(e)(9)$ of this section shall be prohibited from engaging in hazardous waste operations." 


\title{
REQUIREMIENT SOURCE: 29CFR1910 Part 120(q)(0), Introduction
}

\author{
Author's Note: This training applies to first responder awareness level, operations level, and \\ hazardous materials technicians.
}

"Training. Training shall be based on the duties and function to be performed by each responder of an emergency response organization. The skill and knowledge levels required for all new responders, those hired after the effective date of this standard, shall be conveyed to them through training before they are permitted to take part in actual emergency operations on an incident."

\section{REQUIREMENT SOURCE: 29CFR1910 Part 147(c)(7)(i), Sentence 1}

"The employer shall provide training to ensure that the purpose and function of the energy control program are understood by employees and that the knowledge and skills required for the safe application, usage, and removal of the energy controls are acquired by employees."

\section{REQUIREMENT SOURCE: 49CFR172 Part 704}

"Training requirements.

(a) Hazmat employee training shall include the following:

(1) General awareness/familiarization training. Each hazmat employee shall receive general awareness/familiarization training designed to provide familiarity with the requirements of this subchapter and to enable the employee to recognize and identify hazardous materials consistent with the hazard communication standards of this subchapter.

(2) Function-specific training.

(i) Each hazmat employee shall receive function-specific training concerning requirements of this subchapter which are specifically applicable to the functions the employee performs.

(ii) Training conducted by hazmat employers, as necessary, to comply with, and when subject to, the requirements of the ICAO Technical Instructions or the IMDG Code, as authorized in 171.11 and 171.12 of this subchapter, respectively, may be used, when appropriate, to the extent they serve as a substitute for the requirements of this section.

(3) Safety training. Each hazmat employee shall receive safety training concerning-

(i) Emergency response information required by subpart G of part 172;

(ii) Measures to protect the employee from the hazards associated with hazardous materials to which they may be exposed in the work place, including specific measures the hazmat employer has implemented to protect employees from exposure; and

(iii) Methods and procedures for avoiding accidents, such as the proper procedures for handling packages containing hazardous materials.

(b) OSHA or EPA Training. Training conducted by employers to comply with the hazard communication programs required by the Occupational Safety and Health Administration (OSHA) of the Department of Labor (29 CFR 1910.120) or the Environmental Protection Agency (EPA) (40 CFR 311.1), to the extent that training addresses the training specified in paragraph (a) of this section, may be used to satisfy the training requirements in paragraph (a) of this section, in order to avoid unnecessary duplication of training. 
(c) Initial and recurrent training.-

(1) Initial training. Each hazmat employer shall train each hazmat employce as follows:

(i) Training for a hazmat employee employed on or before November 15, 1992, shall be completed prior to April 1, 1993.

(ii) Training for a hazmat employee employed after November 15, 1992, shall be completed within 90 days after employment.

(iii) A hazmat employee who changes hazardous materials job functions shall complete training in the new job function(s) within 90 days after the change.

(iv) A hazmat employee described in paragraph (c)(1) (ii) or (iii) of this section, may perform new hazardous materials job functions prior to the completion of training provided the employee performs those functions under the supervision of a properly trained and knowledgeable hazmat employee.

(2) Recurrent Training. A hazmat employee shall receive the training required by this subpart at least once every two years.

(3) Relevant Training. Relevant training received from a previous employer or other source may be used to satisfy the requirements of this subpart provided a current record of training is obtained from hazmat employees' previous employer.

(4) Compliance. Each hazmat employer is responsible for compliance with the requirements of this subchapter regardless of whether the training required by this subpart has been completed.

(d) Recordkeeping. A record of current training, inclusive of the preceding two years, in accordance with this subpart shall be created and retained by each hazmat employer for each hazmat employee for as long as that employee is employed by that employer as a hazmat employee and for 90 days thereafter. The record shall include:

(1) The hazmat employee's name;

(2) The most recent training completion date of the hazmat employee's training;

(3) A description, copy, or the location of the training materials used to meet the requirements in paragraph (a) of this section;

(4) The name and address of the person providing the training; and

(5) Certification that the hazmat employee has been trained and tested, as required by this subpart.

(e) Limitation. A hazmat employee who repairs, modifies, reconditions, or tests packagings as qualified for use in the transportation of hazardous materials, and who does not perform any other function subject to the requirements of this subchapter, is not subject to the safety training requirement of paragraph (a)(3) of this section.

Pt. 172, App. A" 


\section{REQUREMENT SOURCE: 49CFR174 Part 7}

"Compliance and training.

(a) Unless this subchapter specifically provides that another person is to perform a particular. duty, each carrier, including a connecting carrier, shall perform the duties specified and comply with all applicable requirements of this part and shall thoroughly instruct hazmat employees in relation thereto.

(b) A carrier may not transport a hazardous material by rail unless each of its hazamat employees involved in that transportation is trained as required by subpart $\mathrm{H}$ of part 172 of this chapter."

\section{REQULREMENT SOURCE: 49CFR177 Part 800}

"Purpose and scope of this part and responsibility for compliance and training.

(a) Purpose and scope. This part prescribes requirements, in addition to those contained in parts $171,172,173,178$ and 180 of this subchapter, that are applicable to the acceptance and transportation of hazardous materials by private, common, or contract carriers by motor vehicle.

(b) Responsibility for compliance. Uniess this subchapter specifically provides that another person shall perform a particular duty, each carrier, including a connecting carrier, shall perform the duties specified and comply with all applicable requirements in this part and shall ensure its hazmat employees receive training in relation thereto.

(c) Responsibility for training. A carrier may not transport a hazardous material by motor vehicle unless each of its hazmat employees involved in that transportation is trained as required by this part and subpart $H$ of part 172 of this subchapter."

\section{REQUREMENT SOURCE: DOE5480.20A Chapter I, Section 7.e Introduction}

"General Employee Training (GET) Requirements. All persons employed either full- or part-time in DOE nuclear facilities shall be trained commensurate with their job duties"

\section{TRAINING RECORDS AND DOCUMENTATION}

\section{REQUIREMENT SOURCE: DOE/EH0256T(940431) Chapter 7, Part 2, Article 725.3}

"Personnel training records shall be controlled and retained. At a minimum, these records shall include the following:
a. Course title;
b. Attendance sheets with instructor's name;
c. Employee's name, identification number and signature;
d. Date of training;
e. Identification of the examination or evaluation form, including sufficient data to identify
which test each person completed;
f. Verification document or record confirming satisfaction of the training requirement;
g. Documentation related to exceptions for training requirements and extensions of qualification;

h. Quizzes, tests, responses and acknowledgements of training, with the date and signature of the person trained; 
Westinghouse Hanford Company (WHC)

Standards/Requirements Identification Document

4.0 Training and Qualification
WHC-SD-MP-SRID-002

January 10, 1996

Rev. 0

Page 9 of 13

i. Special instructions to females, their supervisors and coworkers concerning prenatal radiation dose, acknowledged by the worker's signature."

\section{REQUREMIENT SOURCE: DOE5480.20A Chapter I, Section 15.a}

"Qualification and certification of personnel shall be documented in an easily auditable format. Individual record documentation shall include the following at a minimum:

(1) Education, experience, and employment history and most recent health evaluation summary (e.g., similar to NRC Form 396);

(2) Training programs completed and qualification/certification achieved;

(3) Latest completed checklists, graded written examinations (with answers corrected as necessary or examination keys), simulator examinations (where applicable), and operational evaluations used for certification (this requires controlling access to training records to maintain examination security). The record should include an evaluation of knowledge and performance during operational evaluations;

(4) Lists of questions asked and the examiner's overall evaluation of the responses on oral examinations;

(5) Correspondence relating to exceptions to training requirements and extensions of qualification/certification;

(6) Records of qualification for one-time-only special tests or operations; and

(7) Attendance records for required training courses or sessions."

\section{REQUIREMENT SOURCE: DOE5480.20A Chapter I, Section 15.b}

Author's Note: DOE 1324.2A references the General Record Schedules (GRS) published by the National Archives and Records Administration (NARA). These have been implemented by WHC.

"A historical record that documents initial qualification or certification, and applicable information from the above list that verifies the most recent qualification or certification shall be retained in individual records. Superseded information should be handled in accordance with DOE 1324.2A, RECORDS DISPOSITION."

\section{5}

4.6

4.6.1

\section{ACCREDITATION}

Development and submission of documentation to support successful accreditation of training programs, where required, is a facility specific responsibility therefore, accreditation requirements are not detailed in this S/RID.

\section{KEY INTERFACES}

\section{Ouality Assurance}

Training needs and requirements should be identified by the management of the Quality Assurance functional area at the site level and at each facility. 
4.6 .2

4.6 .3

\subsection{4}

$\underline{4.6 .5}$

$\underline{4.6 .6}$

$\underline{4.6 .7}$

$\underline{4.6 .8}$

\section{Fmercency Management}

Formal training for Emergency Management should be established as defined by the management of the Emergency Management functional area to support general employee training and the Hanford Emergency Response Organization (ERO).

\section{Safequards and Security}

Formal training for Safeguards and Security (SAS) is established as defined by management of the Safeguards and Security functional area. To support the general Site population, input is provided for use in Hanford General Employee Training (HGET). Training topics include: Personnel Security, Information Security, Computer Security, access control, visitor control, escort requirements and protection of classified and non-classified assets.

Additionally, SAS provides initial new hire briefings, comprehensive briefings (for personnel with an access authorization), and vendor/visitor briefings to provide an overview of general security requirements. SAS also supports the employee population with special security education briefings focusing on current Site and facility specific issues as requested.

In addition to meeting facility specific training requirements (radiation protection, etc.), general and specialized protective force training is provided by the Department of Energy Central Training Academy and the Hanford Patrol Training Academy. Such training includes all elements and sub-elements identified in DOE 5632.7A, "Protective Force Program," and DOE M 5632.1C-1, "manual for Protection and Control of Security Interests."

\section{Construction Program}

Training requirements for construction personnel are identified by the project management and are covered in the facility specific S/RIDs.

\section{Operations}

Formal training for the Operations functional area is covered in the facility specific S/RIDs.

\section{Maintenance}

Formal training of Maintenance personnel is determined by the facilities Maintenance Managers and is included in the facility specific S/RIDs.

\section{Radiation Protection}

Formal training provides both general and specific training curricula in the area of radiation protection. Core training requirements are identified in previous sections of this document. Additionally facility specific rad protection training requirements are addressed in the facility specific S/RIDs.

\section{Fire Protection}

Formal training in Fire Protection and Emergency Services is performed by the Hanford Fire Department. All training requirements will be found in the Company Fire Protection Functional Area Document. 


\section{Packaging and Transportation}

Formal training for the Packaging and Transportation functional area provides appropriate personnel with a detailed understanding of applicable Federal, State and local regulations as well as pertinent DOE Orders. Training syllabi is developed in accordance with the needs and requirements identified by the management of the Packaging and Transportation functional area.

\section{Waste Management}

Formal training for the Waste Management functional area is addressed in the facility specific S/RIDs.

\subsubsection{Occupational Safety and Health}

Formal training in Occupational Safety and Health, as defined by functional area management, ensures consistent and thorough understanding of fundamentals for general employees, managers/supervisors, and ensures visitors and contractors are adequately trained prior to performing work.

\section{Environmental Protection}

Formal training in the area of Environmental Protection should be defined by the management of the functional area.

\section{REFERENCES}

\subsection{1}

\section{Requirement Source Documents}

The following documents were used as requirement sources in the development of this Standards/Requirements Identification Document:

10CFR830 Code of Federal Regulations, Nuclear Safety Management, 5/5/94

10CFR835 Code of Federal Regulations, Occupational Radiation Protection, 12/3/93

29CFR1910 Code of Federal Regulations, Occupational Safety and Health, 7/1/94

49CFR172 Hazardous Materials Table, Special Provisions, Hazardous Materials Communications Requirements and Emergency Response Information Requirements, 10/01/92

49CFR174 Carriage by Rail, 10/01/92

49CFR177 Carriage by Public Highway, 10/01/92

DOE-5480.20A Personnel Selection, Qualification, Training, and Staffing Requirements at DOE Reactor and Non-Reactor Nuclear Facilities, 11/15/94

DOE-5500.3A Planning and Preparedness For Operational Emergencies, Change 1, 2/27/92 
Westinghouse Hanford Company (WHC)

Standards/Requirements Identification Document

4.0 Training and Qualification
WHC-SD-MP-SRID-002

January 10, 1996

Rev. 0

Page 12 of 13

\section{$\underline{\mathbf{4 . 7 . 2}}$}

Reviewed Documents Not Used as Reruirement Sources

The following documents were reviewed as requirements sources but were not used in the development of this Standards/Requirements Identification Document:

29CFR1926 Code of Federal Regulations, Safety and Health Regulations for Construction, $7 / 1 / 94$

49CFR175 Carriage by Air, 10/01/92

WAC-173-303-330 Dangerous Waste Regulations, 12/8/93

WA7890008967-DW Dangerous Waste Portion of The Resource Conservation and Recovery Act Permit For The Treatment, Storage, and Disposal of Dangerous Waste (Second Draft), $8 / 29 / 94$

DOE-1324.2A Records Disposition, 9/13/88

DOE-1324.5A Records Management Program, 4/30/92

DOE-4330.4B Maintenance Management Program, 2/10/94

DOE-5000.3B Occurrence Reporting and Processing of Operations Information, 1/19/93

DOE-5400.1 General Environmental Protection Program, 11/9/88

DOE-5400.3 Hazardous and Radioactive Mixed Waste Program, 2/22/89

DOE-5480.1B Environment, Safety and Health Program for Department of Energy Operations, 9/23/86

DOE-5480.4 Environmental Protection, Safety, and Health Protection Standards, Change 4, $1 / 7 / 93$

DOE-5480.5 Safety of Nuclear Facilities, 9/23/86

DOE-5480.7A Fire Protection, 2/17/93

DOE-5480.10 Contractor Industrial Hygiene Program, 6/26/85

DOE-5480.18B Accreditation of Performance-Based Training for Category A Reactors and Nuclear Facilities, 8/31/94

DOE-5480.19 Conduct of Operations Requirements For DOE Facilities, Change 1, 5/18/92

DOE-5480.21 Unreviewed Safety Questions, 12/24/91

DOE-5820.2A Radioactive Waste Management, 9/26/88

DOE-5633.3B Control and Accountability of Nuclear Material, 9/7/94

DOE-5700.6C Quality Assurance, 8/21/91

DOE-5480.23 Nuclear Safety Analysis Reports, 4/30/92 
DOE-5483.1A Occupational Safety and Health Program For DOE Contractor Employees at Government-Owned Contractor-Operated Facilities, 6/22/83

DOE/EH0135 Performance Objectives and Criteria for Technical Safety Appraisals at Department of Energy Facilities and Sites, 6/28/90

DOE-TAP 1 Training Program Manual, 2/4/91

DOE-TAP 2 Performance-Based Training Manual, 2/4/91

DOE-TAP 3 Training Program Suppon Manual, 2/4/91

DOE-RL-91-28 Hanford Facility Dangerous Waste Permit Application, General Information, Revision 1, 5/28/93

ASME-NQA-1-1989-1A Quality Assurance Program Requirements for Nuclear Facilities, 1989

EEl Chapter II EEI Guide to Effective Drug and Alcohol/Fitness for Duty Policy Development, Rev. 0, 8/1/85

ES\&H Guide, Draft C, 4/1/94 
This page intentionally left biank. 
Westinghouse Hanford Company (WHC)

Standards/Requirements Identification Document

5.0 Emergency Management
WHC-SD-MP-SRID-002

January 10, 1996

Rev. 0

Page $i$ of ii

\section{TABLE OF CONTENTS}

5.0 EMERGENCY MANAGEMENT

5.1

5.2

5.3

5.4

5.4 .1

5.4 .2

5.4 .3

5.5

5.6

5.6 .1

5.6 .2

5.6 .3

5.6 .4

5.7

5.8

5.9

5.10

5.10.1

5.10 .2

5.10 .3

5.10 .4

5.11

5.11 .1

5.11 .2

5.11 .3

5.11 .4

5.11 .5

5.11 .6

5.11 .7

5.11 .8

5.11 .9
MANAGEMENT AND ADMINISTRATION $\ldots \ldots \ldots \ldots \ldots \ldots$

EMERGENCY RESPONSE TRAINING $\ldots \ldots \ldots \ldots \ldots \ldots \ldots$

HAZARDS ASSESSMENT $\ldots \ldots \ldots \ldots \ldots \ldots \ldots$

FACILITIES, EQUIPMENT AND RESOURCES $\ldots \ldots \ldots \ldots \ldots$

Emergency Response Facilities $\ldots \ldots \ldots \ldots \ldots$

Emergency Equipment and Supplies $\ldots \ldots \ldots \ldots \ldots$

Communications Equipment $\ldots \ldots \ldots \ldots \ldots$

CLASSIFICATION, NOTIFICATION AND REPORTING $\ldots \ldots \ldots, 7$

PERSONNEL PROTECTION . . . . . . . . . . . . . . 9

Consequence Assessment $\ldots \ldots \ldots \ldots \ldots \ldots$

Protective Actions $\ldots \ldots \ldots \ldots \ldots \ldots \ldots$

Personnel Accountability and Evacuation ........... 9

Medical Response . . . . . . . . . . . . . . . . 10

RECOVERY AND REENTRY $\ldots \ldots \ldots \ldots \ldots \ldots \ldots$

PUBLIC INFORMATION $\ldots \ldots \ldots \ldots \ldots \ldots$

COORDINATION WITH OFFSITE AGENCIES . . . . . . . . 10

DEMONSTRATING, MONITORING AND IMPROVING

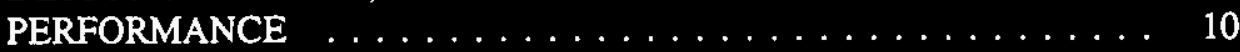

Drill and Exercise Program . . . . . . . . . . . . . . 10

Reviews, Audits and Evaluations $\ldots \ldots \ldots \ldots \ldots \ldots$

Emergency Readiness Assurance Program . . . . . . . . . 11

Deficiency Identification and Correction $\ldots \ldots \ldots \ldots \ldots \ldots$

KEY INTERFACES $\ldots \ldots \ldots \ldots \ldots \ldots \ldots \ldots \ldots \ldots \ldots \ldots$

Safeguards and Security $\ldots \ldots \ldots \ldots \ldots \ldots \ldots \ldots$

Operations .......................... 12

Training and Qualification $\ldots \ldots \ldots \ldots \ldots \ldots \ldots$

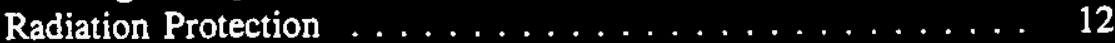

Waste Management . . . . . . . . . . . . . . . . 12

Occupational Safety and Health $\ldots \ldots \ldots \ldots \ldots \ldots$

Fire Protection . . . . . . . . . . . . . . . . 13

Medical ...................... 13

Packaging and Transportation $\ldots \ldots \ldots \ldots \ldots \ldots$ 
5.11 .10

5.11 .11

5.12
Quality Assurance ................... 13

Environmental Protection . . . . . . . . . . . . 13
5.12 .1

5.12 .2

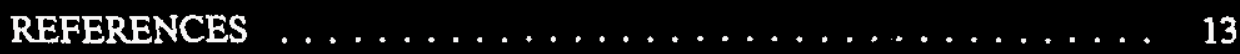

Requirement Source Documents . . . . . . . . . . . . 13

Reviewed Documents Not Used as Requirement Sources . . . . 14 


\subsection{EMERGENCY MANAGEMENT}

\section{INTRODUCTION}

A Standards/Requirements Identification Document (S/RID) sets forth the Environmental Safety and Health (ES\&H) standards/requirements. This S/RID is applicable to the appropriate life cycle phases of design, construction, operation, and decommissioning for each of the categories of facilities addressed in Revision 5 of the Department of Energy Implementation Plan for the Defense Nuclear Facilities Safety Board (DNFSB) Recommendation 90-2. This Recommendation calls for the strengthening of DOE weapons complex activities through the identification and application of relevant DOE Orders, regulations, industry codes/standards, industry guidance documents and, as appropriate, good industry practices. These standards/requirements are adequate to ensure protection of the health and safety of workers, the public and the environment.

The Westinghouse Hanford Company S/RID, as defined in Revision 5 of the Department of Energy Implementation Plan for DNFSB Recommendation 90-2, contains standards/requirements applicable companywide that are necessary for safe operation of the site and its associated facilities, and that are not the direct responsibility of a specific facility manager (e.g., a companywide fire department). Facility S/RIDs contain standards/requirements applicable to a specific facility that are the direct responsibility of the facility manager.

This Standards/Requirements Identification Document (S/RID) defines the Westinghouse Hanford Company (WHC) Emergency Management Program in place at Hanford. The Emergency Management program defined in this document is described in general accordance with the (ES\&H) Configuration Guidelines, Revision 0, dated July 30,1993, and is presented in the form of program elements and subelements. The specific DOE Orders, regulations, industry codes/standards, guidance documents and good industry practices which serve as the basis for each element/subelement are identified and aligned with each subelement.

It is intended that this document be used as a baseline from which to compare the existing Emergency Management program at WHC for determination of the level of program definition and maturity including the existence of an overall site infrastructure and clearly defined interfaces with other relevant functional areas. Additionally, this S/RID may be used as the basis against which future program definition and improvement efforts, including procedures development and/or revisions, can be compared to ensure consistency, completeness and proper integration with other functional programs.

\section{SCOPE OF FUNCTIONAL AREA}

The Emergency Management program exists at Hanford to ensure the safety and health of workers and the public and to protect property and the environment in the event of an emergency. The technical basis for emergency planning is provided by a hazards identification and assessment process, which is used to determine the extent and scope of emergency management activities.

The Emergency Management program complies with state and Federal environmental and occupational health laws and regulations. Washington State is a RCRA Authorized state and therefore WAC-173-303 is used in lieu of 40CFR264 and 40CFR265 with the exception of the Hazardous Solid Waste 
Amendments for which the state has not yet been authorized. This S/RID also cites the extensive series of recently revised DOE Orders which address emergency management. It should be noted that regulatory citations may span functional areas in which case responsibility for compliance may be shared. This is discussed in the Interfaces Section. Additionally, some of the requirements cited in this document are intentionally duplicated in corresponding facility S/RIDs. This was necessary to address required implementation responsibilities occurring at both the company and the facility level.

This document in conjunction with the DOE-RL and facility S/RIDs, define the Emergency Management controls, activities, personnel, and programs implemented by WHC. 


\title{
REQUIREMENT SOURCE: DOE5500.3A Section 11.a
}

\begin{abstract}
Author's Note: Offsite Response Interfaces and Public Information elements are the responsibility of DOE-RL; Medical Support elements are either the responsibility of the Hanford Environmental Health Foundation, Hanford Fire Department and/or RL; and drills are the responsibility of the facility.
\end{abstract}

"As part of the EMS, DOE elements and DOE contractors shall establish and maintain emergency management programs consisting of plans and procedures for response to Operational Emergencies involving or affecting DOE facilities, including DOE transportation activities. These emergency management programs must be commensurate with the assessment of potential hazards and targets and must include the following elements:Emergency Response Organization, Offsite Response Interfaces, Operational Emergency Event Classes, Notification, Consequence Assessment, Protective Actions, Medical Support, Recovery and Reentry, Public Information, Emergency Facilities and Equipment, Training, Drills and Exercises, and Program Administration."

\section{REQUREMENT SOURCE: DOE5500.3A Section 11.c.(1)}

Author's Note: Section (d) is not applicable to WHC.

"Emergency Response Organization. An element with clearly specified authorities and responsibilities for emergency response and mitigation have overall responsibility for the initial and ongoing response to, and mitigation of, an emergency, and must:

(a) Perform, but not be limited to, the following functions: event categorization, determination of the emergency class, notification, provision of protective action recommendations, management and decision making, control of onsite emergency activities, consequence assessment, protective actions, medical support, public information, activation and coordination of onsite response resources, security, communications, administrative support, and coordination and liaison with offsite support and response organizations;

(b) Consist of an adequate number of experienced and trained personnel, including designated alternates, for timely performance of the functions identified above;

(c) Assign emergency response responsibilities and tasks to specific individuals identified by name, title, or position; and

(d) Integrate local agencies and organizations which would be relied upon to provide onsite response services and include those contractor and private organizations that may be relied upon to provide specialized expertise and assistance to all emergency planning, preparedness, and readiness assurance activities."

\section{REQUIREMENT SOURCE: WAC-173-303 Section 360(1)}

Author's Note: Within the context of this requirement, "facility" applies to the Hanford site.

"Emergency coordinator. At all times, there must be at least one employee either on the facility premises or on call with the responsibility for coordinating all emergency response measures. This emergency coordinator must be thoroughly familiar with all aspects of the facility's contingency plan, required by WAC 173-303-350(2), all operations and activities at 
the facility, the location and properties of all wastes handled, the location of all records within the facility, and the facility layout. In addition, this person must have the authority to commit the resources needed to carry out the contingency plan."

\section{REQUIREMENT SOURCE: WAC-173-303(940523) Section 810(2)}

Author's Note: This requirement is cited in the EM functional area due to site-wide contingency plan management responsibility.

"Duty to comply. The permittee must comply with all conditions of his permit. Any permit noncompliance constitutes a violation and is grounds for enforcement action; for permit termination, revocation and reissuance, or modification; or for denial of a permit renewal application. The permittee need not comply with the conditions of his permit to the extent and for the duration such noncompliance is authorized in an emergency permit."

\section{EMERGENCY RESPONSE TRAINING}

Author's Note: The WHC Emergency Management organization provides the training to fulfill this requirement. Other training requirements, for emergency management, are addressed in the functional area(s) that provide the training.

\section{REQUIREMENT SOURCE: DOE5500.3A Section 11.c.(11)(b) Introduction}

Author's Note: Within the context of this requirement, "facility" applies to the Hanford site.

"A formal training program must be in place for the instruction and qualification of all personnel (i.e., primary and alternate) comprising the facility emergency response organization to include initial training and annual retraining for both onsite and offsite incidents, including transportation incidents."

\section{REQUIREMENT SOURCE: DOE5500.3A Section 11.c.(11)(b)(1)}

"All training must be systematic and performance based, i.e., based on an analysis of tasks to be performed during an emergency, and developed with performance objectives, emphasis on team training, and facility-specific emergency response scenarios."

\section{REQUIREMENT SOURCE: DOE5500.3A Section 11.c.(11)(b)(2)}

"Annual retraining shall include training on weaknesses detected during drills and exercises, changes to plans, procedures, and lessons learned from emergencies at DOE and other industrial facilities."

\section{HAZARDS ASSESSMENT}

Author's Note: WHC Emergency Management is the lead for Hazard Assessment.

\section{REQUIREMENT SOURCE: DOE5500.3A Section 11.b.(1)}

"Hazards Assessment. A hazards assessment shall be prepared and maintained for each facility and shall be used for emergency planning purposes. This hazards assessment provides the technical basis for the emergency management program and shall include information sufficient to determine the scope and extent of the program elements comprising the emergency management program for the respective facility. This hazards assessment shall be derived 
from information provided by the assessment of the potential DOE requirements. The use of vulnerability and target analyses may include sensitive or classified information which will need special handling."

\section{REQUIREMENT SOURCE: DOE5500.3A Section 11.b.(2)}

"The hazards assessment shall consider the broad range of emergency events that could affect the facility. These emergency events may result from operation of the facility; accidents; hostile attack, terrorism, sabotage, or malevolent acts; or earthquakes or other natural phenomena. The bazards assessment shall include descriptions of those hazards relevant to potential Operational Emergencies and characterizations of the potential consequences on workers, the public, and the environment. For each potential Operational Emergency events, accident mechanisms, equipment or system failures, event indications, contributing events, source terms, material release characteristics, topography, environmental transport and diffusion, and exposure considerations."

\section{REQUIREMENT SOURCE: DOE5500.3A Section 11.b.(3)}

"Assumptions, methodology, models, and evaluation techniques used in the hazards assessment shall be fully documented. Also, the hazards assessment shall include a determination of the size of the EPZ, i.e., the area surrounding the facility for which special planning and preparedness efforts are required to ensure that prompt and effective protective actions can be taken to minimize the risk to workers, the general public, and the environment."

\section{REQUIREMENT SOURCE: DOE5500.3A Section 11.c.(13)(b)}

Author's Note: The Hanford Site Emergency Plan (DOE/RL-94-02) is the responsibility of DOE-RL.

"The emergency plan and implementing procedures shall be controlled distribution documents and shall be annually reviewed and updated."

\section{REQUREMENT SOURCE: DOE5500.3A Section 11.d.(2)(a)}

"Procedures must consist of special emergency plan implementing procedures (e.g, EALs, event categorization, notification, EOC operation) as well as other procedures currentiy in use (e.g., equipment operation, chemistry controls, radiological monitoring, and maintenance) which would be utilized in, or associated with, emergency response activities."

\section{REQUIREMENT SOURCE: DOE5500.3A Section 11.d.(2)(b)}

"Procedures which describe how the emergency plan shall be implemented. Procedures must be consistent and compatible with the emergency plan. Emergency procedures must contain the detailed information and the specific instructions needed to carry out the emergency plan during a drill, exercise, or actual emergency. Procedures must clearly and concisely identify the individual(s) responsible for performance of response activities and delineate the specific actions/steps to be performed. Procedures must identify the relevant prerequisites (i.e., conditions which must exist prior to specific actions being performed) and precautions (regarding personnel safety and equipment operation) associated with the response actions." 


\title{
REQURRMENT SOURCE: WAC-173-303(940523) Section 350(1)
}

"Purpose. The purpose of this section and WAC 173-303-360 is to lessen the potential impact on the public health and the environment in the event of an emergency circumstance, including a fire, explosion, or unplanned sudden or nonsudden release of dangerous waste or dangerous waste constituents to air, soil, surface water, or ground water by a facility. A contingency plan must be developed to lessen the potential impacts of such emergency circumstances, and the plan shall be implemented immediately in such emergency circumstances."

5.4

$\underline{5.4 .1}$

$\underline{5.4 .2}$

\section{$\underline{5.4 .3}$}

\section{FACILITIES, EQUTPMENT AND RESOURCES}

\author{
Emergency Response Facilities
}

\section{REQUREMENT SOURCE: DOE5500.3A Section 11.c.(10)(a)}

Author's Note: Sentence one is not applicable to WHC.

"An EOC must be established from which the emergency response organization assesses, evaluates, coordinates, and directs emergency response activities and communicates within DOE and with other Federal, state, tribal, and local response organizations. Additional emergency facilities must be designated commensurate with the scope and characteristics of response activities (e.g., technical support, security, personnel assembly, decontamination, medical services, process control, and chemical/radiological analyses)."

\section{Emergency Equipment and Supplies}

\section{REQUIREMENT SOURCE: DOE5500.3A Section 11.c.(10)(d)}

"Adequate equipment and supplies must be available and operable for emergency response personnel to carry out their respective duties and responsibilities."

\section{Communications Equipment}

Author's Note: Within context of this subelement, 29CFR1910 applies to Hanford site-wide sirens and alarms.

\section{REQUIREMENT SOURCE: 29CFR1910 Part 38(a)(3)}

"Employee emergency plans and fire preventions. Emergency action plan. Alarm System.

(i) The employer shall establish an employee alarm system which complies with 1910.165 .

(ii) If the employee alarm system is used for alerting fire brigade members, or for other purposes, a distinctive signal for each purpose shall be used."

\section{REQUTREMENT SOURCE: 29CFR1910 Part 165(b)(1)}

"The employee alarm system shall provide warning for necessary emergency action as called for in the emergency action plan, or for reaction time for safe escape of employees from the workplace or the immediate work area, or both." 


\section{REQUIREMENT SOURCE: 29CFR1910 Part 165(b)(2)}

"The employee alarm shall be capable of being perceived above ambient noise or light levels by all employees in the affected portions of the workplace. Tactile devices may be used to alert those employees who would not otherwise be able to recognize the audibile[SIC] or visual alarm."

\section{REQUIREMENT SOURCE: 29CFR1910 Part 165(b)(3)}

"The employee alarm shall be distinctive and recognizable as a signal to evacuate the work area or to perform actions designated under the emergency action plan."

\section{REQUIREMENT SOURCE: 29CFR1910 Part 165(b)(5)}

"The employer shall establish procedures for sounding emergency alarms in the workplace. For those employers with 10 or fewer employees in a particular workplace, direct voice communication is an acceptable procedure for sounding the alarm provided all employees can hear the alarm. Such workplaces need not have a back-up system."

Author's Note: Within the context of this element, "Notification" applies to emergencies rather than occurrence reporting.

\section{REQUIREMINT SOURCE: DOE5500.1B Section 10.w(20)(a)1}

"Ensure the proper identification, categorization, and notification of emergencies or other reportable occurrences to line management and the HQ EOC, in accordance with applicable DOE policies and requirements; ${ }^{n}$

\section{REQUIREMENT SOURCE: DOE5500.2B Section 11.a.2(a)4e}

"Transportation. An Alert shall be declared when events are in progress or have occurred which involve an actual or potential substantial degradation of the safety of the shipment. Any release of hazardous materials (radiological or non-radiological) is expected to be limited to small fractions of the appropriate PAG or ERPG exposure levels."

\section{REQUTREMENT SOURCE: DOE5500.2B Section 11.a.2(b)7.e}

"Transportation. A Site Area Emergency shall be declared when events are in progress or have occurred which involve an actual or potential major reduction in the safety of the shipment. Any release of hazardous materials (radiological or non-radiological) is expected to exceed appropriate PAG or ERPG exposure levels in the immediate vicinity of the accident or incident but is not expected to exceed the appropriate PAGs or ERPGs in a general public area."

\section{REQUIREMENT SOURCE: DOE5500.2B Section 11.a.2(c)7.e}

"Transportation. A General Emergency shall be declared when events have occurred which involve an actual or imminent catastrophic reduction in the safety of the shipment. Any release of hazardous materials (radiological or non-radiological) is expected to exceed appropriate PAG or ERPG exposure levels in a general public area. If the event has occurred 
on a DOE site, the release is expected to exceed appropriate PAG or ERPG exposure levels offsite"

\section{REQUIREMENT SOURCE: DOE5500.2B Section 12.b(2)(a)}

"The Manager/Administrator of each DOE- or contractor-operated facility shall:

Concurrently notify the HQ EOC and the Field Element of the emergency as soon as crucial information is available but no later than 15 minutes after categorization of the event as an Emergency;"

\section{REQUIREMENT SOURCE: DOE5500.2B Section 12.b(2)(b)}

"Concurrently notify the HQ EOC and the Field Element of all changes in the emergency class within 15 minutes of the redesignation;"

\section{REQUTREMENT SOURCE: DOE5500.2B Section 12.b(2)(e)}

"Notify appropriate regional Federal, state, tribal, and local agencies in accordance with the approved emergency plans and procedures and appropriate memoranda of understanding or other written agreements. Verbal notifications shall be made within 15 minutes of the categorization of the event as an emergency."

\section{REQUIREMENT SOURCE: DOE5500.3A Section 11.c.(3)}

Author's Note: The last sentence is not applicable as offsite interface elements are a responsibility of DOE-RL.

"Operational Emergency Event Classes. Operational Emergencies involving or affecting DOE facilities must be characterized as one of the Operational Emergency classes (e.g., Alert, Site Area Emergency, or General Emergency) in accordance with DOE 5500.2B. EALs, the specific criteria used to recognize and categorize events, must be developed for the spectrum of potential Operational Emergencies identified by the hazards assessment. EALs form the basis for notification and participation of offsite organizations and for determining what and when protective measures will be implemented. EAL initiating conditions (i.e., individual instrument readings, equipment status, valve positions, parameter values, onsite and/or offsite monitor readings, etc.) must be specifically identified in procedures and must be observable and recognizable in a timely manner by responsible personnel. The EALs and related information must be consistent and integrated with the emergency plans and procedures of offsite Federal, state, tribal, and local organizations, and should be reviewed annually, as appropriate, by all parties involved in response activities."

\section{REQUIREMENT SOURCE: DOE5500.3A Section 11.c.(4)}

"Notification. Notification and communication of emergency information must be consistent with the requirements of DOE 5000.3A and 5500.2B. Provisions must be in place for prompt initial notification of appropriate DOE elements and other Federal, state, tribal, and local organizations, and for continuing effective communication among the response organizations throughout an emergency. The content and format of the initial notification and follow-up messages must be prearranged and standardized in the emergency plan. The handling of classified and/or controlled information during an emergency must be in accordance with established procedures and DOE requirements." 


\section{PERSONNEL PROTECTION}

\section{$\underline{5.6 .1}$}

\section{Consequence Assessment}

Author's Note: WHC Emergency Management is the lead for consequence assessment for the Hanford site even though facilities perform this task for their individual structures.

\section{REQUIREMENT SOURCE: DOE5500.3A Section 11.c.(5)}

"Consequence Assessment. Provisions must be in place to adequately assess the actual or potential onsite and offsite consequences of an emergency and must include:

(a) Timely initial assessment of the actual or potential consequences of an emergency and continuous, in-depth assessment of events throughout an emergency;

(b) Integration of the consequence assessment process with the process for categorization of an event as an emergency, determination of the appropriate emergency class, and protective action decision making, including projections of onsite and offsite consequences;

(c) Monitoring and evaluation of the specific indicators necessary to continually assess the consequences of emergency events and to monitor safety, health, environmental, and security conditions which may affect or exacerbate the emergency; and

(d) Coordinate with Federal, state, tribal, and local organizations to locate and track hazardous materials released to the environment; estimate the integrated impact of such release on the public and the environment; and locate and recover materials, especially those with national security implications."

Protective Actions

\section{REQUIREMENT SOURCE: DOE5500.3A Section 11.c.(6)(a)}

Author's Note: Within the context of this requirement, (PAGs) and (ERPGs) are defined as the levels at which protective actions are required.

"Protection Action Guides (PAGs) and Emergency Response Planning Guidelines (ERPGs), prepared in conformance with DOE approved guidance applicable to the actual or potential release of hazardous materials to the environment for use in protective action decision making;"

\section{Personnel Accountability and Evacuation}

\section{REQUIREMENT SOURCE: DOE5500.3A Section 11.c.(6) Introduction}

Author's Note: In this instance this requirement pertains to declared emergency events at the Hanford site.

"Provisions must be in place for specific, predetermined actions to be taken in response to emergency conditions to protect onsite personnel and the public...." 
Author's Note: Requirement DOE5500.3A Section 11.c.(7) was deleted from this subelement and applicable portions addressed in the WHC and facility Fire Protection S/RIDs.

Author's Note: This requirement is cited in this document, though implementation occurs at the facility level, to address site Emergency coordinator authorization required to approve reentry.

"Recovery and Reentry. Provisions must be made for recovery from an Operational Emergency and reentry into the affected facility.

(a) The approach and general procedures for recovery include: decision making and communications associated with termination of an emergency; dissemination of information to Federal, state, tribal, and local organizations regarding the emergency and relaxation of public protective actions; establishment of a recovery organization; and establishment of general criteria for resumption of normal operations.

(b) The means must exist for estimating dosage and for protecting workers and the general public from hazardous exposure during recovery and reentry activities."

\section{PUBLIC NFORMATION}

This function is the responsibility of DOE-RL.

COORDINATION WITH OFFSITE AGENCIES

This function is the responsibility of DOE-RL.

\section{Drill and Exercise Proaram}

Author's Note: Requirements relative to "Drills" are appropriately addressed in facility S/RIDs. Requirements relative to "exerçises" are appropriately addressed in the site-wide document.

REQUTREMENT SOURCE: DOE5500.3A Section 11.c.(12)(b)(1)

"A full participation exercise shall be conducted annually for at least one facility on each DOE site to test and demonstrate an integrated emergency response capability. For multiple-facility sites, the basis of the exercise scenario shall be rotated among those facilities with EPZs extending offsite;

\section{REQUIREMENT SOURCE: DOE5500.3A Section 11.c.(12)(b)(3)}

"Full participation exercises shall require the full participation of HQ and Field Elements. Federal, state, tribal, and local regulatory and/or emergency response organization 
Westinghouse Hanford Company (WHC)

Standards/Requirements Identification Document

5.0 Emergency Management
WHC-SD-MP-SRID-002

January 10, 1996

Rev. 0

Page 11 of 16

participation shall be requested. When these groups respond affirmatively, they shall be accommodated;"

REQUIREMENT SOURCE: DOB5500.3A Section 11.c.(12)(b)(4)

"A control group shall be established for each exercise to ensure that events occur which address the objectives for the exercise;"

REQUIREMENT SOURCE: DOE5500.3A Section 11.c.(12)(b)(5)

"An evaluation group shall be established for each exercise to assess the performance of the exercise participants against the objectives; and"

REQUTREMENT SOURCE: DOE5500.3A Section 11.c.(12)(b)(6)

"A critique process shail be conducted for each exercise to provide initial impressions of accomplishments and shortcomings discovered during the exercise;"

5.10.2 Reviews, Audits and Evaluations

\section{REQUTREMENT SOURCE: DOE5500.10 Section $10 . \mathrm{a}$}

"DOE- or contractor-operated facilities shall conduct annual internal readiness assurance assessments of their emergency management programs. These assessments shall be conducted by contractor personnel not directly responsible during an emergency for performing the functions being assessed. The assessment process will include implementation of management controls for evaluation and correction of assessment results. Assessment results shall be documented and reported to the Head of Field Element."

5.10.3 Emergency Readiness Assurance Program

REQUIREMENT SOURCE: DOE5500.10 Section 8.d(7)

Author's Note: Within the context of this requirement, "facility" applies to the Hanford site.

"Ensure that the Manager/Administrator of each DOE- or contractor-operated facility, as the first or operating level of the line management structure:

(a) Performs internal EMS readiness assurance assessments of the facility, in coordination with the Head of Field Element; and

(b) Prepares the ERAPs and annual updates required by this Order."

\section{REQUIREMENT SOURCE: DOE5500.10 Section 9 General}

"Emergency Readiness Assurance Plans (ERAPs)

a. ERAPs addressing planning and preparedness for emergency response shall be developed for each facility. The initial ERAP and all annual updates shall cover a planning cycle of 5 fiscal years from the date of initial or updated ERAP. Each ERAP section should be organized so as to separate the following information: 
5.10 .4

\subsection{1}

$\underline{5.11 .1}$

$\underline{5.11 .2}$

$\underline{5.11 .3}$

5.11 .4

$\underline{5.11 .5}$

(1) Background material and procedures not subject to change from year-to-year, unless the facility, operation or activity changes; and

(2) Annually updated information containing reports on the activities and accomplishments of the past year and plans, schedules, and budgets for the next 5 fiscal years."

\section{Deficiency Identification and Correction}

WHC Emergency Management is responsible for identification and correction of deficiencies in their respective functional area. Requirements relative to this subelement are addressed in the Quality Assurance functional area.

\section{KEY INTERFACES}

\section{Safequards and Security}

Key interfaces with the WHC Safeguards and Security organization are necessary for the completion of various EM tasks. Although the WHC EM organization takes the lead on these tasks, they require input from the SAS organization in the following areas: development of scenarios for emergency exercises; development of hazards assessments, and radiological and toxicological sabotage assessments; and coordination of access control provisions during emergencies.

\section{Operations}

EM interfaces with various Facility Operations personnel to develop credible operational scenarios for emergency exercises; to ensure coordination between emergency operating procedures and emergency plan implementing procedures; and to coordinate plans for on-scene incident command during emergencies. EM has one area of overiapping responsibility with Operations, that being WAC-173-303-360 which addresses operational procedures used in emergency mitigation.

\section{Training and Oualification}

Key interfaces with WHC Training Services are necessary for successful implementation of EM responsibilities, such as: ensuring inclusion of appropriate emergency plan/response information in HGET programs; tracking of training completion documentation; and coordination of onsite and imported training conducted relative to Occurrence Reporting.

\section{Radiation Protection}

Key interfaces with Radiation Protection are necessary for technical support of EM activities, and they include: Identification of dose limits, coordination to support onsite and offsite environmental radiological monitoring and sampling; assistance in scenario development; and support for the development of hazards assessments.

\section{Waste Management}

Key interfaces with Waste Management are not required to support the EM operations. Waste Management related interfaces necessary to support EM activities are addressed in the Operations interface subelement $(5.11 .2)$ above. 


\subsection{1 .6}

$\underline{5.11 .7}$

$\underline{5.11 .8}$

$\underline{5.11 .9}$

$\underline{5.11 .10}$

5.11 .11

5.12

$\underline{5.12 .1}$

\section{Occupational Safety and Health}

Key interfaces with OS\&H are necessary for development of hazards assessments and exercise scenarios development.

\section{Fire Protection}

Key interfaces with the Hanford Fire Department are necessary for successful operations during emergency activities related to HAZMAT, medical, fire suppression, rescue, and support for exercise scenario development and exercise participation.

\section{Medical}

Refer to 5.11.7, Fire Protection.

\section{Packaging and Transportation}

EM interfaces with Packaging and Transportation to provide appropriate emergency response information and carrier jinstructions, including organizations and authorities to be notified in the event of release of materials. Coordination between the Transportation Program and EM ensures that commonly handled hazardous materials are known and included in emergency plans for the facility, and that special equipment or vehicles for transportation are known and available for emergency situations.

\section{Ouality Assurance}

EM interfaces with Quality Assurance (QA) to ensure that independent assessments, audits, and corrective action programs meet site QA standards. QA may perform independent assessments of the EM program.

\section{Environmental Protection}

EM interfaces with Environmental Protection in coauthorship of the Hanford Facility Contingency Plan which addresses RCRA permit requirements. EM has several areas of overlapping responsibility with Environmental Protection, including the RCRA permit, 40 CFR 302,40 CFR 355, and WAC-173-303.

\section{REFERENCES}

\section{Requirement Source Documents}

The following documents were used as requirement source in the development of this EM Functional Area Document.

29 CFR 1910, Hazardous Waste Operations and Emergency response; OSHA, effective $07 / 01 / 93$

WAC-173-303, Dangerous Waste Regulations; WA Department of Ecology, 05/23/94

DOE 5500.2B, Emergency Categories, Classes, and Notification and Reporting Requirements, $04 / 30 / 91$ 
Westinghouse Hanford Company (WHC)

Standards/Requirements Identification Document

5.0 Emergency Management
WHC-SD-MP-SRID-002

January 10, 1996

Rev, 0

Page 14 of 16

DOE 5500.3A, Planning and Preparedness for Operational Emergencies, 04/30/91

DOE 5500.10, Emergency Readiness Assurance Program, 04/30/91

$\underline{5.12 .2}$

\section{Reviewed Documents Not Used as Requirement Sources}

The following documents were reviewed but not cited:

Public law 94-580, Resource Conservation and Recovery Act of 1976, as amended, 90 Stat. 2795,42 US 6901 et seq.

Public law 94-95, Clean Air Act of 1977, as amended, 91 Stat. 685, 42 USC 7401

Public law 95-217, Clean Water Act of 1977, as amended, 92 Stat. 1566, 33 USC 1251

Public law 95-510, Comprehensive Environmental Response, Comprehensive and Liability Act of 1980, as amended, 94 Stat. 2767, 42 USC 96012 et seq.

50 FR 46542, Federal Radiological Emergency Response Plan; 11/08/85, and FRERP Agency Coordinating Draft of $03 / 12 / 94$

40 CFR 265, Interim Status Standards for Owners and Operators of Hazardous Waste Treatment, Storage, and Disposal Facilities; EPA, effective 07/01/92

40 CFR 302, Designation, Reportable Quantities, and Notification; EPA, effective 07/01/92

40 CFR 355, Emergency Planning and Notification; EPA, effective 07/01/92

WA7890008967, RCRA Permit for the Treatment, Storage, and Disposal of Hazardous Waste; DOE, EPA, and WA Department of Ecology, 02/94

WAC-296-62, Hazardous Waste Operations and Emergency Response; WA Department of Labor and Industries, 1990 Edition

DOE 1324.2A, Records Disposition; 09/13/88, Page Chg. 1: 04/09/92

DOE 5000.3B, Occurrence Reporting and Processing of Operations Information; 01/19/93

DOE 5300.1B, Telecommunications; $12 / 02 / 88$

DOE 5480.10, Contractor Industrial Hygiene Program; 06/26/85

DOE 5480.19, Conduct of Operations Requirements for DOE Facilities; 007/09/90, Page Chg. 1: $05 / 18 / 92$

DOE 5480.20A, Personnel Selection, Qualification, Training, and Staffing Requirements at DOE Reactor and Non-Reactor Nuclear Facilities; 11/15/94

DOE 5500.1B, Emergency Management System, 04/30/91

DOE 5480.23, Nuclear Safety Analysis Reports; 04/10/92, Page Chg. 1: 03/10/94

DOE 5481.1B, Safety Analysis and Review System; 09/23/86, Page Chg. 1: 05/19/87 
DOE 5482.1B, Environmental, Safety, and Health Appraisal Program; 09/23/86, Page Chg. 1: $11 / 18 / 91$

DOE 5484.1, Environmental Protection, Safety and Health Protection information Reporting Requirements; 02/24/81, Page Chg. 7: 10/17/90

DOE 5500.4A, Public Affairs Policy and Planning Requirements for Emergencies, 06/08/92

DOE 5500.7B, Emergency Operating Records Protection Program; 10/23/91

DOE 5530.1A, Accident Response Group; 0*/20/91

DOE 5530.2, Nuclear Emergency Search Team; 09/20/91

DOE 5530.3, Radiological Assistance Program; 01/14/92

DOE 5530.4, Aerial Measuring Systems; 09/20/91

DOE 5530.5, Federal Radiological Monitoring and Assessment Center; 07/10/92, Page Chg. 1: $12 / 02 / 92$

DOE 5632.8, Protection Program Operations: System Performance Tests, 02/04/88

DOE 5630.11A, Safeguards and Security Program; $12 / 07 / 92$

DOE/RL-91-28, Hanford Facility Contingency Plan, Rev. 1; Appendix 7A to the RCRA Permit for the Treatment, Storage, and Disposal of Hazardous Waste; DOE, EPA, and WA Department of Ecology, 05/28/93

DOE/RLID 5630.3A, Protection of Hanford Facilities against Radiological and Toxicological Sabotage, 09/29/94

DOE/EH 0135, Performance Objectives and Criteria for Technical Safety Appraisals at Department of Energy Facilities and Sites, 06/28/90

EMG-ADM, Program Administration, 12/11/91

EMG-CA, Guidance for Consequence Assessment, 07/28/92

EMG-D/EX, Guidance for Event Classifịcation and Emergency Action Levels; 06/26/92

EMG-EC, Guidance for Event Classification and Emergency Action Levels; 06/26/92

EMG-EDR, Emergency Deployment Readiness Evaluation; 12/11/91

EMG-EMS, Interim Guidance for Emergency Medical Support, 06/26/92

EMG-ERAP, Guidance for Emergency Readiness Assurance Plans (ERAPs); 07/23/93

EMG-ERO, Interim Guidance for Emergency Response Organization, 07/30/93

EMG-EXEC, Emergency Exercise Evaluation Criteria; 12/11/91

EMG-FAC/EQ, Interim Guidance for Emergency Facilities and Equipment, 07/30/93 
EMG.HAZ, Guidance for Hazards Assessment, 06/26/92

EMG-INT, Introduction to Emergency Management Guide

EMG-N, Interim Guidance for Notification, 07/28/92

EMG-ORI, Interim Guidance on Offsite Response Interfaces; 07/28/92

EMG-PA, Interim Guidance for Protective Actions, 06/01/93

EMG-PI, Guidance for Public Information; 06/26/92

EMG-R/R, Interim Guidance for Reentry and Recovery, 06/01/93

EMG-TRNG, Interim Guidance for Emergency Management Training, 07/28/92

BMP 85-001, Performance Objectives and Criteria for Operating and Near-term Operating License, Rev. 1; 04/87

BMP 85-014, Generic Guidance for Emergency Preparedness Program Review, Rev. 1, 04/91

BMP 87-019, Maintaining Emergency Preparedness Manual, Rev. 0, 11/87 
Westinghouse Hanford Company (WHC)

Standards/Requirements Identification Document

6.0 Safeguards and Security
WHC-SD-MP-SRID-002

January 10, 1996

Rev. 0

Page $i$ of ii

\section{TABLE OF CONTENTS}

6.0 SAFEGUARDS AND SECURITY $\ldots \ldots \ldots \ldots \ldots \ldots \ldots \ldots \ldots \ldots \ldots$

6.1

6.2 .1

6.3

6.3 .1

6.3 .2

6.3.3

6.3.3.1

6.3.3.2

6.3 .4

6.3 .5

6.3.6

6.4

6.4.1

6.4 .2

6.4 .3

6.5

6.6

6.6 .1

6.6 .2

6.6.3

6.6 .4

6.6 .5

6.6.6

6.7

6.8

6.9
MANAGEMENT AND ADMINISTRATION $\ldots \ldots \ldots \ldots \ldots . \ldots . \ldots$

PERSONNEL SECURTYY $\ldots \ldots \ldots \ldots \ldots \ldots \ldots \ldots$

Personnel Security Assurance Program (PSAP) $\ldots \ldots \ldots \ldots$

PROTECTION PROGRAM OPERATIONS $\ldots \ldots \ldots \ldots \ldots$

Physical Security $\ldots \ldots \ldots \ldots \ldots \ldots \ldots \ldots \ldots$

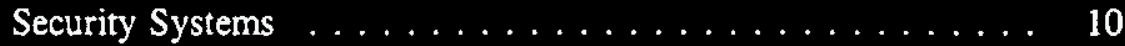

Protective Forces $\ldots \ldots \ldots \ldots \ldots \ldots \ldots \ldots$

Training and Equipment . . . . . . . . . . . 13

Communications $\ldots \ldots \ldots \ldots \ldots \ldots \ldots$

Security Identification Badges and Passes $\ldots \ldots \ldots \ldots$

Incident Response and Management $\ldots \ldots \ldots \ldots \ldots$

Transportation Security $\ldots \ldots \ldots \ldots \ldots$

MATERIAL CONTROL AND ACCOUNTABILITY FOR SPECIAL

NUCLEAR . . . . . . . . . . . . . . . . . . . . 19

Material Control and Accountability Plan . . . . . . . . . . 20

Special Nuclear Material Accountability System . . . . . . . . 22

Material Control System . . . . . . . . . . . . 27

FACILITY APPROVALS, SECURITY AND NUCLEAR MATERIAL

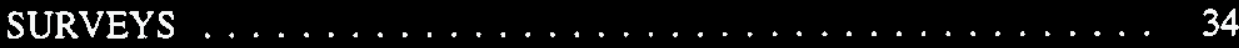

INFORMATION SECURITY $\ldots \ldots \ldots \ldots \ldots \ldots \ldots \ldots \ldots$

Classified Matter Protection and Control (CMPC) $\ldots \ldots \ldots$

Technical Surveillance Countermeasures (TSCM) . . . . . . 42

Automated Information Systems Security Program (Classified

Computer Security) . . . . . . . . . . . . . . . . . . 42

Unclassified Computer and Sensitive Automated Data Processing

Systems ... . . . . . . . . . . . . . . . 44

Communications Security $\ldots \ldots \ldots \ldots \ldots \ldots$

Counterintelligence .................. 45

OPERATIONS SECURITY (OPSEC) $\ldots \ldots \ldots \ldots \ldots \ldots$

FOREIGN OWNERSHIP, CONTROL OR INFLUENCE (FOCI) $\ldots .48$

EVALUATION OF RADIOLOGICAL AND TOXICOLOGICAL

SABOTAGE ....................... 
Westinghouse Hanford Company (WHC)

Standards/Requirements Identification Document

6.0 Safeguards and Security
WHC-SD-MP-SRID-002

January 10, 1996

Rev. 0

6.10

KEY INTERFACES $\ldots \ldots \ldots \ldots \ldots \ldots \ldots \ldots \ldots \ldots, 50$

6.10 .1

Emergency Management $\ldots \ldots \ldots \ldots \ldots \ldots \ldots \ldots, 50$

6.10 .2

Packaging and Transportation $\ldots \ldots \ldots \ldots \ldots \ldots \ldots, 51$

6.11

REFERENCES $\ldots \ldots \ldots \ldots \ldots \ldots \ldots \ldots \ldots \ldots \ldots \ldots$

6.11 .1

Requirement Source Documents . . . . . . . . . . . . 51

6.11 .2

Reviewed Documents Not Used as Requirement Sources

52 


\subsection{SAFEGUARDS AND SECURITY}

\section{INTRODUCTION}

A Standards/Requirements Identification Document (S/RID) sets forth the Environmental Safety and Health (ES\&H) standards/requirements. This S/RID is applicable to the appropriate life cycle phases of design, construction, operation, and decommissioning for each of the categories of facilities addressed in Revision 5 of the Department of Energy Implementation Plan for the Defense Nuclear Facilities Safety Board (DNFSB) Recommendation 90-2. This Recommendation calls for the strengthening of DOE weapons complex activities through the identification and application of relevant DOE Orders, regulations, industry codes/standards, industry guidance documents and, as appropriate, good industry practices. These standards/requirements are adequate to ensure protection of the health and safety of workers, the public, and the environment.

The Westinghouse Hanford Company S/RID, as defined in Revision 5 of the Department of Energy Implementation Plan for DNFSB Recommendation 90-2, contains standards/requirements applicable companywide that are necessary for safe operation of the site and its associated facilities, and that are not the direct responsibility of a specific facility manager (e.g., a companywide fire department). Facility S/RIDs contain standards/requirements applicable to a specific facility that are the direct responsibility of the facility manager.

This Standards/Requirements Identification Document (S/RID) defines the Westinghouse Hanford Company (WHC) Safeguards and Security program in place at Hanford. The Safeguards and Security program defined in this document is described in general accordance with the (ES\&H) Configuration Guidelines, Revision 0, dated July 30,1993, and is presented in the form of program elements and subelements. The specific DOE Orders, regulations, industry codes/standards, guidance documents and good industry practices which serve as the basis for each element/subelement are identified and aligned with each subelement.

It is intended that this document be used as a baseline from which to compare the existing Safeguards and Security Program for determination of the level of program definition and maturity, generation of implementing requirements and documents, existence of an overall site infrastructure and clearly defined interfaces with other relevant functional areas. Additionally, this S/RID may be used as the basis against which future program definition and improvement efforts, including procedures development and/or revisions, can be compared to ensure consistency, completeness and proper integration with other functional programs. For application in this S/RID, the words "shall" and "should" in requirement statements both indicate mandatory compliance. The key interface information is provided for general recognition and understanding and is not considered to contain prescriptive requirements.

\section{SCOPE}

This document, in conjunction with the DOE-RL and facility S/RIDs, defines the Safeguards and Security controls, activities, personnel, and programs implemented by Westinghouse Hanford Company. Some requirements contained in this document were intentionally duplicated in facility level S/RIDs to capture the joint responsibility for implementation by both the company and facility. 
For purposes of this document and as it pertains to Safeguards and Security, the term "facility" is defined as the Hanford site. Additionally, there are no vital areas/vital equipment on the Hanford site, as defined in the DOE Safeguards and Security Orders. 
Author's Note: Westinghouse Hanford Company (WHC) will comply with all contractually imposed Safeguards and Security (SAS) requirements, identified in orders and directives, unless specifically exempted by DOE. The WHC SAS Functional Area identifies Environmental, Safety and Health related requirements implemented by a company level organization.

\section{REQUTREMINT SOURCE: DOE-M-5632.1C-1 Chapter I, Section 4}

Author's Note: Only 4.a is applicable at this time.

"PLANNING.

a. Site Safeguards and Security Plans. The details of site protection measures shall be addressed in the Site Safeguards and Security Plan, as required by DOE 5630.14A, SAFEGUARDS AND SECURITY PROGRAM PLANNING.

b. Security Plans. At locations where a Site Safeguards and Security Plan is not required due to the limited scope of safeguards and security interests, a security plan shall be developed to describe the protection program in place."

\section{REQUTREMENT SOURCE: DOE5630.11B Section 7}

"POLICY.

a. DOE interests shall be protected against a range of threats which include unauthorized access; theft or diversion of nuclear weapons, weapons components, or special nuclear material; sabotage; espionage; loss or theft of classified matter or Government property; and other hostile acts which may cause unacceptable adverse impacts on national security or on the health and safety of DOE and contractor employees, the public, or the environment.

b. Design Basis Threat Policy, issued by the Director of Security Affairs, shall be utilized in the design and implementation of protection programs.

c. Levels of protection appropriate to particular security interests shall be provided in a graded manner in accordance with the potential risks.

d. Protection levels shall be comparable in effectiveness to other federally regulated programs with similar security interests, such as the Nuclear Regulatory Commission and the Department of Defense, when such leveis are consistent with DOE protective needs, and national security interests.

e. Deviations from the requirements of Safeguards and Security directives are only permissible with the written approval of the responsible officials according to this Order. Variances, waivers, and exceptions to Safeguards and Security directive requirements may be granted on a case-by-case basis.

f. Deviations from the requirements of Safeguards and Security directives relating to Sensitive Compartmented Information Facilities and other intelligence facilities will be coordinated with the Director of Energy Intelligence and the Office of Safeguards and Security." 


\section{REQUIREMENT SOURCE: DOE5630.11B Section 9.d}

"Site Specific Programs. Individual safeguards and security programs shall be tailored to address specific site characteristics. The Site Safeguards and Security Planning process enables cognizant line organization program offices and field managers, in consultation with. the Director of Safeguards and Security, to design and implement a protection program tailored to their respective operational needs, recognizing ongoing programs, current threat guidance, current policy and technology, and unique site specific requirements. Site-specific protection programs shall be documented in SSSPs. The residual risks to be accepted by the Department will be identified by vulnerability/risk analyses."

\section{REQUIREMENT SOURCE: DOE5630.13A Section 5.a}

"Levels of protection shall be provided in consideration of the potential risks to national security and the health and safety of the public."

\section{REQUIREMENT SOURCE: DOE5630.13A Section 5.b}

"The levels of protection identified in approved facility MSSA's shall be the basis for facility planning, executing, and evaluating the protection program."

\section{REQUIREMENT SOURCE: DOE1240.2B Preamble, Section 9.a}

"Origination and Processing. Requests for unclassified foreign national visits and assignments originate in various ways: with field elements or DOE contractors; with Headquarters offices, or with foreign entities. All assignments require the use of DOE F IA-473, as do certain visits, as specified in paragraph 9b, below. (See foreign nationals proposed for visits or assignments.) For a visit not requiring use of DOE F IA-473 to an access-controlled facility, the visit shall be documented and a record kept to show the name, date of birth, place of birth, and nationality of the visitor, the date(s) of the visit, the host(s), and the purpose."

\section{REQUIREMENT SOURCE: DOE5631.1C PREAMBLE, Section 5.a}

"The formulation and maintenance of a structured safeguards and security awareness program is required for all Departmental elements and contractors."

\section{REQUIREMENT SOURCE: DOE5631.1C PREAMBLE, Section 5.b}

"As a condition of access to DOE security areas or classified information, all DOE and DOE contractor employees shall attend briefings as required by this Order. Failure of an individual to attend specified briefing(s) shall be grounds for denial of access to classified information and security areas."

\section{REQUIREMENT SOURCE: DOE5631.2C Preamble, Section 7.b}

"DOE contractors may not request clearances for the purpose of establishing cleared pools of potential employees or to alleviate responsibilities for escorting uncleared individuals within a security area. A clearance shall be requested only for individuals who have been offered employment or for personnel who are expected to fill projected vacancies or requirements." 
"Recertification. Prior to forwarding an individual's security forms to DOE personnel security for reinvestigation processing, a review of the individual's continuing need for a DOE access authorization at the existing level will be conducted by the individual's sponsor, i.e., the entity or person that originally requested the individual be processed for DOE access authorization. The sponsor must certify to DOE that the individual requires continuation of the access authorization and indicate the level of classified information or category(ies) of special nuclear material the individual requires access to in order to perform the official duties of the position. The recertification that is provided by the sponsor will be reviewed by the cognizant Departmental security office and must be approved prior to the initiation of the reinvestigation described in paragraph 3 , below. If the individual no longer requires access to classified matter or special nuclear material in order to perform official duties, the access authorization shall be terminated."

\section{REQUIREMENT SOURCE: DOE5631.2C(940217) Chapter VII, Section 2.c, Sentence 1}

"Review of Continued Eligibility. The reeveluation[SIC] of continued eligibility for the access authorization and a review of the individual's eligibility for continuation of DOE access authorization will be completed every 5 years."

\section{REQUREMENT SOURCE: DOE5631.4A Preamble, Section 7.g(1)}

"Implement the visitor control system for facilities under their jurisdiction to assure that:

(a) The identity and clearance status of visitors are determined.

(b) Limitations with respect to access to classified information are established.

(c) Timely notice is given to persons concerned of all visits to facilities under their jurisdiction."

\section{Personnel Security Assurance Program (PSAP)}

Author's Note: The PSAP program is administered by WHC Human Resources Organization.

\section{REQUIREMENT SOURCE: DOE-0-472.1 Attachment 1, Part 12}

"PERSONNEL SECURITY ASSURANCE PROGRAM REOUIREMIENTS. Contractors shall prepare a Personnel Security Assurance Program (PSAP) Implementation Plan when their site, facility, or operations are identified as having PSAP Positions and implement the provisions of the PSAP Implementation Plan within 30 working days of its approval. The PSAP Implementation Plan, prepared in accordance with requirements in 10 CFR 710, Subpart B and DOE O 472.1, shall reflect the PSAP requirements to which the contractor has agreed."

\section{REQUIREMENT SOURCE: DOE-0-472.1 Part 4.a}

"Personnel Security Assurance Program (PSAP).

(1) An individual shall not be processed under 10 CFR 710 , Subpart $B$, to determine suitability for Federal, contractor, or other employment. 
(2) An individual shall not occupy a PSAP designated position until approval has been granted by a PSAP Approving Official.

(3) A PSAP Implementation Plan shall be prepared for each site or facility with PSAP designated positions."

\section{REQUTREMENT SOURCE: DOE-0-472.1 Part 5.1}

"Managers of DOE Organizations and Contractors Having PSAP Positions.

(1) Prepare a PSAP Implementation Plan and manage PSAP activities consistent with 10 CFR 710, Subpart B, which includes the identification of PSAP positions at sites/facilities under their cognizance.

(2) Conduct a drug testing program for incumbents in, and applicants for, PSAP positions in accordance with 10 CFR 707.

(3) Ensure that supervisory reviews and medical assessments are conducted and make recommendations on PSAP applicants and employees pursuant to initial and annual reviews, and at any other time as appropriate.

(4) Immediately notify the PSAP Approving Official of information that represents a security concem regarding a PSAP designated employee."

\section{REQUIREMENT SOURCE: DOE-0-472.1 Part 5.p}

"Individuals Assigned to a PSAP Designated Position.

(1) Execute PSAP releases, acknowledgments, and waivers to facilitate the collection and dissemination of information and the performance of drug testing and medical examinations.

(2) Notify the Site Occupational Medical Director immediately of a physical or mental condition requiring medication or treatment.

(3) Report in person, prior to retuming for work, to the Site Occupational Medical Director following periods of sick leave of 5 or more consecutive workdays.

(4) Comply with the requirements listed below in subparagraph 5q."

\section{REQUTREMENT SOURCE: DOE-M-5632.1C-1 Chapter I, Section 1}

"SITE-SPECIFIC CHARACTERISTICS: Protection programs shall be tailored to address specific site characteristics and requirements, current technology, ongoing programs, operational needs, and to achieve acceptable protection levels that reduce inherent risks on a cost-effective basis."

Physical Security

REQUIREMENT SOURCE: DOE-M-5632.1C-1 Chapter IX, Section 2.c

"Emergency Procedures. Procedures shall be developed for safeguarding classified matter in emergency situations. 
(1) If feasible, classified matter shall be secured in security containers and the intrusion detection system activated.

(2) If the emergency is life threatening, the health and safety of personnel shall take precedence over the need to secure classified matter. Security containers, vaults, and vault-type rooms shall be inspected on return to the facility to determine whether classified information has been compromised or if any classified matter is missing."

\section{REQUREMENT SOURCE: DOE-M-5632.1C-1 Chapter IX, Section 2.d, Sentence 1}

"Protection of Security Containers and Combinations. Combinations shall be protected at the classification level and category of the matter being protected."

\section{REQUIREMENT SOURCE: DOE-M-5632.1C-1 Chapter IX, Section 2.e, Introduction, Sentence 1}

"Changing Combinations. Combinations shall be changed by an appropriately cleared authorized individual."

\section{REQUIREMENT SOURCE: DOE-M-5632.1C-1 Chapter IX, Section 2.h}

"Damage and Repair of General Services Administration-Approved Security Containers. Neutralization of lockouts or repair of any damage that affects the integrity of a security container approved for the storage of classified information shall be accomplished only by appropriately cleared locksmiths."

\section{REQUIREMENT SOURCE: DOE-M-5632.1C-1 Chapter V, Section 1.f}

"Means shall be provided to deter and detect unauthorized intrusion into Security Areas. Means include use of intrusion detection sensors and alarm systems, random patrols, and/or visual observation. The protection program shall include suitable means to assess alarms."

\section{REQUREMENT SOURCE: DOE-M-5632.1C-1 Chapter V, Section 1.h}

"Clearly defined physical barriers, such as fences, walls, and doors, shall be used to define the boundary of a Security Area. Barriers shall meet the following requirements, as well as supplementary requirements at paragraph 1, page VII-1:

(1) Barriers shall direct the flow of personnel and vehicles through designated entry control portals.

(2) Barriers and entry control portals, supplemented by other systems such as patrols or surveillance, shall be used to deter and detect introduction of probibited articles or removal of safeguards and security interests.

(3) Barriers shall be used to deter and/or prevent penetration by motorized vehicles where vehicular access could significantly enhance the likelihood of a successful malevolent act.

(4) Barriers shall be capable of controlling, impeding, or denying access to a Security Area." 


\section{REQUREMENT SOURCE: DOE-M-5632.1C-1 Chapter V, Section 3.a}

"Requirements. A Limited Area shall have barriers identifying its boundaries and encompassing the designated space, as well as access controls to provide reasonable assurance that only authorized personnel are allowed to enter and exit the area. Limited Area access. requirements shall be administered as follows:

(1) Individuals permitted unescorted access shall have access authorization and need-to-know consistent with the matter under protection in the area.

(2) When access to a Limited Area is authorized for a person without appropriate access authorization or need-to-know, measures shall be taken to prevent compromise of classified matter.

(3) Access to safeguards and security interests within a Limited Area, when not in approved storage, shall be controlled by the custodian(s) or authorized user(s). ${ }^{n}$

\section{REQUREMENT SOURCE: DOE-M-5632.1C-1 Chapter V, Section 5.a(1) and (2) Introduction}

"Inspections. Inspections for a Protected Area shall be as follows:

(1) Entrance inspections of personnel, vehicles, and hand-carried items shall be conducted to deter and detect the unauthorized introduction of prohibited articles. Specific inspection procedures and special nuclear material/metal detection levels and limitations shall be established and documented.

(2) Exit inspections of personnel, vehicles, and hand-carried items shall be conducted to deter and detect the unauthorized removal of special nuclear material. Specific inspection procedures and special nuclear material/metal detection levels and limitations shall be established and documented. When the Protected Area encompasses a Material Access Area, the exit inspections at the Protected Area boundary may be performed on a random basis with the extent and frequency determined by the cognizant local DOE authority for safeguards and security."

\section{REQUIREMENT SOURCE: DOE-M-5632.1C-1 Chapter V, Section 5.b}

"Personnel and Vehicie Access Control. Validation of the identity and access authorization of persons authorized access shall be administered by armed protective force personnel and/or an automated access control system as determined by local safeguards and security authorities. Access control requirements shall be as follows:

(1) Private vehicles shail be prohibited from a Protected Area.

(2) Government-owned or Government-leased vehicles shall be admitted only when on official business and when operated by properly cleared and authorized drivers, or when escorted by properiy cleared, authorized personnel. Service and delivery vehicles shall be admitted only when on authorized business and when driven or when escorted by properly cleared, authorized personnel. Entry of service and delivery vehicles shall be kept to an operational minimum." 
"Requirements. Inspections shall provide reasonable assurance against the unauthorized introduction of prohibited articles or removal of special nuclear material by force, stealth, or deceit.

(1) Entrance inspections of personnel, vehicles, and hand-carried items shall be conducted to deter and detect the unauthorized introduction of prohibited articles.

(2) Exit inspections of personnel, vehicles, and hand-carried items shall be conducted to deter and detect the unauthorized removal of special nuclear material. Specific inspection procedures and special nuclear material/metal detection levels and limitations shall be established and documented. "

\section{REQUIREMENT SOURCE: DOE-M-5632.1C-1 Chapter V, Section 7.b Introduction}

"Personnel and Vehicle Access Control. Access control shall be administered by armed protective force personnel and/or automated access control systems as determined by local safeguard and security authorities."

\section{REQUIREMENT SOURCE: DOE-M-5632.1C-1 Chapter V, Section 7.b(1)}

"Validation of the identity, access authorization, and authority to enter for persons allowed access shall be accomplished at Material Access Area entrances,"

\section{REQUREMENT SOURCE: DOE-M-5632.1C-1 Chapter V, Section 8.b}

"Central Alarm Station. A Central Alarm Station shall be used in protection of Category I and Category II quantities of special nuclear material. A Central Alarm Station shall meet the requirements of a hardened post and shall be located, as a minimum, within a Limited Area. Requirements are as follows:

(1) An access control system shall be used to restrict admittance to persons who require access in the performance of official duties.

(2) A Central Alarm Station shall be attended constantly by personnel who possess access authorizations that are commensurate with the most sensitive asset that is under the protection of the Central Alarm Station.

(3) A Central Alarm Station protecting classified matter shall be of sound construction meeting local building codes."

REQURREMENT SOURCE: DOE-M-5632.1C-1 Chapter VII, Section 2.b, Sentences 1 and 2

"Key Management. Security keys shall be protected at the same level as the asset under protection. An inventory and accountability system shall be implemented." 


\section{REQUIREMENT SOURCE: DOE-M-5632.1C-1 Chapter I, Section 3.e}

"Safeguards and security systems and critical systems elements shall be performance tested to ascertain their effectiveness in providing countermeasures to address design basis threats."

\section{REQUTREMENT SOURCE: DOE-M-5632.1C-1 Chapter V, Section 8.c}

"Secondary Alarm Stations. Facilities with Category I or II quantities of special nuclear material shall have a Secondary Alarm Station. Used as an alternative alarm annunciation point to the Central Alarm Station, the Secondary Alarm Station shall be maintained at a location continuously manned, such that a response can be initiated in the event a Central Alarm Station is unable to perform its intended function. Secondary Alarm Stations shall meet the operational requirements of Central Alarm Stations with the exception of hardening and location within a Limited Area. The Secondary Alarm Station need not be fully redundant to the Central Alarm Station, but shall be capable of providing effective control response to safeguards and security incidents."

\section{REQUIREMENT SOURCE: DOE-M-5632.1C-1 Chapter VI, Section 1, Introduction}

"GENERAL. Intrusion detection systems shall be installed to provide reasonable assurance that breaches of security boundaries are detected and that assessment information is provided to protective personnel. Intrusion detection systems shall be provided for Protected Areas as required at page V-5, paragraph 5, Vital Areas as required at page V-6, paragraph 6, and for Material Access Areas and special nuclear material as discussed in paragraphs $2 b, 3$, and 4 below. Intrusion detection systems shall be provided for protection of classified matter as described at page III-1, paragraph 3. Intrusion detection systems shall also be provided for vaults, vault-type rooms, Sensitive Compartmented Information Facilities, Classified Automated Information System facilities, and Secure Communications Centers. For other applications, the impact of loss or destruction of property and facilities shall be considered when assessing the need for intrusion detection systems."

\section{REQUIREMENT SOURCE: DOE-M-5632.1C-1 Chapter VI, Section 2.c}

"Compensatory measures shall be provided during times when the intrusion detection system is not in operation or at temporary locations where a permanent intrusion detection system is not practical or cost effective.

\section{REQUIREMENT SOURCE: DOE-M-5632.1C-1 Chapter VI, Section 3.f}

"Systems shall be functionally tested in accordance with established procedures at a frequency that is documented."

\section{REQUREMENT SOURCE: DOE-M-5632.1C-1 Chapter VI, Section 7.a}

"Auxiliary power shall be available and shall be capable of maintaining full operation of the intrusion detection and assessment system for 8 hours, or such a time as would be needed to implement contingency plans. The period of time necessary to implement contingency plans shall be documented." 


\section{REQUIREMENT SOURCE: DOE-M-5632.1C-1 Chapter VI, Section 8.a}

"General. Security related equipment shall be protected from unauthorized access in a graded manner consistent with its importance. For protection of Categories I and II special nuclear material, Vital Equipment, and Top Secret and Secret classified matter, all detection/alarm devices, including transmission lines to annunciators, shall be tamper-indicating in both the access and secure modes. System components used for protection of other interests shall be protected, consistent with a cost/benefit analysis determined by each facility."

\section{REQUREMENT SOURCE: DOE-M-5632.1C-1 Chapter X, Section 1.c}

"Systems shall remain operable in the event of loss of primary electrical power."

\section{REQUIREMENT SOURCE: DOE-M-5632.1C-1 Chapter XI, Section 1}

"GENERAL. Acceptance and validation tests are performed to confirm the ability of an implemented and operating system element or total system to meet an established protection requirement. Two levels of tests shall be addressed in an overall safeguards and security acceptance and validation test program. First level operability tests shail be used to provide a simple measure of integrity on a frequent basis. Second level effectiveness tests shall be used to provide a comprehensive assurance of integrity on an infrequent basis."

\section{REQUREMENT SOURCE: DOE-M-5632.1C-1 Chapter XI, Section 3, Introduction}

"OPERABILITY TESTING. System elements shall be evaluated for continuing operability. Intervals may be justified based on site-specific conditions. Operability involves checking the system element to verify that it is still operational."

\section{REQUIREMENT SOURCE: DOE-M-5632.1C-1 Chapter XII, Section 4}

"MAINTENANCE PERSONNEL ACCESS AUTHORIZATION. Personnel who test, maintain, or service critical systems shall have access authorization consistent with the category of special nuclear material and/or classified matter being protected, uniess such testing and maintenance is performed as bench services away from the Security Area or is performed under the supervision of an appropriately cleared, knowledgeable custodian of the system and/or critical component. Systems or critical components bench tested or maintained away from a Security Area by personnel without appropriate access authorization shall be inspected and operationally tested by qualified and cleared personnel prior to being put into service."

\section{Protective Forces}

\section{REQUIREMENT SOURCE: 10CFR1046 Part 11(a)}

"Except as provided in subparagraph (b) DOE contractors shall not employ as protective force personnel any individual who fails to meet the applicable medical and physical fitness qualification standards as set forth in appendix A, to this subpart, "Medical and Physical Fitness Qualification Standards." " 


\section{REQUIREMINT SOURCE: 10CFR1046 Part 11(c)}

"Each security inspector shall meet the applicable medical and physical fitness qualification standards every twelve months after the initial qualification. Each guard shall meet the applicable medical standards every two (2) years after the initial qualification."

\section{REQUIREMINNT SOURCE: 10CFR1047 Part 6(a)}

"When a protective force officer has the right to make an arrest as discussed above, the protective force officer may use only that physical force which is reasonable and necessary to apprehend and arrest the offender; to prevent the escape of the offender; or to defend himself or herself or a third person from what the protective force officer believes to be the use or threat of imminent use of physical force by the offender. It should be noted that verbal abuse alone by the offender cannot be the basis under any circumstances for use of physical force by a protective force officer."

\section{REQUIREMENT SOURCE: DOE-M-5632.1C-1 Chapter II, Section 1.f}

"Protective force personnel, as determined by a vulnerability assessment and documented in the Site Safeguards and Security Plan, shall be available and positioned to respond to a verified threat occurrence to contain, interrupt, and/or neutralize adversaries within the required response times."

\section{REQUIREMENT SOURCE: DOE-M-5632.1C-1 Chapter V, Section 1.g,} Introduction

"Entrance/exit inspections, as required, shall be made by protective personnel or with detection equipment designed to detect prohibited articles (See subparagraph (2), below). Inspections of personnel, hand-carried items, and/or vehicles shall provide reasonable assurance that prohibited articles are not introduced and that safeguards and security interests are not removed from the area without authorization."

\section{REQUREMENT SOURCE: DOE5632.7A Chapter I, Section 3.a}

Author's Note: Only sentence I applies.

"Location, Manning, and Scheduling. The location and manning of fixed and mobile posts shall be determined using the "Design Basis Threat Policy for Department of Energy (DOE) Programs and Facilities (U); " local vulnerability analyses; characteristics of the facility or site, terrain, and environment; and appropriate Departmental directives. When planning for response times, the delay provided by physical barriers after the initial detection of the intrusion shall be considered. Work schedules for protective force personnel shall be developed and monitored on a site-specific basis to provide adequate relief, training time, balanced overtime, and sufficient time off to ensure on-dury personnel work at peak physical and mental effectiveness."

\section{REQUREMENT SOURCE: DOE5632.7A Chapter 1, Section 3.b}

Author's Note: Only sentence I applies.

"Supervision. Supervision of protective personnel shall be provided to the extent required to ensure proper and adequate performance of duties. 
(1) Personnel. At sites where more than six protective force employees are assigned per shift, there shall be full-time personnel supervision.

(2) Other Means. Various means and devices, such as telephonic or radio contact or contact by another supervisor who is physically closer to the post, may be used as supplements to personal supervision or, in the case of small facilities or remote areas, to supplant personal supervision as a means of assuring that the necessary areas are patrolled and other functions are performed."

\section{REQURREMENT SOURCE: DOE5632.7A(950213) Chapter VI, Section 1.a(1), Sentence 1}

"Contractor protective force personnel shall be required to be distinctively uniformed while on duty and to be identified with their function by appropriate emblems or badges."

\section{REQUIREMENT SOURCE: DOE5632.7A(950213) Chapter VI, Section 2.a}

"Location. Routine and emergency duty fixed posts should be located so that the efficiency of routine duties is enhanced and likely routes of adversary ingress and egress are clearly observable, and protected routes or methods of approach are available to protective personnel."

\section{REQUIREMENT SOURCE: DOE5632.7A(950213) Chapter VI, Section 2.b}

"Routine and emergency duty fixed posts shall provide adequate human engineering so that the protective personnel occupying the posts can perform their duties efficiently. Routine duty fixed posts shall provide occupants with adequate protection from weather and temperature variations."

\section{REQUTREMENT SOURCE: DOE5632.7A(950213) Chapter VII, Section 1, Introduction, Sentence 1}

"Performance tests shall be used to realistically evaluate, and verify the effectiveness of protective force programs; identify and provide training for personnel; identify areas requiring system improvements; validate implemented improvements; and motivate protective force personnel."

\section{REQUIREMENT SOURCE: DOE5632.7A(950213) Chapter VII, Section 1.c,} Sentences 1,2 and 3

"Force-on-Force Exercise. A force-on-force exercise is a major test of the overall effectiveness of all elements involved in response to a Design Basis Threat and site-specific threats. These tests shall be held at all facilities meeting the requirements listed in paragraph 8a, page 4. Exercises shall be pre-planned, announced in advance to all participating parties, and conducted during specified time periods (exercise windows)."

\subsubsection{Training and Equipment}

\section{REQUIREMENT SOURCE: DOE5632.7A Chapter I, Section 2.d(2)}

"As a minimum, each Federal Officer and Security Police Officer shall be required to meet the applicable firearms qualification standards every 6 months. Requalification shall occur in the 6th month from the previous qualification. The requalification may be accomplished at any 
time during the requalification month. If the Federal Offices or Security Police Officer does not requalify prior to or during the requalification month, the individual's authority to carry firearms and make arrests shall be suspended until such time as requalification is completed. If requalification occurs prior to the requalification month, the next requalification shall become due 6 months from the new month."

\section{REQUIREMONT SOURCE: DOE5632.7A Chapter II, Section 5}

"SPECLAL SKILLS.

a. General. Protective force operations may require individuals with additional special skills, such as pilots, communications and alarm station operators, canine handlers, and crisis negotiators. The scope of such duties will be locally determined based on site-specific needs. Personnel assigned to such duties shall be required to be proficient in their performance.

b. Crisis Negotiation Team. Each crisis negotiator shall bave successfully completed a Central Training Academy or other Department-approved crisis negotiating training. Negotiation teams should be integrated into Special Response Team exercises semiannually. Members of Crisis Negotiation Teams shall be familiar with protective force, including Special Response Team, tactics and operations, but do not need to be Security Police Officer-trained and certified."

\section{REQUTREMENT SOURCE: DOE5632.7A Preamble, Section 6.b}

"Protective forces shall be provided training, equipment, and resources to ensure effective performance of assigned functions and tasks under normal and emergency conditions."

\section{REQUIREMENT SOURCE: DOE5632.7A(950213) Chapter VI, Section 1.a(2)(c)}

"Armed protective force personnel are to be assigned equipment that provides an alternative, in the appropriate circumstances, to the use of deadly force."

REQUIREMENT SOURCE: DOE5632.7A(950213) Chapter VI, Section 1.b, Sentence 1

"Firearms, Pyrotechnics, and Explosives. Firearms, pyrotechnics, and explosives must be available in sufficient numbers to permit protective forces to act according to response plans."

\section{REQUIREMIENT SOURCE: DOE5632.7A(950213) Chapter VI, Section 1.c(1),} Sentences 1 and 2

"Protective force vehicles shall exhibit a degree of reliability commensurate with their intended function. Vehicles shall enhance the efficiency, speed, and safety of routine and emergency duties under all expected weather conditions."

6.3.3.2 Communications

REQUREMENT SOURCE: DOE-M-5632.1C-1 Chapter X, Section 1, Introduction, Sentence 1

"GENERAL. Communications equipment shall be provided to aid reliable information exchange between protective personnel." 


\section{REQUIREMENT SOURCE: DOE-M-5632.1C-1 Chapter X, Section 2}

"DURESS SYSTEMS. Facilities with Protected Areas, Material Access Areas, and Vital Areas shall have duress capabilities between mobile and fixed posts and shall meet the following requirements:

a. Activation of the duress alarm shall be accomplished in as unobtrusive a manner as practicable.

b. Duress alarms shall not annunciate at the post initiating the duress alarm.

c. The duress alarm for a Central Alarm Station shall annunciate at the Secondary Alarm Station or another fixed protective force post.

d. The duress alarm for the Secondary Alarm Station shall annunciate at the Central Alarm Station or another fixed post.

e. Mobile duress alarms shall annunciate at the Central Alarm Station, Secondary Alarm Station, or another fixed post."

REQUIREMENT SOURCE: DOE-M-5632.1C-1 Chapter X, Section 3.a, Sentence 1

"A continuous electronic recording system shall be provided for all security radio traffic."

\section{REQUIREMENT SOURCE: DOE-M-5632.1C-1 Chapter X, Section 4}

"SPECIAL RESPONSE TEAM RADIO COMMUNICATIONS. Special Response Team radio communications equipment shail be capable of transmitting routine and emergency information. Equipment shall meet all requirements of the radio system for the rest of the facility, except that the Special Response Team two-way radio communications shall be equipped with digital encryption, meeting the requirements of DOE 5300.3D. Special Response Team radio equipment shall use channels separate from the normal operational channels."

\section{REQUREMENT SOURCE: DOE5632.7A(950213) Chapter VI, Section 1.d(1),} Sentences 1,2 and 4

"Facilities Containing Category I or Il Quantities of Special Nuclear Material. Security Police Officers at fixed posts shall have both normal telephone service and two-way radio communication with central stations, as well as points from which backup forces may be disparched. Duress alarms shall be provided at Security Police Officer posts."

\section{REQUIREMENT SOURCE: DOE5632.7A(950213) Chapter VI, Section 1.d(2)}

"Special Response Teams shall be equipped with digital encryption two-way radio communication. Dedicated channels for team operations shall be considered to include separate team and Precision Rifle/Forward Observer Team channels."

REQUTREMENT SOURCE: DOE5632.7A(950213) Chapter VI, Section 1.d, Introduction

"Communications Equipment for Protective Personnel. Protective force communications equipment shall provide multichannel capability with clear transmissions. It shall also exhibit 
the necessary degree of reliability commensurate with the intended use. Communications equipment shall be readily available in sufficient numbers to equip protective forces."

\section{Security Identification Badges and Passes}

\section{REQUIREMENT SOURCE: DOE-M-5632.1C-1 Chapter VII, Section 2.b(9)}

"Records reflecting active assignments of badges, personal identification numbers, levels of access, security clearances, and similar system-related records shall be maintained. Records concerning personnel removed from the system shall be retained for 1 year unless a longer period is specified by other requirements."

\section{REQUIREMENT SOURCE: DOE-M-5632.1C-1 Chapter XIV, Section 1.a}

"Standard Security Badge. These badges will be issued to DOE and DOE contractor employee who have long-term routine access to Departmental facilities. Each organization responsible for issuing security badges shall follow the specifications for the standard badge format as set forth in Attachment XIV-1. This format provides for: uniform placement of required features such as organization identification, serial number, magnetic stripe, and photograph; designated indicators for access authorizations, and other features."

\section{REQUIREMENT SOURCE: DOE-M-5632.1C-1 Chapter XIV, Section 1.b}

"Foreign Visitor or Assignee Badge. (Refer to DOE 1240.2B, UNCLASSIFIED VISITS AND ASSIGNMENTS BY FOREIGN NATIONALS, for a description of the Unclassified Visits and Assignments by Foreign Nationals Program.) Badges for foreign visitors and assignees who require access to Security Areas shall adhere to the standard badge format. A distinctive marking shall be placed on the face of the badge to permit ready identification of the authorized holder as not possessing U.S. citizenship."

\section{REQUIREMENT SOURCE: DOE-M-5632.1C-1 Chapter XT, Section 1.c}

"Temporary Badges. Temporary badges may be utilized for a range of purposes including short period issuance to visitors, construction workers, and to DOE employees, DOE contractors, consultants, or assignees whose security badge has been lost, misplaced, forgotten, or stolen. The cognizant DOE authority for safeguards and security may prescribe provisions for issuance, use (e.g., supplementary photo identification), and retum of temporary badges. Temporary badges do not need to conform to the standard badge format, except that they shall conform to the designated indicators for indicating access authorizations used for standard security badges. The badge shall so indicate if the individual (e.g., visitor) is not a U. S. citizen."

\section{REQUREMENT SOURCE: DOE-M-5632.1C-1 Chapter XIV, Section 3.a}

\footnotetext{
"Appropriately coded security badges will be used and accepted as evidence of an access authorization (or security clearance). Such security badges shall be accepted for admittance to Limited and Protected Areas without a need for additional badging. Site or facility procedures may be established to require presentation of additional photo-identification media.

Verification of an individual's DOE access authorization level and determination of "need-to-know" remain the responsibility of the individual or organization being visited prior to granting access to special nuclear material according to table II-1, page II-3, and/or the release of classified information,"
} 


\section{$\underline{6.3 .5}$}

Incident Response and Management

\section{REQUIREMENT SOURCE: DOE5632.7A Chapter IV, Section 4.a, Sentences 1 and 2}

Author's Note: Only sentence 1 applies.

"General Training Requirements. Prior to initial assignment to duty, each Security Police Officer trainee shall be required to successfully complete a basic training course designed to provide the minimum level of skills and knowledge needed to competently perform all tasks associated with Security Police Officer job responsibilities. The required tasks and minimum levels of competency shall be based on a site-specific job analysis, and shall include task areas found in Chapter II, paragraph 2, as appropriate."

\section{REQUIREMENT SOURCE: DOE5632.7A Chapter IV, Section 4.b}

Author's Note: Only b(1) Sentence 1 applies.

"Refresher Training.

(1) Formal Program. Except as stated in (3) below, each Security Police Officer shall be required to successfully complete formal annual refresher training to maintain the level of competency required for the successful performance of tasks associated with Security Police Officer job responsibilities. The type and intensity of training shall be determined by a site-specific job analysis and shall be approved by the cognizant local Departmental authority for safeguards and security.

(2) Remedial Training. Failure to achieve a minimum level of competency will result in the Security Police Officer's placement in a remedial training program. The remedial training program will be tailored to provide the Security Police Officer with the necessary training to afford a reasonable opportunity to meet the level of competency required by the job analysis. Failure to demonstrate competency at the completion of the remedial program shall result in loss of Security Police Officer status.

(3) Training Exemption. Except for firearms and annual physical fitness requirements, portions of formal annual refresher training may be exempted when a Security Police Officer satisfactorily demonstrates a knowledge, skill, or ability."

\section{REQUIREMENT SOURCE: DOE5632.7A Chapter IV, Section 4.c, Sentence 1}

"Security Police Officer III Training Requirements. Prior to initial assignment to duties as a Special Response Team member, a Security Police Officer shall be required to successfully complete a basic training course designed to provide the minimum level of skills and knowledge necessary to competently perform all tasks associated with Special Response Team job responsibilities."

\section{REQUTREMENT SOURCE: DOE5632.7A Chapter IV, Section 5}

Author's Note: Only sentences 1 and 2 apply.

"WEAPONS QUALIFICATIONS. SPO-IIIs sball qualify semiannually with all assigned weapons and special weapons (as designated by position or job requirement). DOE M 5632.7-1 standard qualification courses will be used for all assigned and special weapons. When Deparmental standard qualification courses do not exist, site-specific supplemental 
courses will be developed and approved by the cognizant local Departmental authority for safeguards and security after review and comment by the Office of Safeguards and Security."

\section{REQUIREMENT SOURCE: DOE5632.7A Chapter IV, Section 10}

Author's Note: Only 10.a and 10.b apply.

"PERFORMANCE TESTING. Detailed guidance for performance testing Protective Force programs is found in chapter VII. However, for general purposes, exercises of various types shall be included in the training process for the purposes of achieving and maintaining skills and assessing individual and team competency levels. The types and frequency of training exercises shall be approved by the Head of the Field Element and may be determined by the training needs analysis conducted as part of the training program.

a. Exercises shall be conducted involving each shift of the protective force. These exercises are to be planned so as to test the protective force's ability to prevent the successful completion of adversarial acts defined in the approved site-threat statement.

b. Personnel assigned Special Response Team responsibilities shall be required to participate in training exercises at least monthly. Such exercises will involve the type of situations and scenarios appropriate to site-specific conditions.

c. Protective forces shall request the Federal Bureau of Investigation, state, and local law enforcement agencies that would assist the protective force during an incident to participate in exercises at least annually.

d. Reports of each training exercise, summarizing results and problem areas, shall be prepared for management review and to aid in planning protective force activities."

\section{REQUIREMENT SOURCE: DOE5632.7A(950213) Chapter III, Section 1, Introduction, Sentence 2}

"Special Response Teams shall be capable of effective and timely response as dictated by site or activity specific vulnerability assessments. Teams shall be trained and equipped to conduct interdiction, internuption, neutralization, and recapture operations directed against an adversary."

\section{REQUIREMENT SOURCE: DOE5632.7A(950213) Chapter VI, Section 1.d,} Sentence 1

"Command Post Exercise. A command post exercise is conducted to observe and evaluate a crisis management team's overall handling of a simulated safeguards and/or security emergency."

\section{REQUREMENT SOURCE: DOE5639.3 Chapter II, Section 2.a}

"Safeguards and Security Representatives. Representatives of safeguards and security offices may conduct preliminary internal inquiries as required to establish the circumstances surrounding a suspected or alleged criminal violation or loss involving a national security interest. The authority to conduct such inquiries remains with the Head of the Field Element and, in the case of Headquarters, with SA-10." 


\section{Transportation Security}

\section{REQUREMENT SOURCE: DOE-M-5632.1C-1 Chapter II, Section 5.c}

Author's Note: Only 5.c(3) is applicable.

"In-Transit. Protection requirements for material in transit shall be as follows:

(1) Domestic offsite shipments of Category I quantities of special nuclear material shall be made by the Transportation Safeguards System, operated under the auspices of the Albuquerque Operations Office.

.(2) Packages or containers containing special nuclear material shall be sealed with tamper-indicating devices.

(3) Protection measures for movements of material between Protected Areas at the same site, or between Protected Areas and staging areas at the same site, shall be under direct surveillance by the number of Security Police Officers necessary to protect against threats as established in the Deparment's threat policy (See paragraph 3, page I-1)."

MATERIAL CONTROL AND ACCOUNTABILITY FOR SPECIAL NUCLEAR MATERIAL

Author's Note: This element addresses all nuclear materials.

\section{REQUTREMENT SOURCE: DOE-M-5632.1C-1 Chapter II, Section 1.d}

"Factors, such as ease of separability, accessibility, and concealment; quantity, chemical form, isotopic composition, purity, and containment; portability; protection strategies; radioactivity; and self-protecting features, shall be considered in determining physical protection systems for each category of special nuclear material."

\section{REQUIREMENT SOURCE: DOE5633.3B Chapter I, Section 1.c}

Author's Note: Only Sentences 1 and 2 apply.

"A management official responsible for the control and accountability of nuclear materials shall be designated for each facility. This official shall be organizationally independent from responsibility for other programs. A Nuclear Materials Representative responsible for nuclear materials reporting and data submission to the Nuclear Materials Management and Safeguards System shall be designated for each facility or site having a Reporting Identification Symbol."

\section{REQUIREMENT SOURCE: DOE5633.3B Chapter I, Section 1.k}

\section{Author's Note: Only sentence 1 applies.}

"For each facility a materials control and accountability program shall be established for all nuclear materials on inventory under a three letter Reporting Identification Symbol, including those designated as uneconomical to recover. For Attractiveness Level D or higher special nuclear material that has been removed from inventory as waste and for which a vulnerability resulting in an unacceptable level of risk has been identified, the Manager, Operations Office, or the cognizant Head of a Headquarters Element may require that applicable nuclear material safeguards measures as outlined in this Order be maintained and/or implemented. Otherwise, 
materials previousiy removed from inventory that meet all of the following conditions are exempt from the requirements of this Order:

(1) They have been previously declared as waste prior to issuance of this Order;

(2) They have been written off the material control and accountability records; and

(3) They are under the control of a waste management organization."

\section{REQUIREMENT SOURCE: DOE5633.3B Chapter I, Section 2.a}

Author's Note: Only sentence 1 applies.

"DOE Field Offices and facilities shall establish and follow a graded safeguards program for nuclear materials. Graded safeguards is the concept of providing the greatest relative amount of control and effort to the types and quantities of SNM that can be most effectively used in a nuclear explosive device. Categories of nuclear material for implementation of DOE's graded safeguards program are shown in Figure I-2. The "Guide for Implementation of DOE $5633.3 \mathrm{~A}$ " contains more descriptive guidance for material attractiveness and examples of category determination."

\section{Material Control and Accountability Plan}

\section{REQUREMENT SOURCE: DOE5633.3B Chapter I, Section 1.d}

"For each facility, facility management shall maintain documentation defining authorities and responsibilities for material control and accountability functions (e.g., accounting system, measurements, measurement control, inventories, audit, material access controls, and surveillance). For each facility, there shall be a program to assure that personnel performing materials control and accountability functions are trained and qualified to perform their duties and responsibilities, and are knowledgeable of requirements and procedures reiated to their functions."

\section{REQUIREMENT SOURCE: DOE5633.3B Chapter I, Section 1.e}

Author's Note: Only sentence 1 applies.

"An Material Control and Accountability Plan shall be developed for each facility possessing nuclear materials (including facility review and frequency and change control), and approved by the cognizant Manager, Operation Office. The Materials Control and Accountability Plan may, at the option of the cognizant Manager, Operation Office, be a separate document or a part of an existing document such as a Site Safeguards and Security Plan.

(1) Category I and II. For facilities possessing Category I and II quantities of special nuclear material, the plan shall reflect requirements for material control and accountability program planning and management, threat considerations, performance criteria, the accounting system, physical inventories, measurement control, control limits, loss detection elements, training, response to nuclear material alarms, access control, anomaly resolution, containment, and surveillance. 
Westinghouse Hanford Company (WHC)

Standards/Requirements Identification Document

WHC-SD-MP-SRID-002

January 10, 1996

Rev. 0

6.0 Safeguards and Security

Page 21 of 52

\begin{tabular}{|l|l|l|l|l|l|}
\hline \multicolumn{1}{|c|}{$\begin{array}{c}\text { MATERIAL } \\
\text { TYPE }\end{array}$} & \multicolumn{1}{|c|}{$\begin{array}{c}\text { SNM, } \\
\text { SOURC, }\end{array}$} & \multicolumn{1}{c|}{$\begin{array}{c}\text { REPORTABLE } \\
\text { QUANTITY }\end{array}$} & \multicolumn{2}{c|}{$\begin{array}{c}\text { WEIGHT FIELDS USED } \\
\text { FOR REPORTING } \\
\text { ELEMENT }\end{array}$} & $\begin{array}{c}\text { MATERIAL } \\
\text { TYPE } \\
\text { CODE }\end{array}$ \\
\hline Depleted Uranium & SOURCE & Kilogram & Total U & U-235 & 10 \\
\hline Enriched Uranium & SNM & Gram & Total U & U-235 & 20 \\
\hline Normal Uranium & SOURCE & Kilogram & Total U & - & 81 \\
\hline Uranium-233 & SNM & Gram & Total U & U-233 & 70 \\
\hline Plutonium-242 & SNM & Gram & Total Pu & Pu-242 & 40 \\
\hline $\begin{array}{l}\text { Plutonium-239- } \\
\text { 241 }\end{array}$ & SNM & Gram & Total Pu & $\begin{array}{l}\text { Pu-239 } \\
\text { Pu-241 }\end{array}$ & 50 \\
\hline Plutonium-238 & SNM & Tenth of a Gram & Total Pu & Pu-238 & 83 \\
\hline Americium-241 & OTHER & Gram & Total Am & Am-241 & 44 \\
\hline Americium-243 & OTHER & Gram & Total Am & Am-243 & 45 \\
\hline Berkelium & OTHER & Microgram & - & Bk-249 & 47 \\
\hline Californium-252 & OTHER & Microgram & - & Cf-242 & 48 \\
\hline Curium & OTHER & Gram & Total Cm & Cm-246 & 46 \\
\hline Deuterium & OTHER & Tenth of a Kilogram & D20 & D & 86 \\
\hline Lithium-6 & OTHER & Kilogram & Total Li & Li-6 & 60 \\
\hline Neprunium-237 & OTHER & Gram & Total Np & - & 82 \\
\hline Thorium & SOURCE & Kilogram & Total Th & - & 88 \\
\hline Tritium & OTHER & Hundredth of a Gram & Total ${ }^{3} \mathrm{H}$ & - & 87 \\
\hline
\end{tabular}

Figure I-1

Nuclear Materials

* For reporting purposes: materials are reported to the nearest whole unit except for plutonium-238, deuterium, and tritium.

' Uranium in cascades is treated as enriched uranium. For reporting purposes uranium in cascades should be reported as material type 89.

${ }^{2}$ Report as plutonium-242 if the contained Pu-242 is $20 \%$ or greater of total Plutonium by weight; otherwise report as plutonium 239-241.

${ }^{3}$ Report as plutonium-238 if the contained Pu-238 is $10 \%$ or greater of the total by weight Plutonium; otherwise report as plutonium 239-241.

4 Tritium contained in water $\left(\mathrm{H}_{2} \mathrm{O}\right.$ or $\left.\mathrm{D}_{2} \mathrm{O}\right)$ used as a moderator in a nuclear reactor is not an accountable material. For reporting purposes: if in the form of heavy water, both the element and isotope weight fields will be used; otherwise report isotope weight only. 
(2) Category III and IV. For Category III and IV facilities, requirements for the scope and content of Material Control and Accountability Plans are to be determined by the Manager, Operations Office."

\section{REQUREMINT SOURCE: RIID5633.3 Section 7.1.d}

"Training and Qualification of MC\&A Personnel. Each contractor shall have a training program for personnel performing MC\&A functions which meets the requirements of DOE 5630.15. In addition, the training plan shall be a component of the MCAP, which addresses such subjects as who requires training, type of training, frequency of training, and conditions requiring training. The basis for qualifying and maintaining qualification for MC\&A personnel shall be documented in the MCAP."

\section{REQUIREMENT SOURCE: RLID5633.3 Section 7.3.j}

"Daily Administrative Checks (DAC). DAC for each Category I MBA will be defined in the contractor's MCAP, including the scope and extent of the checks."

\section{Special Nuclear Material Accountability System}

\section{REQUIREMENT SOURCE: DOE5633.3B Chapter I, Section 6.c}

Author's Note: Only sentence 1 applies.

"For each facility, management shall establish controls that limit access to the accounting system and nuclear materials accounting data. For automated systems, controls shall be designed to deter and detect unauthorized access to the data bases and data processing systems that, through tampering, modification, or alteration could lead to defeat of the accounting system. Nuclear materials accounting data shall be protected in accordance with applicable classification, automated data processing, and computer security regulations."

\section{REQUIREMENT SOURCE: DOE5633.3B Chapter I, Section 6.d}

Author's Note: Numbers 1 and 3 do not apply.

"The facility nuclear materials accounting system shall include checks and balances, and be structured to ensure:

(1) Identification of omission(s) of data for any reportable transaction.

(2) Timely detection (normally within 24 hours but in no case later than the subsequent inventory reconciliation) of errors/discrepancies in records associated with a Category I or II quantity of special nuclear material including where possible detecting falsified data and identifying the responsible person(s).

(3) Detection of data discrepancies and errors to ensure that no discrepancies exist in control indicator accounts.

(4) The completeness of the nuciear materials accounting system records." 


\section{REQUIREMENT SOURCE: DOE5633.3B Chapter II, Section 2, Introduction}

Author's Note: Only sentence I applies.

"ACCOUNTING SYSTEMS. Each facility shall have a system that provides for tracking nuclear material inventories, documenting nuclear material transactions, issuing periodic reports, and assisting with the detection of unauthorized system access, data falsification, and material gains or losses. The accounting system shall provide a complete audit trail on all nuclear material from receipt through disposition. The Generally Accepted Accounting Principles, as promulgated by Financial Standards Accounting Board, shall be used in the design and operations of the nuclear material accounting system unless otherwise directed by DOE directives."

\section{REQUIREMENT SOURCE: DOE5633.3B Chapter II, Section 2.c}

Author's Note: Only number 2 and number 3 sentences 1, 3, and 4 are applicable.

"Records and Reports.

(1) For each facility, management shall maintain records, submit data, and issue reports as required by page II-19, paragraph 7 and facility procedures. These reports shall accurately describe all nuclear material transactions and inventories. Inventory adjustments shall be identified by Materials Balance Area and shall be reported consistent with requirements of this Order, page II-19, paragraph 7.

(2) Nuclear materials records shall be updated only by authorized personnel, and the records system shall provide an audit trail for all transactions affecting the nuclear materials database.

(3) The Materials Balance Area records system shall be capable of being updated daily or upon demand for all nuclear materials transactions. (This requirement is for the updating of records based on reports or information; it is not a requirement on how quickly a facility must be able to complete measurements.) In addition, the records system shall be capable of generating book inventory listings for all special nuclear material within 3 hours. For all other nuclear material, the timing for generation of book inventories shall be within 24 hours. Validating the accuracy of the accounting record system shall be conducted according to testing methodology, testing frequency, and record maintenance requirements contained in DOE 5630.16A and applicable Department guidance. Performance requirements for accounting record system accuracy are contained on page I-10, paragraph 4."

\section{REQUTREMENT SOURCE: DOE5633.3B Chapter II, Section 3.a}

Author's Note: Only numbers 2 and 6 are applicable.

"Periodic Physical Inventories.

(1) Physical Inventories. Inventories shall be based on measured values and, where feasible, measurements or technically justifiable estimates of holdup shall be made so that holdup quantities can be used in determining inventory values or explaining the inventory difference. Process monitoring techniques may be used for material which is undergoing processing and recovery operation but inaccessible for measurements by sampling. Process monitoring, in addition to material control procedures and specific action criteria, subject to the approval of the Manager, Operations Office, should be used routinely to track materials in process until operations permit an accountability measurement. 
(2) Conduct of Inventories. For each facility, there shall be documented plans and procedures defining responsibilities for performing inventories and specifying criteria for conducting, verifying, and reconciling inventories of nuclear material. Verification of the presence of items during inventories may be performed on a statistical sampling basis. Sampling plans shall be consistent with the graded safeguards concept. Parameters for statistical sampling . plans and inventory stratifications used with statistical sampling plans shall be defined by the facility management and approved by the Manager, Operations Office.

(3) Holdup Inventory. Holdup inventory shall be measured, where feasible, or estimated on the basis of throughput, process data, modeling, engineering estimates, or other technically defensible factors as a regular part of inventory for facilities with Category I, II, and III quantities of special nuclear material and for facilities with Category IV quantities of special material that have more than 5 kilograms of special nuclear material as holdup on a p611Xnuc regular basis. The method, justification, and supporting documentation should be included in the Materials Control and Accountability Plan.

(4) Physical Inventory Frequencies. For each facility, physical inventories shall be performed for Category I and II Materials Balance Areas involving activities other that processing at a frequency determined by the Manager, Operations Office, but at least semiannually. For Category I and Il Materials Balance Areas where processing occurs, physical inventories shall be preformed at a frequency determined by the Manager, Operations Office, but at least bimonthly. Factors to be taken into consideration for frequency determination include personnel radiation exposure, the operational mode of the facility, and credible protracted diversion scenarios.

Category IV source and/or other nuclear material in Category I and II Materials Balance Areas shall be inventories on a schedule defined by the Manager, Operations Office, but at least annually, except when the source and/or other nuclear material is a credible substitution material. In situations where substitution materials are collocated with special nuclear material, facilities shall inventory substitution materials with the same frequency as the special nuclear material and implement the use of inventory measurement methods that can distinguish between special nuclear material and source and other nuclear material.

In addition to the above requirements, inventory checks for Category IA items not in storage shall be performed weekly for physical count verification, and monthly for serial number verification. Inventory checks for stored Category IA items shall consist of a physical count whenever the storage area is accessed and a serial number verification on a monthly basis.

For each facility, physical inventories shall be performed for Category III and IV Materials Balance Areas at a frequency to be determined by the Manager, Operations Office, but at least biennially.

For facilities having multiple Materials Balance Areas with varied inventory frequencies, a simultaneous inventory of the complete facility shall be performed at least once biennially.

(5) Deviations to Inventory Frequencies. Deviations to inventory frequency requirements described in subparagraph (4) above may be approved in accordance with DOE 5630.11B, for situations where alternative control mechanisms provide assurance that unreported changes in inventories would be detected. Inventory values shall be determined in time to provide for computation and reconciliation of inventories and determination of inventory differences, consistent with DOE reporting requirements stated on page II-19, paragraph 7, and approved inventory frequencies. See "Guide for Implementation of DOE 5633.3A." 
(6) Physical Inventory Reconciliation Program. For each facility, management shall implement a physical inventory reconciliation program designed to provide assurance that all nuclear material has been accounted for and that the facility's record system reflects the physical inventory. Upon completion of the physical inventory, the book inventory for each Materials Balance Area shall be compared with and, if necessary, adjusted to the physical inventory." .

\section{REQUREMENT SOURCE: DOE5633.3B Chapter II, Section 3.b}

"Special Inventories. At each facility, management shall establish and implement procedures for conducting special inventories as a result of routine disassembly of critical assemblies, changes in custodial responsibilities, missing items, inventory differences exceeding established control limits, abnormal occurrences, or at the request of authorized facility personnel or the cognizant Operations Office."

REQUREMENT SOURCE: DOE5633.3B Chapter I, Section 3.d.(1)

Author's Note: Only sentence $l$ is applicable.

"At each facility, management shall establish and implement a system for performing measurements as part of a physical inventory. Verification measurements shall be made on special nuclear material items that are not tamper-indicating. Confirmation measurements shall be made on items that are tamper-indicating. Such measurements are intended to detect diversion or theft of material and shall use a statistically-based sampling plan applied in a manner consistent with the graded safeguards concept. Separate sampling plans shall be implemented for verification and confirmation measurements to assure that a sufficient number of non-tamper-indicating items are measured. Parameters for statistical sampling plans and inventory stratifications used with statistical sampling plans shall be defined by facility management and approved by the Manager, Operations Office. The Manager, Operations Office, may establish a material quantity threshold for requiring inventory verification/confirmation measurements. It is recognized that certain materials are not amenable to verification measurements. Such materials shall be documented in the Materials Control and Accountability Plan and, for these materials, confirmatory measurements of two material attributes may be substituted for the verification measurement. Material not amenable to measurement shall be identified as on page II-6, paragraph 4."

\section{REQUREMENT SOURCE: DOE5633.3B Chapter II, Section 4, Introduction}

Author's Note: Only sentence 1 is applicable.

"MEASUREMENTS AND MEASUREMENT CONTROL. At all facilities possessing nuclear material, measurement and measurement control programs shall be implemented. The object of measurement and measurement control is to establish nuclear material values and to assure the quality of the data. Measurements programs used to determine Category I or II inventories of special nuclear material or used to determine a Category I or II special nuclear material throughput over a 6 month period shall address the topics identified in this paragraph and shall be consistent with facility-specific measurement program objectives. For other measurement and measurement control programs (those used only to determine Category III or IV inventories), the scope and content of the programs shall be approved by the Manager, Operations Office. For Category I and II facilities, these programs shall address the topics identified in this paragraph and shall be consistent with facility-specific measurement program objectives. 
Materials not amenable to measurement by the site shall be identified in the facility's Material Control and Accountability Plan. Inventory values for these materials shall be based on measured values made at other sites or technically justified estimates. Justification and supporting documentation for these inventory values shall be include as part of the Materials Control and Accountability Plan.

Additional guidance on measurement control is provided in the DOE "Measurement Control Guide," (3-93)."

\section{REQURDMENT SOURCE: DOE5633.3B Chapter II, Section 4.c}

Author's Note: Only number 2 sentence 1 is applicable.

"Training and Qualification of Measurement Personnel. The objective is to assure that the individuals responsible for performing measurements have sufficient knowledge to perform the measurements in an acceptable manner.

(1) Training. Each facility shall have a documented plan for the training of measurement personnel. The plan shall be reviewed annually and updated as necessary to reflect changes in measurement technology and shall specify training, qualification, and requalification requirements for each measurement method.

(2) Qualification. Each facility shall have a documented qualification program that ensures that measurement personnel demonstrate acceptable levels of proficiency before performing measurement, and that measurement personnel are requalified according to requirements in the training plan. For destructive analysis of nuclear material, this proficiency shall be demonstrated, at a minimum, once per day for each method that the individual will use that day."

\section{REQUIREMENT SOURCE: DOE5633.3B Chapter II, Section 4.d.(2)}

Author's Note: Only the introduction sentence 1 is applicable.

"Measurement Methods. For each facility, measurement methods shall be developed, documented, and maintained for all nuclear material on inventory except for those materials not amenable to measurement. These methods shall be written to provide clear direction to the analyst or operator, and shall be validated initially and revalidated whenever changes are made.

(a) In determining inventory values and consistent with the graded safeguards concept, the selection of the measurement methods shall assure that the contribution of the measurement error to the uncertainty of the inventory. difference is minimized.

(b) Verification measurements, when used to adjust accountability records, shall have accuracy and precision comparable to, or better than, the original measurement method.

(c) For confirmatory measurements, the measurement method used shall be capable of determining the presence or absence of a specific attribute of the material, consistent with valid acceptance/rejection criteria.

(d) All measurement methods shall be calibrated using Standard Reference Materials, Certified Reference Materiais, or secondary standards traceable to the national measurement base, and revalidated as necessary. 
(e) Equipment and instrumentation used in performing measurements shall moet precision and accuracy requirements under in-plant conditions.

(f) Documentation of measurement data shall be maintained to provide an audit trail from source data to accounting records."

Material Control System

\section{REQURREMENT SOURCE: DOE5633.3B Chapter I, Section 1.j}

"For Category I facilities and for Category II facilities within the Protected Area for which rollup to a Category I quantity is possins, temn Iaclity's safeguards and security system shall provide aefenso in donth to cosure thas the faiture or defeat of a single component will not increase the level of tisk for the system above an acceptable level. A part of the vulnerability assessmest pracess shall be to determine the extent to which the failure or defeat of a single component increases this risk and if the increase in risk is acceptable. When the increase in risk exceeds an acceptable level, compensatory measures shall be immediately taken and upgrades to the system shall be initiated. The acceptability of the risk shall be documented as a part of the Master Safeguards and Security Agreement or Site Safeguards and Security Plan for the faciliny."

\section{REQUIREMENI sounce: DNE5633.3B Chapter I, Section 1.0}

Author's Note: Only sentence $I$ applies.

"Procedures, techniques, and standards as promulgated by the American snciety for Teaning and Materials (ASTM) and the American National Standards Institute (ANSI) shall bo used, when such standards exist, in developing the basis for nuclear material control, measuremoors and measurement control, accounting, and statistical methods that are employed by a facility for safeguarding of nuclear material, unless otherwise directed by DOE directives. Standards issued by the International Atomic Energy Agency and the Nuclear Regulatory Commission should also be used when appropriate and when consistent with DOE regulatory goals."

\section{REQUIREMENT SOURCE: DOE5633.3B Chapter I, Section 4.b}

Author's Note: Only 4.b(2) applies.

"Performance Testing. DOE 5630.16A, SAFEGUARDS AND SECURITY ACCEPTANCE AND VALIDATION TESTING PROGRAM, contains requirements for the design, planning, and documentation of performance tests. Material control and accountability performance testing programs shall meet the requirements of DOE 5630.16A. For each facility, management shall establish and implement a documented testing program to verify materials control and accountability procedures and practices and to demonstrate that material controls are effective.

(1) These tests shall be designed to demonstrate that the system is functional and to assure that the system performs as specified and/or required. In addition, facilities shall:

(a) Identify those components of the materials control and accountability system that provide the greatest effectiveness against theft and diversion;

(b) Design, conduct, and document tests which substantiate component effectiveness; and 
(c) Integrate the results of these component tests into safeguards and security vulnerability assessments.

(2) Performance testing shall include not only those elements that can detect-in-time-to-prevent but also those elements that can effectively account for special nuclear material in order to provide assurance that safeguards and security systems are functioning properly.

(3) The design of the performance testing program shall be focused on testing individual detection elements. Elements identified in a vulnerability assessment that contribute to detection capability shall be tested on a frequency based on the level of threat/risk established by the vulnerability assessment.

(4) The design of performance tests should cansides prudent judgment and use of resources.

(a) The scope and extent of testing should be based on the graded safeguards concept with the testing program including more testing for higher category facilities than for lower category facilities.

(b) Guidance for performing testing is contained in DOE's Master Safeguards and Security Agreement Verification Guide (Section 4.0, Performance Testing; Appendix F., Checklist for Performance Requirements; and Appendix G., Materials Control and Accountability Checklist). In addition, Office of Safeguards and Sucurity has provided guidance for the evaluation of the detection elements of the materials control and accountability system which will facilitate the design and validation of the performance testing program in the "Guide to the Evaluation of Selected Materials Control and Accountability (MC\&A) Detection Elements."

(5) Tcsing data and results shall be classified in accordance with CG.SS-3.

(6) Corrective actions shall be taken for vulnerabilities identified during system testing."

\section{REQUTREMENT SOURCE: DOES633.3B Chapter I, Section 5}

Author's Note: Only sentences 1 through 4 apply.

-OCCURRENCE INVESTIGATION AND REPORTING. Each facility shall identify materials control and accountability loss detection elements for each Materials Balance Area and shall establish a graded program for monitoring these elements and associated data to determine the status of nuclear material inventories and to identify reportable occurrences. Reportable occurrences involving Category I, II, and III nuclear materials shall be reported as an Emergency, Unusual Occurrence, or Off-Normal Occurrence in accordance with DOE 5000.3B. For reportable occurrences involving Category IV nuclear materials, the Manager, Operations Office, will define the extent of the investigation required to resolve the occurrence. When losses of Category IV nuclear materials which have been identified as credible radiological sabotage targets or when radiological sabotage events involving Category IV materials have occurred, reporting and investigation under DOE 5000.3B may be required. The categorization of materials control and accountability occurrences are contained in DOE $5000.3 B$. In addition to the reporting required by DOE $5000.3 B$, the DOE facility representative, as defined in DOE $5000.3 \mathrm{~B}$, shall notify the head of the appropriate division within the cognizant Operations Office responsible for the implementation of this Order. The head of the appropriate Operations Office division is responsible for notifying Office of Safeguards and Security and the local office of the Federal Bureau of Investigation of reportable occurrences for which there is both an indication of a loss of nuclear material and evidence of a malevolent act. In addition, the Operations Office shall independently evaluate 
the occurrence based upon its significance. Information reiated to monitoring and assessment activities shall be documented and retained."

\section{REQUIREMENT SOURCE: DOE5633.3B Chapter II, Section 4.e.(1)}

\section{Author's Note: Only the introduction sentence $l$ is applicable.}

"Measurement Control Programs. For each facility, measurement control programs shall be developed and implemented for all measurement systems used for accountability purposes. A measurement control program, as referred to herein, shall include at a minimum the following elements:

(a) Scales and Balances Program. All scales and balances used for accountability purposes shall be maintained in good working condition, recalibrated according to an established schedule, and checked for accuracy and linearity on each day that the scale or balance is used for accountability purposes.

(b) Analytical Quality Control. Data from routine measurements shall be analyzed statistically to determine and ensure accuracy and precision of the measurements.

(c) Sampling Variability. The uncertainty associated with each sampling method, or combination of sampling and measurement method, shall be determined and maintained on a current basis.

(d) Physical Measurement Control. The precision and accuracies of volume, temperature, pressure, and density measurements shall be determined and assured.

(e) Instrument Calibration. Instrumentation shall be calibrated using appropriate standards, when available, or at a minimum, measurement values shall be compared with more accurate measurement systems values on a prescribed basis, with the frequency being defined by demonstrated instrument performance.

(f) Reference Materials (Standards). All calibration and working standards used in a measurement control program shall be traceable to the national measurement base through the use of standard reference materials or certified reference materials and shall have smaller uncertainties associated with their reference values than the uncertainties of the measurement method in which they are used. Working standards used in a measurement control program shall be representative of the type and composition of the material being measured when the material matrix affects the measured values. For additional information see "Guidance on Meeting DOE Order Requirements for Traceable Nondestructive Assay Measurements."

(g) Sample Exchange Programs. Each facility's measurement control program shall include participation in appropriate interlaboratory control programs to provide independent verification of internal analytical quality control.

(h) Statistical Controls. For each measurement method used for accountability purposes, control limits shall be calculated and monitored, and documented procedures shall exist to correct out-of-limits conditions. Control limits shall be established at the two sigma level (warning limits) and three sigma level (alarm limits). Control data exceeding the two sigma limits shall be investigated, and, when warranted, timely corrective action shall be taken. Whenever a single data point exceeds the three sigma level, the measurement system in question shall not be used for an accountability measurement until the measurement system has been demonstrated to be within statistical control. For measurement methods relying substantially on operator technique, control limits shall include uncertainties for each 
analyst/method combination. Statistical control limits shall be monitored to assure that they are consistent with target values agreed to by the facility management and the Manager, Operations Office.

(i) Measurement Method Qualification. Each facility shall have a documented method qualification program that ensures that a measurement method shall demonstrate acceptable performance before being used for performing accountability measurements. For destructive analysis and nondestructive assay of nuclear material, this performance shall be demonstrated, at a minimum, once per day that each method is used. For nondestructive analysis measurement systems where meeting this requirement is impractical or unnecessary, the control measurement frequency shall be at least one of every five measurements, unless otherwise approved by the Manager, Operations Office.

(j) Measurement Control Procedures. Documented measurement control procedures shall be developed at each facility for all measurement methods used for accountability, and each facility shall have a program to assure that measurement control procedures are followed."

\section{REQUIREMENT SOURCE: DOE5633.3B Chapter II, Section 4.e.(2)}

Author's Note: Only the introduction sentences 1 and 2 are applicable.

"Statistical Programs. Each facility shall have a documented program for the statistical evaluation of measurement data for determining control limits, calibration limits, and precision and accuracy levels for each measurement system used for accountability. The objective is to ensure the quality of measurement and measurement control data and to provide estimates of uncertainty on inventory and inventory control statements. The program, at a minimum, shall contain the following elements:

(a) Valid statistical techniques to determine the total random error and the measurement biases generated for each measurement system or sampling/measurement system, and to determine control limits, rejection limits, and outlier criteria.

(b) A valid statistical technique to develop sampling plans for inventory and measurement of nuclear material.

(c) Analyses of measurement control data and reporting to the responsible organization at specified times and frequencies.

(d) Documentation of all major assumptions made in each data evaluation process."

\section{REQUIREMENT SOURCE: DOE5633.3B Chapter II, Section 5, Introduction}

\section{Author's Note: Only sentence $l$ is applicable.}

"MATERIAL TRANSFERS. Each facility shall have a program to control and account for internal and external facility transfers of nuclear materials. This program shall include documented procedures that specify requirements for authorization, documentation, tracking, verification, and response to abnormal situations that may occur during transfer of nuclear materials. For additional details, see page II-19, paragraph 7. Page II-19, paragraph 7, provides specific directions for preparing and submitting DOE/NRC F 741, "Nuclear Material Transaction Report," and DOE forms required for documenting external transfers for materials accounting purposes." 


\section{REQUIREMENT SOURCE: DOE5633.3B Chapter II, Section 5.b}

\section{Author's Note: Only number 1 is applicable.}

"Internal Transfers.

(1) Each facility's management shall provide a graded system of measurements and records to reflect the flow of material between Material Balance Areas within that facility and between it and other facilities on the same site.

(2) The facility control system shall be designed to monitor transfer activities and to deter and/or detect unauthorized removal of material during transfers. The system should flag abnormal situations, e.g., when inappropriate transfers of quantities and/or materials are made, when unauthorized personnel receive or ship materials.

(3) Transfers shall be documented on nuclear material transfer forms, or an electronic equivalent, that contain required information, are prepared and distributed within established timeframes, and are signed by authorized custodians or their alternates.

(4) Materials shall be subjected to a transfer check within one workday after receipt. These checks shall include verification of shipping container or item count, tamper-indicating devices integrity, and identification number. These transfer checks shall be compared to appropriate documentation. All irradiated special nuclear material requires only a transfer check.

(5) If the isotope content of special nuclear material (excluding uranium enriched below 20 percent U-235) transferred between Materials Balance Areas is 50 grams (fissile) or more, the transfer shall be measured, or a confirmatory measurement made, by the receiver. Measurements are not required for transfers that:

(a) Consist of assembled components in which the special nuclear material is physically inaccessible;

(b) Are sent to laboratories or nondestructive analysis measurement areas for analysis or examination under conditions which provide adequate internal controls to maintain a continuous awareness of the location and integrity of the special nuclear material until it is retumed;

(c) Are tamper-safed and contain only Category IIl or IV quantities of material; or

(d) Consist entirely of small items containing less than 25 grams each and for which unauthorized accumulation of a Category III quantity of material is not credible.

Measurements shall be accomplished in accordance with the schedules shown in Figure II-1. Materials not amenable to measurement may be subject to measurement requirements in accordance with paragraph $5 \mathrm{a}(4)(\mathrm{g})$.

(6) Documented acceptance/rejection criteria shall be established and used to evaluate measurement data for internal material transfers. In addition, procedures shall specify notification and response requirements if material removal or another abnormal situation is detected. These requirements shall be consistent with page 1-13, paragraph 5, and DOE 5000.3B." 
Westinghouse Hanford Company (WHC)

Standards/Requirements Identification Document

6.0 Safeguards and Security
WHC-SD-MP-SRID-002

January 10, 1996

Rev. 0

Page 32 of 52

REQUIREMENT SOURCE: DOE5633.3B Chapter II, Section 6.b.(1)

Author's Note: Only sentence 1 is applicable.

"Each facility shall have a documented program for evaluating all special nuclear material . inventory differences, including those involving missing items. Programs for evaluation of inventory differences for other nuclear materials may be established at the option of the Manager, Operations Office. Procedures shall be provided for establishing control limits and requiring investigation when those limits are exceeded. Warning limits will be set at the 95 percent confidence level. Alarm limits will be set at the 99 percent confidence level. All inventory differences exceeding warning or alarm limits shall be reported in accordance with DOE 5000.3B and page I-13, paragraph 5. Assessments of inventory differences shall include statistical tests (e.g., tests of trends and biases), and shall be applied, as appropriate, to both total inventory difference and actual inventory difference on an individual and cumulative basis for each processing Materials Balance Area."

\section{REQUIREMENT SOURCE: DOE5633.3B Chapter II, Section 6.c.(1)}

Author's Note: Only sentence $I$ is applicable.

"Each facility's management shall establish a documented program for evaluating all inventory adjustments entered in the accounting records. The program shall include written procedures including equations for applying radioactive decay and fission/transmutation adjustments. A program for holdup adjustments must be justified on the basis of measurements or other factors. Procedures shall be outlined for the statistical review of inventory adjustments using techniques such as tests of trends, biases, and correlation."

REQUIREMENT SOURCE: DOE5633.3B Chapter III, Section 2, Introduction

Author's Note: Only Sentences 1 and 2 apply at the WHC company level.

"ACCESS CONTROLS. Each facility shall have a graded program for controlling personnel access to: nuclear materials; nuclear materials accountability, inventory, and measurement data; and data generating equipment and other items/equipment where misuse or tampering could lead to compromise of the safeguards system. The graded access control system shall consider the quantity and attractiveness of the material in the area and impacts of threats, as weil as other control systems that are in place and which may mitigate these threats. These access controls may range from extensive and complex access control systems for Category IA areas and materials to simple administratively controlled access systems for Category IV areas. For facilities that have Category III and IV areas containing Attractiveness Level B and C material outside of a Protected Areas, the facility's management shall assure that these areas do not possess a Category I or II quantity of special nuclear material unless a vulnerability assessments demonstrates that an unauthorized accumulation of a Category I quantity of material from these facilities is not credible. Personnel security assurance programs shall be used as a component in the prevention of the theft or diversion of special nuclear material and shall be considered in assessments of vulnerability related to theft of Category I quantities of special nuclear material. Testing of access control systems and procedures shall be conducted according to testing methodology, testing frequency, and record maintenance requirements contained in DOE 5630.16A and applicable Department guidance. Performance requirements for access controls are contained on page I-10, paragraph 4." 
Westinghouse Hanford Company (WHC)

Standards/Requirements Identification Document

6.0 Safeguards and Security
WHC-SD-MP-SRID-002

January 10, 1996

Rev. 0

Page 33 of 52

\section{REQUIREMENT SOURCE: DOE5633.3B Chapter III, Section 2.b}

"Data Access. Each facility shall have a graded program to assure that only authorized persons have the ability to enter, change, or access material control and accountability data and information."

\section{REQUIREMENT SOURCE: DOE5633.3B Chapter II, Section 2.c}

"Equipment Access. Each facility shall have a graded program to control access to data-generating and other equipment used in material control activities, thereby assisting in providing assurance of the integrity of equipment and data used for material control. Such equipment includes measurement equipment, data recording devices, and tamper-indicating devices. An access control program comparable to that required for classified computer systems may be required if such controls are necessary to assure the integrity of the data system."

\section{REQUIREMENT SOURCE: DOE5633.3B Chapter III, Section 5, Introduction}

"Detection/Assessment. Each facility shall have the capability to detect and assess the unauthorized removal of nuclear materials, consistent with the graded safeguards concept. The system shall be interfaced with the facility's physical protection and other organizational systems, as appropriate, and shall be able to detect removal of special nuclear material from its authorized location (theft/diversion/errors) and provide notification to the protective force and other organizations to respond when such events are detected."

\section{REQUIREMENT SOURCE: DOE5633.3B Chapter III, Section 5.a}

"Tamper-Indicating Devices. The reliance on tamper-indicating devices as a safeguards measure is directly dependent on the environment in which the tamper-indicating device resides and the material being tamper-safed. Each facility shall have a documented program, administered by the materials control and accountability organization, for control of tamper-indicating devices and to assure that tamper-indicating devices are used to the extent possible to detect violations of container integrity. DOE-wide standardized tamper-indicating devices should be used when available through DOE standardized procurement (see DOE 5630.17, SAFEGUARDS AND SECURITY (S\&S) STANDARDIZATION PROGRAM). Testing of tamper-indicating device integrity, location, and application and the tamper-indicating device record system shall be conducted according to testing methodology, testing frequency, and record maintenance requirements contained in DOE 5630.16A and applicable Departmental directives and guidance. Performance requirements for tamper-indicating devices are contained on page I-10, paragraph 4 , of this Order. The "Safeguards Seal Reference Manual," issued by Office of Safeguards and Security, can facilitate in the selection, application, and verification of tamper-indicating devices. The tamper-indicating device control program shall specify, as a minimum, the following elements:

(1) Acquisition/procurement/destruction;

(2) Types of tamper-indicating devices utilized;

(3) Assurance of unique tamper-indicating devices identification;

(4) Storage;

(5) Issuance; 
(6) Personnel authorized to apply, remove, and dispose of tamper-indicating devices;

(7) Containers on which tamper-indicating devices are to be applied;

(8) Procedures for application of tamper-indicating devices;

(9) Frequency and method of tamper-indicating devices verification;

(10) Response procedures for tamper-indicating devices violations;

(11) Assurance that tamper-indicating devices cannot be reused after violation;

(12) Frequency and method of internal program audits; and

(13) Procedures for reporting tamper-indicating device violations."

\section{REQUIREMENT SOURCE: DOE5633.3B Chapter III, Section 5.d}

"Daily Administrative Checks. A facility-specific daily administrative checks program shall be implemented for each Category I Materials Balance Area (or multiple Materials Balance Areas where rollup to a Category I quantity of special nuclear material is credible). The scope and extent of the checks shall be determined and approved by the Operations Office based upon recognized vulnerabilities. The administrative checks program shall specify the detection objectives, performance procedures, documentation requirements, and response actions."

\section{REQUIREMENT SOURCE: RLID633.3 Section 7.2.i(1)}

"Contractors shall establish a program for continuing trend analysis of current and historical control indicator data. The results will be documented and maintained in an auditable file."

\section{REQUREMENT SOURCE: RLID5633.3 Section 7.3.b(1)}

"The apparent loss or loss of Category I and II quantities of NM shall be investigated and verbally reported, as specified..."

\section{REQUREMENT SOURCE: RUID633.3 Section 7.3.c(1)}

"Accidental losses of Category I and II quantities of NM shall be reported immediately, during day-shift work hours, to the Safeguards and Classification Program Manager, and during other hours to the RL-SAS Duty Officer through the Patrol Operations Center (373-3800)."

\section{REQUIREMENT SOURCE: RLID5633.3 Section 7.3.d(1)}

"When unauthorized access to NM may have occurred due to an unsecured facility, RL-SAS and other required personnel shall be notified immediately... 


\section{REQUIREMENT SOURCE: DOE5630.11B Preamble, Section 8.k(1)(e)}

"Develop, validate, and submit to cognizant Program Office for approval Site Safeguards and Security Plans based on vulnerability/risk analyses for a comprehensive safeguards and security program."

\section{REQUIREMINT SOURCE: DOE5630.16A Preamble, Section 8.a(1)}

"Safeguards and security acceptance and validation tests shall be developed for each facility to validate functional requirements and effectiveness of the safeguards and security elements implemented and operating as part of a total system and to assure continuing operation as a total system."

\section{REQUIREMENT SOURCE: DOE5630.16A Preamble, Section 8.a(5)}

"Validation testing of safeguards systems shall include elements that can detect-in-time-to-prevent (e.g., portal monitors and material surveillance procedures) and elements that can effectively account for special nuclear material in order to provide assurance that safeguards and security systems are functioning properly (e.g., physical inventory). Testing of some safeguards systems, such as the physical inventory, does not necessarily require a specific stand alone test, but instead a check and evaluation of accounting records, measurements data, and procedures. "

\section{REQUTREMENT SOURCE: DOE5634.1B Chapter IV, Section 7}

"PERFORMANCE SEGMENT. Surveys of facilities shall include a performance evaluation to assess the capability of the safeguards and security system to meet performance objectives. The performance evaluation shall determine system performance against scenarios for applicable threats/targets."

\section{REQUIREMENT SOURCE: DOE-M-5632.1C-1 Chapter III, Section 1.a}

"Classification levels shall be used in determining the degree of protection and control required for classified matter."

\section{REQULREMENT SOURCE: DOE-M-5632.1C-1 Chapter III, Section 1.b}

"Access to classified matter shall be limited to persons who possess appropriate access authorization and who require such access (need-to-know) in the performance of official duties. Controls shall be established to detect and deter unauthorized access to classified matter."

\section{REQUTRMENT SOURCE: DOE-M-5632.1C-1 Chapter III, Section 1.c}

"Custodians and authorized users of classified matter are responsible for the protection and control of such matter." 


\section{REQUREMENT SOURCE: DOE-M-5632.1C-1 Chapter III, Section 1.d}

"Buildings and rooms containing classified matter shall be afforded the security measures necessary to prevent unauthorized persons from gaining access to classified matter, specifically to include security measures to prevent persons outside the facility protective zone from viewing or hearing classified information. Conference rooms and areas specifically-designated for classified discussions shall follow Technical Surveillance Countermeasures Program requirements."

\section{REQUIREMENT SOURCE: DOE-M-5632.1C-1 Chapter III, Section 2, Sentence 1}

"IN USE. Classified matter in use shall be constantly attended by or under the control of a person or persons having the proper access authorization and a need-to-know, who are responsible for its protection."

\section{REQUREMENT SOURCE: DOE-M-5632.1C-1 Chapter III, Section 3.a}

"General. Classified matter shall be stored in a manner to prevent unauthorized persons from gaining access."

REQUTREMENT SOURCE: DOE5639.1 Preamble, Section 8.b(13)(j)

"Submit reports of unauthorized disclosures of classified information."

REQUIREMENT SOURCE: DOE5639.1 Preamble, Section 8.b(13)(k)

"Maintain records of security infractions and determine the disciplinary or corrective action to be taken as a result of infractions."

REQUIREMENT SOURCE: DOE5639.1 Preamble, Section 8.1(6)

"Ensure appropriate issuance of infractions to DOE and DOE contractor personnel by:

(a) Designating a DOE Safeguards and Security employee who is knowledgeable in the issuance of infractions.

(b) Ensuring the appointment of DOE contractor personnel knowledgeable in the issuance of infractions."

REQUTREMENT SOURCE: DOE5639.1 Preamble, Section 13.a

"Unaccounted-For Matter. This paragraph pertains to those situations where classified matter has been or may have been lost, missing, or otherwise unaccounted-for.

(1) Discovery. Any person who determines that classified matter has been or may have been lost, is missing, or is otherwise unaccounted-for shall take immediate action to preclude any further or potential compromises and report this information to the custodian or security officer. The measures listed below apply to custodians who determine or learn that classified matter is unaccounted-for.

(2) Initial Search. Upon determining or learning that classified matter may be unaccounted-for, a search of the immediate area where the matter was stored, handied, or 
processed shall be conducted. When applicable, the accountability records shall be audited for evidence of destruction; transmission, or other disposition.

(a) If the matter is found or otherwise accounted-for with no indication of compromise, no further actions need to be taken.

(b) If Secret or Confidential matter is unaccounted-for, the cognizant safeguards and security organization or officer shall be notified within 24 hours from initial indications of the unaccounted-for status.

(c) If Sigma 1 or Sigma 2 Weapon Data matter is unaccounted-for, the Office of Safeguards and Security (SA-10), the appropriate Secretarial Officer, and the Office of Military Applications (DP-20), through the cognizant safeguards and security organization or officet shall be notified within 24 hours.

(d) If Top Secret matter, classified matter of another agency, or classified matter of a foreign government is unaccounted-for, SA-10 and the appropriate Secretarial Officer, through the cognizant safeguards and security organization or officer, shall be notified within 24 hours. Documents related to the Joint Atomic Information Exchange Group (JAIEG) shall also be reported to DP-20 who will ensure appropriate reporting to JAIEG.

(3) Detailed Search. Unaccounted-for matter that cannot be reconciled after the initial search and audit of records shall require a more detailed search of the area where the matter may have been stored, processed, and handled. Additionally, custodians of document control stations providing immediate adjacent support, as well as one level above and one level below the holder must be queried. The facility's security organization shall initiate a detailed search in an attempt to ascertain whether or not a transmittal, receipt, or destruction may have been administratively mishandled. The detailed search and query process shall be completed within 48 hours. If the matter is found, or otherwise accounted-for, the search process will be discontinued; however, the facility security office shall review the surrounding circumstances and procedures for possible corrective action.

(4) Preliminary Inquiry. The purpose of a preliminary inquiry is to establish whether a compromise of classified information or a violation of law has occurred. Preliminary inquiries shall be conducted as expeditiously as possible and shall not be used as a means of holding in abeyance a decision to initiate a full-scale inquiry.

(a) When all efforts fail to reconcile unaccounted-for matter, the facility security office shall initiate a preliminary inquiry to document and ensure all basic areas of consideration have been satisfied. As a minimum the preliminary inquiry shall:

1 Include an interview with the last known custodian and require that individual, and any other personnel who may have pertinent information, prepare signed memoranda on the protection and control of the matter or the circumstances under which the matter became unaccounted-for.

2 Include a review by an authorized classifier of the classification assigned to the matter at the time it was determined unaccounted-for. If another copy of the unaccounted-for matter exists, arrangements shall be made to review the current classification and hold the copy for possibie future reviews.

3 Ensure the conduct of a physical search of the office of the last known holder and other offices where the matter may logicaliy be found. A part of any search shall include a review of the custodian's records, the central files, and the local central document control office 
(including downgrade and declassification notices, destruction certificates, classified document receipts, letters or transmittal, and incoming and outgoing mail logs).

4 Determine the reason why the matter is unaccounted-for and recommend action to prevent recurrence.

5 Assess the potential for compromise and determine if additional investigation is required.

6 Provide adequate information to be used to complete the Department of Justice eleven point criteria if deemed necessary.

(b) The preliminary inquiry shall be completed and a written report, DOE F 5635.11, "Reporting Unaccounted For Documents," or a form similar in content, with supporting statements/documentation, shall be forwarded to the cognizant Deparmental Element safeguards and security organization or officer. A classification review of the form shall be performed by an authorized derivative classifier. An example of DOE F 5635.11 is shown as Attachment 3. The cognizant Departmental Element safeguards and security organization or officer shall notify SA-10 and the responsible Secretarial Officer in accordance with DOE 5000.3A, OCCURRENCE REPORTING AND PROCESSING OF OPERATIONS INFORMATION, of 5-30-90.

(c) The preliminary inquiry shall review the circumstances, procedures, and activities surrounding the incident, and provide for corrective action to preclude recurrence.

(5) Records. (See paragraph 13e for records retention). For accountability purposes, classified matter may be removed from accountability records, if any, and maintained in a separate record of unaccounted-for matter when:

(a) All inquiries have been completed; and

(b) Corrective actions have been implemented (commitments to implement shall not constitute implementation)."

\section{REQUTREMENT SOURCE: DOE5639.1 Preamble, Section 13.e}

"Records Retention. Records of all actions pertaining to unaccounted-for/compromised matter or compromises of information must be maintained by the facility and the cognizant Departmental Element safeguards and security organization or officer. In accordance with DOE 1324.2A, RECORDS DISPOSITION, of 9-13-88, records shall be destroyed 5 years after the close of all associated actions. These records will not be sent to Federal Records Centers."

\section{REQUIREMENT SOURCE: DOE5639.1 Preamble, Section 14.b}

"Report of Security Infraction. DOE F 5630.13, "Report of Security Infraction" or a form similar in content shall be used to document security infractions and a copy of the report kept in the employee's official DOE personnel security file. An example of DOE F 5630.13 is shown as Attachment 4 . With each occurrence security practices or procedures shall be reviewed and revised if necessary to preclude recurrence." 
REQUIREMINT SOURCE: DOE5650.2B Chapter II, Part C, Section 3

Author's Note: Only 3.a applies.

"CLASSIFICATION OFFICERS (FIELD ELEMENT AND CONTRACTOR).

a. Qualifications. Classification Officers must have a scientific or technical degree. This qualification requirement may be waived by SA-20 on a case-by-case basis for those having suitable experience. (Classification Officers shall be designated as Autborized Classifiers.)

b. Appointment. Heads of Field Elements shall designate, when needed and with the approval of SA-20, persons to serve as Classification Officers. Field Element Classification Officers shall review contractor nominations for Classification Officers and recommend SA-20 approval. SA-20 approval of DOE and DOE contractor Classification Officers is contingent upon successful completion of a training course specified by SA-20."

REQUIREMENT SOURCE: DOE5650.2B Chapter V, Part A, Section 5.a

"DERIVATIVE CLASSIFICATION AUTHORITY.

a. Applicability. Individuals with Derivative Classification Authority may classify documents or material that contain or reveal RD, FRD, or NSI in accordance with classification guides authorized for the classifier's use, source documents, or instructions from an Original Classifier."

\section{ReQUIREMENT SOURCE: DOE5650.2B Chapter V, Part A, Section 5.b}

"Qualifications, A Derivative Classifier must (1) have demonstrated competence in the subject area in which the authority will be used; (2) be knowledgeable in DOE classification policy and procedures (especially with all classification guides in the subject area in which the authority will be used); (3) be in a position with a proven or anticipated need for Derivative Classification Authority; (4) have successfully completed a training program and examination given by the local classification office; and (5) be so designated in writing by appropriate authority as described below."

\section{REQUIREMENT SOURCE: DOE5650.2B Chapter V, Part A, Section 5.g}

"Recordkeeping Requirements. Each appointing official shall maintain a list of all individuals with Derivative Classification Authority under his or her purview. This list shall include (1) the level of the authority granted, (2) the name and title of the individual granted the authority, (3) the individual's Departmental Element or contractor organization, and (4) the effective date and expiration date of the designation."

\section{REQUIREMENT SOURCE: DOE5650.2B Chapter V, Part G, Section 2}

Author's Note: Only the first sentence of 2.b, the first sentence of 2.c, and the part about DOE contractor in 2.d are applicable.

"DOCUMENTS ORIGINATED BY DEPARTMENTAL ELEMENTS OR DEPARTMENTAL CONTRACTOR PERSONNEL. These procedures apply to all documents originated by a DOE or DOE contractor personnel who possess valid security clearances. SA-20 or Heads of Field Elements may exempt specific categories of documents or subject areas from these procedures. 
a. Documents That Concern Category I Activities or non-R\&D subjects having no potential for using or generating classified information do not require classification review. However, it is the originator's responsibility to refer questionable cases to an Authorized Classifier.

b. Documents That Concem Category II or Category III Activities or non-R\&D subjects having a potential for using or generating classified information must be reviewed by an Authorized Classifier. Such a review is sufficient for documents that the Authorized Classifier determines(1) to be classified or(2) to be unclassified, but which will receive limited distribution. Examples of such unclassified but limited distribution documents include most letters, memorandums, internal analyses, and planning documents.

c. Documents Intended for Widespread Distribution or Public Release. A DOE contractor classification office or SA-20 must review all documents, regardless of format, that concern Category II, Category III, or other classified program areas and are intended for public release is likely. Heads of HQ and Field Elements may delegate this authority to specified Authorized Classifiers. Formal reports, journal articles, press releases, speeches, and conference papers are examples of this type of document.

d. Oral Presentations. The review requirements described in subparagraphs $a, b$, and $c$, above, are also applicable to any oral presentations, including speeches, briefings, or interviews, to be made by DOE or DOE contractor personnel. Whenever possible, the speakers should use prepared texts, reviewed in accordance with the requirements outlined above. When such prior review is not possible, or when extemporaneous remarks are likely, local DOE or DOE contractor classification office representatives will prebrief the speaker on classification guidance pertinent to the presentation subject matter, including danger areas in post-presentation discussions."

\section{REQUREMENT SOURCE: DOE5650.2B Chapter VI, Part A, Section 2.b}

Author's Note: Only $2 . b(1)$ and $2 . b(2)(b)$ Sentence 1 are applicable.

"b. Derivative Declassification Authority.

(1) Qualifications. A Derivative Declassifier must (a) have demonstrated competence in the subject area in which the authority will be used; (b) be knowledgeable in DOE classification policy and procedures (especially with all classification guides in the subject area in which the authority will be used); (c) be in a position with a proven or anticipated need for Derivative Declassification Authority; (d) have successfully completed a training program and examination; and (e) be so designated in writing by SA-20 as described below. SA-20 may grant a waiver of the training and examination requirements for Classification Officers.

(2) Designation.

(a) Requests for Derivative Declassification Autbority must be submitted to SA-20 in the format of Attachment X-1 or any other format containing the same information.

(b) Individuals for whom Derivative Declassification Authority has been requested must have successfully completed a training program and examination and received official notification of approval by SA-20 prior to assuming classification authority. SA-20 may grant a waiver of the training and examination requirements for Classification Officers.

(c) When an individual assumes a position for which Derivative Declassification Authority has previously been granted, a request for declassification authority must be submitted to SA-20 for approval using the format of Attachment X-1 or any other format that contains the same 
information. The individual may not assume Derivative Declassification Authority until he or she has completed the requirements given in paragraph (b) above, except that the appointing official may waive the requirements if the individual has met such requirements within the past 3 years and is transferring to a similar programmatic position.

(d) Derivative Declassification Authority may not be redelegated.

(e) Derivative Declassification Authority is granted for a period of 3 years at which time the individual must be recertified by passing an examination. SA-20 may grant a waiver of this examination requirement.

(f) Past frequency of use of Derivative Declassification Authority is a factor in determining whether renewal of such authority is needed by an individual. Such use includes the review of documents to determine whether they can or cannot be declassified.

(3) Cancellation.

(a) If the Head of a Departmental Element determines that an individual's position no longer requires Derivative Declassification Authority, the Element Head shall promptly inform SA-20 using the format of Attachment X-2 or any other format that contains the same information.

(b) When an individual with Derivative Declassification Authority vacates a position, the Head of the individual's Departmental Element will promptly inform SA-20 using the format of Attachment X-2 or any other format containing the same information.

(c) If SA-20 determines that an individual no longer requires Derivative Declassification Authority, SA-20 shall advise the Head of the individual's Departmental Element of such determination, of the reason(s) therefor, and of the date on which the authority will end.

(4) Recordkeeping Requirements. SA-20 shall maintain a list of all individuals with Derivative Declassification Authority. This list shall include (a) the name and title of the individual granted the authority, (b) the individual's Departmental Element or contractor organization, and (c) the effective date and expiration date of the designation. In addition, each Departmental Element and contractor organization shall maintain a similar list of all individuals with Derivative Declassification Authority within its jurisdiction.

(5) Authority Definition. (See page X-23, Chapter X, Part C.)

(a) An individual with Derivative Declassification Authority may derivatively declassify or downgrade documents or material originated by his or her organization, its contractors, or the predecessors of these organizations. In certain circumstances, SA-20 may grant broader declassification authority to an individual.

(b) Derivative Declassifiers may declassify documents or material only in the areas in which they have been delegated such authority and which disclose only:

1 Information falling within the "unclassified" topics of classification and/or declassification guidance specifically authorized for their use in declassifying documents; or

2 Information identified as unclassified or that has been declassified by SA-20; or

3 Information of an administrative nature that reveals no technical or programmatic data.

(Caution: This criterion is intended for historical documents and is to be interpreted very 
narrowly. If there is any doubt as to whether information is "purely administrative, " specific guidance must be sought.)"

\section{REQUREMENT SOURCE: DOE5650.2B(930428) Chapter VII, Section 2.a, Sentence 1}

"All new DOE and DOE contractor employees must understand their classification responsibilities before being given access to classified information."

\section{REQUREMENT SOURCE: DOE5650.2B(930428) Chapter VI, Section 2.b}

"All DOE and DOE contractor classification offices shall conduct a continuing classification education program for all cleared employees to maintain classification awareness and apprise employees of applicable changes in classification policies, principles, guidance, and procedures."

\section{$\underline{6.6 .2}$}

\section{Technical Surveillance Countermeasures (TSCM)}

Author's Note: Westinghouse Hanford Company has no qualifying facilities.

\section{REQUIREMENT SOURCE: DOE-M-5639.6A-1 Chapter VI, Section 1}

"BASELINE REQUIREMENTS, Each classified AIS, including remote terminals, printers, or other output devices, communication links, memory, and other interconnected devices, shall be afforded physical security commensurate with the highest classification level and most restrictive classification category of information to which it provides access. Components of the classified AIS shall be contained in security areas authorized by an approved Site Safeguards and Security Plan or a Site Security Plan. Security controls to protect the equipment apply not only to the classified AIS and its components but also to all removable media such as magnetic tapes, magnetic disk packs, and spare or replacement parts once they are identifiable with a specific Classified AIS or Network."

\section{REQUIREMENT SOURCE: DOE5639.6A Preamble, Section 5.c. Introduction and} 5.c.(1)

"The following subparagraphs elaborate the Departmental classified AIS security policy:

(1) Protection of Classified Information and Resources. The Classified AIS Security Program shall be implemented to ensure that:

(a) The integrity of the information on the classified AIS is preserved;

(b) Information processed on a classified AIS is protected from unauthorized access, alteration, modification, disclosure, transmission, or destruction;

(c) The classified AISs resources provide an appropriate level of protection against denial of service, subversion of security measures, or improper use; and

(d) The classified AISs resources are protected from damage, destruction, and unauthorized modification." 


\section{REQUTREMIENT SOURCE: DOE5639.6A Preamble, Section 5.c.(2)}

"Protection Measures. DOE and covered contractors shall use all reasonable measures to protect AISs that process, store, transfer, or provide access to classified information. These measures include but are not limited to the following:

(a) Measures related to personnel security, physical security, telecommunications security, administrative security, technical security, and hardware and software security shail be used to provide the necessary protection for the information on the Classified AIS in a manner that shall result in an acceptable level of risk against loss, improper use, compromise, or unauthorized alteration or modification of classified information.

(b) Acquisitions or other procurement actions to obtain AIS equipment or related contractual services (as defined in DOE 1360.1B, ACQUISITION AND MANAGEMENT OF COMPUTING RESOURCES) that will be used to process, store, transfer, or provide access to classified information shall be:

1) Evaluated by the Classified AIS Security Site Manager (CSSM) to assure that appropriate security technology is being specified; and

2) Integrated into the Information Resources Management Long Range Plan in accordance with DOE $1360.1 \mathrm{~B}$.

(c) AISs used to process, store, transfer, or provide access to classified information shall be:

1) Accredited by a Designated Accrediting Authority (DAA) to be operated:

a. In a particular mode of operation as defined in DOE M 5639.6A-1;

b. With a prescribed set of personnel, administrative, operational, physical, telecommunications, hardware, software, and technical requirements;

c. Under a stated operational concept; and

d. With identified interconnections to other AISs.

2) Reaccredited by a DAA at least once every 3 years except for classified AISs processing Sensitive Compartmented Information.

3) Protected in accordance with the requirements of this Order and DOE M 5639.6A-1.

4) Covered by a continuity of operations decision or a plan (see Page I-6, paragraph 9 , DOE M 5639.6A-1).

5) Operated under the oversight of a designated Departmental or covered contractor manager or supervisor.

6) Accessed only by personnel who have:

a. Received training in their security responsibilities;

b. A proper level of security clearance and need-to-know; and 
c. Acknowledged, in writing, their responsibilities to protect classified information on classified AISs.

7) Located in a Limited, Protected, or Exclusion Area as required by DOE 5632.5, PHYSICAL PROTECTION OF CLASSIFIED MATTER."

\section{RDQURRMIENT SOURCE: DOE5639.6A Preamble, Section 7.i.(2)}

"Appoint, in writing, an employee as the CSSM to implement the site Classified AIS Security Program described in this Order and DOE M 5639.6A-1."

\section{Unclassified Computer and Sensitive Automated Data Processing Systems}

\section{REQUIREMENT SOURCE: DOE1360.2B Section 11.a}

"The site (DOE or contractor) manager will assure that a management official, knowledgeable in both computing and computer security methods and practices, is designated as the Computer Protection Program Manager (CPPM). In cases where multiple computer installations, computer systems, or program-area applications exist, the CPPM may designate assistant CPPM's to accomplish specific security responsibilities."

\section{REQUTREMENT SOURCE: DOE1360.2B Section 11.c}

"The management control process must ensure that the following, as a minimum, are carried out:

(1) Periodic risk assessments are conducted for new and existing computer installations to ensure that appropriate, cost-effective safeguards are incorporated commensurate with the sensitivity and value of associated computer systems, computer applications, and unclassified information processed. (See paragraph 11f, below, for description of risk assessment process.)

(2) Procedures are established for defining functional security requirements, developing security specifications, conducting security design reviews and system tests, certifying and recertifying unclassified computer applications processing sensitive information at appropriate phases of the systems life cycle, and approving security specifications for the acquisition of computer resources or related services. (See paragraph $11 \mathrm{~g}$, below, for minimum security sequirements.)

(3) Personnel who participate in managing, designing, developing, operating, or maintaining unclassified computer applications processing sensitive information, or who access automated sensitive unclassified information, are appropriately screened to a level commensurate with the sensitivity of the data to be accessed or handled and the risk and magnitude of loss or harm that could be caused by the individual. Federal personnel are to be screened in accordance with the Office of Personnel Management policies and procedures. (Guidelines on screening non-Federal personnel are available from AD-24.)

(4) Appropriate protection measures are established, to the extent economically and technically feasible, for maintaining personal accountability of individual users granted access to sensitive unclassified automated information, and that they have access to no more information than authorized. 
(5) Follownup procedures are in place to ensure implementation of protective measures in accordance with recommendations from compliance review and certification/recertification review activities.

(6) Appropriate installation disaster recovery plans (DRP) and application contingency plans are established and maintained for computer installations and applications supporting DOE mission-essential functions to prevent loss of information, minimize interruption, and provide reasonable continuity of computer services should adverse events occur that would prevent normal operations.

(7) CPPs are approved by appropriate management officials."

\section{Communications Security}

Author's Note: The DOE COMSEC Procedural Guide, which is "Official Use Only", contains prescriptive requirements relative to COMSEC.

\section{REQUTREENT SOURCE: DOE5300.3D Preamble, Section 10.a(2)}

"Appoint in writing communications security control officers, custodians, and their alternates. Instructions for preparation of the written appointment letters are contained in the "Department of Energy Communications Security Procedural Gujde." Appointment letters are required for all crypio-personnel."

REQUIREMENT SOURCE: DOE5300.3D Preamble, Section 10.h., Introduction and $h(1 \& 2)$

"Other Communications Security Personnel. The "Department of Energy Communications Security procedural Guide" provides detailed descriptions with respect to the following functions and their responsibilities assigned to the:

(1) Communications security control officer;

(2) Communications security custodian;"

\section{Counterintelligence}

\section{REQUIREMENT SOURCE: DOE5670.3 Preamble, Section 8.g}

"Field Office Counterintelligence Program Managers shall:

(1) Ensure the development and implementation of a CI Program for DOE Field Offices, contractors, and subcontractors consistent with the intent of the Departmental CI Program.

(2) Develop and implement a CI Awareness Program to meet CI program objectives in conjunction with the security education and awareness program.

(3) Perform liaison with authorized local intelligence community and law enforcement agencies on counterintelligence matters.

(4) Advise IN-20 of any specific $\mathrm{Cl}$ educational requirements in conjunction with unique facility needs to ensure that specialized training curriculum may be tailored accordingly. 
(5) Establish a system for limited CI incident examination, inquiries, resolutions, and/or referral to the appropriate Intelligence Community/law enforcement agency.

(6) Notify IN-20 within 24 hours of all incidents involving suspected or identified foreign intelligence activities and all incidents involving suspected or identified technical penetrations affecting persons or facilities under their jurisdiction.

(7) Coordinate with the Office of Safeguards and Security (SA-10) to provide CI information for the foreign travel and contacts briefing program. Provide $\mathrm{CI}$ information for safeguards and security orientation briefings for new Federal and contractor employees.

(8) Establish and conduct a program for foreign travel and contacts debriefings.

(9) Establish a system to assure prompt transmittal of current CI threat information to contractor $\mathrm{Cl}$ program designee."

REQUIREMENT SOURCE: DOE5639.7 Preamble, Section 8.h., Introduction and 8.h.(1-13)

"Managers of DOE Field Offices, Administrators of the Power Marketing Administrations and the Director of Safeguards and Security, for the organizations under their area of cognizance (SA-10 has the following responsibilities for Headquarters, and organizations not reporting through a DOE Field Office), shall:

(1) Institute, modify, and manage OPSEC programs and procedures at their respective locations and contractor facilities in accordance with this Order's policy statement and procedural guidelines; and, through their respective contracting officers, assure that contractors are required to comply with applicable provisions of this Order. This includes the identification of Class B and C facilities under their jurisdiction which warrant OPSEC protection and ensuring the implementation of an appropriate OPSEC program at such facilities.

(2) Establish a sufficient number of OPSEC working groups under the cognizance of each field element and at Headquarters, to perform the necessary management and support functions required for an effective OPSEC Program, to include OPSEC education and awareness. The working groups shall develop and set priorities for their OPSEC Program objectives consistent with approved plans and policies, meet on a regular basis, and maintain records of meeting, a copy of which shall be held by the responsible OPSEC Manager.

(3) Conduct OPSEC assessments of all Class A facilities falling within their purview. A copy of these assessments to include findings, recommendations, and actions taken will be provided to SA-10 for historical purposes.

(a) Either the programmatic or facility approach may be used to conduct the OPSEC assessment. If the facility approach is used, all activities at the facility will be included in the assessment. If the programmatic approach is used, all activities within the individual program will be included in the assessment.

(b) All Class A facilities which were not the subject of an OPSEC assessment under the requirements of DOE 5632.3B are required to have an assessment completed within 1 year of the effective date of this Order. 
(c) Effective immediately, all Class $\mathrm{A}$ facilities are required to have an OPSEC assessment conducted at least every 2 years, or sooner if there are significant changes in the facility environment. If the programmatic approach is used and there is more than one major program located at the facility, a schedule will be developed and implemented which provides for the conduct of a minimum of one programmatic assessment annually. Major programs will be identified by the local OPSEC Working Group.

(4) Complete an initial OPSEC review of other sensitive activities and facilities within 1 year of the effective date of this Order, and conduct an OPSEC review whenever:

(a) New construction is planned that will process or store classified or sensitive information or material; or

(b) New sensitive activities are initiated or when significant changes occur to existing programs.

(5) Conduct OPSEC liaison with other field elements and local agencies. Advise SA-10 of broadly based OPSEC initiatives involving these organizations.

(6) Ensure facilities included in the OPSEC Program develop and maintain OPSEC plans, procedures and program files to assist in implementing an active program, and approve these plans and procedures, as appropriate. OPSEC plans will include, at a minimum, goals milestones, a timetable for accomplishing same, and, where applicable, an annex describing actions to identify and counter imagery collection from air- and space-borne platforms.

(7) Appoint an OPSEC Manager to implement the OPSEC program and ensure that OPSEC information promulgated by SA-10 is properly safeguarded and disseminated to authorized recipients.

(8) Ensure that OPSEC is addressed in safeguards and security planning and in Site Safeguards and Security Plans (SSSPs) and amendments, as appropriate.

(9) Analyze the results of OPSEC assessments and develop and implement countermeasures, as appropriate.

(10) Prepare a threat statement which describes the local OPSEC threat and develop a Critical and Sensitive Information List (CSIL) and supporting Essential Elements of Friendly Information (EEFI), which will be appropriately classified, set according to priorities, and disseminated to cognizant managers for review, comment and action based on the adequacy of countermeasures in place at each site. The threat statement and CSIL/EEFI will be reviewed by the cognizant OPSEC Working Group and senior Headquarters' program management and updated at least annually. The results of such reviews will be recorded in OPSEC Managers' files. Ensure that the periodic security surveys of facilities within the purview of the field element include a thorough inspection of the OPSEC Program and an assessment of the practical impacts and effectiveness of the program.

(11) Conduct an initial review of all ongoing sensitive activities to identify those that are susceptible to imaging exploitation. Upon receipt of the multispectral imagery threat, the initial review will be refined for potential application of imagery countermeasures.

(12) Report annually, on November 1, to SA-10, and applicable program officials, on the status of their respective Operations Security programs for the preceding fiscal year. 
(13) Ensure an individual(s) is designated to be responsible for bringing to the attention of the contracting officer each procurement falling within the scope of this Order. Unless another individual is designated, the responsibility is that of the procurement request originator."

Author's Note: As required, Westinghouse Hanford Company provides the necessary information to facilitate DOE FOCI determination(s).

"On contracts or agreements requiring access authorization(s) for which they are responsible, ensure that the contracting officer provides written notification to his/her servicing safeguards and security office in each of the following instances:

(a) When there is no longer a need for a requested FOCI review.

(b) When a FOCI determination was rendered on an offeror/bidder who was not the successful bidder.

(c) Within 30 days of the termination or completion of a contract or agreement involving FOCI."

\section{EVALUATION OF RADIOLOGICAL AND TOXICOLOGICAL SABOTAGE CONSEQUENCES}

\section{REQUIREMENT SOURCE: DOE5630.11B Preamble, Section 9.c}

"Risk Analysis. The acceptance of some level of risk is inherent in any activity. The determination of the appropriate level of protection shall take into account the nature of the threat, the vulnerability of the potential target, and the potential consequences of an adversarial act. A rational and responsible balance will be obtained through the planning and execution of a comprehensive safeguards and security program. Specific site safeguards and security programs shall be based on vulnerability/risk analyses. These programs shall be designed to provide a high degree of assurance that threats are deterred, denied, contained, mitigated, or neutralized, as appropriate. Risk associated with safeguards and security vulnerabilities should be reduced even where not mandated by specific requirements, when such reduction is consistent with the Department's mission and when supported by appropriate cost/benefit analyses."

\section{REQUIREMENT SOURCE: DOE5632.1C Preamble, Section 5.a}

"Safeguards and security interests shall be protected and controlied to preclude or minimize unauthorized access, unauthorized disclosure, loss, destruction, modifications, theft, compromise, or miscue."

\section{REQUIREMENT SOURCE: DOE5632.1C Preamble, Section 5.b}

"Protection and control shall be provided in a graded, cost-effective fashion, in accordance with the potential risks to the national security and/or the health and safety of DOE and contractor employees, the public, and the environment." 


\section{REQUTREMENT SOURCE: DOE5632.1C Preamble, Section 7.b}

"Threat. The "Design Basis Threat Policy for the Department of Energy Programs and Facilities (U)" shall be used to identify and characterize the range of potential adversary threats to Departmental programs and facilities. Field Elements should review and develop, as appropriate, supplementary local threat policy to take into account site-specific and regional-specific threat considerations."

\section{REQUTREMENT SOURCE: DOE5632.1C Preamble, Section 7.d.(1)}

"Protection Strategy. A protection strategy shail be developed and delineated by each DOE site and approved by the Head of the Field Element for all safeguards and security interests. The strategy used will be determined by the impact that a malevolent act would have on the national security, program continuity, the health and safety of DOE and contractor employees, the public, and/or the environment. (NOTE: Safeguards and security programs shall provide a high degree of assurance of the capability to deter, detect, assess, delay, prevent, and/or inhibit unauthorized access to nuclear weapons, nuclear test devices, or completed nuclear assemblies, Category II or greater quantities of special nuclear material, and Vital Equipment. The safeguards and security system shall be capable of responding, denying access, preventing removal, and/or recovering these Departmental assets from an adversary, while providing command and control to protective forces. Strategies for protection and control of classified matter shall incorporate the applicable requirements established in DOE M 5632.1C-1)."

\section{REQUIREMENT SOURCE: DOE5633.3B Chapter I, Section 1.f}

"Planning for materials control and accountability shall consider the potential of an insider threat, as detailed in "DESIGN BASIS THREAT POLICY FOR THE DEPARTMENT OF ENERGY (DOE) PROGRAMS AND FACILITIES (U)", issued by the Office of Security Affairs. Planning shall address the theft and diversion of special nuclear material, and the unauthorized control of a weapon, test device, or improvised nuclear device, where appropriate. The materials control and accountability program shall support activities to mitigate sabotage."

\section{REQURREMENT SOURCE: DOE5633.3B Chapter I, Section 4.a}

"Vulnerability Assessment. Detailed vulnerability assessments identifying and evaluating the capability for detection of a loss of a Category I quantity of special nuclear material shall be developed by each Category I facility and approved by the head of the Operations Office materials control and accountability organization. Requirements for preparation of the Site Safeguards and Security Plan documents shail be used as the basis for these assessments.

Vulnerability assessments shall cover the full threat spectrum specified in Office of Safeguards and Security guidance. Potential targets shall include all Category I areas and any Category II or III areas for which a credible scenario for unauthorized accumulation of a Category I quantity has been identified. Performance testing programs shall be developed to support and verify vulnerability assessments. Vulnerability assessments shall be reviewed annually and updated when system changes or new information indicate a potentially significant change in the risk of unauthorized removal of Category I quantities of special nuclear material. Results of reviews including changes in vulnerability assessments shall be documented and classified in accordance with CG-SS-3." 


\section{REQUIREMENT SOURCE: DOE5633.3B Chapter III, Section 3.b.(1)}

"Category I and II. The material surveillance program for Category I and II quantities of special nuclear material shall assure that materials are in authorized locations and shall detect unauthorized material flows and transfers. Evaluations of Category I locations shall be performed to determine system capabilities to assess material losses from Materials Access Area and Protected Area boundaries. Evaluations of Category II locations shall be performed to determine system capabilities to assess material losses from the Protected Area boundary. Material surveillance procedures for all areas having Category I or II quantities of special nuclear material shall include the following:

(a) Only appropriately authorized personnel and knowledgeable personnel (i.e., individuals who are capable of detecting incorrect or unauthorized actions) shall be assigned responsibility for surveillance of special nuclear material.

(b) Controls shall be sufficient to ensure that one individual cannot gain access to a secure storage area.

(c) Procedures to ensure constant surveillance of all persons in secure storage areas (e.g., two-person rule or equivalent surveillance procedures) shall be in effect at any time the storage area is not locked and protected by an active alarm system.

(d) Surveillance shall be sufficient to ensure that unauthorized or unaccompanied authorized personnel cannot enter the storage area undetected when the door is unlocked or open.

(e) When two persons are assigned responsibility for maintaining direct control of the item(s) outside an alarmed storage area within an Materials Access Area or Protected Area, either the two authorized persons shall be physically located such that they have an unobstructed view of the item(s) and can positively detect unauthorized or incorrect procedures, or there shall be a system of hardware, procedures, and administrative controls sufficient to ensure no unauthorized accumulation of a Category I quantity without timely detection.

(f) Special nuclear material in use or process shall be under material surveillance procedures, under alam protection, or with the approval of responsible Heads of Field Elements, protected by alternative means which can be demonstrated to provide equivalent protection."

\section{REQUIREMENT SOURCE: RLID5630.3A Section 7.0, Paragraph 1}

"All RL contractors possessing hazardous materials in use or storage, including that contained in waste, shall perform graded assessments of the risk, due to radiological/toxicological sabotage consistent with the levels of hazards present within the facility. Graded assessments are performed by determining the amounts of radioactive and non-radioactive (toxicological) materials."

\section{KEY INTERFACES}

\section{Emergency Management}

Author's Note: This applies to both the facility level and the company level.

"Facility emergency plans shall address conditions that indicate possible loss of control of special nuclear material. The emergency plan shall be consistent with safeguards and security 
Westinghouse Hanford Company (WHC)

Standards/Requirements Identification Document

6.0 Safeguards and Security
WHC-SD-MP-SRID-002

January 10, 1996

Rev. 0

Page 51 of 52

directives, and shall specify materials control and accountability measures to be taken prior to resumption of operations following emergency operations.

$\underline{6.10 .2}$

6.11

$\underline{6.11 .1}$

\section{Packaging and Transportation}

The Safeguards and Security organization establishes security requirements for onsite and offsite shipments of radioactive material, including special nuclear material shipments.

\section{REFERENCES}

\section{Requirement Source Documents}

The following documents were used as requirement sources in the development of this S/RID:

DOE 1240.2B, Unciassified and Assignments by Foreign Nationals, 08/21/92

DOE 1360.2B, Unclassified Computer Security Program, 05/18/92

DOE 5630.11B, Safeguards and Security Program, 08/02/94

DOE 5300.3D, Telecommunications: Communications Security, 08/03/93

RLID 5630.3A, Protection of Hanford Facilities Against Radiological and Toxicological Sabotage, 09/29/94

DOE 5630.13A, Master Safeguards and Security Agreements, 06/08/92

DOE 5631.1C, Safeguards and Security Awareness Program, 05/04/94

DOE 5630.16A, Safeguards and Security Acceptance and Validation Testing Program, $06 / 03 / 93$

DOE 5631.2C, Personnel Security Program, 02/17/94

DOE 5631.4A, Control of Classified Visits, 07/08/92

DOE 5632.1C, Protection and Control of Safeguards and Security Interests, 07/15/94

DOE 5632.7A, Protective Force Program, 04/13/94

DOE 5633.3B, Control and Accountability of Nuclear Materials, 02/12/93

RLID 5633.3, Control and Accountability of Nuclear Materials

DOE 5634.1B, Facility Approvals, Security Surveys, and Nuclear Materials Surveys, 09/15/92

DOE 5634.3, Foreign Ownership, Control, or Influence Program, 06/14/93

DOE 5639.1, Information Security Program, 10/19/92

DOE 5639.3, Violation of Laws, Losses, and Incidents of Security Concern, 09/15/92

DOE 5639.6A, Classified Automated Information System Security Program, 07/15/94 
Westinghouse Hanford Company (WHC)

Standards/Requirements Identification Document

6.0 Safeguards and Security
WHC-SD-MP-SRID-002

January 10, 1996

Rev. 0

Page 52 of 52

DOE 5639.7, Operations Security Program, 04/30/92

DOE M 5632.1C-1, Manual for Protection and Control of Safeguards and Security Interests, $07 / 15 / 94$

DOE 5650.2B, Identification of Classified Information, 04/28/93

DOE 5670.3, Counterintelligence Program, 09/04/92

DOE 0 472.1, Personnel Security Activities, 09/25/95

10CFR1046, Subpart B (1046.11), Protective Force Personnel, 01/01/93

10CFR1047, Part 6, Use of Physical Force when making and arrest, 01/01/93

$\underline{6.11 .2}$

Revieured Documents Not Used as Requirement Sources

The following documents were reviewed as requirement sources but were not used in the development of this S/RID:

DOE 5630.3A, Protection of Departmental Facilities Against Radiological and Toxicological Sabotage, 6/28/93

DOE 5630.14A, Safeguards and Security Program Planning, 06/09/92

DOE 5631.6A, Personnel Security Assurance Program, 09/15/92

DOE 5639.5, Technical Surveillance Countermeasures Program, 08/03/92

DOE 5636.3A, Technical Surveillance Countermeasures Program, 02/03/88

DOE 5637.1, Classified Computer Security Program, 01/29/88

DOE 5639.7, Operational Security Program, 04/30/92

DOE M 5639.6A-1, Manual of Security Requirements for the Classified Automated Information System Security Program, 07/15/94 
Westinghouse Hanford Company (WHC)

Standards/Requirements Identification Document

7.0 Engineering Program
WHC-SD-MP-SRID-002 January 10, 1996 Rev. 0 Page i of $i$

\section{TABLE OF CONTENTS}

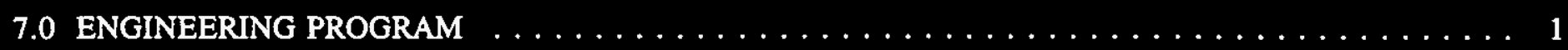


This page intentionally left blank. 


\subsection{ENGINEERING PROGRAM}

\section{INTRODUCTION}

A Standards/Requirements Identification Document (S/RID) set forth the Environmental Safety and Health (ES\&H) standards/requirements. This S/RID is applicable to the appropriate life cycle phases of design, construction, operation, and decommissioning for each of the categories of facilities addressed in Revision 5 of the Department of Energy Implementation Plan for the Defense Nuclear Facilities Safety Board (DNFSB) Recommendation 90-2. This Recommendation calls for the strengthening of DOE weapons complex activities through the identification and application of relevant DOE Orders, regulations, industry codes/standards, industry guidance documents and, as appropriate, good industry practices. These standards/requirements are adequate to ensure protection of the health and safety of workers, the public, and the environment.

The Westinghouse Hanford Company S/RID, as defined in Revision 5 of the Department of Energy Implementation Plan for DNFSB Recommendation 90-2, contains standards/requirements applicable company-wide that are necessary for safe operation of the site and its associated facilities, and that are not the direct responsibility of a specific facility manager (e.g., a company-wide fire department). Facility S/RIDs contain standards/requirements applicable to a specific facility that are the direct responsibility of the facility manager.

\section{SCOPE}

The Westinghouse Hanford Company (WHC) S/RID contains standards/requirements applicable to WHC that are adequate to ensure protection of the health and safety of workers, the public, and the environment, and that are not the direct responsibility of a specific facility manager (e.g., a company fire department).

\section{JUSTIFICATION OF FUNCTIONAL AREA NONAPPLICABILITY}

The Functional Areas listed below have been determined to be nonapplicable, for purposes of Westinghouse Hanford Company S/RID development, for one or more of the following reasons:

1. The Functional Area is outside the Scope statement above in that the applicable requirements/standards are the direct responsibility of a specific facility manager and identified in facility level S/RIDs;

2. Responsibility for implementation of the Functional Area lies within an organization other than Westinghouse Hanford Company; or 
3. Applicable requirements/standards are appropriately identified within other WHC Functional Areas.

\section{Maintenance}

Management Systems

Configuration Management

Construction

Decontamination \& Decommissioning

Engineering Programs

Environmental Restoration

Nuclear Safety

Operations

Research \& Development

Waste Management 
Westinghouse Hanford Company (WHC)

Standards/Requirements Identification Document

8.0 Construction Program
WHC-SD-MP-SRID-002

January 10, 1996

Rev. 0

Page $i$ of $i$

TABLE OF CONTENTS

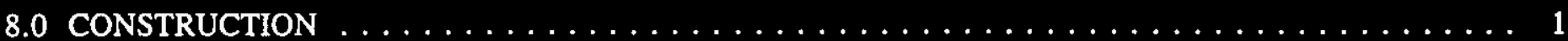


This page intentionally left biank. 


\subsection{CONSTRUCTION}

\section{INTRODUCTION}

A Standards/Requirements Identification Document (S/RID) set forth the Environmental Safety and Health (ES\&H) standards/requirements. This S/RID is applicable to the appropriate life cycle phases of design, construction, operation, and decommissioning for each of the categories of facilities addressed in Revision 5 of the Department of Energy Implementation PIan for the Defense Nuclear Facilities Safety Board (DNFSB) Recommendation 90-2. This Recommendation calls for the strengthening of DOE weapons complex activities through the identification and application of relevant DOE Orders, regulations, industry codes/standards, industry guidance documents and, as appropriate, good industry practices. These standards/requirements are adequate to ensure protection of the health and safety of workers, the public, and the environment.

The Westinghouse Hanford Company S/RID, as defined in Revision 5 of the Department of Energy Implementation Plan for DNFSB Recommendation 90-2, contains standards/requirements applicable company-wide that are necessary for safe operation of the site and its associated facilities, and that are not the direct responsibility of a specific facility manager (e.g., a company-wide fire department). Facility S/RIDs contain standards/requirements applicable to a specific facility that are the direct responsibility of the facility manager.

\section{SCOPE}

The Westinghouse Hanford Company (WHC) S/RID contains standards/requirements applicable to WHC that are adequate to ensure protection of the health and safety of workers, the public, and the environment, and that are not the direct responsibility of a specific facility manager (e.g., a company fire department).

\section{JUSTIFICATION OF FUNCTIONAL AREA NONAPPLICABILITY}

The Functional Areas listed below have been determined to be nonapplicable, for purposes of Westinghouse Hanford Company S/RID development, for the following reasons:

1. The Functional Area is outside the Scope statement above in that the applicable requirements/standards are the direct responsibility of a specific facility manager and identified in facility level S/RIDs;

2. Applicable requirements/standards are appropriately identified within other WHC Functional Areas. 
This page intentionally left blenk. 
Westinghouse Hanford Company (WHC)

Standards/Requirements Identification Document

9.0 Operations

TABLE OF CONTENTS
WHC-SD-MP-SRID-002

January 10, 1996

Rev. 0

Page $i$ of $i$

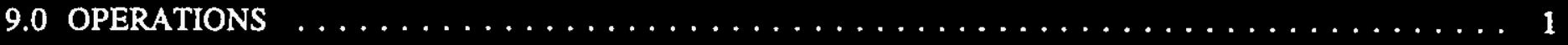


This page intentionally left blank. 


\subsection{OPERATIONS}

\section{INTRODUCTION}

A Standards/Requirements Identification Document (S/RID) set forth the Environmental Safety and Health (ES\&H) standards/requirements. This S/RID is applicable to the appropriate life cycle phases of design, construction, operation, and decommissioning for each of the categories of facilities addressed in Revision 5 of the Department of Energy Implementation Plan for the Defense Nuclear Facilities Safety Board (DNFSB) Recommendation 90-2. This Recommendation calls for the strengthening of DOE weapons complex activities through the identification and application of relevant DOE Orders, regulations, industry codes/standards, industry guidance documents and, as appropriate, good industry practices. These standards/requirements are adequate to ensure protection of the health and safety of workers, the public, and the environment.

The Westinghouse Hanford Company S/RID, as defined in Revision 5 of the Department of Energy Implementation Plan for DNFSB Recommendation 90-2, contains standards/requirements applicable company-wide that are necessary for safe operation of the site and its associated facilities, and that are not the direct responsibility of a specific facility manager (e.g., a company-wide fire department). Facility S/RIDs contain standards/requirements applicable to a specific facility that are the direct responsibility of the facility manager.

\section{SCOPE}

The Westinghouse Hanford Company (WHC) S/RID contains standards/requirements applicable to WHC that are adequate to ensure protection of the health and safety of workers, the public, and the environment, and that are not the direct responsibility of a specific facility manager (e.g., a company fire department). The applicability for operations is identified in the facility/activity Conduct of Operations Applicability Matrix. The company retains responsibility to ensure those documents identified as company level requirements in the applicability matrices are current. This will be identified as a WHC requirement in the Management Systems Functional Area document which is under development.

\section{JUSTIFICATION OF FUNCTIONAL AREA NONAPPLICABILITY}

The Operations Functional Area has been determined to be nonapplicable, for purposes of Westinghouse Hanford Company S/RID development, for the following reasons:

1. The Functional Area is outside the Scope statement above in that the applicable requirements/standards are the direct responsibility of a specific facility manager and identified in facility level S/RIDs; 
Westinghouse Hanford Company (WHC)

Standards/Requirements Identification Document

9.0 Operations

2. Applicable requirements/standards are appropriately identified within other WHC Functional Areas.
WHC-SD-MP-SRID-002

January 10, 1996

Rev. 0

Page 2 of 2 
Westinghouse Hanford Company (WHC)

Standards/Requirements Identification Document

10.0 Maintenance
WHC-SD-MP-SRID-002

January 10, 1996

Rev. 0

Page $i$ of $i$

\section{TABLE OF CONTENTS}

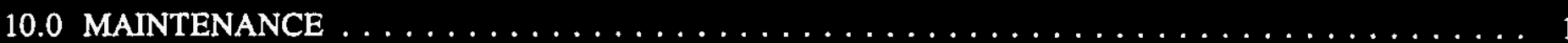


This page intentionally left blank. 


\subsection{MAINTENANCE}

\section{INTRODUCTION}

A Standards/Requirements Identification Document (S/RID) set forth the Environmental Safety and Health (ES\&H) standards/requirements. This S/RID is applicable to the appropriate life cycle phases of design, construction, operation, and decommissioning for each of the categories of facilities addressed in Revision 5 of the Department of Energy Implementation Plan for the Defense Nuclear Facilities Safety Board (DNFSB) Recommendation 90-2. This Recommendation calls for the strengthening of DOE weapons complex activities through the identification and application of relevant DOE Orders, regulations, industry codes/standards, industry guidance documents and, as appropriate, good industry practices. These standards/requirements are adequate to ensure protection of the health and safety of workers, the public, and the environment.

The Westinghouse Hanford Company S/RID, as defined in Revision 5 of the Department of Energy Implementation Plan for DNFSB Recommendation 90-2, contains standards/requirements applicable company-wide that are necessary for safe operation of the site and its associated facilities, and that are not the direct responsibility of a specific facility manager (e.g., a company-wide fire department). Facility S/RIDs contain standards/requirements applicable to a specific facility that are the direct responsibility of the facility manager.

\section{SCOPE}

The Westinghouse Hanford Company (WHC) S/RID contains standards/requirements applicable to WHC that are adequate to ensure protection of the health and safety of workers, the public, and the environment, and that are not the direct responsibility of a specific facility manager (e.g., a company fire department).

\section{JUSTIFICATION OF FUNCTIONAL AREA NONAPPLICABILITY}

The Functional Areas listed below have been determined to be nonapplicable, for purposes of Westinghouse Hanford Company S/RID development, for one or more of the following reasons:

1. The Functional Area is outside the Scope statement above in that the applicable requirements/standards are the direct responsibility of a specific facility manager and identified in facility level S/RIDs;

2. Responsibility for implementation of the Functional Area lies within an organization other than Westinghouse Hanford Company; or 
3. Applicable requirements/standards are appropriately identified within other WHC Functional Areas.

Maintenance

Management Systems

Configuration Management

Construction

Decontamination \& Decommissioning

Engineering Programs

Environmental Restoration

Nuclear Safety

Operations

Research \& Development

Waste Management 
Westinghouse Hanford Company (WHC)

Standards/Requirements Identification Document

11.0 Radiation Protection
WHC-SD-MP-SRID-002

January 10, 1996

Rev. 0

Page i of ii

\section{TABLE OF CONTENTS}

11.0 RADIATION PROTECTION

11.1

11.1.1

11.1.2

11.1 .3

11.1 .4

11.1 .5

11.1 .6

11.1 .7

11.1 .8

11.2

11.2 .1

11.2 .2

11.2 .3

11.2 .4

11.3

11.3.1

11.3.2

11.3 .3

11.3 .4

11.4

11.4 .1

11.4 .2

11.5

11.5 .1

11.5 .2

11.5 .3

11.6

11.6 .1

11.6 .2

\section{MANAGEMENT}

Exposure Reduction and ALARA

Radiation Protection Training

RP Selection and Qualification .

Radiological Program Performance Goals

Program Policy and Procedures

Policy for Response to Abnormal Situations

Rad Protection Program Assessments/Internal Audits

Recordkeeping and Reporting

MONITORING AND SURVEYS

Radiation Monitors, Alarms and Surveys

Airborne Radioactivity Monitors, Alarms and Surveys

Contamination Monitoring and Surveys

Abnormal Response Monitoring

PERSONNEL EXPOSURE MONITORING

Personnel Monitoring

Exposure Limit .

Dosimetry Program .

Calculation Methods and Models

RADIATION AREA ACCESS CONTROL

Access Restrictions and Posting

Radiation Work Permits

RADIOACTIVE MATERIALS MANAGEMENT

Storage, Labels and Transportation

Movement of Material

Specific Nuclide Control 
11.8 .1

11.8 .2

11.8 .3

11.9

11.9 .1

11.9 .2

11.9 .3

11.9 .4

11.10

11.10 .1

11.10.2

11.10 .3

11.10.4

11.10 .5

11.10 .6

11.10 .7

11.10 .8

11.10 .9

11.11

11.11 .1

11.11 .2
Monitoring and Survey Instrumentation . . . . . . . . . . . . . 14

Respiratory Equipment and Supplies . . . . . . . . . . . 15

Protective Clothing . . . . . . . . . . . . . . . . 15

RADIATION PROTECTION OF THE PUBLIC AND ENVIRONMENT $\ldots$.

Dose Limits . . . . . . . . . . . . . . . . . . . . . . 15

Liquid Waste Discharges . . . . . . . . . . . . . . . 15

Solid Waste Disposal . . . . . . . . . . . . . . . . . . . . . 15

Demonstration of Compliance $\ldots \ldots \ldots \ldots \ldots \ldots$

KEY INTERFACES $\ldots \ldots \ldots \ldots \ldots \ldots \ldots \ldots \ldots \ldots$

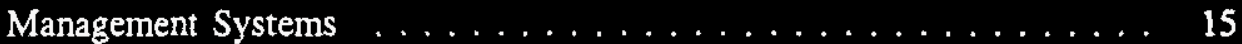

Quality Assurance . . . . . . . . . . . . . . . 16

Configuration Management $\ldots \ldots \ldots \ldots \ldots \ldots \ldots$

Training and Qualifications . . . . . . . . . . . . . . 16

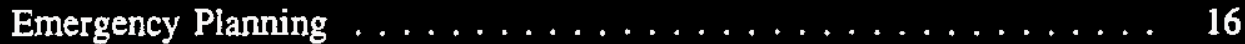

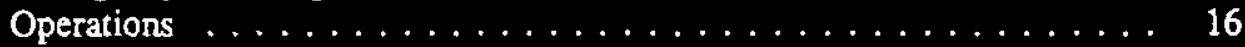

Maintenance . . . . . . . . . . . . . . . . . 16

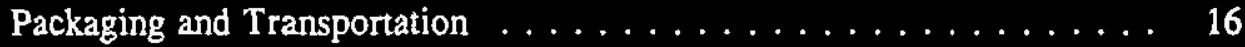

Environmental Protection . . . . . . . . . . . . . . 16

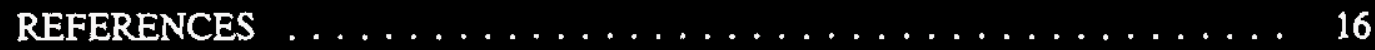

Requirement Source Documents . . . . . . . . . . . . . . . . 16

Reviewed Documents Not Used as Requirement Sources . . . . . . . 17 


\subsection{RADIATION PROTECTION}

\section{INTRODUCTION}

A Standards/Requirements Identification Document (S/RID) sets forth the Environmental Safety and Health (ES\&H) standards/requirements. This S/RID is applicable to the appropriate life cycle phases of design, construction, operation, and decommissioning for each of the categories of facilities addressed in Revision 5 of the Department of Energy Implementation Plan for the Defense Nuclear Facilities Safety Board (DNFSB) Recommendation 90-2. This Recommendation calls for the strengthening of DOE weapons complex activities through the identification and application of relevant DOE Orders, regulations, industry codes/standards, industry guidance documents and, as appropriate, good industry practices. These standards/requirements are adequate to ensure protection of the health and safety of workers, the public, and the environment.

The Westinghouse Hanford Company S/RID, as defined in Revision 5 of the Department of Energy Implementation Plan for DNFSB Recommendation 90-2, contains standards/requirements applicable companywide that are necessary for safe operation of the site and its associated facilities, and that are not the direct responsibility of a specific facility manager (e.g., a companywide fire department). Facility S/RIDs contain standards/requirements applicable to a specific facility that are the direct responsibility of the facility manager.

This Standards/Requirements Identification Document (S/RID) defines the Westinghouse Hanford Company (WHC) Radiation Protection program in place at Hanford. The Radiation Protection program defined in this document is described in general accordance with the (ES\&H) Configuration Guidelines, Revision 0, dated July 30,1993, and is presented in the form of program elements and subelements. The specific DOE Orders, regulations, industry codes/standards, guidance documents and good industry practices which serve as the basis for each element/subelement are identified and aligned with each subelement. Some of the requirements contained in the document were intentionally duplicated in facility S/RIDs. This was necessary to capture implementation responsibilities that occur at both the company and facility level.

\section{SCOPE}

The Radiological Protection (RP) functional area includes the management related controls, activities, programs, and personnel necessary to ensure adequate protection of the health and safety of workers.

The Westinghouse Hanford Company will conduct the radiation protection program in accordance with the requirements of 10 CFR 835 and the Hanford Site Radiological Control Manual by implementation of the DOE approved WHC 10 CFR 835 Radiation Protection Program and WHC Radiological Control Manual Implementation Plan. 
NOTE: The Westinghouse Hanford Company will conduct the Radiation Protection Program in accordance with the requirements of 10 CFR 835 and the Hanford Site Radiological Control Manual by implementation of the DOE-approved WHC 10 CFR 835 Radiation Protection . Program and WHC Radiological Control Manual Implementation Plan.

This element defines management requirements and commitments related specifically to Westinghouse Company Hanford Site Radiation Protection programs and the policy for response to abnormal radiological situations.

The Management and Organization element for Radiation Protection includes requirements which are specific to Radiation Protection and likely do not apply to other functional areas at the Westinghouse Hanford Site Facilities. Because of the nature of these requirements, they are not included in the Management Systems functional area.

\section{REQUIREMENT SOURCE: 10CFR835 Part 101}

"Radiation protection programs.

(a) A DOE activity shall be conducted in compliance with a documented radiation protection program (RPP) as approved by the DOE.

(b) The DOE may direct or make modifications to a RPP.

(c) The content of each RPP shall be commensurate with the nature of the activities performed and shall include formal plans and measures for applying the as low as reasonably achievable (ALARA) process to occupational exposure.

(d) The RPP shall specify the existing and/or anticipated operational tasks that are intended to be within the scope of the RPP. Except as provided in 835.101(i), any task outside the scope of a RPP shall not be initiated until an update of the RPP is approved by DOE.

(e) The content of the RPP shall address but shall not necessarily be limited to each requirement in this part.

(f) The RPP shall include plans schedules, and other measures for achieving compliance with regulations of this part. Compliance with this part shall be achieved no later than January 1 1996.

(g) The RPP for an existing activity shall be submitted to DOE no later than January 11995.

(h) An update of the RPP shall be submitted to DOE:

(1) Whenever a change or an addition to the RPP is made;

(2) Prior to the initiation of a task not within the scope of the RPP; or

(3) Within 180 days of the effective date of any modifications to this part.

(i) Changes additions, or updates to the RPP may become effective without prior Department approval only if the changes do not decrease the effectiveness of the RPP and the RPP as changed continues to meet the requirements of this part. Proposed changes that decrease the 
Westinghouse Hanford Company (WHC)

Standards/Requirements Identification Document

11.0 Radiation Protection
WHC-SD-MP-SRID-002

January 10, 1996

Rev. 0

Page 3 of 17

\section{$\underline{11.1 .1}$}

$\underline{11.1 .2}$

$\underline{11.1 .3}$

$\underline{11.1 .4}$

$\underline{11.1 .5}$

$\underline{11.1 .6}$

Policy for Response to Abnomal Situations

REQUIREMENT SOURCE: 10CFR835 Part 1301(a)

"A general employee whose occupational exposure bas exceeded any of the limits specified in $\$ \$ 835.202$ or $\$ 35.205$ may be permitted to return to work in radiological areas during the current year providing that all of the following conditions are met:

(1) Approval is first obtained from the contractor management and the Head of the responsible DOE field organization; 
(2) The individual receives counseling from radiological protection and medical personnel regarding the consequences of receiving additional occupational exposure during the year; and

(3) The affected employee agrees to return to radiological work."

\section{REQUIREMENT SOURCE: 10CFR835 Part 1301(b)}

"All exposures exceeding the limits specified in $\$ \$ 835.202$ or 835.205 shall be recorded in the affected individual's occupational exposure file and reported to the DOE in accordance with Deparmental requirements for occurrence reporting and processing."

\section{REQUIREMENT SOURCE: 10CFR835 Part 1302(d)}

"The dose limits (Whole Body) for individuals performing these operations are as follows:

5 rems-All Activities

10 rems-Protecting major property (Where lower dose limit not practicable)

25 rems-Lifesaving or protection of large populations (Where lower dose limit not practicable)

$>25$ rems-Lifesaving or protection of large populations (Only on a voluntary basis to personnel fully aware of the risks involved)

NOTE: The lens of the eye dose limit is three times the listed values. Thie shallow dose limit to the skin of the whole body and the extremities is ten times the listed values. These doses are in addition to and accounted for separately from the doses received under the limits in $\$ \S$ 835.202 and 835.205."

\section{REQUIREMENT SOURCE: DOE/EH0256T(940431) Chapter 5, Part 4, Article} 542.2 and 2.e

"2. The treatment of contaminated injuries should include the following:

e. Initiation of appropriate bioassay monitoring"

\section{Requiremint SOURCE: DOE/EH0256T(940431) Chapter 5, Part 4, Article 542.3, Sentence 1}

"An injured person should be counseled promptly on the medical and radiological implications resulting from contaminated wounds that result in internal doses greater than 2 percent of the Table $2 \cdot 1$ limits."

\section{Rad Protection Prooram Assessments/Internal Audits}

See Quality Assurance Functional Area for requirements.

\section{RSQUIREMENT SOURCE: 10CFR835 Part 102}

"Internal audits. Internal audits of all functional elements of the radiation protection program shall be conducted no less frequently than every 3 years and shall include program content and implementation." 
Recordkeeping and Reporting

REQUIREMENT SOURCE; 10CFR835 Part 204(e)

"Records of the conduct of a planned special exposure shall be maintained and a written repart submitted within 30 days after the planned special exposure to the approving organizations identified in $\$ 835.204(a)(3)$."

\section{REQUIREMENT SOURCE: 10CFR835 Part 701(a)}

"Records shall be maintained to document compliance with this part and with radiation protection programs required by $\$ 835.101$."

\section{REQUIREMENT SOURCE: 10CFR835 Part 701(b)}

"Unless otherwise specified in this subpart, records shall be retained until final disposition is authorized by DOE."

\section{REQUIREMENT SOURCE: 10CFR835 Part 702(a)}

"Records shall be maintained to document doses received by all individuals for whom monitoring was required pursuant to $\$ 835.402$ and doses received during planned special exposures, accidents, and emergency conditions."

\section{REQUIREMENT SOURCE: 10CFR835 Part 702(b)}

"The results of individual external and internal dose measurements that are performed, but are not required by $\S 835.402$, shall be recorded. Recording of the non-uniform shailow dose equivalent to the skin caused by contamination on the skin (see $\$ 835.205$ ) is not required if the dose is less than 2 percent of the limit specified for the skin in $\$ 835.202(a)(4)$."

REQUIREMENT SOURCE: 10CFR835 Part 702(c)(1)

"(c) The records required by this section shall:

(1) Be sufficient to evaluate compliance with $\S 835.202 ; "$

\section{REQUIREMENT SOURCE: 10CFR835 Part 702(c)(2)}

"(2) Be sufficient to provide dose information necessary to complete reports required by subpart I of this part and by Departmental requirements for occurrence reporting and processing;"

REQUTREMENT SOURCE: 10CFR835 Part 702(c)(4)(iii)

"(iii) Estimated intake and jdentity of radionuclides."

REQUIREMINT SOURCE: 10CFR835 Part 702(c)(5)(iii)

"(iii) Cumulative total effective dose equivalent received from external and internal sources while employed at the site or facility, since January $1,1989 . "$ 


\section{REQURREMINT SOURCE: 10CFR835 Part 702(d)}

"Documentation of all occupational exposure received during the current year shall be obtained when demonstrating compliance with $\$ 835.202$ (a). In the absence of formal records of previous occupational exposure during the year, a written estimate signed by the individual

\section{REQULREMENT SOURCE: 10CFR835 Part 702(e)}

"Efforts shall be made to obtain records of prior years occupational internal and external
exposure."

\section{REQUTREMENT SOURCE: 10CFR835 Part 702(f)}

"The records specified in this section that are identified with a specific individual shall be
readily available to that individual." REQUTREMENT SOURCE: 10CFR835 Part 702(g)

"Data necessary to allow future verification or reassessment of the recorded doses shall be REQUTREMENT SOURCE: 10CFR835 Part 702(h)

"All records required by this section shall be transferred to the DOE upon cessation of activities at the site that could cause exposure to individuals."

\section{REQUTREMENT SOURCE: 10CFR835 Part 703(a)} "(a) Results of surveys for radiation and radioactive material in the workplace as required by
$\$ \$ 835.401,835.403$, and $835.404 ; "$

\section{REQUTREMENT SOURCE: 10CFR835 Part 703(c)}

"(c) Results of surveys for the release of material and equipment as required by $\S 835.1101$ (d); and"

\section{REQUIREMENT SOURCE: 10CFR835 Part 703(d)(1)}

"(d) Results of maintenance and calibration performed on: (1) Instruments used for area monitoring and contamination control as required by $\S 835.401$;
and

REQUTREMENT SOURCE: 10CFR835 Part 703(d)(2)

"(2) Devices used for individual monitoring as required by $\$ \S 835.401$ and 835.402 ." 


\section{REQUTREMENT SOURCE: 10CFR835 Part 704(b)}

"Actions taken to maintain occupational exposures as low as reasonably achievable, including the actions required for this purpose by $\$ 835.101$, as well as facility design and control actions required by $\$ \$ 835.1001,835.1002$, and 835.1003 , shall be documented."

\section{REQUIREMIENT SOURCE: 10CFR835 Part 704(c)}

"Records shall be maintained to document the results of internal audits and other reviews of program content and implementation."

\section{REQUIREMENT SOURCE: 10CFR835 Part 704(d)}

"Written declarations of pregnancy shall be maintained. "

\section{REQUIREMENT SOURCE: 10CFR835 Part 704(e)}

"Changes in equipment, techniques, and procedures used for monitoring in the workplace shail be documented."

\section{REQUIREMENT SOURCE: DOE/EH0256T(940431) Chapter 6, Part 6, Article 521.6}

"Personnel shall be notified promptly of positive bioassay results and the results of dose assessments and subsequent refinements. Dose assessment results shall be provided in terms of rem or mrem."

\section{REQUREMENT SOURCE: DOE5484.1 Chapter IV, Section 4.a}

"Annual Radiation Exposure Reports. Heads of Field Elements shall submit the following reports ("Annual Radiation Dose Summary," and DOE F 5484.7, "Summary of Exposures Resulting in Internal Body Depositions of Radioactive Materials for CY 19_,") to the System Safety Development Center (SSDC), EG\&G Idaho, Inc., by 3-31 for the preceding calendar year for monitored Department of Energy and Department of Energy contractor employees and for visitors to Department of Energy or Department of Energy contractor facilities."

\section{REQUTREMENT SOURCE: DOEN5400.9 Preamble, Section 7.a(1), Sentence 1}

"Source Inventory

The Radiation Protection Organization shall maintain or cause to be maintained the records related to the accountability of sealed radioactive sources for the facility."

\section{MONITORING AND SURVEYS}

\section{REQUIREMENT SOURCE: 10CFR835 Part 403(b)}

"Monitoring of radiation in the workplace shall be performed using stationary (area) or portable radiation instruments, or a combination thereof. The instruments shall be readily available and shall be capable of measuring ambient radiation dose rates for the purpose of controlling radiation exposures." 
11.2.1

11.2 .2

$\underline{11.2 .3}$

11.2 .4

\section{3}

$\underline{11.3 .1}$
Radiation Monitors, Alarms and Survers

Author's Note: Requirements for this subelement are located in the facility specific S/RID.

Airborne Radioactivity Monitors, Alarms and Survers

Author's Note: Requirements for this subelement are located in the facility specific S/RID.

Contamination Monitoring and Survers

Author's Note: Requirements for this subelement are located in the facility specific S/RID.

\section{Abnormal Response Monitoring}

Author's Note: This requirement is included in the WHC company level RP functional area S/RID document, and may also be included in facility level S/RID documents. Performance/implementation of DOE Order 5500.3A Section 11.c.(5)(c) is a shared responsibility between a company level RP monitoring group and the facility RP personnel.

\section{REQUIREMENT SOURCE: DOE5500.3A Section 11.c.(5)}

"Consequence Assessment. Provisions must be in place to adequately assess the actual or potential onsite and offsite consequences of an emergency and must include:

(a) Timely initial assessment of the actual or potential consequences of an emergency and continuous, in-depth assessment of events throughout an emergency;

(b) Integration of the consequence assessment process with the process for categorization of an event as an emergency, determination of the appropriate emergency class, and protective action decision making, including projections of onsite and offsite consequences;

(c) Monitoring and evaluation of the specific indicators necessary to continually assess the consequences of emergency events and to monitor safety, health, environmental, and security conditions which may affect or exacerbate the emergency; and

(d) Coordinate with Federal, state, tribal, and local organizations to locate and track hazardous materials released to the environment; estimate the integrated impact of such release on the public and the environment; and locate and recover materials, especially those with national security imoplications."

\section{PERSONNEL EXPOSURE MONITORING}

\section{Personnel Monitoring}

Author's Note: Requirements for this subelement are located in the facility specific S/RID. 


\section{Exposure Limits}

\section{REQUIREMENT SOURCE: 10CFR835 Part 202(a)}

"The occupational exposure to general employees resulting from DOE activities, other than planned special exposures under \$ 835.204 and emergency exposure situations under $\$$ 835.1302, shall be controlled so the following annual limits are not exceeded:

(1) A total effective dose equivalent of 5 rems (0.05 sievert);

(2) The sum of the deep dose equivalent for external exposures and the committed dose equivalent to any organ or tissue other than the lens of the eye of 50 rems ( 0.5 sievert);

(3) A lens of the eye dose equivalent of 15 rems ( 0.15 sievern); and

(4) A shallow dose equivalent of 50 rems ( 0.5 sievert) to the skin or to any extremity."

\section{REQUIREMENT SOURCE: 10CFR835 Part 202(b)}

"All occupational exposure received during the current year shall be included when demonstrating compliance with $\$ 835.202$ (a)."

\section{REQUTREMENT SOURCE: 10CFR835 Part 202(c)}

"Exposures from background, therapeutic and diagnostic medical radiation, and voluntary participation in medical research programs shall not be included in dose records or in the assessment of compliance with the occupational exposure limits."

\section{REQUIREMENT SOURCE: 10CFR835 Part 204(a)}

"A planned special exposure may be authorized for a radiological worker to receive doses in addition to and accounted for separately from the doses received under the limits specified in $\$$ 835.202(a), provided that each of the following conditions is satisfied:

(1) The planned special exposure is considered only in an exceptional situation when alternatives that might prevent a radiological worker from exceeding the limit in $\$$ 835.202(a)(1) are unavailable or impractical;

(2) The contractor management (and employer, if the employer is not the contractor) specifically requests the planned special exposure, in writing; and

(3) Joint written approval from the appropriate DOE Headquarters program office and the Assistant Secretary for Environment, Safety and Health is received."

\section{REQUIREMENT SOURCE: 10CFR835 Part 204(c)}

"An individual shall not receive a planned special exposure that, in addition to the doses determined in $\$ 835.204$ (b), would result in a dose exceeding the following:

(1) A total effective dose equivalent of 5 rems ( 0.05 sievert) in the current year; and

(2) A cumulative total effective dose equivalent of 25 rems ( 0.25 sievert)." 


\section{REQUIREMIENT SOURCE: 10CFR835 Pant 206(a)}

"The dose equivalent limit for the embryo/fetus from the period of conception to birth, as a result of occupational exposure of a declared pregnant worker, is 0.5 rem (0.005 sievert)."

\section{REQUIREMIENT SOURCE: 10CFR835 Part 207}

"Any minor exposed to radiation and/or radioactive material during direct on-site access at a DOE site or facility shall not exceed $0.1 \mathrm{rem}(0.001$ sievert) total effective dose equivalent in a year."

\section{REQUIREMINT SOURCE: 10CFR835 Part 208}

"Any member of the public exposed to radiation and/or radioactive material during direct on-site access at a DOE site or facility shall not exceed $0.1 \mathrm{rem}(0.001$ sievert) total effective dose equivalent in a year."

\section{REQUREMENT SOURCE: DOE/EH0256T(940431) Chapter 2, Part 1, Article 211.1}

"A DOE Administrative Control Level of 2,000 mrem per year per person is established for all DOE activities. Approval by the appropriate Secretarial Officer or designee shall be required prior to allowing a person to exceed 2,000 mrem."

\section{Dosimetry Proqram}

\section{REQUTEMENT SOURCE: 10CFR835 Part 402(b)}

"Personnel external dosimetry programs shall be adequate to demonstrate compliance with $\$$ 835.202, including routine dosimeter calibration and conformance with the requirements of the DOE Laboratory Accreditation Program for Personnel Dosimetry."

\section{REQURRMENT SOURCE: 10CFR835 Part 402(d)}

"Internal dose evaluation programs shall be adequate to demonstrate compliance with $\S$ 835.202."

\section{REQUIREMENT SOURCE: 10CFR835 Part 801(a)}

"Radiation exposure data for individuals monitored in accordance with $\$ 835.402$ shall be reported as specified in this section. The information shall include the data required under $\S$ 835.702(c). Each notification and report shall be in writing and include: the DOE site or facility name, the name of the individual, and the individual's social security number or employee number."

\section{REQUTREMENT SOURCE: 10CFR835 Part 801(b)}

"Upon the request from an individual terminating employment, records of exposure shall be provided to that individual as soon as the data are available, but not later than 90 days after termination. A written estimate of the radiation dose received by that employee based on available information shall be provided at the time of termination, if requested." 


\section{REQUIREMENN SOURCE: 10CFR835 Part 801(c)}

"Each DOE- or DOE-contractor-operated site or facility shall, on an annual basis, provide a radiation dose report to each individual monitored during the year at that site or facility in accordance with \& 835.402."

\section{REQUREMENT SOURCE: 10CFR835 Part 801(d)}

"Detailed information concerning any individual's exposure shall be made available to the individual upon request of that individual, consistent with the provisions of the Privacy Act (5 U.S.C. 552a)."

\section{REQUIREMENT SOURCE: 10CFR835 Part 801(e)}

"When a DOE contractor is required to report to the Department, pursuant to Departmental requirements for occurrence reporting and processing, any exposure of an individual to radiation and/or radioactive material, or planned special exposure in accordance with $\S$ 835.204(e), the contractor shall also provide that individual with a report on his or her exposure data included therein. Such report shall be transmitted at a time not later than the transmittal to the Department."

\section{REQUREMINT SOURCE: 10CFR835 Part 1304(b)}

Author's Note: Only (1) thru (3) apply at the company level.

"Nuclear accident dosimetry shall include the following:

(1) A method to conduct initial screening of personnel involved in a nuclear accident to determine whether significant exposures to radiation occurred;

(2) Methods and equipment for analysis of biological materials;

(3) A system of fixed nuclear accident dosimeter units; and

(4) Personal nuclear accident dosimeters worn by all personnel who enter locations in which installed criticality alarm systems are required."

\section{REQUIREMENT SOURCE: DOE/EH0256T(940431) Chapter 5, Part 1, Article 512.6}

"A dose assessment shall be performed for each instance of a lost, damaged or contaminated personnel dosimeter."

\section{REQUIREMENT SOURCE: DOE/EH0256T(940431) Chapter 5, Part 2, Article 522.6}

"Levels of intakes that warrant the consideration of medical intervention shall be established for site-specific radionuclides. The effectiveness of medical intervention, such as blocking or chelating agents, shall be documented using bioassay results." 
REQUREMENT SOURCE: DOE5480.11 Section 9.q(1)

Author's Note: Only (b), (c), and (e) apply.

"(a) A method to conduct initial "screening" of personnel involved in nuclear accidents to . determine if they have received a significant radiation exposure.

(b) Methods for analysis of biological materials (including sodium-24 activity in blood and phosphorus-32 activity in hair).

(c) A system of fixed units capable of yielding estimated radiation dose and the approximate neutron spectrum at their locations.

(d) Personnel dosimeters capable of furnishing sufficient information to determine neutron and gamma dose and/or dose equivalent.

(e) Counting facilities to evaluate fixed and/or personnel dosimeters, sodium in blood, and phosphorus in hair."

\section{Calculation Methods and Models}

\section{REQUREMENT SOURCE: 10CFR835 Part 4}

"Radiological units. Unless otherwise specified the quantities used in the records required by this part shall be clearly indicated in special units of curie rad, or rem, including multiples and subdivisions of these units. The SI units becquerel $(\mathrm{Bq})$, gray $(\mathrm{Gy})$, and sievert (Sv) are only provided parenthetically in this part for reference with scientific standards. These SI units are not authorized for use in records required under this part."

\section{REQUIREMENT SOURCE: 10CFR835 Part 203(a)}

"The total effective dose equivalent during a year shall be determined by summing the effective dose equivalent from external exposures and the committed effective dose equivalent from intakes during the year. For purposes of compliance with this part, deep dose equivalent to the whole body may be used as effective dose equivalent for external exposures."

\section{REQUIREMIONT SOURCE: .10CFR835 Part 203(b)}

"Determinations of the effective dose equivalent shall be made using the weighting factor values provided in $\$ 835.2$."

\section{REQUIREMENT SOURCE: 10CFR835 Part 204(f)}

"The dose from planned special exposures is not to be considered in controlling future occupational dose of the individual under $\S 835.202$ (a), but is to be included in records and reports required under this part."

\section{REQUIREMENT SOURCE: 10CFR835 Part 205(a)}

"Non-uniform exposures of the skin from X-rays, beta radiation, and/or radioactive material on the skin are to be assessed as specified in this section." 


\section{REQURRBMENT SOURCE: 10CFR835 Part 205(b)}

"For purposes of demonstrating compliance with $\S 835.202$ (a)(4), assessments shall be conducted as follows:

(1) Area of skin irradiated is $100 \mathrm{~cm} 2$ or more. The non-uniform dose equivalent received during the year shall be averaged over the $100 \mathrm{~cm} 2$ of the skin receiving the maximum dose, added to any uniform dose equivalent also received by the skin, and recorded as the shallow dose equivalent to any extremity or skin for the year.

(2) Area of skin irradiated is $10 \mathrm{~cm} 2$ or more, but is less than $100 \mathrm{~cm} 2$. The non-uniform dose equivalent $(\mathrm{H})$ to the irradiated area received during the year shall be added to any uniform dose equivalent also received by the skin and recorded as the shallow dose equivalent to any extremity or skin for the year. $H$ is the dose equivalent averaged over the $1 \mathrm{~cm} 2$ of skin receiving the maximum absorbed dose, $D$, reduced by the fraction $f$, which is the irradiated area in $\mathrm{cm} 2$ divided by $100 \mathrm{~cm} 2$ (i.e., $\mathrm{H}=\mathrm{fD}$ ). In no case shall a value of $f$ less than 0.1 be used.

(3) Area of skin irradiated is less than $10 \mathrm{~cm} 2$. The non-uniform dose equivalent shall be averaged over the $1 \mathrm{~cm} 2$ of skin receiving the maximum dose. This dose equivalent shall:

(i) Be recorded in the individual's occupational exposure history as a special entry; and

(ii) Not be added to any other shallow dose equivalent to any extremity or skin recorded as the dose equivalent for the year."

\section{REQUTREMENT SOURCE: 10CFR835 Part 209(c)}

"The estimation of internal dose shall be based on bioassay data rather than air concentration values unless bioassay data are:

(1) unavailable;

(2) inadequate; or

(3) internal dose estimates based on representative air concentration values are demonstrated to be as or more accurate."

11.4

$\underline{11.4 .1}$

$\underline{11.4 .2}$
RADIATION AREA ACCESS CONTROL

Access Restrictions and Posting

\section{REQUIREMENT SOURCE: DOE/EH0256T(940431) Chapter 3, Part 3, Article 336.1}

"Site procedures shall identify area entry requirements and access restrictions for visitors."

\section{Radiation Work Permits}

Author's Note: Requirements for this subelement are located in the facility specific S/RID. 
Westinghouse Hanford Company (WHC)

Standards/Requirements Identification Document

11.0 Radiation Protection
WHC-SD-MP-SRID-002

January 10, 1996

Rev. 0

Page 14 of 17
11.5

11.5.1

11.5 .2

$\underline{11.5 .3}$

11.6

$\underline{11.6 .1}$

$\underline{11.6 .2}$

11.7

11.8

$\underline{11.8 .1}$

\section{RADIOACTIVE MATERIALS MANAGEMENT}

\section{Storage, Labels and Transportation}

Author's Note: Requirements for this subelement are located in the facility specific S/RID..

\section{Movement of Material}

Author's Note: Requirements for this subelement are located in the facility specific S/RID.

Specific Nuclide Control

Author's Note: Requirements for this subelement are located in the facility specific S/RID. CONTAMINATION CONTROL

Personnel, Equipment and Area Contamination Control

Author's Note: Requirements for this subelement are located in the facility specific S/RID.

Personnel, Equipment and Area Decontamination

Author's Note: Requirements for this subelement are located in the facility specific S/RID.

LABORATORY ANALYSIS

Author's Note: No Company level requirements are applicable.

RADIOLOGICAL PROTECTION EQUIPMENT AND SUPPLIES

REQUTREMENT SOURCE: DOE/EH0256T(940431) Chapter 4, Part 6, Article 462.3

"Clothing and equipment should be screened before they are laundered to segregate those that are damaged, present special handling problems, or require disposal."

Monitoring and Survev Instrumentation

REQUIREMENT SOURCE: 10CFR835 Part 401(c)

Author's Note: Only (1) thru (3) apply at the company level.

"Instruments used for monitoring and contamination control shall be:

(1) Periodically maintained and calibrated on an established frequency of at least once per year;

(2) Appropriate for the type(s), levels, and energies of the radiation(s) encountered;

(3) Appropriate for existing environmental conditions; and

(4) Routinely tested for operability." 
$\underline{11.8 .2}$

11.8 .3

11.9

$\underline{11.9 .1}$

$\underline{11.9 .2}$

$\underline{11.9 .3}$

$\underline{11.9 .4}$

11.10

$\underline{11.10 .1}$

\section{Respiratory Equipment and Supplies}

Requirements to this subelement are located in company and facility OSHA functional areas.

Protective Clothing

REQUTREMENT SOURCE: DOE/EF0256T(940431) Chapter 4, Part 6, Article 461.1

"Protective clothing designated for radiological control use shall be specifically identified by color, symbol or appropriate labeling."

\section{RADIATION PROTECTION OF THE PUBLIC AND ENVIRONMENT}

\section{Dose Limits}

Dose limits and other requirements related to general public exposures and exposures from discharges/effluents are included in the Environmental Protection Functional Area.

\section{Liquid Waste Discharges}

Requirements which specify control of radioactive liquid discharges to surface waters, aquifers or public sewerage systems are included in the Environmental Protection Functional Area and the Waste Management Functional Area.

\section{Solid Waste Disposal}

Requirements which regulate the disposal of solid radioactive waste are included in the Waste Management Functional Area.

\section{Demonstration of Compliance}

Requirements for the monitoring and surveillance of radioactive effuents are included in the Waste Management Functional Area and the Environmental Protection Functional Area.

\section{KEY INTERFACES}

To the extent practicable, all functional areas should consider their potential interface to Radiation Protection to ensure that plans and activities are reviewed based on the ALARA principle, and that potential releases to the environment are considered when radioactive materials are handled. Specific interface areas which have been identified are included as sub-elements.

\section{Management Systems}

An interface to Management Systems is needed to ensure that a commitment to radiation protection and ALARA is incorporated into every aspect of operations at the highest management level. 
$\underline{11.10 .2}$

$\underline{11.10 .3}$

11.10 .4

$\underline{11.10 .5}$

$\underline{11.10 .6}$

$\underline{11.10 .7}$

$\underline{11.10 .8}$

11.10 .9

11.11

11.11 .1

\section{Quality Assurance}

An interface to the Quality Assurance Functional Area is needed to ensure that all requirements for the radiation protection of the workers.

\section{Confiquration Management}

Activities in the Configuration Management Functional Area must interface to the RP Functional Area to ensure that current radiation protection systems are not compromised by modifications, and that new activities receive the proper review in case new systems are
needed.

\section{Training and Oualifications}

An interface to Training and Qualifications is necessary to ensure that the specific RP training requirements are included in the worker training profiles.

\section{Emergency Planning}

Because of the potential for emergency situations involving radioactive material and potential exposure of emergency response personnel, an interface to Emergency Planning is required.

\section{Operations}

An interface to the Operations Functional Area is needed to ensure that radiation protection and the ALARA principle is incorporated into daily operations.

\section{Maintenance}

An interface with the Maintenance Functional Area is needed because the monitoring systems used for radiation protection must have a maintenance plan, and because other areas of maintenance must be aware of potential radiation hazards.

\section{Packaging and Transportation}

Physical management of radioactive materials requires an interface to the Packaging and Transportation Functional Area to ensure proper labeling, packaging and transportation of those materials.

\section{Environmental Protection}

Because of the requirements for limiting release of radioactive materials to the environment, the RP Functional Area should interface to the Environmental Protection Functional Area to ensure a consistent approach to application of environmental protection requirements.

\section{REFERENCES}

\section{Requirement Source Documents}

The following documents were used as requirement sources in the development of this S/RID:

10CFR835, Occupational Radiation Protection, 12/13/93 
Westinghouse Hanford Company (WHC)

Standards/Requirements Identification Document

11.0 Radiation Protection
WHC-SD-MP-SRID-002

January 10, 1996

Rev. 0

Page 17 of 17

DOE 5400.5, Radiation Protection of the Public and the Environment, 2/8/90

DOE 5400.9, Sealed Radioactive Source Accountability, 2/8/90

DOE 5480.11, Radiation Protection for Occupational Workers, 6/17/92

DOE 5484.1, Environmental Protection, Safety, and Health Protection Information Reporting Requirements, 2/24/81

DOE 5500.3a, Chg. 1, Planning and Preparedness for Operational Emergencies, 4/30/91

DOE-EH0256T, DOE Radiological Control Manual, 4/30/94

$\underline{11.11 .2}$

Reviewed Documents Not Used as Requirement Sources

The following Documents were reviewed as requirement sources but were not used in the development of this S/RID.

DOE 5480.15, Department of Energy Laboratory Accreditation Program for Personnel Dosimetry, $12 / 14 / 87$

DOE 5480.20, Personnel Selection, Qualification, Training and Stafing Requirements at DOE Reactor and Non-Reactor Nuclear Facilities, 6/19/91

DOE 5000.3B, Occurrence Reporting and Processing of Operations Information.

DOE 5480.24, Nuclear Criticality Safety Program, 8/12/92

DOE/EH0173T, Environmental Regulatory Guide for Radiological Effluent Monitoring and Environmental Surveillance, 1/91

DOE-PNL-6577, Health Physics Manual of Good Practices for Reducing Radiation Exposure to Levels That Are As Low As Reasonably Achievable (ALARA), 1988

ANSI-N43.3-1993, Installations using Non-Medical X-Ray and Sealed Gamma Ray Sources Energies up to $10 \mathrm{Mev}, 1 / 28 / 93$

ANSI-N323, Radiation Protection Instrumentation Test and Calibration, 1978

ANS1-N319-1976, Personnel Neutron Dosimeters (Neutron Energies Less Tha 20...), 1976

ANSI-N343, Standard for Intemal Dosimetry for Mixed Fission and Activation Products, 1978

ANSI-Z88.2-1992, Practices for Respiratory Protection, 1992

NCRP 65, Management of Persons Accidentally Contaminated with Radionuclides, 4-15-80 
This page intentionally left blank. 


\section{TABLE OF CONTENTS}

12.0 FIRE PROTECTION

12.1

12.1.1

12.1.2

12.2

12.2.1

12.2 .2

12.2.2.1

12.2.2.1.1

12.2 .2 .1 .2

12.2.2.2

12.2.2.2.1

12.2.2.2.2

12.2.2.2.3

Fire Protection Suppression Systems $\ldots \ldots \ldots \ldots \ldots$

Water Supply and Distribution Systems $\ldots \ldots \ldots \ldots \ldots$

Water Supply Systems . . . . . . . . . . . 7

Mains, Water Storage, and Fire Pumps . . . . 8

Redundant Water Supply . . . . . . . . 8 8

Water Distribution System $\ldots \ldots \ldots \ldots \ldots$

Fire Hydrant Capacity . . . . . . . . . . . 8

Dedicated Water Storage and Distribution Systems 9

Underground Fire Water System Design,

Installation, Testing, and Operation . . . . . . 9

12.2 .3

Construction

FIRE ALARM AND DETECTION

10

12.3

12.4

12.5

FIRE PREVENTION (BUILDING DESIGN) . . . . . . . . . 10

FIRE, HAZMAT AND MEDICAL SUPPORT $\ldots \ldots \ldots \ldots \ldots$

12.5 .1

Fire Department $\ldots \ldots \ldots \ldots \ldots \ldots \ldots \ldots$

12.5 .1 .1

Plans, Procedures, Devices, and Trained Personnel .... 11

12.5 .2 Contingency Plan and Emergency Responses . . . . . . . 12

12.5.2.1

12.5.2.2

12.5.2.3

Site Emergency Organizations . . . . . . . . . 19

Mutual Aid .................. 20

Medical Response ................ 20

12.6 
Safeguards and Security $\ldots \ldots \ldots \ldots \ldots \ldots \ldots$

12.7 .2

Radiation Protection $\ldots \ldots \ldots \ldots \ldots \ldots \ldots \ldots \ldots$

12.7 .3

Training and Qualification $\ldots \ldots \ldots \ldots \ldots . \ldots \ldots$

12.7 .4

Environmental Protection . . . . . . . . . . . . . . 24

12.7 .5

Emergency Management $\ldots \ldots \ldots \ldots \ldots \ldots . \ldots \ldots$

12.7 .6

Fire Protection Program . . . . . . . . . . . . . . . 24

12.7 .7

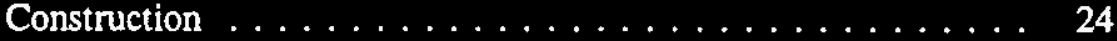

12.7 .8

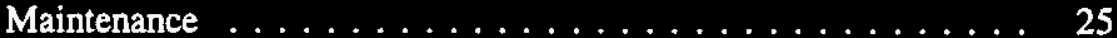

12.7 .9

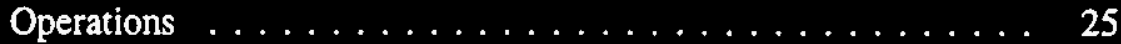

12.7 .10

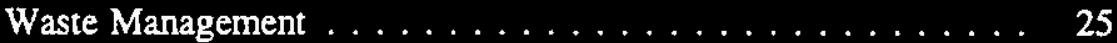

12.7.11

Nuclear Safety . . . . . . . . . . . . . . . . . 25

12.7 .12

12.7.13

Occupational Safety and Health $\ldots \ldots \ldots \ldots 25$

Configuration Management $\ldots \ldots \ldots \ldots \ldots \ldots$

12.7.14

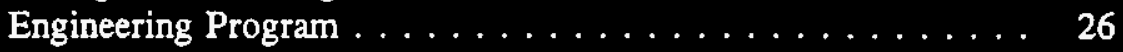

Requirement Source Documents . . . . . . . . . . . 26 


\subsection{FIRE PROTECTION}

\section{INTRODUCTION}

A Standards/Requirements Identification Document (S/RID) sets forth the Environmental Safety and Health (ES\&H) standards/requirements. This S/RID is applicable to the appropriate life cycle phases of design, construction, operation, and decommissioning for each of the categories of facilities addressed in Revision $\mathbf{5}$ of the Department of Energy Implementation Plan for the Defense Nuclear Facilities Safety Board (DNFSB) Recommendation 90-2. This Recommendation calls for the strengthening of DOE weapons complex activities through the identification and application of relevant DOE Orders, regulations, industry codes/standards, industry guidance documents and, as appropriate, good industry practices. These standards/requirements are adequate to ensure protection of the health and safety of workers, the public, and the environment.

The Westinghouse Hanford Company S/RID, as defined in Revision 5 of the Department of Energy Implementation Plan for DNFSB Recommendation 90-2, contains standards/requirements applicable company-wide that are necessary for safe operation of the site and its associated facilities, and that are not the direct responsibility of a specific facility manager (e.g., a company-wide fire department). Facility S/RIDs contain standards/requirements applicable to a specific facility that are the direct responsibility of the facility manager.

This Standards/Requirements Identification Document (S/RID) defines the Westinghouse Hanford Company (WHC) Fire Protection program in place at Hanford. The Fire Protection program defined in this document is described in general accordance with the (ES\&H) Configuration Guide, Revision 0 , dated July 30, 1993, and is presented in the form of program elements and subelements. The specific DOE Orders, regulations, industry codes/standards, guidance documents and good industry practices which serve as the basis for each element/subelement are identified and aligned with each subelement.

It is intended that this document be used as a baseline from which to compare the existing Fire Protection Program for determination of the level of program definition and maturity, generation of implementing requirements and documents, existence of an overall site infrastructure and clearly defined interfaces with other relevant functional areas. Additionally, this S/RID may be used as the basis against which future program definition and improvement efforts, including procedures development and/or revisions, can be compared to ensure consistency; completeness and proper integration with other functional programs. For application in this S/RID, the words "shall" and "should" in requirement statements both indicate mandatory compliance. The key interface information is provided for general recognition and understanding and is not considered to contain prescriptive requirements.

The reference documents and requirements included herein are those which mandate the inclusion of an element or subelement as an essential component in the development of a comprehensive Fire Protection Program in support of existing and future activities. It is not the intent of this document to identify all requirements which have a potential relevancy or application. For example, included in this document are references to NFPA Codes and Standards. This document has not specifically identified the requirements contained in applicable NFPA codes and standards. However, compliance with the salient details contained in NFPA Codes and Standards relevant to activities is required to be 
demonstrated. Additionally, some requirements contained in this document may be intentionally duplicated in facility S/RIDs. This is necessary in some cases to adequately capture implementation responsibilities at both the company and facility level.

The requirements identified in this document are verbatim text from the referenced document. Due to the evolution cycle of documents, references identified in the requirements may not be to the latest revision. For example DOE Order 6430.1A references DOE Order 5480.7. The latest revision is 5480.7A.

Source document 5480.7A is utilized extensively throughout this document. Within the requirements extracted, by verbatim text, referrals are made to various sections within $5480.7 \mathrm{~A}$ Therefore, it is important to remember that requirements are associated with a topical element as defined in the table of contents. S/RID requirements are identified by source document, part, section or paragraph (e.g. DOE5480.7A Section 9.b.(15.).

Fire Department activities are to adhere with the requirements specified in Washington State WACs. Therefore, the WACs are to be reviewed at regular intervals to verify that Fire Department activities comply with requirements specified.

Upon completion this document will be utilized as the basis to evaluate compliance of the Fire Protection Program being implemented at the Company level with the requirements of DOE Orders and industry codes and standards.

The interface with other functional areas are defined to ensure total integration and support of a Fire Protection Program Plan across disciplines relevant to design, construction and operational life activities. Section 12.7 provides a brief description of the interface with other functional areas.

SCOPE

This document in conjunction with the DOE-RL and facility S/RIDs, define the Fire Protection controls, activities, personnel, and programs implemented by WHC. 


\section{REQUIREMENT SOURCE: RLID5480.7 Section 6.2}

Author's Note: The introduction and $a$ and $b$ are applicable to the company level. Subpart $d(4), d(5)$ and $d(8)$ are applicable to the facility level. Subpart $l$ and $m$ are applicable to both company and facility level.

"RL Contractors shall assure that facilities and programs under their jurisdiction provide a level of fire protection adequate to meet the objectives of DOE $5480.7 \mathrm{~A}$ for protection of the public, personnel, environment, and property. RL Contractors shall also:

a. Submit the "Annual Industrial Summary of Fire and Other Property Damage Experience" report (three copies) for the previous calendar year to the RL Director of QSH by February 1st of each year, as required by DOE 5484.1 and as supplemented by RL direction.

b. Report fires to QSH and losses, in accordance with paragraph 8.8 of this directive.

c. Property loss valuation shall be determined by utilizing the property valuation and loss estimation guidelines found in DOE 5484.1.

d. Schedule and preform fire protection assessments for all facilities, including those for which the contractor has only landlord or lessee responsibility. Assure that the fire protection program elements, described in DOE 5480.7A and this directive, are being implemented.

(1) Annual fire protection assessments shall be made of facilities valued in excess of $\$ 50$ million; where considered to be moderate (Category 2 Hazard) or high hazard (Category 1 Hazard), as defined in DOE 5481.1B, for non-nuclear facilities and in DOE 5480.23, for nuclear facilities; or in which vital programs are involved.

(2) Fire protection assessments shall be made at least every two years of facilities valued at $\$ 10$ million to $\$ 50$ million.

(3) Fire protection assessments shall be made at least every three years of facilities valued and $\$ 1$ million to $\$ 10$ million.

(4) Except for paragraph 6.2d.(5) of this directive, fire protection facility assessments shall contain the required nature and scope elements contained in DOE 5480.7A. Facility assessments shall also contain findings and observations of fire protection deficiencies jdentified.

(5) Facilities, where property is less than $\$ 1$ million, shall not require a fire protection facility assessment that contains the required nature and scope elements contained in DOE 5480.7A, unless significant programmatic impacts, hazardous materials, or radioactive materials are involved. Such facility assessments shall be made at least every three years.

Exception: A fire protection assessment shall be made at least every three years of facilities valued at $\$ 250,000$ to $\$ 1$ million. The documented assessment for these facilities only needs to include findings, observations, and recommendations. Where applicable, these assessments should include, as a minimum, findings and observations and supporting documentation that identify fire hazards that could cause facility loss or life safety concerns. 
(6) Fire protection facility assessments shall retained by the contractor, and made available to RL representatives upon request. Copies of the two most recent assessment reports shall be kept readily accessible on file.

(7) Facility assessments findings, observations, and/or recommendations shall be entered into data base tracking system and assigned and appropriate prioritization, to ensure that effective actions are being taken to correct deficiencies identified in accordance with RLID 1000.1.

(8) MCFL and MPFL values described in the assessments shall be as required by DOE 5480.7A utilizing the property valuation and loss estimation guidelines found in DOE 5484.1.

(9) Maintain a list of facilities which require assessment, indicating the assessment frequency.

e. Perform FHA of facilities in accordance with DOE 5480.7A and EH-31.3, Guidance on Performance of Fire Hazard Analyses, memorandum dated 11-07-91. FHA shall be completed for all new facilities, as required by DOE 6430.1 version in effect, and all existing nuclear facilities, where safety analyses are required by DOE 5480.23 . The development of a facility design basis fire in accordance with DOE 6430.1 version in effect, as required in safety analysis documentation, must be consistent with the MPFL event and documented in the facility FHA.

The FHA shall be referenced by the safety analysis documentation. MCFL and MPFL values described in the FHA shall be as required by DOE 5480.7A, utilizing the property valuation and loss estimation guidelines found in DOE 5484.1. New facility and nuclear facility FHA shall be reviewed and approved by QSH. When directed by the PSO, the FHA shall also follow the same review and approval process as safety analysis documentation for DOE 5480.23. A copy of the current FHA shall be retained by the contractor and be kept readily accessible on file.

f. Provide fire protection overview and assistance for subcontractor activities and facilities.

g. Carry out those responsibilities assigned by DOE 5480.7A, paragraphs $8 \mathrm{i}(1)$ through $8 \mathrm{i}(8)$, and comply with the applicable provisions of DOE 6430.1 versions in effect.

h. Establish a written and documented fire protection program for facilities and operations managed, including:

(1) A statement of management commitment to achieve the above stated objectives.

(2) A policy statement that implements DOE 5480.7A, other DOE fire protection related mandatory codes and standards, and requirements contained in this directive.

(3) Fire protection criteria that reflect site-specific aspects of the fire protection program, including the organization and responsibilities of the fire protection staff, administrative aspects of the Fire Protection Program, and requirements for physical fire protection features.

(4) See paragraph 8.12 of this directive for guidance on developing the documented fire protection program.

i. Maintain a current statement of programmatic impact on every vital program, as determined by RL or the PSO. The statement of programmatic impact will be updated every three years. The statement will include facilities, material, and equipment that are vital to the operation of that program. 
j. Each prime contractor shall have on staff at least one qualified Fire Protection Engineer (see paragraph 5.2).

k. Provide and maintain a system to ensure that the requirements of the DOE Fire Protection Program are documented and incorporated in the plans and specifications for all new facilities, and for major modifications of existing facilities. This includes review and comment by the fire protection engineering group of design documentation and testing of fire protection features.

1. Provide fire protection representation at the Hanford Fire Protection Forum meeting, as described in the Hanford Fire Protection Forum Charter.

$m$. Attend and provide representation at the monthly program interface meetings with the RL fire protection representative."

Management

\section{REQUIREMENT SOURCE: 29CFR1910 Part 156(a)(2)}

Author's Note: The Hanford Site uses a dedicated industrial fire department and does not use fire brigades for fire protection.

"Application. The requirements of this section apply to fire brigades, industrial fire departments and private or contractual type fire departments. Personal protective equipment requirements apply only to members of fire brigades performing interior structural fire fighting. The requirements of this section do not apply to airport crash rescue or forest fire fighting operations."

\section{REQUTREMENT SOURCE: 29CFR1926 Part 150(a)(1)}

"Occupational Health and Safety Standards for the Construction Industry - Fire Protection General requirements. The employer shall be responsible for the development of a fire protection program to be followed throughout all phases of the construction and demolition work, and he shall provide for the firefighting equipment as specified in this subpart. As fire hazards occur, there shall be no delay in providing the necessary equipment."

\section{REQUIREMENT SOURCE: DOE5480.7A Section 8.i}

Author's Note: Numbers 1 and 4 apply to Westinghouse Company. Number 6 applies jointly 10 both the company level and the facility level. The rest of the numbers apply to the facility level.

"As required by the PSO or the Heads of Field Organizations and directed by the Contracting Officer, contractors shall be required to:

(1) Provide and maintain a level of fire protection to meet the objectives of paragraph 4, and the criteria of paragraph 9 .

(2) Provide and maintain a system to ensure that the requirements of the DOE fire protection program are documented and incorporated in the plans and specifications for all new facilities and for major modifications of existing facilities. This includes review and comment by a qualified fire protection engineer of plans, specifications and test procedures and results for fire protection features. 
(3) Assists DOE in coordinating fire safety assessments at those facilities included in the survey program, establish action plans for compliance with recommendations resulting from the assessments, and forward compliance plans, exemption requests, and other requested data to DOE field organizations.

(4) Establish and maintain a list of facilities for which the contractor has fire protection assessment responsibility.

(5) Conduct fire protection assessments of facilities according to the scope and frequency established by this Order.

(6) Provide fire protection technical assistance to DOE.

(7) Submit request for exemptions and fire safety equivalencies to the Head of the Field Organization for those facilities where compliance with specific program elements is not attainable and where an acceptable level of safety has been achieved.

(8) Maintain or have access to an adequate fire protection staff, including a qualified fire protection engineer(s). Continuing education and training should be provided to maintain and enhance the level of competency of the fire protection staff."

$\underline{12.1 .2}$

12.2

\section{Administrative}

\section{REQUREMENT SOURCE: DOE5480.7A Section 9(1)}

"A DOE facility shall be characterized by a level of fire protection sufficient to fulfill the requirements for the best protected class of industrial risks (Highly Protected Risks/lmproved Risks). This program is characterized by the inclusion of a continuing, sincere interest on the part of management and employees in minimizing losses from fire and related perils and the inclusion of preventive features necessary to ensure the satisfaction of objectives related to safety."

\section{REQUIREMENT SOURCE: DOE5480.7A Section 9(2)}

"Based on the above paragraph the DOE Fire Protection Program shall meet or exceed the minimum requirements established by the National Fire Protection Association as directed by the PSO. Basic requirements shall include: a reliable water supply of acceptable capacity for fire suppression; noncombustible construction of an acceptable nature for the occupancy of the facility; automatic fire extinguishing systems; a fully staffed, trained, and equipped emergency response force; a means to summon the emergency response force in the event of a fire; and a means to notify and evacuate building occupants in the event of a fire. For areas subject to significant life safety risks, serious property damage, program interruption, or loss of safety class equipment as defined in the relevant facility SAR, additional protection measures may be necessary as determined by the AHJ."

\section{FIRE PROTECTION PROGRAM}

Note: Application of Codes and Standards.

The fire protection related codes and standards in effect when facility design commences (code of record) remain in effect for the life of the facility. When modifications of a substantial nature occur, as determined by the authority having jurisdiction (AHJ), the current edition of the code shall apply to the modification. 
EXCEPTION: If there is significant hazard that endangers building occupants or the public, as determined by the AHJ, the facility shall be upgraded to the requirements of the current edition of the code of standards.

\section{REQUIREMENT SOURCE: DOE5480.7A Section 5 Introduction, and 5.a thru 5.h}

"5. MANDATORY FIRE PROTECTION CRITERIA. Fire protection criteria, delineated in the following codes, standards and other documents are the minimum requirements for the implementation of the DOE Fire Protection Program. These criteria are mandatory as a result of statutory requirements or DOE policy requirements. Where conflicts in the application of these codes and standards arise, the more restrictive requirements apply.

a. Code of Federal Regulations (CFR) 29, Part 1910.

b. CFR 29, Part 1926.

c. National Fire Protection Association (NFPA) Codes and Standards.

d. DOE 5480.4, ENVIRONMENTAL PROTECTION, SAFETY, AND HEALTH PROTECTION STANDARDS, of 5-15-84, which specifies requirements for the application of environmental protection, safety, and health standards.

e. DOE 6430.1A, GENERAL DESIGN CRITERIA, of 4-6-89, which provides general design criteria for use in the acquisition of the Department's facilities.

f. DOE/EP-0108, "Standard for Fire Protection of AEC Electronic Computer Data Processing Systems".

g. DOE/EV-0043, 8-79, "Standard on Fire Protection for Portable Structures".

h. Other DOE Orders and statutory requirements, not listed above, that contain requirements of a more limited extent relating to the DOE Fire Protection Program."

$\underline{12.2 .1}$

$\underline{12.2 .2}$

12.2 .2 .1

\section{Fire Protection Suppression Systems}

Author's Note: Requirements relevant to fire protection suppression systems are addressed in the facility level S/RID.

\section{Water Supply and Distribution Systems}

Water Supply Systems

\section{REQUIREMENT SOURCE: DOE5480.7A Section 9.b.(8)}

Author's Note: Although facility involvement may be required for adequate implementation, this requirement is cited in this document because the company organization is responsible for the actual delivery of the water supply.

"Fire Protection Water Supply - An automatic water supply for fire protection having a minimum two hours stored water capacity shall be maintained. Municipal supplies having the same capability are acceptable, Facilities having a MPFL in excess of $\$ 50$ million shall be provided with an additional, independent source of fire protection water. 
12.2 .21 .1

\section{2 .21 .2}

$\underline{12.2 .2 .2}$

12.2 .22 .1
A water supply dedicated for fire protection may be necessary as determined by the PSO. A dedicated system shall be able to meet hose stream and sprinkler system demands.

A combined fire and process/domestic system shall be able to deliver the fire demand plus the maximum daily domestic demand for the required duration."

\section{REQUIREMENT SOURCE: DOE6430.1A Division 15, Section 1540-99.0.5}

"On-site water supplies and other utilities shall be provided as necessary for emergency use. The design of each utility service or cooling water system shall consider the demands for normal operations, anticipated operational occurrences, and DBA conditions."

\section{Mains, Foter Storege and totre Punes}

\section{REQUREMENT SOURCE: RLID5480.7 Section 8. 1.d}

"Fire flows shall be available for a period of at least two hours. A minimum four-hour supply shall be provided for large building sites, or groups of combustible buildings. Combined systems serving fire protection and other water demands (domestic and/or process), the supply and its distribution system shall be adequately sized to serve the combined peak flow for all uses. When storage tanks are used for combined service water and fire protection water, the minimum volume for fire uses shall be assured by dedicated tank(s) or other physical means, such as a vertical standpipe."

\section{Redundant Wiater Supply}

\section{REQUIREMENT SOURCE: DOE6430.1A Division 15, Section 1530-99.0[17]}

"The water supply for the permanent fire protection installation shall have a minimum of two reliable, independent sources each with sufficient capacity (based on maximum demand) for firefighting until other sources become available. Only one of these two sources shall be required to be DBE qualified."

Water Distribution System

Fire Bydrout Comeity

\section{REQURREMENT SOURCE: DOE6430.1A Division 2, Section 0266-4[02]}

"Domestic water distribution systems that also serve fire protection requirements shall be designed to satisfy fire flow requirements plus 50 percent of the average domestic requirements plus any industrial or process demands that cannot be reduced during a fire."

\section{REQUREMENT SOURCE: DOE6430.1A Division 2, Section 0266-4[03]}

"Each fire hydrant within the distribution system must be capable of delivering $1000 \mathrm{gpm}$ at a residual pressure of not less than $10 \mathrm{psi}$. Where domestic water distribution systems are to serve internal fire protection systems (i.e. sprinklers or foamite systems), adequate residual pressures shall be maintained for proper operation of such fire protection systems." 
12.2.2.2.2.

12.2 .2 .2 .3

\section{$\underline{12.2 .3}$}

\section{Dedicuted Fluter Stonte and Distribution Sxytems}

\section{REQUIREMENT SOURCE: DOE6430.1A Division 15, Section 1530-9[1]}

"Wherever practical, dedicated fire water storage and distribution systems shall be used. If a dedicated fire water supply system cannot be provided, the fire protection water supply shall assure availability regardless of simultaneous process and domestic water usage."

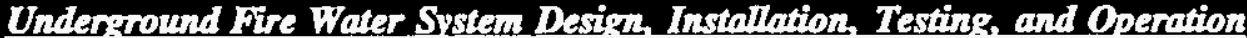

\section{REQUIREMENT SOURCE: RLID5480.7 Section 8. 1.a}

"Distribution mains, either sanitary or raw water, that are being extended to supply water for domestic and/or process water and will provide water for fire suppression systems (sprinklers and/or hydrants), shall be at least 12 inches in diameter."

\section{REQUIREMENT SOURCE: RLID5480.7 Section 8. 1.b}

"Sectional valves shall be installed in the following manner for new installations and water distribution main upgrades:

(1) Multiple sectional isolation valves shall be provided at each intersection between a supply source and a main loop (one valve for each leg).

(2) Sectional valves shail be installed in accordance with a point system, such that no more than six points accumulate between sectional valves. The points for this arrangement are: one point for a fire hydrant, and two points for a automatic sprinkler system. "

\section{REQUIREMENT SOURCE: RLID5480.7 Section 8. 1.c}

"Water supplies for fire protection shall be of the looped grid type, providing two points of supply and two-way flow with sectional valving arranged to provide alternate water flow paths from the source to any point in the distribution system, where MPFL exceeds \$1 million."

\section{Construction}

\section{REQUIREMENT SOURCE: RLID5480.7 Section 8. 4.a}

"Fire protection must be provided on all construction sites, as required by applicable sections of NFPA 241, Safeguarding Construction, Alteration, And Demolition Operations, and NFPA 1141, Fire Protection In Planned Building Groups."

\section{REQUREMENT SOURCE: RLID5480.7 Section 8. 4.b}

"Where underground water mains and hydrants are to be provided, they shall be installed, completed, and in service, prior to accumulation of combustible materials on the project site, and prior to the completion of any project structure." 


\section{REQUIREMIONT SOURCE: RLID5480.7 Section 8. 4.c}

12.3

12.4

12.5

$\underline{12.5 .1}$

"Construction sites shall provide and maintain fire department vehicle access. The access roads shall have an unobstructed driving surface width of at least 20 feet during all weather conditions, and be able to withstand the live loads of fire department apparatus."

\section{FIRE ALARM AND DETECTION}

Requirements for Fire Alarm and Detection are located in the facility Fire Protection Functional Area. For Testing and Maintenance requirements, see Inspection, Testing, and Maintenance section of this document.

\section{FIRE PREVENTION (BUILDING DESIGN)}

"Fire prevention requirements shall comply with 29 CFR 1910, NFPA 1, Fire Prevention Code and Authority, Responsibilities, and Duties of the Hanford Fire Marshall Attachment of the Fire Prevention Program description contained in the HANFORD CHAPTER of the DOE FIRE PROTECTION RESOURCE MANUAL."

Author's Note: Per DOE 5480.7A, this order has primacy over all other DOE Orders with respect to matters concerning Fire Protection.

Fire protection requirements for the storage and use of compressed gases, acetylene, hydrogen, flammable and combustible liquids, and LPG shall be in accordance with 29 CFR 1910 Subpart H, Hazardous Materials.

Electrical installations shall comply with the National Electrical Code, NFPA 70.

Air filter units shall meet the requirements of UL 586 "High Efficiency Particulate Air Filter Units" and UL 900 "Test Performance for Air Filter Units".

Applicable requirements are found in the facility specific S/RID.

\section{FIRE, HAZMAT AND MEDICAL SUPPORT}

Note: It is not currently known by legal interpretation if the WAC-246-976 and WAC-296-305 are reguired at Hanford by statute. Hanford Fire Department ambulance emergency medical services operate under the License of a State of Washington Board Certified Physician. Other Hanford Fire Department emergency services are provided in State jurisdictions (outside of Hanford boundaries) under mutual agreements. As such, compliance with WAC-246-976 and WAC-296-305 are included in this Fire Protection Functional Area.

\section{Fire Department}

Author's Note: The Hanford Fire Department is the designated incident command agency for hazardous materials events, fire suppression activities, emergency medical and ambulance needs, and special emergency rescue situations, excluding State Highways 240 and 24, which are the responsibility of the Washington State Patrol. This designation is registered by DOE-RL with the State of Washington. 


\section{REQUREMENT SOURCE: RUID5480.7 Section 6.3}

"The Hanford Fire Department shall provide fire suppression, rescue, emergency medical and ambulance services, and hazardous material response, that are capable of dealing with the terminating emergency situations, which could threaten the operations, employees, environment, or property on the Hanford Site. The Hanford Fire Department shall also:

a. Comply with applicable fire department provisions of DOE 5480.4 and DOE 5480.7A.

b. Provide emergency response support, as required by agreements or contracts, to other entities or agencies, on the Hanford Site.

c. Maintain mutual aid agreements with surrounding area fire districts.

d. Develop, administer, and enforce the Fire Prevention Program for the Hanford Site, as contained in the Authority, Responsibilities, and Duties of the Hanford Fire Marshal Attachment of the Fire Prevention Program description contained in the Hanford Chapter of the DOE Fire Protection Resource Manual. The Fire Prevention Inspection Program shall apply to all site activities, including operations, demolition, and construction.

e. Provide appropriate sitewide fire protection system inspection, testing, and maintenance for fire alarm and fire suppression systems.

f. Perform self-contained breathing apparatus maintenance.

g. Maintain confined space entry and other emergency rescue readiness, as required by 29 CFR 1910.

h. Develop and maintain pre-fire plans for all major Hanford facilities and operations.

i. Be the designated hazardous materials incident command agency for the Hanford Site.

j. Act as the lead emergency response organization and provide incident command, as required by DOE 5480.4 for fire suppression, emergency medical and ambulance service, special emergency rescue, and hazardous material events for Hanford Sit operations.

k. Provide fire protection representation at the Hanford Fire Protection Forum meeting, as described in the Hanford Fire Protection Forum Charter.

I. Attend and provide representation at the monthly program interface meetings with the RL fire protection representative."

\section{REQUTREMENT SOURCE: RLID5480.7 Section 8.7}

"Employees must be provided annual fire prevention training. The training must be documented and include:

a. Good housekeeping practices.

b. Proper response and notification in the event of fire. 
c. Instructions on the use of portable fire extinguishers. Employees, who perform fire watches, must receive hands-on portable fire extinguisher training, as required by 29 CFR 1910.

\section{d. Recognition of potential fire hazards."}

\section{Contingency Plan and Emergency Responses}

\section{REQUIREMENT SOURCE: DOE-RL-91-28 Appendix 7A, Section 3.0}

"The overall responsibility for implementation of this Plan lies with the building emergency director (BED) or their designated alternates. The BED has the responsibilities of the Emergency Coordinator as discussed in WAC 173-303-360 and is also the Event Commander. A list of all BEDs and alternates is maintained at various locations throughout the Hanford Facility, and these individuals can be reached 24 hours a day. The BEDs have the authority to commit all necessary resources (both equipment and personnei) to respond to any emergency. Additional responsibilities have been delegated to Hanford Fire Department personnel who are authorized to act for the BED when the BED is absent. These Hanford Fire Department personnel have the authority to commit all necessary resources (both equipment and personnel) to respond to any emergency.

Response by a BED (or an Emergency Coordinator) usually is obtained through the DOE-RL single point-of-contact by dialing telephone number 811 [SIC] or $373-3800$ or 375-2400. The single point-of-contact has been designated as the contact point to mobilize a response to any Hanford Facility emergency. The single point-of-contact is available at all times and has the responsibility to initiate notifications to the BED or alternate to begin responses to emergencies, as well as to dispatch emergency responders (Hanford Fire Department, Hanford Patrol, or ambulance services). All emergency notifications to the $\mathrm{BED}$, building managers, etc., can be made directly from the affected TSD unit or through the single point-of-contact.

The unit-specific DOE-RL technical contact responds to regulatory agency inquiries regarding this Plan. The unit-specific DOE-RL technical contact is accessed by contacting $373-3800$ or 375-2400."

\section{REQUIREMENT SOURCE: DOE5500.3A Section 11.c.(7)}

"Medical Support. Provisions must be in place for medical support for workers, including those with radiological and/or hazardous material contamination, and must include:

(a) Immediate, onsite first aid and emergency medical treatment capability;

(b) Transportation of injured onsite personnel to onsite or offsite medical facilities, as appropriate; and

(c) Documented arrangements with onsite and offsite medical facilities to accept and treat contaminated, injured personnel."

\section{REQUIREMINT SOURCE: WAC-173-303 Section 340}

"WAC 173-303-340 Preparedness and prevention.

Facilities shall be designed, constructed, maintained and operated to minimize the possibility of fire, explosion, or any unplanned sudden or nonsudden release of dangerous waste or 
dangerous waste constituents to air, soil, or surface or ground water which could threaten the public health or the environment. This section describes preparations and preventive measures which help avoid or mitigate such situations.

(1) Required equipment. All facilities must be equipped with the following, unless it can be demonstrated to the department that none of the hazards posed by waste handled at the facility could require a particular kind of equipment specified below:

(a) An internal communications or alarm system capable of providing immediate emergency instruction to facility personnel;

(b) A device, such as a telephone or a hand-held, two-way radio, capable of summoning emergency assistance from local police departments, fire departments, or state or local emergency response teams;

(c) Portable fire extinguishers, fire control equipment, spill control equipment, and decontamination equipment; and

(d) Water at adequate volume and pressure to supply water hose streams, foam producing equipment, automatic sprinklers, or water spray systems. All facility communications or alarm systems, fire protection equipment, spill control equipment, and decontamination equipment, where required, must be tested and maintained as necessary to assure its proper operation in time of emergency.

(2) Access to communications or alarms. Personnel must have immediate access to the signalling devices described in the situations below:

(a) Whenever dangerous waste is being poured, mixed, spread, or otherwise handled, all personnel involved must have immediate access to an internal alarm or emergency communication device, either directly or through visual or voice contact with another employee, unless such a device is not required in subsection (1) of this section;

(b) If there is ever just one employee on the premises while the facility is operating, he must have immediate access to a device, such as a telephone or a band-held, two-way radio, capable of summoning external emergency assistance, unless such a device is not required in subsection (1) of this section.

(3) Aisle space. The owner or operator must maintain aisle space to allow the unobstructed movement of personnel, fire protection equipment, spill control equipment, and decontamination equipment to any area of facility operation in an emergency, unless it can be demonstrated to the department that aisle space is not needed for any of these purposes.

(4) Arrangements with local authorities. The owner or operator shall attempt to make the following arrangements, as appropriate for the type of waste handled at his facility and the potential need for the services of these organizations, unless the hazards posed by wastes handled at the facility would not require these arrangements:

(a) Arrangements to familiarize police, fire departments, and emergency response teams with the layout of the facility, properties of dangerous waste handled at the facility and associated hazards, places where facility personnel would normally be working, entrances to and roads inside the facility, and possible evacuation routes; 
(b) Arrangements to familiarize local hospitals with the properties of dangerous waste handled at the facility and the types of injuries or ilinesses which could result from fires, explosions, or releases at the facility;

(c) Agreements with state emergency response teams, emergency response contractors, and equipment suppliers; and

(d) Where more than one party might respond to an emergency, agreements designating primary emergency authority and agreements with any others to provide support to the primary emergency authority.

(5) Where state or local authorities decline to enter into such arrangements, the owner or operator must document the refusal in the operating record."

\section{REQUIREMENT SOURCE: WAC-173-303 Section 350}

"(1) Purpose. The purpose of this section and WAC 173-303-360 is to lessen the potential impact on the public health and the environment in the event of an emergency circumstance, including a fire, explosion, or unplanned sudden or nonsudden release of dangerous waste or dangerous waste constituents to air, soil, surface water, or ground water by a facility. A contingency plan must be developed to lessen the potential impacts of such emergency circumstances, and the plan shall be implemented immediately in such emergency circumstances.

(2) Contingency plan. Each owner or operator must have a contingency plan at his facility for use in emergencies or sudden or nonsudden releases which threaten the public health and the environment. If the owner or operator has already prepared a spill prevention control and countermeasures (SPCC) plan in accordance with Part 112 of Title 40 CFR or Part 1510 of chapter V, or some other emergency or contingency plan, he need only amend that plan to incorporate dangerous waste management provisions that are sufficient to comply with the requirements of this section and WAC 173-303-360.

(3) The contingency plan must contain the following:

(a) A description of the actions which facility personnel must take to comply with this section and WAC 173-303-360;

(b) A description of the actions which shall be taken in the event that a dangerous waste shipment, which is damaged or otherwise presents a hazard to the public health and the environment, arrives at the facility, and is not acceptable to the owner or operator, but cannot be transported, pursuant to the requirements of WAC 173-303-370(5), Manifest system, reasons for not accepting dangerous waste shipments;

(c) A description of the arrangements agreed to by local police departments, fire departments, hospitals, contractors, and state and local emergency response teams to coordinate emergency services;

(d) A current list of names, addresses, and phone numbers (office and home) of all persons qualified to act as the emergency coordinator required under WAC 173-303-360(1). Where more than one person is listed, one must be named as primary emergency coordinator, and others must be listed in the order in which they will assume responsibility as alternates. For new facilities only, this list may be provided to the department at the time of facility certification (as required by WAC 173-303-810 (14)(a)(i)), rather than as part of the permit application; 
(e) A list of all emergency equipment at the facility (such as fire extinguishing systems, spill control equipment, communications and alarm systems, and decontamination equipment), where this equipment is required. This list must be kept up to date. In addition, the plan must include the location and a physical description of each item on the list, and a brief outline of its capabilities; and

(f) An evacuation plan for facility personnel where there is a possibility that evacuation could be necessary. This plan must describe the signal(s) to be used to begin evacuation, evacuation routes, and altemate evacuation routes.

(4) Copies of contingency plan. A copy of the contingency plan and all revisions to the plan shall be:

(a) Maintained at the facility; and

(b) Submitted to all local police departments, fire departments, hospitals, and state and local emergency response teams that may be called upon to provide emergency services.

(5) Amendments. The owner or operator shall review and immediately amend the contingency plan, if necessary, whenever:

(a) Applicable regulations or the facility permit are revised;

(b) The plan fails in an emergency;

(c) The facility changes (in its design, construction, operation, maintenance, or other circumstances) in a way that materially increases the potential for fires, explosions, or releases of dangerous waste or dangerous waste constituents, or in a way that changes the response necessary in an emergency;

(d) The list of emergency coordinators changes; or

(e) The list of emergency equipment changes."

\section{REQUTREMENT SOURCE: WAC-173-303 Section 360(1)}

"Emergency coordinator. At all times, there must be at least one employee either on the facility premises or on call with the responsibility for coordinating all emergency response measures. This emergency coordinator must be thoroughly familiar with all aspects of the facility's contingency plan, required by. WAC 173-303-350(2), all operations and activities at the facility, the location and properties of all wastes handled, the location of all records within the facility, and the facility layout. In addition, this person must have the authority to commit the resources needed to carry out the contingency plan."

\section{REQUTREMENT SOURCE: WAC-173-303 Section 360(2)}

"Emergency procedures. The following procedures shall be implemented in the event of an emergency.

(a) Whenever there is an imminent or actual emergency situation, the emergency coordinator (or his designee when the emergency coordinator is on call) must immediately: 
(i) Activate internal facility alarms or communication systems, where applicable, to notify all facility personnel; and

(ii) Notify appropriate state or local agencies with designated response roles if their help is needed.

(b) Whenever there is a release, fire, or explosion, the emergency coordinator must immediately identify the character, exact source, amount, and areal extent of any released materials.

(c) Concurrently, the emergency coordinator shall assess possible hazards to human health and the environment (considering direct, indirect, immediate, and long-term effects) that may result from the release, fire, or explosion.

(d) If the emergency coordinator determines that the facility has had a release, fire, or explosion which could threaten human health or the environment, he must report his findings as follows:

(i) If his assessment indicates that evacuation of local areas may be advisable, he must immediately notify appropriate local authorities. He must be availabie to help appropriate officials decide whether local areas should be evacuated; and

(ii) He must immediately notify the department and either the government official designated as the on-scene coordinator, or the National Response Center (using their 24-hour toll free number (800) 424-8802).

(e) His assessment report must include:

(i) Name and telephone number of reporter;

(ii) Name and address of facility;

(iii) Time and type of incident (e.g., release, fire);

(iv) Name and quantity of material(s) involved, to the extent known;

(v) The extent of injuries, if any; and

(vi) The possible hazards to human health or the environment outside the facility.

(f) During an emergency, the emergency coordinator must take all reasonable measures necessary to ensure that fires, explosions, and releases do not occur, recur, or spread to other dangerous waste at the facility. These measures must include, where applicable, stopping processes and operations, collecting and containing released waste, and removing or isolating containers.

(g) If the facility stops operations in response to a fire, explosion, or release, the emergency coordinator must monitor for leaks, pressure buildup, gas generation, or ruptures in valves, pipes, or other equipment, wherever this is appropriate.

(h) Immediately after an emergency, the emergency coordinator must provide for treating, storing, or disposing of recovered waste, contaminated soil or surface water, or any other material that results from a release, fire, or explosion at the facility. 
(i) The emergency coordinator must ensure that, in the affected area(s) of the facility:

(i) No waste that may be incompatible with the released material is treated, stored, or disposed of until cleanup procedures are completed; and

(ii) All emergency equipment listed in the contingency plan is cleaned and fit for its intended use before operations are resumed.

(j) The owner or operator must notify the department, and appropriate local authorities, that the facility is in compliance with (i) of this subsection before operations are resumed in the affected area(s) of the facility.

(k) The owner or operator must note in the operating record the time, date, and details of any incident that requires implementing the contingency plan. Within fifteen days after the incident, he must submit a written report on the incident to the department. The report must include:

(i) Name, address, and telephone number of the owner or operator;

(ii) Name, address, and telephone number of the facility;

(iii) Date, time, and type of incident (e.g., fire, explosion);

(iv) Name and quantity of material(s) involved;

(v) The extent of injuries, if any;

(vi) An assessment of actual or potential hazards to human health or the environment, where this is applicable;

(vii) Estimated quantity and disposition of recovered material that resulted from the incident;

(viii) Cause of incident; and

(ix) Description of corrective action taken to prevent reoccurrence of the incident."

\section{REQUTREMENT SOURCE: WAC-173-303 Section 360(2)(a)}

"Whenever there is an imminent or actual emergency situation, the emergency coordinator (or his designee when the emergency coordinator is on call) must immediately:

(i) Activate internal facility alarms or communication systems, where applicable, to notify all facility personnel; and

(ii) Notify appropriate state or local agencies with designated response roles if their help is needed."

\section{REQUIREMENT SOURCE: WAC-173-303 Section 360(2)(b)}

"Whenever there is a release, fire, or explosion, the emergency coordinator must immediately identify the character, exact source, amount, and areal extent of any released materials." 


\section{REQUREMENT SOURCE: WAC-173-303 Section 360(2)(c)}

"Concurrently, the emergency coordinator shall assess possible hazards to human health and the environment (considering direct, indirect, immediate, and long-term effects) that may result from the release, fire, or explosion."

\section{REQUIREMINT SOURCE: WAC-173-303 Section 360(2)(d) and (e)}

"(d) If the emergency coordinator determines that the facility has had a release, fire, or explosion which could threaten buman health or the environment, he must report his findings as follows:

(i) If his assessment indicates that evacuation of local areas may be advisable, he must immediately notify appropriate local authorities. He must be available to help appropriate officials decide whether local areas should be evacuated; and

(ii) He must immediately notify the department and either the government official designated as the on-scene coordinator, or the National Response Center (using their 24-hour toll free number (800) 424-8802).

(e) His assessment report must include:

(i) Name and telephone number of reporter;

(ii) Name and address of facility;

(iii) Time and type of incident (e.g., release, fire);

(iv) Name and quantity of material(s) involved, to the extent known;

(v) The extent of injuries, if any; and

(vi) The possible hazards to human health or the environment outside the facility."

REQUIREMENT SOURCE: WAC-173-303 Section 360(2)(f)

"During an emergency, the emergency coordinator must take all reasonable measures necessary to ensure that fires, explosions, and releases do not occur, recur, or spread to other dangerous waste at the facility. These measures must include, where applicable, stopping processes and operations, collecting and containing released waste, and removing or isolating containers."

\section{REQUIREMENT SOURCE: WAC-173-303 Section 360(2)(g)}

"If the facility stops operations in response to a fire, explosion, or release, the emergency coordinator must monitor for leaks, pressure buildup, gas generation, or ruptures in valves, pipes, or other equipment, wherever this is appropriate."

\section{REQUIREMENT SOURCE: WAC-173-303 Section 360(2)(b) thru (j)}

"(h) Immediately after an emergency, the emergency coordinator must provide for treating, storing, or disposing of recovered waste, contaminated soil or surface water, or any other material that results from a release, fire, or explosion at the facility. 
(i) The emergency coordinator must ensure that, in the affected area(s) of the facility:

(i) No waste that may be incompatible with the released material is treated, stored, or disposed of until cleanup procedures are completed; and

(ii) All emergency equipment listed in the contingency plan is cleaned and fit for its intended use before operations are resumed.

(j) The owner or operator must notify the department, and appropriate local authorities, that the facility is in compliance with (i) of this subsection before operations are resumed in the affected area(s) of the facility."

\section{REQUTREMENT SOURCE: WAC-173-303 Section 360(2)(k)}

"The owner or operator must note in the operating record the time, date, and details of any incident that requires implementing the contingency plan. Within fifteen days after the incident, he must submit a written report on the incident to the department. The report must include:

(i) Name, address, and telephone number of the owner or operator;

(ii) Name, address, and telephone number of the facility;

(iii) Date, time, and type of incident (e.g., fire, explosion);

(iv) Name and quantity of material(s) involved;

(v) The extent of injuries, if any;

(vi) An assessment of actual or potential hazards to human health or the environment, where this is applicable;

(vii) Estimated quantity and disposition of recovered material that resulted from the incident;

(viii) Cause of incident; and

(ix) Description of corrective action taken to prevent reoccurrence of the incident."

Site Emergency Organizations

\section{REQUREMENT SOURCE: DOE-RL-91-28 Appendix 7A, Section 7.6}

"The Hanford Facility has fire and patrol personnel trained and equipped to respond in emergency situations. The Hanford Fire Department is the Hazardous Materials Incident Command Agency for the Hanford Site and has a Hazardous Materials Response Team that is trained to stabilize and control hazardous materials emergencies. A description of equipment for hazardous materials responses available through the Hazardous Materials Response Team is given in Table 3. Locations of the four fire stations on the Hanford Facility are shown on Figure 1.

The Hanford Patrol provides support to the Hanford Fire Department during an incident, including such activities as activation of area crash alarm telephone systems or area sirens (for 
Westinghouse Hanford Company (WHC)

Standards/Requirements Identification Document

12.0 Fire Protection
WHC-SD-MP-SRID-002

January 10, 1996

Rev. 0

Page 20 of 27 $\underline{12.5 .2 .2}$

$\underline{12.5 .2 .3}$

evacuation or take cover), access control, traffic control, and assistance in emergency notifications."

Mutual Aid

Author's Note: Mutual Aid is addressed by subelement 12.5.1 (RLID5480.7, Section 6.3)

Medical Response

\section{REQUIREMENT SOURCE: DOE5480.8A Section 11.f}

"Emergency and Disaster Preparedness.

(1) Integrated Emergency and Disaster Preparedness Planning. The Site Occupational Medical Director is responsible for the development of the medical portion of the site emergency and disaster plan. This input shall be closely integrated with, and made a part of, the overall site emergency and disaster preparedness plan in accordance with DOE 5500.1B. It will require coordination and cooperation with management, emergency preparedness coordinators, safety, health physics, the industrial hygiene, fire and rescue units, security organizations, and offsite medical facilities.

(2) Integration with Community Emergency and Disaster Plans. The occupational medical portion of the site emergency and disaster plan shall also be integrated with surrounding community emergency and disaster plans to the extent consistent with the development of a mutual aid and assistance capability.

(3) Preplanning Requirements.

(a) The medical portion of the site emergency and disaster response capability shall be adequate to meet the type and severity of accidents and trauma dictated by the character and history of plant operations and conditions.

(b) Preplanning and prearrangements are key factors vital to the effectiveness of the medical portion of the site emergency and disaster plan and shall provide the following:

1 Onsite capabilities for medical aid and triage, and personnel decontamination by trained, qualified personnel which shall include onsite capability for cardiopulmonary resuscitation, cardiac defibrillation and advanced cardiac life support;

2 Services of health physicists and industrial hygienists to evaluate any associated radiological or chemical hazards affecting the environment, the casualties, or the general public, and to assist rescue and medical personnel;

3 Arrangements for hospital care shall include the capability to evaluate and treat injuries resulting from exposure to radiation and/or toxic materials, including internal and external contamination, as appropriate;

4 Services of medical specialists and consultants;

5 Services of rescue squads, ambulances (ambulance personnel shall meet the U.S. Department of Transportation guides or State requirements), and helicopters, as needed, with capability for handling radioactively contaminated casualties; 
Westinghouse Hanford Company (WHC) Standards/Requirements Identification Document

12.0 Fire Protection
WHC-SD-MP-SRID-002

January 10, 1996

Rev. 0

Page 21 of 27

6 Medical aid coverage during evacuation operations from facilities and the site; and

7 Communication links between medical aid and triage teams, fire and rescue units, hospitals and hospital teams, local and State police, and DOE Emergency Operating Center."

12.6

12.6 .1

12.6.1.1

\section{ASSESSMIENT}

Fire Protection Investigation and Reporting

\section{REQUTREMENT SOURCE: RLI5480.7 Section 8. 8}

"Fire investigations and reports shall be performed and prepared, in accordance with DOE 5000.3B and DOE 5485.1."

Design Assessment

\section{REQUTREMENT SOURCE: DOE5480.7A Section 9.a.(2)}

Author's Note: Frequencies determined by the AHJ are found in element 12.1, Management and Administration, Requirement Source RLID 5480.7, Section 6.2.d.

Author's Note:

Headquarters requirements are not applicable to contractor. Contractors/Facility Managers:

bullets $1-3$ and 5 apply to facility;

$\sim$ bullets 4 and 5 apply 10 company.

Program-Related applies to both company and facility levels.

- bullets 1, 3-6 apply to the company;

bullets 2.4 and 7-8 apply to the facility.

Facility-Related applies to facility-level.

Combined Aspects (Program \& Facility) applies to both company and facility levels.

( bullets 1-3 apply to the company;

- bullets 3-7 apply to the facility.

"Assessments. Documented evaluations of the fire protection program, including field walkdowns of facilities, shall be performed as follows:

(a) Facilities/contractors shall be assessed to establish that they conform with DOE fire protection criteria.

(b) Minimum Frequency

Headquarters:

— PSO assessment of fieid offices 3 years 
- EH assessment of program offices

Field Office:

- Field office assessment of the fire protection program of each contractor
3 years

2 years

Contractors/Facility Managers:

- Annual fire protection assessments shall be made of facilities valued in excess of $\$ 50$ million; where considered to be a moderate (Category 2 Hazard) or high hazard (Category 1 Hazard) as defined in DOE 5481.1B, SAFETY ANALYSIS AND REVIEW SYSTEM, for nonnuclear facilities and in DOE 5480.23, NUCLEAR SAFETY ANALYSIS REPORTS, for nuclear facilities; or in which vital programs are involved.

- Fire protection assessments shall be made at least every two years of facilities plus equipment valued at $\$ 10$ million to $\$ 50$ million.

- Remaining facilities shall be assessed at least every three years or at frequencies determined by the AHJ.

- Comprehensive assessments of fire protection program elements shall be made every two years.

- Copies of the two most recent assessment reports shall be kept on file.

(c) Nature and Scope - Assessments shall include an evaluation of the following elements of the fire protection program:

Program-Related:

- Comprehensiveness of the fire protection program.

- Procedures for engineering design and review.

- Procedures for maintenance, testing and inspection.

- Fire protection engineering staff (number, qualifications, training).

- Fire suppression organization (personnel and training).

- Fire suppression mutual aid agreements.

- Management support.

- Exemptions and documented equivalencies.

Facility-Related:

- Fire protection of safety class equipment.

- Life safety considerations.

- Fire protection of vital programs.

- Fire protection of high value property.

- Fire suppression equipment.

- Water runoff.

- Pre-fire plans.

- Fire apparatus accessibility.

- Completeness of fire hazards analyses.

- Fire barrier integrity.

- Completeness of fire loss potential (MPFL/MCFL) determinations.

- Fire safety training. 
Westinghouse Hanford Company (WHC)

Standards/Requirements Identification Document

12.0 Fire Protection
WHC-SD-MP-SRID-002

January 10, 1996

Rev. 0

Page 23 of 27

Combined Aspects (Program \& Facility):

- Inspection, testing, and maintenance reports.

- Adequacy of facility appraisal reports.

- Tests of fire suppression systems, water supplies, and procedures for maintaining these in working order.

- Administrative controls.

- Temporary protection and compensatory measures.

- Status of findings from previous assessments.

- Conformance with applicable Orders, codes and standards."

12.6 .1 .2

Inspection. Testing and Maintenance

\section{REQUIREMENT SOURCE: DOE5480.7A Section 9.b.(5)}

"Testing and Maintenance - Fire protection systems shall be tested and maintained in accordance with the applicable NFPA standards and as supplemented by criteria in the DOE Fire Protection Resource Manual."

12.6.2 Control of Fire Protection Impairments

\section{REQUIREMENT SOURCE: DOE5480.7A Section 9.b.(16)}

"Impairment Control - A fire protection system impairment program shall be provided for control of operation and tracking of impairments during periods when fire protection systems are out of service."

\section{REQUIREMENT SOURCE: RLID5480.7 Section 8. 6}

"The Fire Protection Program must include a fire protection system impairment strategy to minimize the duration and impact of fire protection system impairments. Elements of the fire protection impairment strategy must provide that:

a. Fire protection system impairments are identified, assigned priority, and promptly corrected in a reasonable amount of time.

b. A documented impairment program is administrated by trained personnel.

c. Fire protection staff and fire department personnel are advised and updated on impairments.

d. A policy is established for immediate and expedient repair of impairments.

e. Compensatory measures are implemented until the impaired system is restored."

\section{KEY INTERFACES}

The implementation and administration of a Fire Protection Program requires the identification of the interfaces with other functional areas. These interfaces are defined such that applicable requirements are defined and controlled in the appropriate functional area and are not repeated in any other functional area. 
Specific interface boundaries between the Hanford Fire Department (HFD) and other functional areas are defined in the following sections:

$\underline{12.7 .1}$

12.7 .2

$\underline{12.7 .3}$

12.7 .4

$\underline{12.7 .5}$

$\underline{12.7 .6}$

$\underline{12.7 .7}$

\section{Safequards and Security}

Key interfaces with WHC Safeguards and Security organization are necessary for successful completion of emergencies responses by HFD. This to include control of traffic and persons near the emergency site, securing the area for purposes of investigation and preservation of evidence. Safeguards and Security provides emergency dispatch services to HFD for all calls except box alarms.

\section{Radiation Protection}

Key interfaces with Radiation Protection are vital to the protection of HFD personnel when responding to emergencies where radiation is present or could be present. Coordinated support to provided both onsite and offsite for monitoring and hazard assessment.

\section{Training and Oualification}

Key interfaces with Training and Qualification are necessary for technical support of HFD activities, both emergency and non-emergency such as: tacking of specialized training for haz mat personnel; delivery of training for rad workers; and coordination of required WHC training courses for managers, safety, and workers.

\section{Environmental Protection}

Key interfaces with Environmental Protection are necessary to continue compliance with the RCRA Permit for the Hanford Site as HFD completes all inspections as required by the permit and provides resources as listed in the permit application.

\section{Emergency Management}

Key interfaces with Emergency Management are necessary for HFD involvement in site-wide drills and exercises and during periods when emergencies occur by support HFD Incident Command system and interfacing with Event Scene Command (BED) in a coordinated manner.

Specific interface boundaries between the Fire Protection Programs organization are defined in the following section:

Key interfaces with EM are not required to support the activities of the Fire Protection Programs group.

\section{Fire Protection Propram}

Key interfaces with Fire Protection Programs are necessary to ensure design features needed to mitigate fire hazards are incorporated into design and installation work done on Site as a part of fire engineering, fire protection, and fire prevention.

\section{Construction}

Key interfaces with Construction are necessary to maintain Codes and Standards compliance for a new and remodeled facilities related to fire prevention and fire protection services, water supplies, and installed fire protection systems and equipment. 
Westinghouse Hanford Company (WHC)

Standards/Requirements Identification Document

WHC-SD-MP-SRID-002

January 10, 1996

Rev. 0

12.0 Fire Protection

Page 25 of 27

$\underline{12.7 .8}$

$\underline{12.7 .9}$

$\underline{12.7 .10}$

$\underline{12.7 .11}$

$\underline{12.7 .12}$

Occupational Safety and Health

Key interfaces with Waste Management are necessary for control of hazardous materials or processes, inspection, maintenance and testing of fire protection systems, and performance of required fire prevention inspections under the RCRA requirements. Provides hazardous emergency response support as required.

Key interfaces with Operations are necessary to provide HFD support services for Acceptance Test Procedures (ATP's) on installed fire protection systems, Pre-Fire Plans, Fire Department Access, and other fire and life safety from fire requirements.

Specific interface boundaries between the Fire Protection Programs organization are defined in the following section:

Key interfaces between fire protection and Operations occur predominantly at the facility level. Operations supports Fire Protection Programs in the development of fire hazards analyses.

\section{Waste Manaqement}

\section{Nuclear Safety}

Key interfaces with Nuclear Safety are necessary due to the possibility of emergency situations involving radioactive materials either in storage, process, or transportation on-site or off-site.

Specific interface boundaries between the Fire Protection Programs organization are defined in the following section:

The Nuclear Safety functional area supports the Fire Protection Programs functional area in the development of fire hazards analyses.

Key interfaces with Occupational Safety and Health are necessary to ensure compliance with Fire Prevention and Protection Codes and Standards in effect on the Site.

Specific interface boundaries between the Fire Protection Programs organization are defined in the following section:

This functional area interfaces with the Fire Protection Programs group to ensure that the appropriate OSHA fire protection requirements are implemented in to site programs.

\subsubsection{Configuration Management}

Specific interface boundaries between the Fire Protection Programs organization are defined in the following section: 
Configuration Management provides the procedures and processes for generating, storing, and retrieving the documents that are required by the fire protection program. \\ Engincering Proqram}

12.8

\section{$\underline{12.8 .1}$}

Specific interface boundaries between the Fire Protection Programs organization are defined in the following section:

Key interfaces between fire protection and engineering occur predominantly at the facility level. Engineering Programs supports Fire Protection Programs in the development of fire hazards analyses.

\section{REFERENCES}

\section{Requirement Source Documents}

The following documents were used as requirement sources in the development of this S/RID:

29 CFR 1926, Code of Federal Regulations, 7-1-92

29 CFR 1910, Occupational Safety and Health Standards

RCW Chapter 70.136, Hazardous Materials Incidents, 10-19-90

WAC-173-303, Dangerous Waste Regulations, 12-8-93

WAC-296-305, Safety Standards for Fire Fighters, 10-1-94

WAC-246-976, Ground Ambulance and Aid Services, 12-23-91

DOE ORDER 5480.7A, Fire Protection, 2-17-93

DOE ORDER 5480.8A, Contractor Occupational Medical Program, 6-26-92

DOE ORDER 5500.3A, Planning and Preparedness for Operational Emergencies, 4-30-91

DOE ORDER 6430.1A, General Design Criteria, 4-6-89

DOE/RL-91-28 Rev 1, Hanford Facility Dangerous Waste Permit Application, General Information, Appendix 7A, Hanford Facility Contingency Plan, May 93

RLID 5480.7, Fire Protection, 1-17-94

\section{Reviewed Documents Not Used as Requirement Sources}

The following documents were reviewed as requirement sources but were not used in the development of this S/RID:

40 CFR 300, Emergency Planning, and Community Right-To-Know Programs

NFPA CODES AND STANDARDS

Uniform Fire Code 
Uniform Building Code

DOE ORDER 5480.4, Environmental Protection, Safety, and Health Protection Standards, 1-7-93

DOE ORDER 5480.11, Radiation Protection for Occupational Workers, 12-21-88

DOE ORDER 5480.19, Conduct of Operations Requirements For DOE Facilities, 5-18-92

DOE ORDER 5700.6C, Quality Assurance, 8-21-91

DOE ORDER EV-0043, Standard On Fire Protection For Portable Structures, 8-79

DOE ORDER EHO 135 Performance Objectives and Criteria For Technical Safety Appraisals at Department of Energy Facilities and Sites, 6-90

DOE Letter 59000-91-024, dated 1-14-88, Subject: Hazardous Materials Incident Command Agency Designation

DOE Letter 9301108, dated 1-21-93, Subject: Role of the Hanford Fire Department and Contractor Responsibility To Report Fires, Hazardous Material Spills, Emergency Medical, Ambulance and Emergency Rescue Needs

DOE Letter 91011418, dated 3-12-91, Subject: Fire Prevention Program

DOE-RL Letter 9101408, dated 3-14-91, Subject: Fire Protection Program Management DOE-RL Letter 8903462, dated 8-18-89, Subject: Fire Protection System Inspection, Testing, and Maintenance Requirements

DOE ORDER EP/0108, Standard For Fire Protection Of AEC Electronic Computer Data Processing Systems, 1-84 
This page intentionally left blenk. 


\section{WESTINGHOUSE HANFORD COMPANY}

\section{STANDARDS}

\section{REQUIREMENTS}

\section{IDENTIFICATION}

\section{DOCUMENT}

\section{FUNCTIONAL AREA}

Environmental Restoration

NOT APPLICABLE

REVISION 0 
This page intentionally left blank. 
Westinghouse Hanford Company (WHC)

Standards/Requirements Identification Document

14.0 Environmental Restoration
WHC-SD-MP-SRID-002

January 10, 1996

Rev. 0

Page $i$ of $i$

\section{TABLE OF CONTENTS}

14.0 ENVIRONMENTAL RESTORATION $\ldots \ldots \ldots \ldots \ldots \ldots \ldots \ldots \ldots \ldots \ldots \ldots \ldots \ldots$ 
This page intentionally left blank. 
TABLE OF CONTENTS

13.0 PACKAGING AND TRANSPORTATION $\ldots \ldots \ldots \ldots \ldots \ldots \ldots \ldots \ldots \ldots \ldots$

13.1

13.2

MANAGEMENT AND ADMINISTRATION $\ldots \ldots \ldots \ldots \ldots \ldots$

PACKAGING AND TRANSPORTATION OPERATIONS $\ldots \ldots \ldots \ldots 3$

13.2 .1

13.2.1.1

13.2.1.2

13.2 .1 .3

13.2 .2

13.2 .3

13.2.3.1

13.2.3.2

13.2.3.3

13.2 .3 .4

13.2.3.5

13.2 .4

13.2 .5

13.2.5.1

13.2.5.2

13.2.5.3

13.2 .6

13.2.6.1

13.2.6.2

13.2.6.3

13.2.7

13.2.7.1

13.2.7.2

13.2 .8

13.2 .9

13.2.9.1

13.2.9.2

13.2.10

13.2.11

Packaging $\ldots \ldots \ldots \ldots \ldots \ldots \ldots \ldots \ldots \ldots \ldots$

Radioactive Materials ............... 10

NRC Certified Packaging . . . . . . . . . . . 28

Hazardous Materials . . . . . . . . . . . . . 29

Coordination and Planning of Base Technology . . . . . . . 32

Vehicle and Equipment Control and Maintenance . . . . . . . 32

Exclusive Use Vehicles . . . . . . . . . . . . . . . 32

Commercial Motor Vehicles . . . . . . . . . . . . . 33

Vehicle Inspection, Repair, and Maintenance . . . . . . . 34

Inspector Qualifications and Records . . . . . . . . . . 35

IM Portable Tanks . . . . . . . . . . . . . 35

Onsite Material Tracking $\ldots \ldots \ldots \ldots \ldots \ldots \ldots$

Offsite Transportation Management . . . . . . . . . . . . . 36

Licensing and Registration $\ldots \ldots \ldots \ldots \ldots, \ldots$

Import/Export Shipments . . . . . . . . . . . . . 37

Hazardous Waste/Materials Transport . . . . . . . . 40

Marking, Labeling and Placarding $\ldots \ldots \ldots \ldots \ldots$. . . . 42

Marking Requirements . . . . . . . . . . . 42

Labeling Requirements . . . . . . . . . . . . . . . 43

Placarding Requirements $\ldots \ldots \ldots \ldots \ldots \ldots, 44$

Shipping Papers, Bills of Lading and Manifests . . . . . . . 45

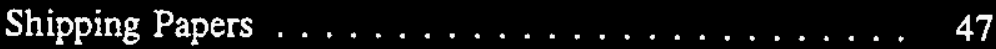

Shipment Records ................. 50

Shipment Plans $\ldots \ldots \ldots \ldots \ldots \ldots \ldots \ldots \ldots \ldots$. 51

Notification of State Authorities of Shipments of High-Hazard

Materials . . . . . . . . . . . . . . . . 51

State Routing Requirements/Notifications . . . . . . . 51

Consignee Notifications $\ldots \ldots \ldots \ldots \ldots \ldots \ldots, 52$

Emergency Response Information . . . . . . . . . . . . . . 53

Receipt Inspection $\ldots \ldots \ldots \ldots \ldots \ldots \ldots \ldots \ldots \ldots$ 
Equipment Inspection $\ldots \ldots \ldots \ldots \ldots \ldots \ldots \ldots \ldots, 57$

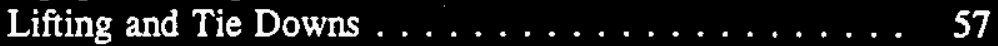

Weight Limitations $\ldots \ldots \ldots \ldots \ldots \ldots \ldots \ldots, 57$

13.3.1

13.3 .2

13.3 .3

13.3 .4

13.3 .5

13.4

13.4.1

13.4 .2

13.4 .3

13.4 .4

13.5

13.5 .1

13.5 .2

13.5 .3

13.5 .4

13.6

Package Standards and Certifications . . . . . . . . . . 58

Safety Analysis . . . . . . . . . . . . . . . . 60

Design, Fabrication, Assembly and Testing QA for OffSite

Shipping Containers $\ldots \ldots \ldots \ldots \ldots \ldots \ldots \ldots \ldots$

QA Testing $\ldots \ldots \ldots \ldots \ldots \ldots \ldots \ldots \ldots \ldots$

Physical Protection for Security . . . . . . . . . . . . 62

Nuclear Explosives, Components, and Assemblies . . . . . 62

ONSITE SAFETY $\ldots \ldots \ldots \ldots \ldots \ldots \ldots \ldots \ldots \ldots \ldots \ldots$

Coordination of Material Transfers . . . . . . . . . . 63

Safety Analyses . . . . . . . . . . . . . . 63

Requirements for Potentially Explosive and Hazardous

Materials . . . . . . . . . . . . . . . . 63

Personnel Protection During Movement of Hazardous

Materials . . . . . . . . . . . . . . . 63

KEY INTERFACES $\ldots \ldots \ldots \ldots \ldots \ldots \ldots \ldots \ldots \ldots \ldots$

Training and Qualification $\ldots \ldots \ldots \ldots \ldots \ldots \ldots$

Safeguards and Security $\ldots \ldots \ldots \ldots \ldots \ldots \ldots \ldots \ldots$

Nuclear Safety . . . . . . . . . . . . . . . . 63

Emergency Management $\ldots \ldots \ldots \ldots \ldots \ldots \ldots, 63$

REFERENCES $\ldots \ldots \ldots \ldots \ldots \ldots \ldots \ldots \ldots \ldots \ldots \ldots$

13.6.1

13.6 .2

Requirement Source Documents . . . . . . . . . . . . . 63

Reviewed Documents Not Used as Requirement Sources . . . . 64 


\subsection{PACKAGING AND TRANSPORTATION}

\section{INTRODUCTION}

A Standards/Requirements Identification Document (S/RID) sets forth the Environmental Safety and Health (ES\&H) standards/requirements. This S/RID is applicable to the appropriate life cycle phases of design, construction, operation, and decommissioning for each of the categories of facilities addressed in Revision 5 of the Department of Energy Implementation Plan for the Defense Nuclear Facilities Safety Board (DNFSB) Recommendation 90-2. This Recommendation calls for the strengthening of DOE weapons complex activities through the identification and application of relevant DOE Orders, regulations, industry codes/standards, industry guidance documents and, as appropriate, good industry practices. These standards/requirements are adequate to ensure protection of the health and safety of workers, the public, and the environment.

The Westinghouse Hanford Company S/RID, as defined in Revision 5 of the Department of Energy Implementation Plan for DNFSB Recommendation 90-2, contains standards/requirements applicable company-wide that are necessary for safe operation of the site and its associated facilities, and that are not the direct responsibility of a specific facility manager (e.g., a company-wide fire department). Facility S/RIDs contain standards/requirements applicable to a specific facility that are the direct responsibility of the facility manager.

This Standards/Requirements Identification Document (S/RID) defines the Westinghouse Hanford Company (WHC) Packaging and Transportation program in place at Hanford. The Packaging and Transportation program defined in this document is described in general accordance with the (ES\&H) Configuration Guide, Revision 0, dated July 30,1993, and is presented in the form of program elements and subelements. The specific DOE Orders, regulations, industry codes/standards, guidance documents and good industry practices which serve as the basis for each element/subelement are identified and aligned with each subelement.

It is intended that this document be used as a baseline from which to compare the existing P\&T Program at the Westinghouse Hanford Company (WHC) for determination of the level of program definition and maturity including the existence of an overall site infrastructure and clearly defined interfaces with other relevant functional areas. Additionally, this S/RID may be used as the basis against which future program definition and improvement efforts, including procedures development and/or revisions, can be compared to ensure consistency, completeness and proper integration with other functional programs.

SCOPE

This S/RID applies to all of the onsite and offsite P\&T activities associated with WHC.

The Packaging and Transportation Functional Area includes program elements that are necessary to assure that operations at DOE facilities are conducted safely, effectively, and in accordance with specified Federal regulations, DOE Orders, selected industry codes, standards, and guidelines. 
Additionally, some requirements contained in this document were intentionally duplicated in facility S/RIDs. This was necessary to adequately address implementation responsibilities at both the company and facility levels. The scope of the Packaging and Transportation Functional Area encompasses the programmatic controls for activities associated with onsite and offsite packaging and transportation of hazardous and radioactive materials and waste. The basis for selecting the requirements applicable to WHC is described in the following key points:

- Offsite shipments consist of both bulk and non-bulk packagings of hazardous and radioactive materials, as well as hazardous waste, dangerous waste, and low-level radioactive and TRU waste.

- Offsite radioactive shipments consist of limited quantity, low specific activity, and Type A and B quantities of radioactive material, as well as fissile classed, normal form, and special form materials.

- Offsite shipments are made by highway, rail, air, and vessel. Offsite shipment campaigns by vessel are made in accordance with a DOE-approved shipping plan.

- Onsite shipments/movements consist of essentially the same materials as for offsite shipments. Onsite rail shipments are in DOE-owned rail cars, which are maintained by a WHC subcontractor.

- Onsite shipments are not directly regulated by federal or state agencies. However, for onsite shipments, WHC has adopted federal and state requirements where appropriate, and has established equivalent safety standards where it is not feasible to comply with DOT regulations onsite.

- Maintenance of the vehicle fleet and driver qualifications/files are the responsibility of a WHC subcontractor, with oversight provided by the Transportation and Packaging Organization. Drug testing and physical examinations for drivers of commercial motor vehicles are performed by Hanford Environmental Health Foundation (HEHF), a DOE contractor. 
Author's Note: Requirements for this element are addressed in the Quality Assurance functional area.

\section{$\underline{13.2 .1}$}

PACKAGING AND TRANSPORTATION OPERATIONS

\section{Packaging}

\section{REQUIREMENT SOURCE: 10CFR71 Part 85}

"Preliminary determinations. Prior to the first use of any packaging for the shipment of licensed material:

(a) The licensee shall ascertain that there are no cracks, pinholes, uncontrolled voids, or other defects which could significantly reduce the effectiveness of the packaging;

(b) Where the maximum normal operating pressure will exceed 34.3 kilopascal (5 psi) gauge, the licensee shall test the containment system at an internal pressure at least $50 \%$ higher than the maximum normal operating pressure to verify the capability of that system to maintain its structural integrity at that pressure.

(c) The licensee shall conspicuously and durably mark the packaging with its model number, gross weight, and a package identification number assigned by the Nuclear Regulatory Commission. Prior to applying the model number, the licensee shall determine that the packaging has been fabricated in accordance with the design approved by the Commission."

\section{REQUIREMENT SOURCE: 10CFR71 Part 87}

"Routine determinations. Prior to each shipment of licensed material, the licensee shall ensure that the package with its contents satisfies the applicable requirements of this part and of the license. The licensee shall determine that:

(a) The package is proper for the contents to be shipped;

(b) The package is in unimpaired physical condition except for superficial defects such as marks or dents;

(c) Each closure device of the packaging, including any required gasket, is properiy installed and secured and free of defects;

(d) Any system for containing liquid is adequately sealed and has adequate space or other specified provision for expansion of the liquid;

(e) Any pressure relief device is operable and set in accordance with written procedures;

(f) The package has been loaded and ciosed in accordance with written procedures;

(g) For fissile material, any moderator or neutron absorber, if required, is present and in proper condition; 
(b) Any structural part of the package which could be used to lift or tie down the package during transport is rendered inoperable for that purpose unless it satisfies the design requirements of 71.45 ;

(i)(1) The level of non-fixed (removable) radioactive contamination on the external surfaces of each package offered for shipment is as low as reasonably achievable. The level of non-fixed radioactive contamination may be determined by wiping an area of 300 square centimeters of the surface concerned with an absorbent material, using moderate pressure, and measuring the activity on the wiping material. Sufficient measurements must be taken in the most appropriate locations to yield a representative assessment of the non-fixed contamination levels. Except as provided under paragraph (i)(2) of this section, the amount of radioactivity measured on any single wiping material when averaged over the surface wiped, must not exceed the limits given in Table $\mathrm{V}$ of this part at any time during transport. Other methods of assessment of equal or greater efficiency may be used. When other methods are used, the detection efficiency of the method used must be taken into account and in no case may the non-fixed contamination on the external surfaces of the package exceed ten times the limits listed in Table V."

\section{REQUIREMENT SOURCE: 49CFR173 Part 24}

"(a) Applicability. Except as otherwise provided in this subchapter, the provisions of this section apply to-

(1) Bulk and non-bulk packagings;

(2) New packagings and packagings which are reused; and

(3) Specification and non-specification packagings.

(b) Each package used for the shipment of hazardous materials under this subchapter shall be designed, constructed, maintained, filled, its contents so limited, and closed, so that under conditions normally incident to transportation-

(1) Except as otherwise provided in this subchapter, there will be no identifiable (without the use of instruments) release of hazardous materials to the environment;

(2) The effectiveness of the package will not be substantially reduced; for example, impact resistance, strength, packaging compatibility, etc. must be maintained for the minimum and maximum temperatures encountered during transportation;

(3) There will be no mixture of gases or vapors in the package which could, through any credible spontaneous increase of heat or pressure, significantly reduce the effectiveness of the packaging.

(c) Authorized packagings. A packaging is authorized for a hazardous material only if-

(1) The packaging is prescribed or permitted for the hazardous material in a packaging section specified for that material in Column 8 of the 172.101 Table and conforms to applicable requirements in the special provisions of Column 7 of the 172.101 Table and, for specification packagings (including U.N. standard packagings), the specification requirements in parts 178 and 179 of this subchapter; or

(2) The packaging is permitted under, and conforms to, provisions contained in 171.11, $171.12,171.12 \mathrm{a}, 173.3,173.4,173.5,173.7,173.27$, or 176.11 of this subchapter. 
(d) DOT specification and U.N. standard packagings. For DOT specification packagings (including U.N. standard packagings), conformance to the applicable specifications in parts 178 and 179 of this subchapter is required in all details. For performance-oriented packagings covered by subpart $L$ of part 178 of this subchapter, each packaging must be capable of meeting the performance test requirements specified in subpart $M$ of part 178 of this subchapter for the applicable packing group shown in Column 5 of the 172.101 Table.

(e) Compatibility.

(1) Even though certain packagings are specified in this part, it is, nevertheless, the responsibility of the person offering a hazardous material for transportation to ensure that such packagings are compatible with their lading. This particularly applies to corrosivity, permeability, softening, premature aging and embrittlement.

(2) Packaging materiais and contents must be such that there will be no significant chemical or galvanic reaction between the materials and contents of the package.

(3) Plastic packagings and receptacles.

(i) Plastic used in packagings and receptacles must be of a type compatible with the lading and may not be permeable to an extent that a hazardous condition is likely to occur during transportation, handling or refilling.

(ii) Each plastic packaging or receptacle which is used for líquid hazardous materials must be capable of withstanding without failure the procedure specified in appendix B of this part ("Procedure for Testing Chemical Compatibility and Rate of Permeation in Plastic Packagings and Receptacles"). The procedure specified in appendix B of this part must be performed on each plastic packaging or receptacie used for Packing Group I materials. The maximum rate of permeation of hazardous lading through or into the plastic packaging or receptacles may not exceed 0.5 percent for materiais meeting the definition of a Division 6.1 material according to 173.132 and 2.0 percent for other hazardous materials, when subjected to a temperature no lower than-

(A) $18^{\circ} \mathrm{C}\left(64^{\circ} \mathrm{F}\right)$ for 180 days in accordance with Test Method 1 in appendix B of this part;

(B) $50^{\circ} \mathrm{C}\left(122^{\circ} \mathrm{F}\right)$ for 28 days in accordance with Test Method 2 in appendix B of this part; or

(C) $60^{\circ} \mathrm{C}\left(140^{\circ} \mathrm{F}\right)$ for 14 days in accordance with Test Method 3 in appendix B of this part.

(iii) Alternative procedures or rates of permeation are permitted if they yield a level of safety equivalent to or greater than that provided by paragraph (e)(3)(ii) of this section and are specifically approved by the Associate Administrator for Hazardous Materials Safety.

(4) Mixed contents. Hazardous materials may not be packed or mixed together in the same outer packaging with other hazardous or nonhazardous materials if such materials are capable of reacting dangerously with each other and causing-

(i) Combustion or dangerous evolution of heat;

(ii) Evolution of flammable or poisonous gases; or

(iii) Formation of unstable or corrosive materials. 
(5) Packagings used for solids, which may become liquid at temperatures likely to be encountered during transportation, must be capable of containing the hazardous material in the liquid state.

(f) Closures.

(1) Closures on packagings shall be so designed and closed that under conditions (including the effects of temperature and vibration) normally incident to transportation-

(i) Except as provided in paragraph ( $\mathrm{g}$ ) of this section, there is no identifiable release of hazardous materiais to the environment from the opening to which the closure is applied; and

(ii) The closure is secure and leakproof.

(2) Except as otherwise provided in this subchapter, a closure (including gaskets or other closure components, if any) used on a specification packaging must conform to all applicable requirements of the specification.

(g) Venting. Venting of packagings, to reduce internal pressure which may develop by the evolution of gas from the contents, is permitted only when-

(1) Transportation by aircraft is not jnvolved;

(2) Except as otherwise provided in this subchapter, the evolved gases are not poisonous, likely to create a flammable mixture with air or be an asphyxiant under normal conditions of transportation;

(3) The packaging is designed so as to preclude an unintentional release of hazardous materials from the receptacle; and

(4) For shipments in bulk packagings, venting is authorized for the specific hazardous material by a special provision in the 172.101 Table or by the applicable bulk packaging specification in part 178 of this subchapter.

(h) Outage and filling limits-

(1) General. When filling packagings and receptacles for liquids, sufficient ullage (outage) must be left to ensure that neither leakage nor permanent distortion of the packaging or receptacle will occur as a result of an expansion of the liquid caused by temperatures likely to be encountered during transportation: Requirements for outage and filling limits for non-bulk and bulk packagings are specified in $173.24 \mathrm{a}(\mathrm{d})$ and $173.24 \mathrm{~b}(\mathrm{a})$, respectively.

(2) Compressed gases and cryogenic liquids. Filling limits for compressed gases and cryogenic liquids are specified in 173.301 through 173.306 for cylinders and 173.314 through 173.319 for bulk packagings.

(i) Air transportation. Packages offered or intended for transportation by aircraft must conform to the general requirements for transportation by aircraft in 173.27, except as provided in $\mathbf{1 7 1 . 1 1}$ of this subchapter." 


\section{REQUIREMIENT SOURCE: 49CFR173 Part 27}

"General requirements for transportation by aircraft.

(a) The requirements of this section are in addition to the requirements in 173.24 and apply to packages offered or intended for transportation aboard aircraft. Notwithstanding any Packing Group III performance level specified in Column 5 of the 172.101 Table, the required performance level for packages containing Class 4, 5, or 8 materials, when offered or intended for transportation aboard aircraft, is at the Packing Group II performance level, unless otherwise excepted from performance requirements in subpart $\mathrm{E}$ of this part.

(b) Packages authorized on board aircraft.

(1) When Column 9a of the 172.101 Table indicates that a material is "Forbidden", that material may not be offered for transportation or transported aboard passenger-carrying aircraft.

(2) When Column 9b of the 172.101 Table indicates that a material is "Forbidden", that material may not be offered for transportation or transported aboard aircraft.

(3) The maximum quantity of hazardous material in a package that may be offered for transportation or transported aboard a passenger-carrying aircraft or cargo aircraft may not exceed that quantity prescribed for the material in Column $9 \mathrm{a}$ or $9 \mathrm{~b}$, respectively, of the 172.101 Table.

(4) A package containing a hazardous material which is authorized aboard cargo aircraft but not aboard passenger aircraft must be labeled with the CARGO AIRCRAFT ONLY label required by 172.402 (b) of this subchapter and may not be offered for transportation or transported aboard passenger-carrying aircraft.

(c) Pressure requirements.

(1) Packagings must be designed and constructed to prevent leakage that may be caused by changes in altitude and temperature during transportation aboard aircraft.

(2) Packagings for which retention of liquid is a basic function must be capable of withstanding without leakage the greater of-

(i) An internal pressure which produces a gauge pressure of not less than $75 \mathrm{kPa}(11 \mathrm{psi})$ for liquids in Packing Group III of Class 3 or Division 6.1 . or $95 \mathrm{kPa}$ (14 psi) for other liquids; or

(ii) A pressure related to the vapor pressure of the liquid to be conveyed, determined by one of the following:

(A) The total gauge pressure measured in the receptacle (i.e., the vapor pressure of the material and the partial pressure of air or other inert gases, less $100 \mathrm{kPa}$ (15 psi)) at $55 \mathrm{C}$ (131 F), multiplied by a safety factor of 1.5 ; determined on the basis of a filling temperature of 15 $\mathrm{C}(59 \mathrm{~F})$ and a degree of filling such that the receptacle is not completely liquid full at a temperature of $55 \mathrm{C}(131 \mathrm{~F})$ or less;

(B) 1.75 times the vapor pressure at $50 \mathrm{C}(122 \mathrm{~F})$ less $100 \mathrm{kPa}(15 \mathrm{psi})$; or

(C) 1.5 times the vapor pressure at $55 \mathrm{C}$ (131) less $100 \mathrm{kPa}(15 \mathrm{psi})$. 
(3) Notwithstanding the provisions of paragraph (c)(2) of this section-

(i) Hazardous materials may be contained in an inner packaging which does not itself meet the pressure requirement provided that the inner packaging is packed within a supplementary packaging which does meet the pressure requirement and other applicable packaging requirements of this subchapter.

(ii) Packagings which are subject to the hydrostatic pressure test and marking requirements of 178.605 and 178.503 (a)(5), respectively, of this subchapter must have a marked test pressure of not less than $250 \mathrm{kPa}$ (36 psi) for liquids in Packing Group I, $80 \mathrm{kPa}$ (12 psi) for liquids in Packing Group III of Class 3 or Division 6.1 , and $100 \mathrm{kPa}$ (15 psi) for other liquids.

(d) Closures. Stoppers, corks or other such friction-type closures must be held securely, tightly and effectively in place by positive means. Each screw-type closure on any packaging must be secured to prevent closure from loosening due to vibration or substantial change in temperature.

(e) Absorbent materials. Except as otherwise provided in this subchapter, liquids in Packing Group I or II of Class 3, 4,5,6, or 8, when in glass or earthenware inner packagings, must be packaged using material capable of absorbing and not likely to react dangerously with the liquid. Absorbent material is not required if the inner packagings are so protected that breakage of them and leakage of their contents from the outer packaging is not likely to occur under normal conditions of transportation and is not required for packagings containing liquids in Packing Group II for transport aboard cargo aircraft only. Where absorbent material is required and an outer packaging is not liguid-tight, a means of containing the liquid in the event of leakage must be used in the form of a leakproof liner, plastic bag or other equally efficient means of containment. Where absorbent material is required, the quantity and disposition of it in each outer packaging must be as follows:

(1) For packagings containing liquids in Packing Group I offered for transportation or transported aboard passenger-carrying aircraft, each packaging must contain sufficient absorbent material to absorb the contents of all inner packagings containing such liquids;

(2) For packagings containing liquids in Packing Group I offered for transportation or transported aboard cargo aircraft only and packagings containing liguids in Packing Group II offered for transportation or transported aboard passenger aircraft, each package must contain sufficient absorbent material to absorb the contents of any one of the inner packagings containing such liquids and, where they are of different sizes and quantities, sufficient absorbent material to absorb the contents of the inner packaging containing the greatest quantity of liquid.

(f) Combination packagings. Unless otherwise specified in this part, or in 171.11 of this subchapter, when combination packagings are offered for transportation aboard aircraft, inner packagings must conform to the quantity limitations set forth in Table 1 of this paragraph for transport aboard passenger-carrying aircraft and Table 2 of this paragraph for transport aboard cargo aircraft only, as follows:

HAZDOCS-2 Table No. 27

HAZDOCS-2 Table No. 28

(g) Cylinders. For any cylinder containing hazardous materials and incorporating valves, sufficient protection must be provided to prevent operation of, and damage to, the valves during transportation, by one of the following methods: 
(1) By equipping each cylinder with securely attached valve caps or protective headings; or

(2) By boxing or crating the cylinder.

(h) Tank cars and cargo tanks. Any tank car or cargo tank containing a hazardous material may not be transported aboard aircraft."

\section{REQUIREMENT SOURCE: DANGEROUS-GOODS-REGU Section 5.0.2. 4}

"Packaging Quality: Dangerous goods must be packed in packagings of good quality which will withstand the conditions normal to transport by air. These packages must be constructed such that when properly packed and closed for shipments, they will not leak because of changes in temperature, humidity or pressure (for example, change in altitude) or because of vibration."

\section{REQUREMENT SOURCE: DOE1540.2 Chapter I, Section 3.a}

"DOE-Approved Packaging. Operations offices and DOE contractors may use any packaging whose design has been certified by DOE, provided the user shall:

(1) Possess a copy of the latest DOE Certificate of Compliance;

(2) Possess a copy of the SARP or at a minimum a copy of the drawings and operating and maintenance instructions for the specific packaging;

(3) Comply with all actions and restrictions specified in the documents described above;

(4) Ensure that the organization is registered as a user of the packaging with the Certifying Official; and

(5) Ensure that a quality assurance program is established to meet the requirements of the packaging. All contractors must be required to establish and maintain an appropriate quality assurance and maintenance program to ensure that DOE-certified packagings in use continue to meet the provisions of the certification and SARP."

\section{REQUTREMENT SOURCE: DOE5480.3 Section 7}

\section{"REQUIREMENTS.}

a. Federal Regulations. When offered to the carrier, each shipment of hazardous materials, hazardous substances, or hazardous wastes shall be in compliance with this Order and the applicable safery regulations of the Department of Transportation, and follow the applicable packaging standards of the Nuclear Regulatory Commission (10 CFR 71).

b. Special Packaging Requirements for Plutonium and Plutonium Bearing Wastes (in addition to other packaging requirements in this Order).

(1) Solid plutonium or plutonium bearing wastes in greater than A2 quantities for normal form or greater than A1 quantities for special form must be packaged in accordance with a specified DOE Certificate of Compliance, an NRC Certificate of Compliance, a DOE exempt packaging system, or a DOE Specification package.

(2) Plutonium (for air transport) in greater than A2 quantities for normal form or greater than A1 quantities for special form must be in DOE or NRC certified packaging (equivalent to, or 
meeting the criteria of NUREG-0360), e.g., USA/0361/BF, USA/9150/B(U) or USA $9509 / \mathrm{B}(\mathrm{U})$ (DOE-A1). The packaging approval shall autborize specifically the air transport of plutonium.

(3) Plutonium packaging requirements for any surface mode of transportation.

(a) Plutonium in excess of 20 curies per package must be shipped as a solid.

(b) Plutonium in excess of 20 curies per package must be packaged in a separate inner container placed within outer packaging that meets the requirements of a Type B package for material in normal form. In addition, the following tests must be performed on the package design:

1 If the entire package is subjected to the design tests specified in paragraph 11, "Normal Conditions of Transport, "the separate inner container must restrict the loss of plutonium to no more than 10-6 A2/hour.

2 If the entire package is subjected to the design tests specified in paragraph 12, "Hypothetical Accident Conditions, "the separate inner container must restrict the loss of plutonium to not more than an $\mathrm{A} 2$ quantity in 1 week.

(4) Solid plutonium in excess of 20 curies per package in the following forms is not subject to the requirements of paragraph $7 \mathrm{~b}(3)$ :

(a) Reactor fuel elements;

(b) Metal or metal alloy;

(c) Special Form materiais; or

(d) Other forms of plutonium-bearing materials, e.g., wastes or contaminated equipment, as approved by the office of Operational Safety."

Radioactive Materials

\section{REQUIREMENT SOURCE: 10CFR71 Part 47}

"External radiation standards for all packages. A package must be designed and prepared for shipment so that the radiation level does not exceed 200 millirem per hour at any point on the extemal surface of the package and the transport index does not exceed 10 (See 71.4 "Definitions"). For a package transported as exclusive use by rail, highway, or water, radiation levels external to the package may exceed those limits, but must not exceed any of the following:

(a) 200 millirem/hour on the accessibie external surface of the package unless the following conditions are met, in which case the limit is 1000 millirem per hour:

(1) The shipment is made in a closed transport vehicle;

(2) Provisions are made to secure the package so that its position within the vehicle remains fixed during transportation; and 
Westinghouse Hanford Company (WHC)

Standards/Requirements Identification Document

13.0 Packaging and Transportation
WHC-SD-MP-SRID-002

January 10, 1996

Rev. 0

Page 11 of 66

(3) There are no loading or unloading operations between the beginning and end of the transportation;

(b) 200 millirem/hour at any point on the outer surface of the vehicle, including the upper and lower surfaces, or, in the case of an open vehicle, at any point on the vertical planes projected from the outer edges of the vehicle, on the upper surface of the load, and on the lower external surface of the vehicle;

(c) 10 millirem/hour at any point two meters from the vertical planes represented by the outer lateral surfaces of the vehicle, or, in the case of an open vehicle, at any point two meters from the vertical planes projected from the outer edges of the conveyance; and

(d) Two millirem/hour in any normally occupied positions of the vehicle, except that this provision does not apply to private motor carriers when persons occupying these positions are provided with special health supervision, personnel radiation exposure monitoring devices, and training in accordance with 19.12 of this chapter."

\section{REQUIREMENT SOURCE: 10CFR71 Part 61(a)}

"Specific Standards for a Fissile Class II Shipment. A package for Fissile Class III shipment must be so designed and constructed and its contents so limited, and number of packages in a Fissile Class III shipment must be so limited, that:

Twice this number of undamaged packages would be subcritical if stacked together in any arrangement, assuming close reflection on all sides of the stack by water; and"

\section{REQUIREMENT SOURCE: 10CFR71 Part 61(b)}

"This number of packages would be subcritical if stacked together in any arrangement, closely reflected on all sides of the stack by water, and with optimum interspersed hydrogenous moderation. Except as permitted under 10 CFR 71.41, each package must be considered to have been subjected to the tests specified in 10 CFR 71.73 (Hypothetical Accident Conditions)."

\section{REQUREMENT SOURCE: 49CFR173 Part 413}

"Requirements for Type B packages.

Each Type $\mathrm{B}(\mathrm{U})$ or Type $\mathrm{B}(\mathrm{M})$ package must be designed and constructed to meet the applicable requirements in 10 CFR part 71."

\section{REQUIREMENT SOURCE: 49CFR173 Part 415}

"Authorized Type A packages.

The following packages are authorized for shipment, if they do not contain quantities exceeding $\mathrm{A} 1$ or $\mathrm{A} 2$ as appropriate:

(a) U.S. Department of Transportation (DOT) Specification 7A (178.350 of this subchapter) Type A general packaging. Each shipper of a Specification 7A package must maintain on file for at least one year after the latest shipment, and shall provide to DOT on request, a complete documentation of tests and an engineering evaluation or comparative data showing that the construction methods, packaging design, and materials of construction comply with that 
specification. Specification 7A packagings designed in accordance with the requirements of 178.350 in effect on June 30,1983 , and constructed prior to July 1, 1985, may continue to be used. Packagings either designed or constructed after June 30, 1985, must meet the requirements of 178.350 applicable at the time of their design or construction.

(b) DOT Specification 55 metal-encased shielded packaging constructed before April 1, $1975^{\circ}$ Such packaging constructed after March 31, 1975 is not authorized unless it is requalified under DOT Specification 7A. Each packaging designed for liquids must also meet the requirements of $173.412(\mathrm{~m})$ and $(\mathrm{n})$. Use of this packaging as DOT Specification 55 is not authorized after June 30, 1985.

(c) Any Type $B, B(U)$ or $B(M)$ packaging pursuant to 173.416 .

(d) Any foreign made packaging that bears the marking "Type $A$ " and which was used for the import of radioactive materiais. Such packagings may be subsequently used for domestic and export shipments of radioactive materials. These packagings shall conform with requirements of the country of origin (as indicated by the packaging marking) applicable to Type A packagings.

(The information collection requirements contained in paragraph (a) were approved by the Office of Management and Budget under control number 2137 0533)"

\section{REQUIREMENT SOURCE: 49CFR173 Part 417}

"Authorized packaging-fissile materials.

(a) Except as provided in 173.453, fissile materials containing not more than A1 or A2 as appropriate, shall be packaged in one of the following packagings:

(1) DOT Specification 6L (178.352 of this subchapter), metal packaging, for materials prescribed in paragraph (b)(1) of this section.

(2) DOT Specification $6 \mathrm{M}$ (178.354 of this subchapter), metal packaging, for materials prescribed in paragraph (b)(2) of this section.

(3) Any packaging listed in 173.415 , limited to the following radioactive materials:

(i) $\mathbf{5 0 0}$ grams of uranium-235 in a single shipment as Fissile Class III or not more than $\mathbf{4 0}$ grams of uranium-235 per package as Fissile Class II. For Fissile Class II shipments, the transport index assigned to each package. shall not be less than 0.4 for each gram of uranium-235 above 15 grams up to the maximum of 40 grams (transport index of 10).

(ii) 320 grams of plutonium-239 as plutonium-beryllium neutron sources in special form. Total radioactivity content may not exceed 20 curies. The transport index to be assigned to each package must be 0.5 for each 20 grams, or fraction thereof, of fissile plutonium.

(4) Any other Type A or Type $B$, Type $B(U)$, or Type $B(M)$ packaging for fissile radioactive materials that also meets the applicable standards for fissile materials in the regulations of the U.S. Nuclear Regulatory Commission (10 CFR part 71), and is used in accordance with 173.471 .

(5) Any other Type A or Type $B$, Type $B(U)$, or Type $B(M)$ packaging that also meets the applicable requirements for fissile material packaging in Section $V$ of the International Atomic Energy Agency "Regulations for the Safe Transport of Radioactive Materials, Safety Series 
No. 6," and for which the foreign competent authority certificate has been revalidated by the U.S. Competent Authority, in accordance with 173.473. These packages are authorized only for export and import shipments.

(6) A 55-gallon 1 A2 steel drum, subject to the following conditions:

(i) The quantity may not exceed 350 grams of uranium-235 in any non-pyrophoric form, enriched to any degree in the uranium-235 isotope.

(ii) Each drum must have a minimum 18 gauge body and bottom head and 16 gauge removable top head with one or more corrugations in the cover near the periphery.

(iii) Closure must conform to 178.352 of this subchapter.

(iv) At least four equally spaced 12 millimeter $(0.5$ inch) diameter vent boles shall be provided on the sides of the drum near the top, each covered with weatherproof tape; or equivalent device.

(v) Appropriate primary inner containment of the contents and sufficient packaging material, such as plastic or metal jars or cans shall be provided such that Specification 7A (178.350 of this subchapter) provisions are satisfied by the inner packaging.

(vi) Each inner container shall be capable of venting if subjected to the thermal test described in 10 CFR part 71.

(vii) Liquid contents shall be packaged in accordance with $173.412(\mathrm{~m})$ and (n).

(viii) The maximum weight of contents including internal packaging may not exceed 91 kilograms (200 pounds) with fissile material content limited as shown in Table 2:

HAZDOCS-2 Table No. 78

(7) Any metal cylinder that meets the performance requirements of 173.415 and 178.350 of this subchapter for Specification 7A Type A packaging may be used as a Fissile Class I package for the transport of residual "beels" of enriched solid uranium hexafluoride without a protective overpack in accordance with Table 3:

HAZDOCS-2 Table No. 79

(8) Packagings as prescribed in paragraph (b)(5) of this section, for materials, quantities and conditions as authorized and prescribed therein.

(b) Fissile radioactive materials with radioactive content exceeding A1 or A2 shall be packaged in one of the following packagings:

(1) DOT Specification 6L (178.352 of this subchapter), metal packaging. Authorized only for uranjum-235, plutonium-239 or plutonium-241, as metal, oxide, or compounds that do not decompose at temperatures up to $149 \mathrm{C}(300 \mathrm{~F})$. Radioactive decay heat output may not exceed 5 watts. Radioactive materials in normal form shall be packaged in one or more tightly sealed metal cans or polyethylene bottles within a DOT Specification 2R (178.360 of this subchapter) containment vessel. Packages are authorized as Fissile Class II and III with materials limited in accordance with Table 4: HAZDOCS-2 Table No. 80 
Westinghouse Hanford Company (WHC)

Standards/Requirements Identification Document

13.0 Packaging and Transportation
WHC-SD-MP-SRID-002

January 10, 1996

Rev. 0

Page 14 of 66

(2) DOT Specification $6 \mathrm{M}$ (178.354 of this subchapter), metal packaging. Authorized only for solid radioactive materials that will not decompose at temperatures up to $121 \mathrm{C}(250 \mathrm{~F})$. Radioactive decay heat output may not exceed 10 watts. Radioactive materials in other than special form shall be packaged in one or more tightly sealed metal cans or polyethylene bottles within a DOT Specification 2R (178.360 of this subchapter) containment vessel. For fissile materials:

(i) Fissile Class I packages are limited to the following amounts of fissile radioactive materials: 1.6 kilograms of uranium-235; 0.9 kilograms of plutonium (except that due to the 10-watt thermal decay beat limitation, the limit for plutonium-238 is 0.02 kilograms); and 0.5 kilograms of uranium-233. The maximum ratio of bydrogen to fissile material must not exceed three, including all of the sources of hydrogen within the DOT Specification $2 R$ containment vessel.

(ii) Maximum quantities of fissile material for Fissile Class II and Fissile Class III, and other restrictions are given in Table 5. For a Fissile Class Il package, the minimum transport index to be assigned is shown in Table 5 and for a Fissile Class III shipment, the allowable number of similar packages per conveyance and per transport vehicle is shown. Each Fissile Class III shipment is also subject to the requirements in 173.457 . Where a maximum ratio of hydrogen to fissile material is specified in Table 5, only the hydrogen interspersed with the fissile material need be considered. For a uranium-233 shipment, the maximum inside diameter of the inner containment vessel must not exceed 12.1 centimeters ( 4.75 inches). Where necessary, a tight fitting steel insert shall be used to reduce a larger diameter inner containment vessel specified in 178.1043 (b) of this subchapter to the 12 centimeter ( 4.75 inch) limit.

HAZDOCS-2 Table No. 81

(3) Type $B$, or Type $B(U)$ or $B(M)$ packaging that meets the standards for packaging of fissile materials in 10 CFR part 71, and is approved by the U.S. Nuclear Regulatory Commission in accordance with 173.471 .

(4) Type $B(U)$ or $B(M)$ packaging that meets the applicable requirements for fissile radioactive materials in Section V of the IAEA "Regulations for the Safe Transport of Radioactive Materiais, Safety Series No. $6^{\prime \prime}$ and for which the foreign competent authority certificate has been revalidated by the U.S. Competent Authority in accordance with 173.473. These packagings are authorized only for import and export shipments.

(5) DOT Specifications 20PF 1, 20PF 2, or 20PF 3 (178.356 of this subchapter), or Specifications 21PF 1, 21PF 1A, 21PF 1B, or 21PF 2 (178.358 of this subchapter) phenolic-foam insulated overpack with snug fitting inner metal cylinders, meeting all requirements of 173.24, 173.411, and 173.412, and the following:

(i) Handling procedures and packaging criteria must be in accordance with DOE Report ORO 651 or ANSI N14.1.

(ii) DOT Specification 21PF 1 overpacks in use or under construction before April 1, 1989, must be modified to DOT Specification 21PF 1A before April 1, 1991. Use of unmodified DOT 21PF 1 overpacks is prohibited after March 31, 1991. All new construction to DOT Specification 21PF 1 beginning after March 31, 1989, must meet DOT Specification 21PF 1B.

(iii) Quantities of uranium hexafluoride are authorized as shown in Table 6, with each package to be shipped as Fissile Class II, and assigned a minimum transport index as also shown: 
Westinghouse Hanford Company (WHC)

Standards/Requirements Identification Document

13.0 Packaging and Transportation
WHC-SD-MP-SRID-002

January 10, 1996

Rev. 0

Page 15 of 66

HAZDOCS-2 Table No. 82"

\section{REQUIREMENT SOURCE: 49CFR173 Part 421}

"Limited quantities of radioactive materials.

Radioactive materials whose activity per package does not exceed the limits specified in 173.423 are excepted from the specification packaging, shipping paper and certification, marking, and labeling requirements of this subchapter and requirements of this subpart if:

(a) The materials are packaged in strong, tight packages that will not leak any of the radioactive materials during conditions normally incident to transportation;

(b) The radiation level at any point on the external surface of the package does not exceed 0.5 millirem per hour;

(c) The nonfixed (removable) radioactive surface contamination on the external surface of the package does not exceed the limits specified in 173.443(a);

(d) The outside of the inner packaging or if there is no inner packaging, the outside of the packaging itself bears the marking "Radioactive";

(e) Except as provided in 173.424 , the package does not contain more than 15 grams of uranium-235; and

(f) The material is otherwise prepared for shipment as specified in $173.4211 . "$

\section{REQUIREMENT SOURCE: 49CFR173 Part 421(2)(a)}

"Requirements for multiple hazard limited quantity radioactive materials. Except as provided in paragraph (b) of this section or in 173.4 of this subchapter, when a limited quantity Class 7 material meets the definition of another hazard class or division, it shall be:

(1) Classed for the additional hazard;

(2) Packaged to conform with the requirements specified in 173.421 (a) through (e) or 173.422

(a) through (g), as appropriate; and

(3) Offered for transportation in accordance with the requirements applicable to the hazard for which it is classed."

\section{REQUIREMENT SOURCE: 49CFR173 Part 421(2)(b)}

"When a limited quantity Class 7 material meets the definition of Class 9 or is a combustible liquid in a non-bulk packaging, it shall be:

(1) Classed as a Class 7 material if:

(i) The material is not a hazardous waste or hazardous substance; and

(ii) The material is offered for transportation in a mode to which requirements of this subchapter pertaining to the specific material do not apply; 
(2) Classed combustible liquid or Class 9, as appropriate, if:

(i) The material is a hazardous waste or hazardous substance; or

(ii) The material is offered for transportation in a mode to which requirements of this subchapter pertaining to the specific material do apply;

(3) Packaged to conform with requirements specified in 173.421 (a) through (e) or 173.422 (a) through (g), as appropriate; and

(4) Offered for transportation in accordance with requirements applicable to the hazard for which it is classed."

\section{REQUIREMENT SOURCE: 49CFR173 Part 421(2)(c)}

"A limited quantity Class 7 material which is classed other than Class 7 under the provisions of paragraph (a) or (b) of this section is excepted from the requirements of 173.4211 (a), 172.203(d), and 172.204(c)(4) of this subchapter if the entry "Limited quantity radioactive material" appears on the shipping paper in association with the basic description."

\section{REQUIREMIENT SOURCE: 49CFR173 Part 422}

"Exceptions for instruments and articles.

Instruments and manufactured articles (including clocks, electronic tubes or apparatus) or similar devices having radioactive materials in gaseous or non-dispersible solid form as a component part are excepted from the specification packaging, shipping paper and certification, marking and labeling requirements of this subchapter and requirements of this subpart, if:

(a) The activity of the instrument or article does not exceed the relevant limit listed in Table 7 in 173.423;

(b) The total activity per package does not exceed the relevant limit listed in Table 7 in 173.423;

(c) The radiation level at 10 centimeters ( 4 inches) from any point on the external surface of any unpackaged instrument or article does not exceed 10 millirem per hour;

(d) The radiation level at any point on the external surface of a package bearing the articie or instrument does not exceed 0.5 millirem per bour, or, for exclusive use domestic shipments, 2 millirem per hour;

(e) The nonfixed (removable) radioactive surface contamination on the external surface of the package does not exceed the limits specified in 173.443(a);

(f) Except as provided in 173.424, the package does not contain more than 15 grams of uranium-235; and

(g) [Reserved]

(h) The instrument or article is otherwise prepared for shipment as specified in 173.421" 


\section{REQUIREMENT SOURCE: 49CFR173 Part 424}

"Excepted articles containing natural uranium or thorium.

Manufactured articles in which the sole radioactive material content is natural or depleted uranium or natural thorium are excepted from the specification packaging, shipping paper and certification, marking and labeling requirements of this subchapter and requirements of this subpart if:

(a) The outer surface of the uranium or thorium is enclosed in an inactive sheath made of metal or other durable protective material;

(b) The conditions specified in 173.421 (b), (c), and (d) are met; and

(c) The article is otherwise prepared for shipment as specified in $173.4211 \mathrm{f}^{\mathrm{n}}$

\section{REQUREMENT SOURCE: 49CFR173 Part 425}

"Transport requirements for low specific activity (LSA) radioactive materiais.

In addition to other applicable requirements specified in this subchapter, low specific activity (LSA) materials shall be transported in accordance with paragraph (a) of this section, or if transported as exclusive-use may be transported in accordance with paragraph (b) or (c) of this section.

(a) DOT Specification 7A (178.350 of this subchapter) Type A package. The requirements of 173.412 (a), (b), (d), and (n) do not apply.

(b) Packaged shipments of LSA material consigned as exclusive use shall either be in accordance with paragraph (a) of this section or shall comply with the following in which case they are excepted from specification packaging, marking and labeling:

(1) Materials must be packaged in strong, tight packages so that there will be no leakage of radioactive material under conditions normally incident to transportation.

(2) Packages must not have any significant removable surface contamination (see 173.443).

(3) External radiation levels must comply with 173.441 .

(4) Shipments must be loaded by consignor and unloaded by consignee from the conveyance or freight contained in which originally loaded.

(5) There must be no loose radioactive material in the conveyance.

(6) Shipment must be braced so as to prevent shifting of lading under conditions normally incident to transportation.

(7) Except for shipments of unconcentrated uranium or thorium ores, the transport vehicle must be placarded with the placards prescribed in accordance with subpart $F$ of part 172 of this subchapter, as appropriate. 
(8) The exterior of each package must be stenciled or otherwise marked "Radioactive-LSA". Packages, with a capacity of 110 gallons or less, that contain a hazardous substance, must be stenciled or otherwise marked with the letters "RQ" in association with the above description.

(9) Specific instructions for maintenance of exclusive use shipment controls must be provided by the shipper to the carrier. Such instructions must be included with the shipping paper information.

(10) Transportation by aircraft is prohibited.

(c) Uapackaged (bulk) shipments of LSA materials shall be transported only in exclusive use closed transport vehicles and shall comply with the following:

(1) Authorized materials are limited to the following:

(i) Uranium or thorium ores and physical or chemical concentrates of those ores.

(ii) Uranium metal or natural thorium metal, or alloys of these materials.

(iii) Materials of low radioactive concentration, if the average estimated radioactivity concentration does not exceed 0.001 millicurie per gram and the contribution from materials with an A2 value (see 173.435) of less than 0.05 curie does not exceed one percent of the total radioactivity.

(iv) Objects of nonradioactive material externally contaminated with radioactive material, if the radioactive material is not readily dispersible and the surface contamination, when averaged over one square meter, does not exceed 0.0001 millicurie per square centimeter of radionuclides for which the $\mathrm{A} 2$ value is less than 0.05 or 0.001 millicurie per square centimeter of other radionuclides. Such objects must be suitably wrapped or enclosed.

(2) Bulk liquids must be transported in the following: (i) Specification 103CW, $111 \mathrm{~A} 60 \mathrm{~W} 7$ (179.200, 179.201, 179.202 of this subchapter) tank cars. Bottom openings in tanks prohibited.

(ii) Specification MC 310, MC 311, MC 312, or MC 331 (178.343 or 178.337 of this subchapter) cargo tanks. Authorized only where the radioactivity concentration does not exceed 10 percent of the specified low specific activity levels (see 173.403(n)). The requirements of $173.412(\mathrm{n})$ do not apply to these cargo tanks. Bottom fittings and valves are not authorized. Trailer-on-flat-car service is not authorized.

(3) External radiation levels must comply with 173.441 (b).

(4) Shipments must be loaded by the consignor, and unloaded by the consignee from the conveyance or freight container in which originally loaded.

(5) Except for shipments of unconcentrated uranium or thorium ores, the transport vehicle must be placarded with the placards prescribed in subpart F of part 172 of this subchapter, as appropriate.

(6) There must be no leakage of radioactive materials from the vehicle.

(7) Specific instructions for maintenance of exclusive use shipment controls must be provided by the shipper to the carrier. Such instructions must be included with the shipping paper information. 
(8) Transportation by aircraft is prohibited.

(d) Except for transportation by aircraft, low specific activity material that conforms with the provisions specified in 10 CFR 20.306 is excepted from all requirements of this subchapter pertaining to radioactive materials when offered for transportation for disposal or recovery. A material which meets the definition of another hazard class is subject to the provisions of this subchapter relating to that hazard class."

\section{REQULREMENT SOURCE: 49CFR173 Part 427}

"Empty radioactive materials packaging.

A packaging which previously contained radioactive materials and has been emptied of contents as far as practical, is excepted from the shipping paper and certification, marking and labeling requirements of this subchapter, and from requirements of this subpart, provided that:

(a) It complies with the requirements of 173.421 (b), (c), and (e);

(b) The packaging is in unimpaired condition and is securely closed so that there will be no leakage of radioactive material under conditions normally incident to transportation;

(c) Internal contamination does not exceed 100 times the limits in 173.443;

(d) Any labels previously applied in conformance with Subpart E of Part 172 of this subchapter are removed, obliterated or covered and the "Empty" label prescribed in 172.450 is affixed to the packaging; and

(e) The packaging is prepared for shipment as specified in $173.4211 . "$

\section{REQUIREMENT SOURCE: 49CFR173 Part 431}

"Activity limits for Type A and Type B packages.

(a) A Type A package shall not contain a quantity of radioactivity greater than A1 (for special form radioactive material) or A2 (for normal form radioactive material) as listed in 173.435, or for radioactive materials not listed in 173.435, as determined in accordance with 173.433.

(b) The limits on activity contained in a Type $\mathrm{B}$, Type $\mathrm{B}(\mathrm{U})$, or Type $\mathrm{B}(\mathrm{M})$ package are those prescribed in 173.416 or in the applicable approval certificate under 173.471 or $173.473 . "$

\section{REQUIREMENT SOURCE: 49CFR173 Part 441}

"Radiation level limitations.

(a) Except as provided in paragraph (b) of this section, each package of radioactive materials offered for transportation shall be designed and prepared for shipment so that under conditions normally incident to transportation the radiation level does not exceed 200 millirem per hour at any point on the external surface of the package, and the transport index does not exceed 10 .

(b) A package which exceeds the radiation level limits specified in paragraph (a) of this section shall be transported by exclusive use shipment only and the radiation levels for such shipment must not exceed the following during transportation: 
(1) 200 millirem per hour ( 2 millisievert per hour) on the external surface of the package unless the following conditions are met, in which case the limit is 1000 millirem per hour (10 millisievert per hour).

(i) The shipment is made in a closed transport vehicle;

(ii) The package is secured within the vehicle so that its position remains fixed during transportation; and

(iii) There are no loading or unloading operations between the beginning and end of the transportation;

(2) 200 millirem per hour ( 2 millisievert per hour) at any point on the outer surfaces of the vehicle, including the top and underside of the vehicle; or in the case of a fiat-bed style vehicle, at any point on the vertical planes projected from the outer edges of the vehicle, on the upper surface of the load (or enclosure is used), and on the lower external surface of the vehicle;

(3) 10 millirem per hour ( 0.1 millisievert per hour) at any point 2 meters (6.6 feet) from the outer lateral surfaces of the vehicle (excluding the top and underside of the vehicle); or in the case of a flat-bed style vehicie, at any point 2 meters $(6.6$ feet) from the vertical planes projected by the outer edges of the vehicle (excluding the top and underside of the vehicle); and

(4) 2 millirem per hour ( 0.02 millisievert per hour) in any normally occupied space, except that this provision does not apply to private carriers if exposed personnel under their control wear radiation dosimetry devices and operate under provisions of a State or Federally regulated radiation protection program.

(c) For shipments made under the provisions of paragraph (b) of this section, the shipper shall provide specific written instructions for maintenance of the exclusive use shipment controls to the carrier. The instructions shall be included with the shipping paper information.

(d) Packages exceeding the radiation level or transport index prescribed in paragraph (a) of this section shall not be transported by aircraft.

(e) The written instnctions required for exclusive use shipments must be sufficient so that, when followed, they will cause the carrier to avoid actions which will unnecessarily delay delivery or unnecessarily result in increased radiation levels or radiation exposures.

(The information collection requirements contained in paragraph (c) were approved by the Office of Management and Budget under control number 2137 0536)"

\section{REQUTREMENT SOURCE: 49CFR173 Part 442}

"Thermal limitations.

Each package of radioactive material shall be designed, constructed, and loaded so that:

(a) The heat generated within the package because of the radioactive contents will not, at any time during transportation, affect the integrity of the package under conditions normally incident to transportation; and 
(b) The temperature of the accessible external surfaces of the loaded package will not, assuming still air in the shade at an ambient temperature of $38^{\circ} \mathrm{C}\left(100^{\circ} \mathrm{F}\right)$, exceed either:

(1) $50^{\circ} \mathrm{C}(122 \mathrm{~F})$ in other than an exclusive use shipment; or

(2) $82^{\circ} \mathrm{C}(180 \mathrm{~F})$ in an exclusive use shipment."

\section{REQUIREMENT SOURCE: 49CER173 Part 443}

"Contamination control.

(a) The level of non-fixed (removable) radioactive contamination on the external surfaces of each package offered for shipment shall be kept as low as practicable. The level of non-fixed radioactive contamination may be determined by wiping an area of 300 square centimeters of the surface concerned with an absorbent material, using moderate pressure, and measuring the activity on the wiping material. Sufincient measurements shall be taken in the most appropriate locations to yield a representative assessment of the non-fixed contamination levels. Except as provided in paragraph (b) of this section, the amount of radioactivity measured on any single wiping material when averaged over the surface wiped shall not exceed the limits given in Table 10 at any time during transport. Other methods of assessment of equal or greater efficiency may be used. When other methods are used the detection efficiency of the method used shall be taken into account and in no case shall the non-fixed contamination on the external surfaces of the package exceed ten times the limits listed in Table 10.

HAZDOCS-2 Table No. 90

(b) Except as provided in paragraph (d) of this section, in the case of packages transported as exclusive use shipments by rail or public highway only, the removable (non-fixed) radioactive contamination on any package at any time during transport shall not exceed ten times the levels prescribed in paragraph (a) of this section. The levels at the beginning of transport shall not exceed the levels prescribed in paragraph (a) of this section.

(c) Except as provided in paragraph (d) of this section, each transport vehicle used for transporting radioactive materials as an exclusive use shipment which utilizes the provisions of paragraph (b) of this section shall be surveyed with appropriate radiation detection instruments after each use. A vehicle shall not be retumed to service until the radiation dose rate at each accessible surface is $\mathbf{0 . 5}$ millirem per hour or less, and there is no significant removable (non-fixed) radioactive surface contamination as specified in paragraph (a) of this section.

(d) Paragraph (b) and (c) of this section do not apply to any closed transport vehicle used solely for the transportation by public highway of radioactive material packages with contamination levels that do not exceed 10 times the levels prescribed in paragraph (a) of this section if:

(1) A survey of the interior surfaces of the empty vehicle shows that the radiation dose rate at any point does not exceed 10 millirem per hour at the surface or 2 millirem per hour at 1 meter (3.3. feet) from the surface;

(2) Each vehicle is stenciled with the words "For Radioactive Materials Use Only" in letters at least 76 millimeters ( 3 inches) high in a conspicuous place on both sides of the exterior of the vehicle; and

(3) Each vehicle is kept closed except for loading or unloading." 


\section{REQUIREMENT SOURCE: 49CFR173 Part 455}

"Classification of fissile materials packages.

(a) Except as provided in 173.453 , each package of fissile materials shall be classified as follows:

(1) Fissile Class I. Packages that may be transported in unlimited number, and in any arrangement, and that require no nuclear criticality safety controls during transportation. A transport index is not assigned to Fissile Class I packages for the purposes of nuclear criticality safety control, although, the external radiation levels may require a transport index number.

(2) Fissile Class II. Packages that may be transported together in any arrangement but in numbers that do not exceed an aggregate transport index of 50 . For the purposes of nuclear criticality safety control, individual packages may have a transport index of not less than 0.1 and not more than 10. However, the external radiation levels may require a higher transport index number. These shipments require no nuclear criticality safety control by the shipper during transportation.

(3) Fissile Class III. Shipments of packages of fissile materials that do not meet the requirements of Fissile Class I or Fissile Class II and that are controlled in transportation as prescribed in 173.457 by appropriate arrangements between the shipper and the carrier.

(b) The numerical values for package assignments as Fissile Class I, the transport indexes for Fissile Class Il packages, and the conveyance and vehicle limitations for Fissile Class III shipments shall be determined in accordance with 10 CFR part 71."

\section{REQUTREMINT SOURCE: 49CFR173 Part 457}

"Transportation of Fissile Class III shipments-specific requirements.

(a) Fissile Class III shipments shall incorporate transportation controls which are performed by the shipper or carrier, as appropriate, and which:

(1) Provide nuclear criticality safety;

(2) Protect against loading, storing, or transporting that shipment with any other fissile material; and

(3) Include in the shipping papers the description required by 172.203 (d) of this subchapter.

(b) Fissile Class III shipments shall be transported:

(1) In a conveyance (transport vehicle if transported by public highway or rail) assigned to the exclusive use of the shipper with a specific restriction for the exclusive use to be provided in the appropriate arrangements between shipper and carrier and with instructions to that effect issued with the shipping papers;

(2) Except for shipments by aircraft, with an escort in a vehicle having the capability, equipment, authority, and instructions to provide administrative controls necessary to assure compliance with this section; 
(3) In a conveyance (transport vehicle if transported by public highway or rail) containing no other packages of radioactive material that are required to bear one of the labels prescribed in 172.403 of this subchapter. Specific arrangements must be made between the shipper and the carrier, with instructions to that effect issued with the shipping papers; or

(4) Under any other procedure specifically authorized by the Associate Administrator for Hazardous Materials Safety in accordance with part 107 of this subchapter.

(The information collection requirements contained in paragraph (b) were approved by the Office of Management and Budget under control number 2137 0535)"

\section{REQUIREMENT SOURCE: 49CFR173 Part 471}

"Requirements for U.S. Nuclear Regulatory Commission approved packages.

In addition to the applicable requirements of the U.S. Nuclear Regulatory Commission (USNRC) and parts 171177 of this subchapter, any shipper of a Type B, Type B(U), Type $B(M)$, or fissile material package that has been approved by the USNRC in accordance with 10 CFR part 71 shall also comply with the following requirements:

(a) The shipper shall be registered with the USNRC as a party to the approval, and the shipment must be made in compliance with the terms of the approval;

(b) The outside of each package shall be durably and legibly marked with the package identification marking indicated in the USNRC approval;

(c) Each shipping paper related to the shipment of the package shall bear the package identification marking indicated in the USNRC approval;

(d) Before the first export shipment of the package, the shipper shall obtain a U.S. Competent Authority Certificate for that package design or if one has already been issued, the shipper shall register with the U.S. Competent Authority as a user of the certificate. Upon registration as a user of the certificate the shipper will be furnished with a copy of it. The shipper shall then submit a copy of the U.S. Competent Authority Certificate applying to that package design to the national competent authority of each country into or through which the package will be transported, uniess a copy has already been furnished;

\section{(e) [Reserved]}

(f) Each request for a U.S. Competent Authority Certificate as required by the IAEA regulations shail be submitted in writing to the address set forth in paragraph (e) of this section. The request shall be in duplicate and include copies of the applicable USNRC approval and a reproducible drawing showing the make-up of the package. Each request is considered in the order in which it is received. To allow sufficient consideration by the Associate Administrator for Hazardous Materials Safety, requests should be received at least 45 days before the requested effective date; and

(g) Import and export shipments may be made in accordance with 171.12 of this subchapter.

(The information collection requirements contained in paragraph (a) were approved by the Office of Management and Budget under control number 2137 0512. The information collection requirements contained in paragraph (d) were approved under control number 2137 0515.)" 


\section{REQUREMINT SOURCE: 49CFR173 Part 472}

"Requirements for exporting DOT Specification Type B and fissile packages.

(a) Any shipper who exports a DOT Specification Type B or fissile material package authorized by $\mathbf{1 7 3 . 4 1 6}$ or $\mathbf{1 7 3 . 4 1 7}$ shall comply with paragraphs $(\mathrm{b})$ through (f) of this section.

(b) The shipper shall register with the U.S. Competent Authority as a user of the appropriate U.S. Competent Authority Certificate and the shipment shall be made in accordance with the certificate;

(c) The outside of each package must be durably and legibly marked with the package identification marking indicated in the U.S. Competent Authority Certificate;

(d) Each shipping paper related to the shipment of the package must bear the package identification marking indicated in the U.S. Competent Authority Certificate;

(e) Before the first export shipment of the package, the shipper must submit a copy of the U.S. Competent Authority Certificate applying to that package design to the national competent authority of each country into or through which the package will be transported, unless a copy has already been furnished; and

(f) Import and export shipments may be made in accordance with 171.12 of this subchapter.

(The information collection requirements contained in paragraphs (b) and (e) were approved by the Office of Management and Budget under control number 2137 0515)"

\section{REQUTREMENT SOURCE: 49CFR173 Part 477}

"Approval for export shipments.

(a) Each export shipment of a package for which an IAEA certificate of competent authority has been issued or revalidated in accordance with $173.471,173.472$, or 173.473 shall have multilateral approval, if the shipment includes:

(1) A vented Type $B(M)$ package;

(2) A Type $B(M)$ packaging containing radioactive materials with an activity greater than $310 \backslash 3 \backslash \mathrm{A} 1$, or $310 \backslash 3 \backslash \mathrm{A} 2$, as appropriate, or $310 \backslash 4 \backslash$ curies, whichever is less;

(3) A Fissile Class III shipment; or

(4) Transportation by special arrangement.

(b) Each application for shipment approval shall contain:

(1) The period of time for which the approval is sought;

(2) A description of the contents, the expected modes of transportation, the type of conveyance to be used, and the proposed route; and

(3) An explanation of how the special precautions and special administrative and operational controls referred to in the package design certificates are to be put into effect. 
(c) The packaging and shipment approvals may be combined into a single approval issued in accordance with $173.471,173.472$ or 173.473 .

(d) Approval by competent authorities is not required for packagings designed for materials covered by 173.421 through 173.427 nor for Type A packagings designed for non-fissile radioactive materials.

(The information collection requirements contained in paragraph (b) were approved by the Office of Management and Budget under control number 2137 0532)"

\section{REQUIREMINT SOURCE: DANGEROUS-GOODS-REGU Section 6.0.6}

"External Contamination. The non-fixed radioactive contamination on any external surface of any package must be kept as low as practicable and, under normal conditions of transport, must not exceed the levels specified in Table 6.0.A. In the case of overpacks and freight containers, the level of non-fixed contamination on the external and internal surfaces must not exceed the limits specified in Table 6.0.A. The level of non-fixed radioactive contamination may be determined by wiping an area of $300 \mathrm{~cm} 2$ (46 in2) of the surface concerned by hand with a dry filter paper, or wad of dry cotton wool or any other material of a similar nature."

\section{REQUREMENT SOURCE: DANGEROUS-GOODS-REGU Section 6.0.7.1}

"Radioactive material which by its nature has a limited specific activity, or radioactive material for which limits of estimated average specific activity apply, is termed low specific activity, or LSA, material. External shielding material surrounding the LSA material must not be considered in determining the estimated average specific activity."

\section{REQUREMENT SOURCE: DANGEROUS-GOODS-REGU Section 6.0.7. 6}

"LSA-III material must be a solid of such a nature that if the entire contents of the package were subjected to the tests specified in 6.0.7.12 the activity in the water would not exceed 0.1 A2."

\section{REQUIREMENT SOURCE: DANGEROUS-GOODS-REGU Section 6.1.0.5}

"When a radioactive material has been packed in compliance with these packing requirements the complete package, in most cases, must be allotted a "transport index." The "transport index" is a number devised with the dual purpose of indicating the relative degree of radiation hazard for packages containing non-fissile radioactive material and the relative degree of either radiation hazard or criticality hazard (whichever is the greater) for packages containing fissile radioactive material."

\section{REQUIREMENT SOURCE: DANGEROUS-GOODS-REGU Section 6.1.2.2}

"Uniisted Single Radionuclides: For individual radionuclides whose identities are known, but which are not listed in Table 6.1.B, the determination of the values of $A 1$ and $A 2$ must have been multilateral approval. Alternatively, the values of A1 and A2 in Table 6.1.A may be used without obtaining such approval." 


\section{REQUIREMENT SOURCE: DANGEROUS-GOODS-REGU Section 6.1.4.3}

"Industrial Packaging. The total activity in a single package of LSA material or in a single package of SCO must be so restricted that the radiation level specified in 6.2.6.1 is not exceeded, and the activity in a single package must also be so restricted that the activity limits for an aircraft specified in.Table 6.2.D are not exceeded."

\section{REQUIREMENT SOURCE: DANGEROUS-GOODS-REGU Section 6.2.1.1}

"General: Radioactive materials in limited quantities, instruments, manufactured articles and empty packagings as specified in 6.2.14 to 6.2.1.7 may be transported as excepted packages, provided that:

- the radiation level at any point on the external surface of the package does not exceed $5 \mu \mathrm{Sv} / \mathrm{h}(0.5 \mathrm{mrem} / \mathrm{h})$;

- if the excepted package contains fissile material, the requirements of 6.2.5.4 to 6.2.5.10 are met; and

- the non-fixed radioactive contamination on any external surface of the excepted package does not exceed the limits in Table 6.0.A.

The transport index for each consignment must be determined in accordance with Table 6.1.D."

\section{REQUIREMENT SOURCE: DANGEROUS-GOODS-REGU Section 6.2.6.1}

"The quantity of low specific activity material (LSA) or surface contaminated objects (SCO) in a single industrial Package Type 1, Industrial Package Type 2, Industrial Package Type 3 or object or collection of objects, whichever is appropriate, must be so restricted that the external radiation level at $3 \mathrm{~m}(9 \mathrm{ft})$ from the unshielded material or object or collection of objects does not exceed $10 \mathrm{mSv} / \mathrm{h}(1 \mathrm{rem} / \mathrm{h}$.)."

\section{REQUIREMENT SOURCE：DANGEROUS-GOODS-REGU Section 6.2.8.1}

"Except for consignments under exclusive use, the transport index of any individual package or overpack must not exceed 10."

\section{REQUREMENT SOURCE: DANGEROUS-GOODS-REGU Section 6.2.8.2}

"Except for packages or overpacks transported under exclusive use under the conditions specified in 9.3.10.4, the maximum radiation level at any point on any external surface of a package or overpack must not exceed $2 \mathrm{mSv} / \mathrm{h}(200 \mathrm{mrem} / \mathrm{h})$."

\section{REQUIREMENT SOURCE: DANGEROUS-GOODS-REGU Section 6.2.8.3}

"The maximum radiation level at any point on any external surface of a package under exclusive use must not exceed $10 \mathrm{mSv} / \mathrm{h}(1000 \mathrm{mrem} / \mathrm{h}) . "$

\section{REQUREMENT SOURCE: DANGEROUS-GOODS-REGU Section 6.2.8.7}

"If the transport index is greater than 10 , the package or overpack must be transported under exclusive use." 
Westinghouse Hanford Company (WHC)

Standards/Requirements Identification Document

13.0 Packaging and Transportation
WHC-SD-MP-SRID-002

January 10, 1996

Rev. 0

Page 27 of 66

\section{REQUREMENT SOURCE: DANGEROUS-GOODS-REGU Section 6.2.8.8}

"If the surface radiation level is greater than $2 \mathrm{mSv} / \mathrm{h}(200 \mathrm{mrem} / \mathrm{h})$ the package or overpack must be transported under exclusive use and under the provisions of 9.3.10.3."

\section{REQUIREMENT SOURCE: DOE5480.3 Section 7.b(1)}

"Solid plutonium or plutonium bearing wastes in greater than A2 quantities for normal form or greater than A1 quantities for special form must be packaged in accordance with a specified DOE Certificate of Compliance, an NRC Certificate of Compliance, an DOT exempt packaging system, or a DOT Specification package."

\section{REQUIREMENT SOURCE: DOE5480.3 Section 7.b(2)}

"Plutonium (for air transport) in greater than A2 quantities for normal form or greater than A1 quantities for special form must by in DOE or NRC certified packaging (equivalent to, or meeting the criteria of NUREG-0360), e.g., USA/0361/BF, USA/9150/B(U), or USA/9509/B(U) (DOE-A1). The packaging approval shall authorize specifically the air transport of plutonium."

\section{REQUTREMENT SOURCE: DOE5480.3 Section 7.b(3)}

"Plutonium packaging requirements for any surface mode of transportation.

(a) Plutonium in excess of 20 curies per package must be shipped as a solid.

(b) Plutonium in excess of 20 curies per package must be packaged in a separate inner container placed within outer packaging that meets the requirements of a Type B package for material in normal form. In addition, the following tests must be performed on the package design:

1 If the entire package is subjected to the design tests specified in paragraph 11, "Normal Conditions of Transport, " the separate inner container must restrict the loss of plutonium to no more than 10-6 A2/hour.

2 If the entire package is subjected to the design tests specified in paragraph 12, "Hypothetical Accident Conditions," the separate inner container must restrict the loss of plutonium to not more than an A2 quantity in 1 week."

\section{REQUTREMENT SOURCE: DOE5480.3 Section 10.b}

"Assumptions as to Unknown Properties. When the isotopic abundance, mass, concentration, degree if irradiation, degree of moderation, or other pertinent property of fissile material in any package is not known, the shipper shall package the fissile material as if the unknown properties have such credible values as will cause the maximum nuclear reactivity. Any special instructions needed to safely open the package are to be made available to the consignee." 


\section{REQUIREMENT SOURCE: WAC-470-12 Section 050(4)}

"Carboys which have been used for the transportation of acids or corrosive liquids shall have been thoroughly drained and washed and there shall be no residual corrosive liquid present on the outer surface of the carboy or the outer container, or within the outer container, before . such carboys are carried as "empty" containers."

\section{NRC Certified Packaging}

\section{REQUIREMENT SOURCE: DOE1540.2 Chapter I, Section 3.b}

"NRC-Approved Packaging.

(1) DOE contractors may use any NRC-certified packaging provided:

(a) The packaging is used in accordance with the limitations specified in the certificate of compliance.

(b) The use of the packaging is not prohibited by DOE 5480.3 .

(c) The contractor complies with the requirements of page V-1, paragraph $2 \mathrm{a}$.

(d) The DOE is registered as a user, and the contractor possesses a copy of the latest NRC Certificate of Compliance.

(2) All requests for NRC Certificates of Compliance by operations offices and/or their contractors shall be directed to DP-4 in accordance with Chapter V. If any of the above organizations contract with an outside contractor to develop and obtain an NRC-certified packaging, the request for the certificate of compliance need not be coordinated through DP-4 provided that the operations office or DOE contractor does not participate in obtaining the NRC certification. However, DP-4 should be fumished preliminary design information so as to avoid any duplication of effort and for distribution to other Departmental Elements having a potential interest. All requests for the registering Departmental Elements as a user of a NRC-certified packaging must be through DP-4.

(3) Each operations office shall ensure that their contractors establish and maintain an appropriate quality assurance and maintenance program to ensure that NRC-certified packagings in use continue to meet the provisions of the certification and SARP. Each operations office will be evaluated on its contractor's transportation quality assurance and maintenance program as part of the Headquarters packaging and transportation appraisal."

\section{REQUIREMENT SOURCE: DOE1540.2 Chapter V, Section 2.a}

"Requirements for Use of NRC-Certified Packagings. Packaging for which the NRC has issued a certificate of compliance may be used by DOE and DOE contractors without further review and certification, provided that the Department is registered as a user or the certificate is issued to DOE, and that all of the conditions of the NRC certificate are met, and the use of the packaging is not prohibited by DOE 5480.3. Specifically, the using contractor shall:

(1) Possess a copy of the latest NRC Certificate of Compliance;

(2) Possess a copy of the operating and maintenance instructions as specified in the license application for the packaging; and 
Westinghouse Hanford Company (WHC)

Standards/Requirements Identification Document

13.0 Packaging and Transportation
WHC-SD-MP-SRID-002

January 10, 1996

Rev. 0

Page 29 of 66

(3) Have an established quality assurance program equivalent to 10 CFR Part 71, subpart H."

REQUREMENT SOURCE: DOE1540.2 Chapter V, Section 2.c

"NRC Licensee Use of DOE-Certified Packagings. Traffic between NRC licensees and DOE contractors requires NRC certified packagings."

13.2 .1 .3

Hazardous Materials

REQUIREMENT SOURCE: 49CFR173 Part 3

Author's Note: Only section (a) of this requirement is applicable to the WHC Site S/RID in this functional area.

"Packaging and exceptions.

(a) The packaging of hazardous materials for transportation by air, highway, rail, or water must be as specified in this part. Methods of manufacture, packing, and storage of hazardous materials, that affect safety in transportation, must be open to inspection by a duly authorized representative of the initial carrier or of the Department. Methods of manufacture and related functions necessary for completion of a DOT specification or U.N. standard packaging must be open to inspection by a representative of the Department.

(b) The regulations setting forth packaging requirements for a specific material apply to all modes of transportation unless otherwise stated, or unless exceptions from packaging requirements are authorized.

(c) Salvage drums. Packages of hazardous materials that are damaged, defective. or found leaking and hazardous materials that have spilled or leaked may be placed in a metal or plastic removable head salvage drum that is compatible with the lading and shipped for repackaging or disposal under the following conditions:

(1) The drum must be a UN 1A2, 1B2, 1N2 or $1 \mathrm{H} 2$ tested and marked for Packing Group III or higher performance standards for liquids or solids and a leakproofness test of $20 \mathrm{kPa}$ (3 psi). Alternatively, a drum manufactured and marked prior to October 1, 1993 as a salvage drum, in accordance with the provisions of this section in effect on September 30, 1991, is authorized. Capacity of the drum may not exceed $450 \mathrm{~L}$ (119 gallons).

(2) Each drum shall be provided when necessary with sufficient cushioning and absorption material to prevent excessive movement of the damaged package and to eliminate the presence of any free liquid at the time the salvage drum is closed. All cushioning and absorbent material used in the drum must be compatible with the hazardous material.

(3) Each drum shall be marked with the proper shipping name of the material inside the packaging and the name and address of the consignee. In addition, the drum shall be marked "Salvage Drum".

(4) Each drum shall be labeled as prescribed for the respective material.

(5) The shipper shall prepare shipping papers in accordance with subpart $\mathrm{C}$ of part 172 of this subchapter. 
(6) The overpack requirements of 173.25 do not apply to drums used in accordance with this paragraph."

\section{REQUIREMENT SOURCE: 49CER173 Part 22}

"Shipper's responsibility.

(a) Except as otherwise provided in this part, a person may offer a hazardous material for transportation in a packaging or container required by this part only in accordance with the following:

(1) The person shall class and describe the hazardous material in accordance with parts 172 and 173 of this subchapter, and

(2) The person shall determine that the packaging or container is an authorized packaging, including part 173 requirements, and that it has been manufactured, assembled, and marked in accordance with:

(i) Section 173.7(a) and parts 173, 178, or 179 of this subchapter;

(ii) A specification of the Department in effect at the date of manufacture of the packaging or container;

(iii) An approval issued under this subchapter; or

(iv) An exemption issued under subchapter B of this chapter.

(3) In making the determination under paragraph (a)(2) of this section, the person may accept:

(i) The manufacturer's certification, specification, approval, or exemption marking (see 178.0

2 and 179.1 of this subchapter); or

(ii) With respect to cargo tanks provided by a carrier, the manufacturer's identification plate or a written certification of specification or exemption provided by the carrier.

(4) For a DOT specification or UN Standard packaging, a person shall perform all functions necessary to bring that package into compliance with part 178 of this subchapter, as identified by the packaging manufacturer or subsequent distributor, in accordance with $178.2(\mathrm{c})$ of this subchapter.

(b) [Reserved]

(c) Prior to each shipment of fissile radioactive materials, and Type B or highway route controlled quantity packages of radioactive materials (see 173.403), the shipper shall notify the consignee of the dates of shipment and expected arrival. The shipper shall also notify each consignee of any special loading/unloading instructions prior to his first shipment. For any shipment of irradiated reactor fuel, the shipper shall provide physical protection in compliance with a plan established under:

(1) Requirements prescribed by the U.S. Nuclear Regulatory Commission, or

(2) Equivalent requirements approved by the Associate Administrator for Hazardous Materials Safety, RSPA. 
(49 U.S.C. 1803, 1804, 1808, and 1809; 49 CFR 1.53, app. A to part 1)"

\section{REQUREMENT SOURCE: DANGEROUS-GOODS-REGU Section 3.0.5}

"Shipper's Responsibility

The shipper is responsible for identifying and classifying all dangerous goods intended for transport by air in compliance with these Regulations. Specifically, before packing any dangerous goods for transport by air, the shipper must:

$\Gamma$ identify, correct and fully, all dangerous articles and dangerous substances within the consignment;

$\Gamma$ classify each item of dangerous goods by determining under which of the nine classes it falls and, where relevant, determining any subsidiary hazards;

$\Gamma$ where relevant, assign each item of dangerous goods to one of three packing groups within the assigned class or division."

\section{REQUTREMENT SOURCE: DANGEROUS-GOODS-REGU Section 5.0.1.4}

"The shipper must ensure that before a packaging authorized for re-use, or an overpack is re-used, all inappropriate dangerous goods markings and labels are removed or completely obliterated."

\section{REQUIREMENT SOURCE: DANGEROUS-GOODS-REGU Section 5.0.2. 8}

"When filling receptacles for liquids, sufficient ullage (outage) must be left to ensure that neither leakage nor permanent distortion of the receptacle will occur as a result of an expansion of the liquid caused by temperatures likely to prevail during transport. Liquids must not completely fill a receptacle at a temperature of 55 degrees C (130 degrees F)."

\section{REQUIREMENT SOURCE: DANGEROUS-GOODS-REGU Section 5.0.3.2}

"Different Dangerous Goods in Limited Quantities in one Package: When different dangerous goods in Limited Quantities are packed together in one outer packaging, the quantities of such dangerous goods must be so limited that:

$\neg$ for Classes 3 and 8 and Divisions 4.1, 4.3 (solid), 5.1, 5.2 and 6.1, the total net quantity in the package must not exceed the lowest het quantity per package permitted for Limited Quantities in the List of Dangerous Goods for any of the dangerous goods in the package. For calculation purposes, when a package contains both liquids and solids, the quantities for the liquids must be converted into kilograms in order to determine that the permitted maximum net quantity has not been exceeded;

$\neg$ for Classes 2 and 9, when packed without dangerous goods of other classes, the gross weight of the package must not exceed $30 \mathrm{~kg}$; or

7 for Classes 2 and 9 when packed with dangerous goods of other classes, the gross weight of the package does not exceed $30 \mathrm{~kg}$ and the maximum net quantity of goods other than in Classes 2 or 9 in the package is limited as provided above." 


\section{REQUIREMENT SOURCE: DANGEROUS-GOODS-REGU Section 5.0.3.3}

"In addition, dangerous goods in Limited Quantities must be packed in accordance with the applicable Limited Quantity packing instruction (identified by the prefix letter "Y")."

\section{REQUIREMENT SOURCE: DANGEROUS-GOODS-REGU Section 6.0.4}

"Packed with Other Items. A package containing radioactive material, other than LSA or SCO, must not contain any other items except such articles and documents as are necessary for the use of the radioactive material. Low specific activity materials (LSA) and surface contaminated objects (SCO) may be packed with other items. Articles and documents (and for LSA and SCO other items) may be included, provided that there is no interaction between them and the packaging or contents that would reduce the safety of the package."

Coordination and Planning of Base Technology

Author's Note: This subelement is not applicable to the WHC packaging and transportation operations.

Vehicle and Equipment Control and Maintenance

\section{REQUIREMENT SOURCE: 49CFR392 Part 2}

"Every motor vehicle must be operated in accordance with the laws, ordinances, and regulations of the jurisdiction in which it is being operated. However, if a regulation of the Federal Highway Administration imposes a higher standard of care than that law, ordinance or regulation, the Federal Highway Administration regulation must be complied with."

Exclusive Use Vehicles

\section{REQUIREMENT SOURCE: 49CFR174 Part 715}

Author's Note: The requirement addresses "railcar."

"Cleanliness of cars after use.

(a) Each transport vehicle used for transporting Class 7 (radioactive) materials as exclusive use, as defined in 173.403 of this subchapter, must be surveyed with appropriate radiation detection instruments after each use. A vehicle may not be returned to service until the radiation dose rate at any accessible surface is 0.5 millirem per hour or less, and there is no significant removable radioactive surface contamination, as defined in 173.443 of this subchapter.

(b) This section does not apply to any rail car used solely for transporting Class 7 (radioactive) materials if a survey of the interior surface of the car shows that the radiation dose rate does not exceed 10 millirem per hour at the interior surface or 2 millirem per hour at $1 \mathrm{~m}$ ( 3 feet) from any interior surface. The car must be stenciled with the words "FOR RADIOACTIVE MATERIALS USE ONLY" in lettering at least $8 \mathrm{~cm}$ ( 3 inches) high in a conspicuous place on both sides of the exterior of the car and it must be kept closed at all times other than during loading and unloading." 


\section{REQUIREMENT SOURCE: 49CFR177 Part 843}

\section{"Contamination of vehicles}

(a) Each motor vehicle used for transporting Class 7 (radioactive) materials under exclusive use conditions in accordance with $173.425(\mathrm{c})$ or $173.443(\mathrm{c})$ shall be surveyed with radiation detection instruments after each use. A vehicle may not be returned to service until the radiation dose rate at each accessible surface is 0.5 millirem per hour or less and the removable (non-fixed) radioactive surface contamination is not greater than the level prescribed in 173.443(a).

(b) This section does not apply to any vehicle used solely for transporting Class 7 (radioactive) material if a survey of the interior surface shows that the radiation dose rate does not exceed 10 millirem per hour at the interior surface or 2 millirem per hour at $1 \mathrm{~m}$ ( 3 feet) from any interior surface. These vehicles must be stenciled with the words "For Class 7 (radioactive) Materials Only" in lettering at least $7.5 \mathrm{~cm}$ ( 3 inches) high in a conspicuous place, on both sides of the exterior of the vehicle. These vehicles must be kept closed at all times other than loading and unloading.

(c) In case of fire, accident, breakage, or unusual delay involving shipments of Class 7 (radioactive) material, see 177.861."

\section{Commercial Motor Vehicles}

\section{REQUTREMENT SOURCE: 49CFR383 Part 23(a)(1)}

"General rule. Effective April 1, 1992, no person shall operate a commercial motor vehicle unless such person has taken and passed written and driving tests which meet the Federal standards contained in subparts F, G, and $\mathrm{H}$ of this part for the commercial motor vehicle that person operates or expects to operate."

\section{REQUIREMENT SOURCE: 49CFR383 Part 23(a)(2)}

"Effective April 1, 1992, except as provided in paragraph (b) of this section, no person shall operate a commercial motor vehicle unless such person possesses a CDL which meets the standards contained in subpart J of this part, issued by his/her State or jurisdiction of domicile."

\section{REQUTREMENT SOURCE: 49CER393 Part 1}

"Scope of the rules in this part

Every employer and employee shall comply and be conversant with the requirements and specifications of this part. No employer shall operate a commercial motor vehicle, or cause or permit it to be operated, unless it is equipped in accordance with the requirements and specifications of this part." 
Westinghouse Hanford Company (WHC)

Standards/Requirements Identification Document

13.0 Packaging and Transportation
WHC-SD-MP-SRID-002

January 10, 1996

Rev. 0

Page 34 of 66

Vehicle Inspection, Repair, and Maintenance

\section{REQUIREMENT SOURCE: 49CFR107 Part 502}

"General registration requirements

(b) No person may engage in the manufacture, assembly, certification, inspection or repair of a cargo tank or cargo tank motor vehicle manufactured under the terms of a DOT specification under subchapter $C$ of this chapter or an exemption issued under this part unless the person is registered with the Department in accordance with the provisions of this subpart. A person employed as an inspector or design certifying engineer is considered to be registered if the person's employer is registered.

(c) A person who performs functions which are subject to the provisions of this subpart may perform only those functions which have been identified to the Department in accordance with the procedures of this subpart.

(d) Registration statements must be in English, contain all of the information required by this subpart, and be submitted to: Approvals Branch, Associate Administrator for Hazardous Materials Safety, Attn: DHM-32, Research and Special Programs Administration, Department of Transportation, Washington, DC 20590-0001."

\section{REQUTREMENT SOURCE: 49CFR392 Part 9(a)}

"General. No person shall drive a motor vehicle and a motor carrier shall not require or permit a person to drive a motor vehicle unless-

(1) The vehicle's cargo is properly distributed and adequately secured as specified in 393.100 . 393.106 of this subchapter.

(2) The vehicle's tailgate, tailboard, doors, tarpaulins, its spare tire and other equipment used in its operation, and the means of fastening the vehicle's cargo are secured; and

(3) The vehicle's cargo or any other object does not obscure the driver's view ahead or to the right or left sides, interfere with the free movement of his arms or legs, prevent his free and ready access to accessories required for emergencies, or prevent the free and ready exit of any person from the vehicle's cab or driver's compartment."

\section{REQUIREMENT SOURCE: 49CFR396 Part 3(a) Paragraph 1}

"General. Every motor carrier shall systematically inspect, repair, and maintain, or cause to be systematically inspected, repaired, and maintained, all motor vehicles subject to its control."

\section{REQUTEMENT SOURCE: 49CFR396 Part 3(a)(1)}

"Parts and accessories shall be in safe and proper operating condition at all times. These include those specified in part 393 of this subchapter and any additional parts and accessories which may affect safety of operation, including but not limited to, frame and frame assemblies, suspension systems, axles and attaching parts, wheels and rims, and steering systems." 
Westinghouse Hanford Company (WHC)

Standards/Requirements Identification Document

WHC-SD-MP-SRID-002

January 10, 1996

Rev. 0

13.0 Packaging and Transportation

Page 35 of 66

\section{REQURRMENT SOURCE: 49CFR396 Part 17(g)}

"It shall be the responsibility of the motor carrier to ensure that all parts and accessories not meeting the minimum standards set forth in appendix $G$ to this subchapter are repaired promptly."

\section{$\underline{13.2 .3 .4}$}

Inspector Qualifications and Records

\section{REQUIREMENT SOURCE: 49CFR396 Part 19(a)}

"Inspector qualifications.

It shall be the motor carrier's responsibility to ensure that the individual(s) performing an annual inspection under 396.17 (d) or (e) is qualified as follows:

(1) Understands the inspection criteria set forth in 49 CFR part 393 and appendix G of this subchapter and can identify defective components;

(2) Is knowledgeable of and has mastered the methods, procedures, tools and equipment used when performing an inspection; and

(3) Is capable of performing an inspection by reason of experience, training, or both as follows:

(i) Successfully completed a State or Federal-sponsored training program or has a certificate from a State or Canadian Province which qualifies the person to perform commercial motor vehicle safety inspections, or

(ii) Have a combination of training and/or experience totaling at least 1 year. Such training and/or experience may consist of:

(A) Participation in a truck manufacturer-sponsored training program or similar commercial training program designed to train students in truck operation and maintenance;

(B) Experience as a mechanic or inspector in a motor carrier maintenance program;

(C) Experience as a mechanic or inspector in truck maintenance at a commercial garage, fleet leasing company, or similar facility; or

(D) Experience as a commercial vehicle inspector for a State, Provincial or Federal Government."

\subsubsection{IM Portable Tanks}

\section{REQUIREMENT SOURCE: 49CFR173 Part 32(h)}

"Damaged tanks. Any tank that has been in an accident and that has been damaged to an extent that may adversely affect its product retention capability, must be retested as prescribed in paragraph $(e)(2)$ of this section." 


\section{REQUREMIENT SOURCD: 49CFR173 Part 32(k)}

"The repair of tanks is authorized, provided such repairs are made under requirements prescribed in the "Code" for the original design and construction.

(1) In addition to any other provisions of the specification, no tank shall be repaired, or remodeled, as to cause leakage or cracks or likelihood of leakage or cracks, by areas of stress concentration due to shrinkage of cooling metal in welding operations, sharp fillets, reversal of stresses, or otherwise.

(2) No field welding shall be done except to non-pressure parts."

13.2 .4

$\underline{13.2 .5}$

13.2.5.1

\section{Onsite Material Tracking}

Author's Note: Onsite material tracking requirements are addressed at the facility level in the Environmental Protection and Safeguards and Security functional areas.

\section{Offsite Transportation Management}

\section{REQUIREMENT SOURCE: DOE1540.1A Chapter I, Section 10.a}

Author's Note: Shipment Mobility/Accountability Concept (SMAC).

"All field elements will participate in SMAC by providing shipment data unless exempted by EM-1. Those exempted from participation will submit an annual transportation report as prescribed in subparagraph $\mathrm{c}$ below and will provide transportation data as required on an ad hoc basis."

\section{Licensing and Registration}

\section{REQUIREMENT SOURCE: 10CFR71 Part 3}

"Requirement for license. A licensee subject to the regulations in this part may not (a) deliver any licensed material to a carrier for transport or (b) transport licensed material except as authorized in a general license or a specific license issued by the Commission, or as exempted in this part."

\section{REQUIREMENT SOURCE: 49CFR107 Part 608(a)}

"General registration requirements. Except as provided in 107.616(d), each person subject to this subpart must submit a complete and accurate registration statement not later than:

(1) August 31, 1992, or in time to comply with paragraph (b) of this section, whichever is later, on DOT Form F 5800.2; and

(2) June 30 for each subsequent registration year, or in time to comply with paragraph (b) of this section, whichever is later, on DOT Form F 5800.2." 


\section{REQUREMENT SOURCE: 49CFR107 Part 620(a)}

"Recordkeeping requirements. Each person subject to the requirements of this subpart, or its agent designated under $107.608(e)$, must maintain at its principal place of business for a period of three years from the date of issuance of each Certificate of Registration:

(1) A copy of the registration statement filed with RSPA;

(2) A copy of the certified or cashier's check, money order, or a copy of the credit card billing statement showing payment for the person's registration and processing fee; and

(3) The Certificate of Registration issued to the registrant by RSPA."

\section{REQUIREMENT SOURCE: 49CFR107 Part 620(c)}

"Each person subject to this subpart must furnish its Certificate of Registration (or a copy thereof) and all other records and information pertaining to the information contained in the registration statement to an authorized representative or special agent of DOT upon request."

\section{REQUIREMENT SOURCE: 49CFR385 Part 21(a)}

"All motor carriers currently conducting operations in interstate or foreign commerce shall file a Motor Carrier Identification Report, Form MCS-150, within 90 days after the effective date of this rule. Exception: The provisions of this section do not apply to a motor carrier that has received written notification of a safety rating from the FHWA."

\subsubsection{Import/Export Shipments}

\section{REQUIREMINT SOURCE: 49CFR171 Part 12}

Author's Note: Intemational Maritime Dangerous Goods (IMDG).

"(a) Importer's responsibility. Except in the case of a shipment from Canada conforming to 171.12a of this subchapter, each person importing a hazardous material into the United States shall provide the shipper and the forwarding agent at the place of entry into the United States timely and complete information as to the requirements of this subchapter that will apply to the shipment of the material within the United States. The shipper, directly or through the forwarding agent at the place of entry, shall provide the initial carrier in the United States the certificate of compliance required by 172.204 of this subchapter. The carrier may not accept the material for transportation unless the required certification is provided.

(b) IMDG Code. The IMDG Code sets forth descriptions, classifications, packagings, labeling and vessel stowage requirements. Notwithstanding the provisions of this subchapter, a material which is packaged, marked, classed, labeled, placarded, described, stowed and segregated, and certified in accordance with the IMDG Code, and otherwise conforms to the requirements of this section, may be offered and accepted for transportation and transported within the United States. The following conditions and limitations apply:

(1) The provisions of this paragraph (b) apply only if all or part of the transportation is by vessel.

(2) A number of materials listed in the IMDG Code are not subject to the requirements of this subchapter. The provisions of this subchapter do not apply to materials listed in the IMDG 
Code which are not designated as hazardous materials under this subchapter. These materials may, however, be transported in the U.S. when described, marked and labeled in accordance with the IMDG Code.

(3) A material designated as a hazardous material under this subchapter which is not subject to the requirements of the IMDG Code may not be transported under the provisions of this section.

(4) A forbidden material or package according to 173.21 of this subchapter or Column 3 of the 172.101 Table may not be transported under the provisions of this section.

(5) Bulk packagings must conform to the requirements of this subchapter.

(6) For export, packagings must conform to the applicable requirements in $173.24,173.24 \mathrm{a}$ and $\mathbf{1 7 3 . 2 8}$ of this subchapter.

(7) A Class 1 material must be classed and approved under the procedures in subpart $C$ of part 173 of this subchapter and conform to the requirements of 172.320 and part 176 of this subchapter.

(8) When a hazardous material, which is subject to the requirements of the IMDG Code, is a material poisonous by inhalation (see 171.8 of this subchapter)

(i) The shipping description must include the words "Poison-Inhalation Hazard" or "Inhalation Hazard", as required in $172.203(\mathrm{~m})$ of this subchapter;

(ii) The material must be packaged in accordance with the requirements of this subchapter; and

(iii) The package must be marked in accordance with 172.313 of this subchapter and labeled and placarded with "POISON" or "POISON GAS", as appropriate, in accordance with subparts $E$ and $F$, respectively, of part 172 of this subchapter.

(9) Class 7 materials must conform to the provisions of paragraph (d) of this section.

(10) For a hazardous waste, as defined in this subchapter.

(j) The word "Waste" must precede the proper shipping name on shipping papers and packages; and

(ii) The requirements of $\mathbf{1 7 2 . 2 0 5}$ of this subchapter with respect to hazardous waste manifests are applicable.

(11) A hazardous substance as défined in this subchapter must conform to the requirements of $172.203(\mathrm{c})$ and $\mathbf{1 7 2 . 3 2 4}$ of this subchapter.

(12) A poisonous material must conform to the requirements of $172.203(\mathrm{~m})$ of this subchapter.

(13) For a Division 4.3 material, the words "Dangerous When Wet" must appear in association with the basic description on shipping papers.

(14) Any ammonium nitrate fertilizer or ammonium nitrate mixed fertilizer must not meet the definition and criteria of a Class 1 (explosive) material. 
(15) Cylinders not manufactured to DOT specifications must conform to the requirements of $173.301(i)$ and (j) of this subchapter.

(16) Shipments of hazardous materials under this section must conform to the requirements for emergency response information as prescribed in subpart $\mathrm{G}$ of part 172 of this subchapter.

(c) Use of IMDG Code in port areas. Section 171.2 notwithstanding, a hazardous material (other than Division 1.1 or 1.2 or Class 7 ) being imported into or exported from the United States or passing through the United States in the course of being shipped between places outside the United States may be offered and accepted for transportation and transported by motor vehicie within a single port area (including contiguous harbors) when packaged, marked, classed, labeled, stowed and segregated in accordance with the IMDG Code, if the hazardous material is offered and accepted in accordance with the requirements of subparts $\mathrm{C}$ and $\mathrm{F}$ of part 172 of this subchapter pertaining to shipping papers and placarding and otherwise conforms to the applicable requirements of part 176 of this subchapter. The requirement in 172.201(d) of this subchapter for an emergency telephone number does not apply to shipments made in accordance with the IMDG Code if the hazardous material:

(1) Is not offloaded from the vessel;

(2) Is offloaded between ocean vessels at a U.S. port facility without being transported by public highway.

(d) Use of IAEA regulations for radioactive materials. Radioactive materials being imported into or exported from the United States, or passing through the United States in the course of being shipped between places outside the United States, may be offered and accepted for transportation when packaged, marked, labeled and otherwise prepared for shipment in accordance with IAEA "Regulations for the Safe Transport of Radioactive Materials, Safety Series No. 6, 1985 Edition" including "Supplement 1988", if

(1) Highway route controlled quantities (see 173.403 of this subchapter) are shipped in accordance with 172.203(d)(1)(iii), 172.507, 173.22(c), and 177.825 of this subchapter;

(2) For fissile materials and Type B packages, the competent authority certification and any necessary revalidation is obtained from the appropriate competent authorities as specified in $173.471,173.472$ and 173.473 of this subchapter and all requirements of the certificates and revalidations are met;

(3) Type A package contents are limited in accordance with 173.431 of this subchapter;

(4) The country of origin for the shipment has adopted the LAEA "Regulations for the Safe Transport of Radioactive Materials, Safety Series No. 6, 1985 Edition", including "Supplement $1988^{\prime \prime}$; and

(5) The requirements of $173.448(\mathrm{e}), 173.448(\mathrm{f})$, and $173.448(\mathrm{~g})(3)$ of this subchapter are fulfilled, when applicable." 
Westinghouse Hanford Company (WHC)

\section{REQUREMENT SOURCE: 49CFR171 Part 2}

"(a) No person may offer or accept a hazardous material for transportation in commerce uniess that material is properly classed, described, packaged, marked, labeled, and in condition for shipment as required or authorized by this subchapter (including 171.11, 171.12, and 176.11).

(b) No person may transport a hazardous material in commerce unless that material is handled and transported in accordance with this subchapter, or an exemption issued under subchapter B of this chapter.

(c) No person may represent, mark, certify, sell, or offer a packaging or container as meeting the requirements of this subchapter or an exemption issued under subchapter B of this chapter, governing its use in the transportation in commerce of a hazardous material, whether or not it is used or intended to be used for the transportation of a hazardous material, unless the packaging or container is manufactured, fabricated, marked, maintained, reconditioned, repaired, or retested, as appropriate, in accordance with this subchapter, an approval issued thereunder, or an exemption issued under subchapter B of this chapter.

(d) The representations, markings, and certifications subject to the probibitions of paragraph

(c) of this section include:

(1) Specification identifications that include the letters "DOT" or "UN";

(2) Exemption, approval, and registration numbers that include the letters "DOT; " and

(3) Test dates displayed in association with specification, registration, approval, or exemption markings indicating compliance with a test or retest requirement of this subchapter, an approval issued thereunder, or an exemption issued under subchapter B of this chapter.

(e) When a person performs a function covered by or having an effect on a specification prescribed in part 178, 179 or 180 of this subchapter, an approval issued under this subchapter, or an exemption issued under subpart B of this chapter, that person must perform the function in accordance with that specification, approval, or exemption, as appropriate.

(f) No person shall, by marking or otherwise, represent that-

(1) A container or package for the transportation of hazardous materials is safe, certified, or in compliance with the requirements of this title unless it meets the requirements of all applicable regulations issued under the Act; or

(2) A hazardous material is present in a package, container, motor vehicle, rail freight car, aircraft, or vessel, if the hazardous material is not present.

(g) No person shall unlawfully alter, remove, deface, destroy, or otherwise tamper with-

(1) Any marking label, placard, or description on a document required by the Act, or a regulation issued under the Act; or

(2) Any package, container, motor vehicle, rail freight car, aircraft, or vessel used for the transportation of hazardous materials. 
Westinghouse Hanford Company (WHC)

Standards/Requirements Identification Document

WHC-SD-MP-SRID-002

January 10, 1996

Rev. 0

13.0 Packaging and Transportation

Page 41 of 66

(49 U.S.C. 1803, 1804, 1808, and 1809; 49 CFR 1.53, app. A to part 1)"

\section{REQUIREMENT SOURCE: 49CFR171 Part 3}

"(a) No person may offer for transportation or transport a hazardous waste (as defined in 171.8 of this subchapter) in interstate or intrastate commerce except in accordance with the requirements of this subchapter.

(b) No person may accept for transportation, transport, or deliver a hazardous waste for which a manifest is required unless that person:

(1) Has marked each motor vehicle used to transport hazardous waste in accordance with 390.21 or 1058.2 of this title even though placards may not be required;

(2) Complies with the requirements for manifests set forth in 172.205 of this subchapter; and

(3) Delivers, as designated on the manifest by the generator, the entire quantity of the waste received from the generator or a transporter to:

(i) The designated facility or, if not possible, to the designated alternate facility;

(ii) The designated subsequent carrier; or

(iii) A designated place outside the United States. Note: Federal law specifies penalties up to $\$ 25,000$ fine and 5 years imprisonment for the willful discharge of hazardous waste at other than designated facilities. 49 U.S.C. 1809.

(c) With regard to hazardous waste subject to this subchapter, any requirement of a state or its political subdivision is inconsistent with this subchapter if it applies because that material is a waste material and applies differently from or in addition to the requirements of this subchapter concerning:

(1) Packaging, marking, labeling, or placarding;

(2) Format or contents of discharge reports (except immediate reports for emergency response); and

(3) Format or contents of shipping papers, including hazardous waste manifests.

Note: See 172.205; each manifest must be prepared in accordance with 40 CFR 262.20 including the instructions and limitations specified for preparation of a manifest.

(d) If a discharge of hazardous waste or other hazardous material occurs during transportation, and an official of a State or local government or a Federal agency, acting within the scope of his official responsibilities, determines that immediate removal of the waste is necessary to prevent further consequence, that official may authorize the removal of the waste without the preparation of a manifest. [Note: In such cases, EPA does not require carriers to have EPA identification numbers.]

Note 1: EPA requires shippers (generators) and carriers (transporters) of hazardous wastes to have identification numbers which must be displayed on hazardous waste manifests. See 40 CFR parts 262 and 263. (Identification number application forms may be obtained from EPA regional offices.) 
Note 2: In 40 CFR part 263, the EPA sets forth requirements for the cleanup of releases of hazardous wastes."

\section{REQUIREMENT SOURCE: 49CFR397 Part 101(a)}

"Requirements for motor carriers and drivers. Except as provided in paragraph (b) of this section or in circumstances when there is only one practicable highway route available, considering operating necessity and safety, a carrier or any person operating a motor vehicle that contains a Class 7 (radioactive) material, as defined in 49 CFR 172.403, for which placarding is required under 49 CFR part 172 shall:

(1) Ensure that the motor vehicle is operated on routes that minimize radiological risk;

(2) Consider available information on accident rates, transit time, population density and activities, and the time of day and the day of week during which transportation will occur to determine the level of radiological risk; and

(3) Tell the driver which route to take and that the motor vehicle contains Class 7 (radioactive) materials."

$\underline{13.2 .6}$

$\underline{13.2 .6 .1}$

\section{Marking, Labeling and Placarding}

\section{Marking Requirements}

The marking requirements associated with shipments of hazardous materials, hazardous waste, dangerous waste, and radioactive materials are delineated within the following sub-elements.

\section{REQUIREMENT SOURCE: 49CFR172 Part 300}

"Applicability.

(a) Each person who offers a hazardous material for transportation shall mark each package, freight container, and transport vehicle containing the hazardous material in the manner required by this subpart.

(b) When assigned the function by this subpart, each carrier that transports a hazardous material shall mark each package, freight container, and transport vehicle containing the hazardous material in the manner required by this subpart."

\section{REQUIREMENT SOURCE: DANGEROUS-GOODS-REGU Section 7.1.1}

"Shipper's Specific Responsibilities

For each such package and overpack requiring marking, the shipper must:

- check that any relevant marking on the package or overpack already on the package is in the correct location and meets the quality and specification requirements of the Regulations;

- remove or obliterate any irrelevant marking already on the package or overpack;

- ensure that each outer or single packaging used for dangerous goods, for which specification packaging is required in Section 5, bears the specification markings as specified in 10.0.4; 
$\Gamma$ apply any appropriate new marking in the correct location, and ensure that it is of durable quality and correct specification;

- ensure that his responsibilities for marking are completely fulfilled when the package or overpack is presented to the operator for shipment."

\section{REQUIREMENT SOURCE: 49CFR172 Part 400}

"General labeling requirements.

(a) Except as specified in 172.400 a, each person who offers for transportation or transports a hazardous material in any of the following packages or containment devices, shall label the package or containment device with labeis specified for the material in the 172.101 Table and in this subpart:

(1) A non-bulk package;

(2) A bulk packaging, other than a cargo tank, portable tank, or tank car, with a volumetric capacity of less than $18 \mathrm{~m} 3$ ( 640 cubic feet), unless placarded in accordance with subpart $F$ of this part;

(3) A portable tank of less than $3785 \mathrm{~L}$ (1000 gallons) capacity, unless placarded in accordance with subpart $F$ of this part;

(4) A DOT Specification 106 or 110 multi-unit tank car tank, unless placarded in accordance with subpart $F$ of this part; and

(5) An overpack, freight container or unit load device, of less than $18 \mathrm{~m} 3$ (640 cubic feet), which contains a package for which labels are required, unless placarded or marked in accordance with 172.512 of this part.

(b) Labeling is required for a hazardous material which meets one or more hazard class definitions, in accordance with Column 6 of the 172.101 Table and the following table:

HAZDOCS-2 Table No. 16"

\section{REQUIREMENT SOURCE: 49CFR172 Part 402}

"Additional labeling requirements.

(a) Subsidiary hazard labels. Each package containing a hazardous material

(1) Shall be labeled with primary and subsidiary hazard labels as specified in Column 6 of the 172.101 Table; and

(2) For other than Class 2 or Class 1 materials (for subsidiary labeling requirements for Class 1 materials see paragraph (e) of this section), if not already labeled under paragraph (a)(1) of this section, shall be labeled with subsidiary hazard labels in accordance with the following table: HAZDOCS-2 Table No. 17 
Westinghouse Hanford Company (WHC)

Standards/Requirements Identification Document

13.0 Packaging and Transportation
WHC-SD-MP-SRID-002

January 10, 1996

Rev. 0

Page 44 of 66

(b) Display of hazard class on labels. The appropriate hazard class or, for Division 5.1 or 5.2 the division number, shall be displayed in the lower comer of a primary hazard label and may not be displayed on a subsidiary label.

(c) Cargo Aircraft Only label. Each person who offers for transportation or transports by aircraft a package containing a bazardous material which is authorized on cargo aircraft only shall label the package with a CARGO AIRCRAFT ONLY label specified in 172.448 of this subpart.

(d) Radioactive Materials. Each package containing a radioactive material that also meets the definition of one or more additional hazards, except Class 9, shall be labeled as a radioactive material as required by $\mathbf{1 7 2 . 4 0 3}$ of this subpart and for each additional hazard.

(e) Class 1 (explosive) Materials. In addition to the label specified in Column 6 of the 172.101 Table, each package of Class 1 material that also meets the definition for:

(1) Division 6.1, Packing Groups I or II, shall be labeled POISON; or

(2) Class 7, shall be labeled in accordance with 172.403 of this subpart."

\section{REQUTREMNT SOURCE: DANGEROUS-GOODS-REGU Section 7.2.1}

"For each such package and overpack requiring labelling, the shipper must:

remove or obliterate any irrelevant labelling already on the package or overpack;

- use only labeis of durabie quality and correct specification;

inscribe on each label, in a durable manner, any required additional information;

affix the appropriate label(s) in the correct location(s) and in a secure manner;

ensure that his responsibilities for labelling are completely fulfilled when the package or overpack is presented to the operator for shipment."

13.2 .6 .3

Placarding Requirements

\section{REQUIREMENT SOURCE: 49CFR172 Part 500}

"Applicability of placarding requirements.

(a) Each person who offers for transportation or transports any hazardous material subject to this subchapter shall comply with the applicable placarding requirements of this subpart.

(b) This subpart does not apply to-

(1) Infectious substances;

(2) Hazardous materials classed as ORM D;

(3) Hazardous materials authorized by this subchapter to be offered for transportation as Limited Quantities when identified as such on shipping papers in accordance with 172.203(b); 
(4) Hazardous materials which are packaged as small quantities under the provisions of 173.4 of this subchapter; and

(5) Combustible liquids in non-bulk packagings."

\section{REQUIREMENT SOURCE: 49CFR172 Part 502}

"Probibited and permissive placarding.

(a) Prohibited placarding. Except as provided in paragraph (b) of this section, no person may affix or display on a packaging, freight container, unit load device, motor vehicle or rail car-

(1) Any placard described in this subpart unless

(i) The material being offered or transported is a hazardous material;

(ii) The placard represents a hazard of the hazardous material being offered or transported; and

(iii) Any placarding conforms to the requirements of this subpart.

(2) Any sign or other device that, by its color, design, shape or content, could be confused with any placard prescribed in this subpart.

(b) Exceptions.

(1) The restrictions in paragraph (a) of this section do not apply to a bulk packaging, freight container, unit load device, transport vehicle or rail car which is placarded in conformance with the TDG Regulations, the IMDG Code or the UN Recommendations.

(2) The restrictions of paragraph (a) of this section do not apply to the display of an identification number on a white square-on-point configuration in accordance with 172.336(b) of this part.

(c) Permissive placarding. Placards may be displayed for a bazardous material, even when not required, if the placarding otherwise conforms to the requirements of this subpart."

\section{Shipping Papers, Bills of Lading and Manifests}

\section{REQUTREMENT SOURCE: 40CFR262 Part 20}

"(a) A generator who transports, or offers for transportation, hazardous waste for offsite treatment, storage, or disposal must prepare a Manifest OMB control number 2050-0039 on EPA form 8700-22A, according to the instructions included in the appendix to part 262.

(b) A generator must designate on the manifest one facility which is permitted to handle the waste described on the manifest.

(c) A generator may also designate on the manifest one alternate facility which is permitted to handle his waste in the event an emergency prevents delivery of the waste to the primary designated facility. 
(d) If the transporter is unable to deliver the hazardous waste to the designated facility or the alternate facility, the generator must either designate another facility or instruct the transporter to return the waste.

(e) The requirements of this subpart do not apply to hazardous waste produced by generators. of greater than $100 \mathrm{~kg}$ but less than $1000 \mathrm{~kg}$ in a calendar month where:

(l) The waste is reclaimed under a contractual agreement pursuant to which:

(i) The type of waste and frequency of shipments are specified in the agreement;

(ii) The vehicle used to transport the waste to the recycling facility and to deliver regenerated material back to the generator is owned and operated by the reclaimer of the waste; and

(2) The generator maintains a copy of the reclamation agreement is his files for a period of at least three years after termination or expiration of the agreement."

\section{REQUTREMENT SOURCE: 40CFR262 Part 21}

"(a) If the State to which the shipment is manifested (consignment State) supplies the manifest and requires its use, then the generator must use that manifest.

(b) If the consignment State does not supply the manifest, but the State in which the generator is located (generator State) supplies the manifest and requires its use, then the generator must use that State's manifest.

(c) If neither the geaerator State nor the consigument State supplies the manifest, then the generator may obtain the manifest from any source."

\section{REQURREMENT SOURCE: WAC-173-303 Section 370(2)}

"If a facility receives dangerous waste accompanied by a manifest, the owner or operator, or his agent, must:

(a) Sign and date each copy of the manifest to certify that the dangerous waste covered by the manifest was received;

(b) Note any significant discrepancies in the manifest, as described in subsection (4) of this section, on each copy of the manifest;

(c) Immediately give the transporter at least one copy of the signed manifest;

(d) Within thirty days after the delivery, send a copy of the manifest to the generator; and

(e) Retain at the facility a copy of each manifest for at least three years from the date of delivery."

\section{REQUREMENT SOURCE: WAC-173-303 Section 370(3)}

"If a facility receives, from a rail or water (bulk shipment) transporter, dangerous waste which is accompanied by a manifest or shipping paper containing all the information required on the manifest (excluding the EPA/state identification numbers, generator's certification, and signatures), the owner or operator, or his agent, must: 
(a) Sign and date each copy of the manifest or shipping paper to certify that the dangerous waste covered by the manifest or shipping paper was received;

(b) Note any significant discrepancies in the manifest or shipping paper, as described in subsection (4) of this section, on each copy of the manifest or shipping paper;

(c) Immediately give the rail or waste (bulk shipment) transporter at least one copy of the manifest or shipping paper;

(d) Within thirty days after the delivery, send a copy of the signed and date manifest or shipping paper to the generator. However, if the manifest or shipping paper to the generator. However, if the manifest is not received within thinty days after the delivery, the owner or operator, or his agent, must send a copy of the signed and dated shipping paper to the generator; and

(e) Retain at the facility a copy of each shipping paper and manifest for at least three years from the date of delivery."

\section{REQUIREMENT SOURCE: WAC-173-303 Section 370(4)}

"Manifest discrepancies.

(a) Manifest discrepancies are significant discrepancies between the quantity or type of dangerous waste designated on the manifest or shipping paper and the quantity or type of dangerous waste a facility actually receives. Significant discrepancies in quantity are variations greater than ten percent in weight for bulk quantities (e.g., tanker trucks, railroad tank cars, etc.), or any variations in piece count for nonbulk quantities (i.e., any missing container or package would be a significant discrepancy). Significant discrepancies in type are obvious physical or chemical differences which can be discovered by inspection or waste analysis (e.g., waste solvent substituted for waste acid).

(b) Upon discovering a significant discrepancy, the owner or operator must attempt to reconcile the discrepancy with the waste generator or transporter. If the discrepancy is not resolved within fifteen days after receiving the waste, the owner or operator must immediately submit to the department a letter describing the discrepancy and attempts to reconcile it, and a copy of the manifest or shipping paper at issue."

13.2.7.1 Shipping Papers

\section{REQUIREMENT SOURCE: 49CFR171 Part 11, Introduction and (a) thru (c)}

"Notwithstanding the requirements of parts 172 and 173 of this subchapter, a hazardous material may be transported by aircraft, and by motor vehicle ejther before or after being transported by aircraft, in accordance with the ICAO Technical Instructions if the hazardous material:

(a) Is packaged, marked, labeled, classified, described and certified on a shipping paper and otherwise in a condition for shipment as required by the ICAO Technical Instructions;

(b) Is within the quantity limits prescribed for transportation by either passenger-carrying or cargo aircraft, as appropriate, as specified in the ICAO Technical Instructions;

(c) Is not a forbidden material or package according to 173.21 of this subchapter or Column 3 of the 172.101 Table; and" 


\section{REQUREMENT SOURCE: 49CER172 Part 201}

"General entries.

(a) Contents. When a description of hazardous material is required to be included on a shipping paper, that description must conform to the following requirements:

(1) When a hazardous material and a material not subject to the requirements of this subchapter are described on the same shipping paper, the hazardous material description entries required by 172.202 and those additional entries that may be required by 172.203 :

(i) Must be entered first, or

(ii) Must be entered in a color that clearly contrasts with any description on the shipping paper of a material not subject to the requirements of this subchapter, except that a description on a reproduction of a shipping paper may be highlighted, rather than printed, in a contrasting color (the provisions of this paragraph apply only to the basic description required by 172.202 (a) (1) and (2), and (3)), or

(iii) Must be identified by the entry of an " $\mathrm{X}$ " placed before the proper shipping name in a column captioned "HM." (The "X" may be replaced by "RQ," if appropriate.)

(2) The required shipping description on a shipping paper and all copies thereof used for transportation purposes, must be legible and printed (manually or mecbanically) in English.

(3) Unless it is specifically authorized or required in this subchapter, the required shipping description may not contain any code or abbreviation.

(4) A shipping paper may contain additional information concerning the material provided the information is not inconsistent with the required description. Unless otherwise permitted or required by this subpart, additional information must be placed after the basic description required by $172.202(a)$.

(b) Name of shipper. A shipping paper for a shipment by water must contain the name of the shipper.

(c) Continuation page. A shipping paper may consist of more than one page, if each page is consecutively numbered and the first page bears a notation specifying the total number of pages included in the shipping paper. For example, "Page 1 of 4 pages."

(d) Emergency response telephone number. A shipping paper must contain an emergency response telephone number, as prescribed in subpart $G$ of par 172 of this subchapter. (49 U.S.C. $1803,1804,1808 ; 49$ CFR 1.53 , app. A to part 1$)^{*}$

\section{REQUIREMENT SOURCE: 49CFR172 Part 204(a)}

"General. Except as provided in paragraphs (b) and (c) of this section, each person who offers a hazardous material for transportation shall certify that the material is offered for transportation in accordance with this subchapter by printing (manually or mechanically) on the shipping paper containing the required shipping description the certification contained in paragraph (a)(1) of this section or the certification (declaration) containing the language contained in paragraph (a)(2) of this section. 
(1) "This is to certify that the above-named materials are properly classified, described, packaged, marked and labeled, and are in proper condition for transportation according to the applicable regulations of the Department of Transportation."

Note: In line one of the certification the words "herein-named" may be substituted for the words "above-named".

(2) "I hereby declare that the contents of this consignment are fully and accurately described above by proper shipping name and are classified, packed, marked and labeled, and are in all respects in proper condition for transport by [*] according to applicable international and national governmental regulations."

*Additional language indicating the modes of transportation to be used may be inserted at this point in the certification. All modes of transportation may be indicated provided that any mode not applicable to a specific shipment is deleted (lined out)."

\section{REQUTREMENT SOURCE: 49CFR177 Part 817(a) and (b)}

"(a) General requirements. A carrier may not transport a hazardous material unless it is accompanied by a shipping paper that is prepared in accordance with $172.200,172.201$, 172.202, and 172.203 of this subchapter.

(b) Shipper certification. An initial carrier may not accept a hazardous material offered for transportation unless the shipping paper describing the material includes a shipper's certification which meets the requirements in $\mathbf{1 7 2 . 2 0 4}$ of this subchapter. Except for a hazardous waste, the certification is not required for shipments to be transported entirely by private carriage and for bulk shipments to be transported in a cargo tank supplied by the carrier."

\section{REQUIREMENT SOURCE: DANGEROUS-GOODS-REGU Section 6.6. 2}

"Language. The declaration form must be completed in the English language. If required by the States of Origin and/or Destination, the wording in English may be accompanied by an accurate translation in another language."

\section{REQUIREMENT SOURCE: DANGEROUS-GOODS-REGU Section 6.6. 3}

"Number of Copies. At least two copies of the declaration form must be completed and signed, with a signature as specified in 6.6 .8 , for presentation to the airline with the shipment. One signed copy must be retained by the accepting airline. The other signed copy must be forwarded with the shipments to its destination. One of the two copies, including the signature thereon, may be a carbon copy."

\section{REQUIREMENT SOURCE: DANGEROUS-GOODS-REGU Section 6.6. 6.1}

"Any alteration or amendment to an entry must be signed by the shipper with the same signature used to sign the document. Alteration of the "Air Waybill Number", the "Airport of Departure" and the "Airport of Destination" are excepted from this provision." 


\section{REQUIREMIJNT SOURCE: DANGEROUS-GOODS-REGU Section 6.6. 8.1}

"Requirements. The Shipper's Declaration for Dangerous Goods form must be signed by the shipper. The signature may be written by hand, or it may be in the form of a facsimile reproduced by printing or stamping or as a carbon copy. A typewritten signature is not acceptable. The declaration form must not, in any circumstances, be completed and/or signed by a consolidator, a forwarder or an IATA Cargo Agent."

\section{REQUIREMENT SOURCE: DANGEROUS-GOODS-REGU Section 6.6. 9.2}

"The applicable competent authority certificate(s) must accompany the shipment."

\section{REQUREMENT SOURCE: DANGEROUS-GOODS-REGU Section 6.6.10.1}

"The "Shipper's Deciaration for Dangerous Goods" form must be completed strictly in accordance with the following instructions. Entries in the boxes for AIR WAYBILL NUMBER, AIRPORT OF DEPARTURE and AIRPORT OF DESTINATION may be inserted either by the shipper, his agent, or by the accepting airline, but all other details must be entered only by the shipper."

\section{REQUTREMENT SOURCE: DOE1540.1A Chapter I, Section 5}

"Commercial bills of lading, air bills, and other commercial documents covering shipments made by or to Department contractors shall provide for consignment of the shipments from or to either the United States Department of Energy "in care of" the Department's contractor or the Department contractor "for the United States Department of Energy." "

13.2.7.2 Shipment Records

\section{REQUIREMENT SOURCE: WAC-173-303 Section 210}

"Generator recordkeeping.

(1) The generator shall keep a copy of each manifest signed by the initial transporter in accordance with WAC 173-303-180(3), manifest procedures, for three years, or until he receives a signed copy from the designated facility which received the waste. The signed facility copy shall be retained for at least five years from the date the waste was accepted by the initial transporter.

(2) The generator shall keep a copy of each annual report and exception report as required by WAC 173-303-220 for a period of at least five years from the due date of each report. The generator shall keep a copy of his most recent notification (Form 2) until he is no longer defined as a generator under this chapter.

(3) The generator shall keep records of any test results, waste analyses, or other determinations made in accordance with WAC 173-303-170(1) for designating dangerous waste for at least five years from the date that the waste was last transferred for on-site or off-site treatment, storage or disposal.

(4) Any other records required for generators accumulating wastes on-site as described in WAC 173-303-170 (4)(b) or 173-303-200 must be retained for at least five years, including, but not limited to such items as inspection logs and operating records. 
(5) The periods of retention for any records described in this section shall be automatically extended during the course of any unresolved enforcement action requiring those records or upon request by the director.

(6) All generator records, including plans required by this chapter, shall be made available and fumished upon request by the director."

$\underline{13.2 .8}$

Shipment Plans

\section{REQUTREMENT SOURCE: DOE1540.1A Chapter II, Section 9.a}

"For all Departmental shipments of highway route-controlled quantities of radioactive materials, or like quantities by rail or barge, a shipment plan will be submitted to EM-561 for all such shipping campaigns $\mathbf{4 5}$ days in advance of such shipments."

\section{REQUIREMENT SOURCE: DOE1540.1A Chapter II, Section 9.c}

"The shipping plan will include material type, shipping dates, estimated number of shipments, mode of transport, carrier proposed routes, package or cask description, and cargo security arrangements if required."

State Routing Requirements/Notifications

\section{REQUIREMENT SOURCE: 10CFR71 Part 97(a)}

"Except as specified in paragraph (b) of this section, prior to the transport or delivery to a carrier for transport of licensed material outside the confines of the licensee's plant or other place of use or storage, each licensee shall provide advance notification to the governor of a state, or the governor's designee, of the shipment to, through, or across the boundry[SIC] of the state."

\section{REQUIREMENT SOURCE: DOE1540.1A Chapter II, Section 8.a}

"DOE Unclassified Spent Fuel.

(1) The notification must be in writing and sent by registered letter, return receipt, to the office of each appropriate Governor or Governor's designee. A notification delivered by mail must be postmarked at least 7 days before transport of a shipment within or through the State. A notification delivered by messenger must reach the office of the Governor or Governor's designee at least 4 days before transport of a shipment within or through the State. A list of the mailing addresses of Governors or Governor's designees has been provided to the Manager of each DOE Field Office. Updates of this list are to be published each year in the June $\mathbf{3 0}$ issue of the Federal Register. Shippers unable to obtain the latest Federal Register listing locally should contact the Transportation Management Division (EM-561).

(2) The notification must include the following information:

(a) The name, address, and telephone number of the shipper, carrier, and receiver.

(b) A description of the shipment as specified by the DOT in 49 CFR, Parts 172.202 and 172.203(d). 
(c) A listing of the routes to be used within the State.

(d) The estimated date and time of departure from the point of origin.

(e) The estimated date and time of entry into the Governor's State.

(f) The estimated date and time of departure from the Governor's State (in such cases where the destination is not within the State).

(g) A statement that the information is required by DOE to be protected against unauthorized disclosure.

(3) A DOE shipper shall notify, by telephone or other means, a responsible individual in the office of the Governor or the Governor's designee of any schedule change that differs by more than 6 hours from the schedule information previously furmished in the written notification.

(4) Notice of cancellation of a spent fuel shipment can be made by telephone to each State affected. No written notice of cancellation must be made to the States. A record should be retained of the responsible individual contacted about the cancellation of a shipment."

Consignee Notifications

\section{REQUIREMENT SOURCE: 49CFR173 Part 22(c)}

"Shipper's responsibility.

(c) Prior to each shipment of fissile radioactive materials, and Type B or highway route controlled quantity packages of radioactive materiais (see 173.403), the shipper shall notify the consignee of the dates of shipment and expected arrival. The shipper shall also notify each consignee of any special loading/unloading instructions prior to his first shipment. For any shipment of irradiated reactor fuel, the shipper shall provide physical protection in compliance with a plan established under:

(1) Requirements prescribed by the U.S. Nuclear Regulatory Commission, or

(2) Equivalent requirements approved by the Associate Administrator for Hazardous Materials Safety, RSPA.

(49 U.S.C. 1803, 1804, 1808, and 1809; 49 CFR 1.53, app. A to part 1)"

\section{REQUREMENT SOURCE: DOE5480.3 Section 10.g(1) Introduction and 10.g(1)}

"Notification Procedures for Shipment and Nonreceipt of Radioactive Materials. To reduce to a minimum the number of shipments that must ultimately be considered lost, the following procedures shall be implemented:

(1) Prior to each shipment of fissile radioactive materials, or shipments of more than Type A quantity of radioactive material, the shipper shall notify the consignee of the dates of the shipment and of expected arrival. The shipper shall also notify each consignee of any special loading or unloading instructions prior to his or her first shipment." 


\section{REQUIREMENT SOURCE: DOE5480.3 Section 10.g(2)}

"The consignee shall be requested to notify the shipper immediately at the end of 4 days after the estimated arrival date if the shipment has not been received. Prompt notification by telephone or teletype should be followed by receipted registered mail to provide a written notice."

\section{REQUIREMENT SOURCE: DOE5480.3 Section 10.g(4)}

"For all radioactive material shipments, (Type A, Type B., low specific activity) a return receipt shall be requested. The shipper shall follow up on the shipment status if the return receipt is not received within 1 month."

\section{Emergency Response Information}

\section{REQUIREMENT SOURCE: 49CFR172 Part 600}

"Applicability and general requirements.

(a) Scope. Except as provided in paragraph (d) of this section, this subpart prescribes requirements for providing and maintaining emergency response information during transportation and at facilities where hazardous materials are loaded for transportation, stored incidental to transportation or otherwise handled during any phase of transportation.

(b) Applicability. This subpart applies to persons who offer for transportation, accept for transportation, transfer or otherwise handle hazardous materials during transportation.

(c) General requirements. No person to whom this subpart applies may offer for transportation, accept for transportation, transfer, store or otherwise handle during transportation a hazardous material unless:

(1) Emergency response information conforming to this subpart is immediately available for use at all times the hazardous material is present; and

(2) Emergency response information, including the emergency response telephone number, required by this subpart is immediately available to any person who, as a representative of a Federal, state or local government agency, responds to an incident involving a hazardous material, or is conducting an investigation which involves a hazardous material.

(d) Exception. The requirements of this subpart do not apply to hazardous materials which are excepted from the shipping paper requirements of this subchapter."

\section{Receipt Inspection}

\section{REQUIREMENT SOURCE: DOE1540.1A Chapter II, Section 7.a.(2)}

"All shipments of hazardous materials received from carriers shall be inspected promptly and carefully for damage and leakage after they are delivered by the carrier, and, if practicable, before the delivery truck departs. Where the DOE consignee is responsible for picking up the shipment from the carrier's terminal facility, the packages shall be picked up as expeditiously as possible, after notification by the carrier of its arrival and checked for leakage." 
Westinghouse Hanford Company (WHC)

Standards/Requirements Identification Document

WHC-SD-MP-SRID-002

January 10, 1996

Rev. 0

13.0 Packaging and Transportation

Page 54 of 66

$\underline{13.2 .11 .1}$

$\underline{13.2 .12}$
Radiation/Contamination Surveys

Radiation and Contamination requirements are contained in the Radiation Protection Functional Area.

Loading Operations

REQUREMENT SOURCE: 49CFR173 Part 448

"General transportation requirements.

(a) Each shipment of radioactive materials shall be secured in order to prevent shifting during normal transportation conditions.

(b) Except as may be specifically required by the competent authority in the applicable certificate, a package of radioactive materials may be carried among packaged general cargo without special stowage provisions, if:

(1) The heat output in watts does not exceed 0.1 times the minimum package dimension in centimeters; or

(2) The average surface heat flux of the package does not exceed 15 watts per square meter and the immediately surrounding cargo is not in sacks or bags or otherwise in a form that would seriously impede air circulation for heat removal.

(c) Packages bearing labels prescribed in $\mathbf{1 7 2 . 4 0 3}$ of this subchapter may not be carried in compartments occupied by passengers, except in those compartments exclusively reserved for couriers accompanying those packages.

(d) Mixing of different kinds of packages, including Fissile Class I packages with Fissile Class II packages, is authorized in accordance with 173.459 .

(e) No person shall offer for transportation aboard a passenger-carnying aircraft any single package with a transport index greater than 3.0 or an overpack with a transport index greater than 3.0.

(f) No person shall offer for transportation aboard a passenger-carrying aircraft any radioactive material unless that material is intended for use in, or incident to, research, medical diagnosis or treatment.

(g) If an overpack is used to consolidate individual packages of radioactive materials, the packages shail comply with the packaging, marking, and labeling requirements of this subchapter, and the following:

(1) The overpack shall be labeled as prescribed in 172.403 of this subchapter except as follows:

(i) The "contents" entry on the label may state "mixed" unless each inside package contains the same radionuclide(s).

(ii) The "activity" entry on the label must be determined by adding together the number of curies of the radioactive materials packages contained therein. 
(iii) For a non-rigid overpack, the required label together with required package markings shall be affixed to the overpack by means of a securely attached, durable tag. The transport index shall be determined by adding together the transport indexes of the radioactive materials packages contained therein.

(iv) For a rigid overpack, the transport index shall be determined by:

(A) Adding together the transport indexes of the radioactive materials packages contained in the overpack; or

(B) Except for fissile radioactive materials, direct measurements as prescribed in 173.403(bb) which have been taken by the person initially offering the packages contained within the overpack for shipment.

(2) The overpack shall be marked as prescribed in subpart D of part 172 of this subchapter and 173.25(a).

(3) The transport index of the overpack shall not exceed 3.0 for passenger-carrying aircraft shipments, or 10.0 for cargo-aircraft only shipments."

\section{REQUIREMENT SOURCE: 49CFR173 Part 459}

"Mixing of fissile material packages.

Shipments of fissile materials packages and the commingling of fissile materials packages with other radioactive materials packages shall be in accordance with the provisions of this section.

(a) Mixing of fissile material packages with other types of radioactive materials, including Fissile Class I with Fissile Class II packages is authorized if the total transport index in any conveyance (transport vehicle if transported by public highway or rail) or storage location does not exceed 50.

(b) For Fissile Class II packages shipped under the exclusive use provisions of $173.441(\mathrm{~b})$, the transport index number which is calculated for nuclear criticality control purposes shall not exceed 10 for any single package nor a total of 50 for the conveyance (transport vehicle if transported by public highway or rail).

(c) Fissile Class II packages may be shipped with an external radiation level greater than 10 millirem per hour at 1 meter ( 3.3 feet), and combined with other packages of the same or different designs in a Fissile Class III shipment, under the conditions prescribed in 173.457, if:

(1) Each package in the shipment has been assigned a transport index for criticality control purposes in accordance with the Fissile Class II criteria;

(2) The transport index which has been assigned in the package approval for nuclear criticality control purposes does not exceed 10 for any single package;

(3) The total transport index for nuclear criticality control purposes does not exceed 100 for all packages in the shipment;

(4) The shipment complies with $173.441(b)$; and

(5) The shipment is not transported by vessel. 
(d) A Fissile Class III shipment of packages may be combined with other packages of the same or different design when each package has been assigned a transport index for nuclear criticality control purposes in accordance with Fissile Class II criteria, and may be combined with Fissile Class II packages into a Fissile Class III shipment under the conditions prescribed in 173.457 , if:

(1) The transport index which has been assigned in the package approval for nuclear criticality control purposes does not exceed 50 for any single package;

(2) The total transport index for nuclear criticality control purposes for all packages in the shipment does not exceed 100;

(3) The shipment satisfies the provisions of 173.441 (b) if any package has a radiation level exceeding 10 millirem per hour at 1 meter $(3.3$ feet) from any accessible external surface of the package; and

(4) The shipment is not transported by vessel."

\section{REQUIREMENT SOURCE: 49CFR177 Part 848}

"Segregation of hazardous materials

(a) This section applies to materials which meet one or more of the hazard classes defined in this subchapter and are:

(1) In packages which require labels in accordance with part 172 of this subchapter;

(2) In a compartment within a multi-compartmented cargo tank subject to the restrictions in 173.33 of this subchapter; or

(3) In a portable tank loaded in a transport vehicle or freight container.

(b) When a transport vehicle is to be transported by vessel, other than a ferry vessel, hazardous materials on or within that vehicle must be stowed and segregated in accordance with $176.83(b)$ of this subchapter.

(c) In addition to the provisions of paragraph (d) of this section, cyanides or cyanide mixtures may not be loaded or stored with acids.

(d) Hazardous materials may not be loaded, transponted, or stored together, except as provided in this section, and in accordance with the following table:"

$\underline{13.2 .13}$

$\underline{13.2 .13 .1}$

\section{Transportation Operations}

Dangerous Waste Transportation

\section{REQUIREMENT SOURCE: WAC-173-303 Section 060(1)}

"Any person who generates, transports, offers for transport, or transfers a dangerous waste, or who owns or operates a dangerous waste TSD facility shall have a current EPA/state identification number (EPA/state ID No.). Any person who offers a dangerous waste to a transporter or to a dangerous waste TSD facility which does not have an EPA/state ID No., or 
Westinghouse Hanford Company (WHC)

Standards/Requirements Identification Document

13.0 Packaging and Transportation
WHC-SD-MP-SRID-002

January 10, 1996

Rev. 0

Page 57 of 66
13.2 .13 .2

$\underline{13.2 .13 .3}$

$\underline{13.2 .13 .4}$

$\underline{13.2 .13 .5}$ whose EPA/state ID No. has been canceled or withdrawn, shall be in violation of this regulation."

Bracing

\section{REQUIREMENT SOURCE: 49CFR177 Part 834}

"General requirements

(a) Packages secured in a vehicle. Any tank, barrel, drum, cylinder, or other packaging, not permanently attached to a motor vehicle, which contains any Class 3 (flammable liquid), Class 2 (gases). Class 8 (corrosive), Division 6.1 (poisonous), or Class 7 (radioactive) material must be secured against movement within the vehicle on which it is being transported, under conditions normally incident to transportation."

Equipment Inspection

REQUIREMENT SOURCE: DOE1540.1A Chapter II, Section 4.b.(1)(b)

"Before a shipment is loaded upon a transport vehicle, the shipper shall visually survey the equipment externally to determine its general operating condition, its capability to transport the shipment, the existence of appropriate restraint devices in good condition, and assure the estimated gross weight of the shipment does not exceed the authorized carrying capacity of the conveyance."

\section{Lifting and Tie Downs}

\section{REQUIREMENT SOURCE: DOE1540.1A Chapter II, Section 4.b.(3)(a)}

"For motor freight, carriers and shippers shall observe the provisions of 49 CFR 393.100-102 to restrain cargo."

\section{REQUIREMENT SOURCE: DOE1540.1A Chapter II, Section 4.b.(3)(h)}

"For domestic rail shipments, the carrier shall observe the provisions of the Association of American Railroad Circulars providing rules for the loading, blocking, and bracing of freight. Circulars are available for the various types of rail cars in service."

Weight Limitations

\section{REQUIREMENT SOURCE: DOE1540.1A Chapter I, Section 4.c}

"Motor carrier shipments shall conform to State and local laws, regulations, and ordinances relating to weight and size limitations. No vehicular movement which exceeds any State's legal weight or size limitation shall be undertaken over public highways unless prior permission is formally granted by the state concerned. The Department or Department's contractor support of a carrier requesting such permission may be furnished only after a determination that it is not practical to divide the load into smaller lots or feasible to move the material by other means of transportation." 


\section{REQUREMMENT SOURCE: 10CFR71 Part 43}

Author's Note: This requirement pertains to "type B material."

"General standards for all packages.

(a) The smallest overall dimension of a package must not be less than $10 \mathrm{~cm}$ (four in.).

(b) The outside of a package must incorporate a feature, such as a seal, which is not readily breakable, and which, while intact, would be evidence that the package has not been opened by unauthorized persons.

(c) Each package must include a containment system securely closed by a positive fastening device which cannot be opened unintentionally.

(d) A package must be of materials and construction which assure that there will be no significant chemical, galvanic, or other reaction among the packaging components or between the packaging components and the package contents, including possible reaction resulting from inleakage of water to the maximum credible extent.

(e) A package valve or other device, the failure of which would allow radioactive contents to escape, must be protected against unauthorized operation and, except for a pressure relief device, must be provided with an enclosure to retain any leakage.

(f) A package must be designed, constructed, and prepared for shipment so that under the tests specified in 71.71 (Normal Conditions of Transport) there would be no loss or dispersal of radioactive contents, no significant increase in external radiation levels, and no substantial reduction in the effectiveness of the packaging.

(g) A package must be designed, constructed, and prepared for transport so that in still air at $38 \mathrm{C}(100 \mathrm{~F})$ and in the shade, no accessible surface of a package would have a temperature exceeding $50 \mathrm{C}(122 \mathrm{~F})$ in a non-exclusive use shipment or $82 \mathrm{C}(180 \mathrm{~F})$ in an exclusive use shipment.

(h) A package must not incorporate a feature which is intended to allow continuous venting during transport."

\section{REQUIREMENT SOURCE: DOE1540.2 Chapter II, Section 2.j}

"Renewal of Certificates of Compliance.

(1) Ninety days prior to the expiration date of a certificate the contractor requesting the renewal shall submit documentation to the Certifying Official through the responsible operations office justifying renewal of the certificate. Such documentation shall include, but not be limited to:

(a) The necessity for renewing the certificate; 
(b) That the SARP has been reviewed and complies with applicable requirements and standards; and

(c) A summary of the history of past usage.

(2) Upon review and approval by the Certifying Official a revised certificate with a new expiration date shall be issued. A copy of the certificate shall be provided to EH-34, each operations office, and to each user of the certificate (see paragraph $2 f(1)$ ).

(3) Operations offices which do not intend to request renewal of a certificate issued to their organization should notify all other operations offices 120 days prior to the expiration date of the certificate. If another operations office requires the continued use of the packaging, that office may request a renewal from the Certifying Official. The request should follow the requirements set forth in subparagraph i(1) above, for renewal of DOE Certificates of Compliance. The new issuing office will be designated on the revised Certificate."

\section{REQUTREMENT SOURCE: DOE1540.2 Chapter V, Section 2.b}

"Requests for NRC Certificates of Compliance.

(1) Applications for an NRC Certificate of Compliance shall comply with the requirements of Title 10 CFR, subpart $D$ and be in the format described in the NRC Regulatory Guide 7.9.

(2) Upon completion of the DOE packaging review and approval process, the request, eight copies of the SARP (in addition to the eight copies of the SARP required for DOE certification). DOE certificate of compliance, applicable drawings, and the DOE evaluation report shall be forwarded to the Certifying Official for filing with the NRC.

(3) All formal communications between operations offices or their contractors and NRC or DOT regarding certifications will be transmitted through DP-4.

(4) Headquarters processing times for requests for NRC certificates range from 14 to 30 days, depending upon the complexity and the issues associated with the packaging. NRC processing times for new applications are 3 to 4 months to identify issues and 1 to $11 / 2$ years for approval if there are issues to be resolved. Amendments require approximately 1 to 2 months to identify issues."

\section{REQUIREMENT SOURCE: DOE5480.3 Section 10 Introduction and 10.f(1)}

Author's Note: This requirement is cited due to the statement in item (1), which states "Heads of Field Organizations shall require contractors under their jurisdiction to prepare... ".

"Documentation of Technical Backup Support for Specification, Certified, and Exempt Packaging. Packaging that have been certified by the Department of Energy as meeting Deparment of Transportation regulations and packaging, for which specifications have been published by the Department of Transportation, may be used by other Department of Energy shippers having authority to ship radioactive or fissile materials. If the Nuclear Regulatory Commission also certifies that the standards of 10 CFR 71 bave been met, licensees can be listed as users by the Nuclear Regulatory Commission and ship in the packaging to either Department of Energy contractors or to other licensees. Therefore it is essential that technical information and limits pertinent to the construction and use of these packaging be available to all potential users. The following are requirements to meet these objectives: 
(1) Heads of Field Organizations shall require contractors under their jurisdiction to prepare a distributable document for each new specification or certified packaging designed, developed, and fabricated for offsite shipment of fissile and other radioactive materials in quantities exceeding Type A. Obsolete packaging no longer in use and containers used for onsite movement of materials are not subject to these documentation requirements unless they are reactivated, altered, or requested for use in offsite shipments. In such instances, the party or parties requiring reactivation or alterations shall prepare or have prepared the appropriate document."

\section{3 .2}

\section{Safety Analysis}

\section{REQUREMENT SOURCE: 49CER173 Part 476}

"Approval of special form radioactive materials.

(a) Each shipper of special form radioactive materials shall maintain on file for at least one year after the latest shipment, and provide to the RSPA on request, a complete safety analysis, including documentation of any tests, demonstrating that the special form material meets the requirements of 173.469. An IAEA Certificate of Competent Authority issued for the special form material may be used to satisfy this requirement.

(b) Prior to the first export shipment of a special form radioactive material from the United States, each shipper shall obtain a Competent Authority Certificate for the specific material. For special form material manufactured outside the United States an IAEA Certificate of Component Authority from the country of origin may be used to meet this requirement. For special form materials manufactured in the United States each shipper shall obtain a U.S. Competent Authority Certificate for the specific material. Each petition for a U.S. Competent Authority Certificate shall be submitted in accordance with $173.471(e)$ and must include the following information:

(1) A detailed description of the material or if a capsule, a detailed description of the contents. Particular reference must be made to both physical and chemical states;

(2) If a capsule is to be used, a detailed statement of its design and dimensions, including complete engineering drawings and schedules of material, and methods of construction; and

(3) A statement of the tests that have been made and their results; evidence based on calculative methods to show that the material is able to pass the tests; or other evidence that the special form radioactive material complies with 173.469 .

(c) Paragraphs (a) and (b) of this section do not apply in those cases where A1 equals A2 and the material is not described on the shipping papers as "Radioactive Material, Special Form, n.o.s."

(The information collection requirements contained in paragraph (a) were approved by the Office of Management and Budget under control number 21370516 . The information collection requirements contained in paragraph (b) were approved under control number 2137 0518)" 
Westinghouse Hanford Company (WHC)

Standards/Requirements Identification Document

13.0 Packaging and Transportation
WHC-SD-MP-SRID-002

January 10, 1996

Rev. 0

Page 61 of 66

REQUIREMENT SOURCE: DOE1540.2 Chapter II, Section 2.a, (1) and (2)

"(1) All Type B and fissile material packaging designs certified by DOE must be supported by a SARP which demonstrates that the packaging design meets the packaging standards specified by DOE 5480.3 .

(2) The SARP must include a description of the proposed packaging in sufficient detail to identify the packaging accurately and provide the basis for evaluating the packaging."

$\underline{13.3 .3}$

Desion, Fabrication, Assembly and Testing OA for Ofrsite Shipping Containers

\section{REQUIREMENT SOURCE: 10CFR71 Part 31}

Author's Note: This requirement is cited as it pertains to "type B" material.

"Contents of application.

(a) An application for an approval under this part must include, for each proposed packaging design, the following information:

(1) A package description as required by 71.33 ;

(2) A package evaluation as required by 71.35 ;

(3) A quality assurance program description as required by 71.37 ;

(4) In the case of fissile material, an identification of the proposed fissile class.

(b) Except as provided in 71.13, an application for modification of a package design, whether for modification of the packaging or authorized contents, must include sufficient information to demonstrate that the proposed design satisfies the package standards in effect at the time the application is filed.

[48 FR 35607, Aug. 5, 1983; 48 FR 38449, Aug. 24, 1983]"

\subsubsection{QA Testing}

\section{REQUTREMENT SOURCE: 10CFR71 Part 41}

Author's Note: This requirement is cited as it pertains to "type B" material.

"Demonstration of compliance.

(a) The effects on a package of the tests specified in 71.71 (Normal Conditions of Transport) and the tests specified in 71.73 (Hypothetical Accident Conditions) must be evaluated by subjecting a sample package or scale model to test, or by other method of demonstration acceptable to the Commission, as appropriate for the particular feature being considered.

(b) Taking into account the type of vehicle, the method of securing or attaching the package, and the controls to be exercised by the shipper, the Commission may permit the shipment to be evaluated together with the transporting vehicle. 
(c) Environmental and test conditions different from those specified in 71.71 and 71.73 may be approved by the Commission if the controls proposed to be exercised by the shipper are demonstrated to be adequate to assure the safety of the shipment."

\section{REQUIREMENT SOURCE: 49CFR173 Part 28(a)}

"General. Packagings and receptacles used more than once must be in such condition, including closure devices and cushioning materials, that they conform in all respects to the prescribed requirements of this subchapter. Before reuse, each packaging must be inspected and may not be reused unless free from incompatible residue, rupture, or other damage which reduces its structural integrity."

\section{REQUIREMENT SOURCE: 49CFR173 Part 463}

"Packaging and shielding--testing for integrity. After each of the applicable tests specified in 173.465 and 173.466 , the integrity of the packaging, or the packaging and its shielding, shall be retained to the extent required by $173.412(\mathrm{~m})$ for the packaging being tested."

\section{REQUTREMENT SOURCE: DANGEROUS-GOODS-REGU Section 5.0.2. 7}

"The body and the closure of any receptacle must be so constructed as to be able adequately to resist the effects of temperature and vibration occurring in normal conditions of transpor. Stopper, corks, or other such friction-type closures must be held in place, securely, tightly and effectively, by positive means. The closure devise must be so designed that it is unlikely that it can be incorrectly or incompletely closed, and must be such that it may be checked easily to determine that it is completely closed."

\subsubsection{Physical Protection for Security}

Author's Note: The Safeguards and Security Department implements security requirements for onsite and offsite shipments of radioactive material, including special nuclear material shipments. Applicable requirements are addressed in the Westinghouse Hanford Company S/RID for the Safeguards and Security functional area.

Nuclear Explosives, Components, and Assemblies

Author's Note: No requirements applicable to WHC P\&T were identified under this sub-element.

\section{ONSITE SAFETY}

Author's Note: Procedures for onsite transportation safety should ensure that movement of hazardous materials comply with DOT regulations if economically and technically feasible. Where compliance with DOT regulations is not feasible, compensatory administrative and technical controls should be used to ensure equivalent safety to workers, the public, and the environment.

An equivalent degree of safety shall be provided for onsite shipments as is afforded by the shipping regulations of DOT. It is RL's policy to use DOT/DOE/NRC approved containers whenever technically and economically practical for onsite shipments and to keep the exposure to individuals during the transportation and handling of material packages as low as practical." 
$\underline{13.4 .1}$

13.4 .2

$\underline{13.5 .1}$

$\underline{13.5 .2}$

$\underline{13.5 .3}$

$\underline{13.5 .4}$

13.6

$\underline{13.6 .1}$

\section{Coordination of Material Transfers}

Author's Note: Refer to 13.4.

\section{Safety Analyses}

Author's Note: Refer to 13.4.

\section{Requirements for Potentially Explosive and Fazardous Materials}

Author's Note: Refer to 13.4

\section{Personnel Protection During Movement of Hazardous Materials}

Author's Note: Refer to 13.4 .

\section{KEY INTERFACES}

\section{Training and Oualification}

Training and Qualification requirements are located in the Training and Qualification Functional Area.

\section{Safequards and Security}

"The Safeguards and Security (SAS) Department ensures implementation of SAS requirements for onsite and offsite shipments of radioactive material, including special nuclear material shipments. Additionally, SAS provides escort services for shipments of hazardous and special nuclear materials as required."

\section{Nuclear Safety}

P\&T key interfaces with nuclear safety operations are addressed in facility S/RIDs.

\section{Emergency Management}

The WHC Site Emergency Preparedness Organization coordinates contractor emergency response to transportation accidents involving DOE-owned hazardous material shipments both on and off the WHC Site. Additionally, this organization develops and maintains implementing procedures for contractor response to transportation accidents involving DOW-owned hazardous material shipments both on and off the WHC Site and provides support to DOE-Headquarters on emergency preparediness matters related to transportation.

\section{REFERENCES}

\section{Requirement Source Documents}

The following references were used as source documents:

10 CFR, 1993, Part 71, Packaging and Transportation of Radioactive Material, U.S. Nuclear Regulatory Commission, Washington, D.C. 
40 CFR, 1992, Chapter I, Parts 260-299, Protection of Environment, Office of Federal Register, Washington, D.C.

49 CFR, 1993, Subtitle B - Other Regulations Relating to Transportation, Parts 100 to 399.

Dangerous Goods Regulations, 1994, International Air Transport Association (IATA), Geneva, Switzerland.

DOE Order 1540.1A, 1992, Materials Transportation and Traffic Management, U.S. Department of Energy, Washington, D.C.

DOE Order 1540.2, Change 1, 1988, Hazardous Material Packaging for Transport Administrative Procedures, U.S. Department of Energy, Washington, D.C.

DOE Order 5480.3, 1985, Safety Requirements for the Packaging and Transportation of Hazardous Materials, Hazardous Substances, and Hazardous Waste, U.S. Department of Energy, Washington, D.C.

WAC-173-303, 1993, Dangerous Waste Regulations, Washington Administrative Code, Olympia, Washington.

WAC-470-12, 1992, Transportation of Dangerous Cargoes, Advisory Committee on, Washington Administrative Code, Olympia, Washington.

\section{Reviewed Documents Not Used as Requirement Sources}

The following documents were reviewed as requirement sources but were not used in the development of this Standards/Requirements Identification Document.

10 CFR, 1993, Part 20, Standards for Protection against Radiation, U.S. Nuclear Regulatory Commission, Washington, D.C.

10 CFR, 1993, Part 70, Domestic Licensing of Special Nuclear Material, U.S. Nuclear Regulatory Commission, Washington, D.C.

29 CFR, 1992, Part 1910, Occupational Safety and Health Standards, Subpart Z, Toxic and Hazardous Substances, Office of the Federal Register, Washington, D.C.

ANSI, 1973, Administrative Guide for Packaging and Transporting Radioactive Materials, Standard N14.10.1, American National Standards Institute, New York, New York.

ANSI, 1973, Administrative Guide for Obtaining DOT Special Permits for Radioactive Materials Shipments, Standard N14.10.2, American National Standards Institute, New York, New York.

ANSI, 1975, Administrative Guide for Verifying Compliance with Packaging Requirements for Shipments of Radioactive Materials, Standard N14.10.3, American National Standards Institute, New York, New York.

ANSI, 1986, American National Standard for Nuclear Materials - Imadiated Shipping Casks Ancillary Features, Standard N14.19, American National Standards Institute, New York, New York. 
DOE Order 1540.3A, 1992, Base Technology for Radioactive Material Transportation Packaging Systems, U.S. Department of Energy, Washington, D.C.

DOE Order 5480.1B, Change 5, 1986, Environment, Safety, and Health Program for Department of Energy Operations, U. S. Department of Energy, Washington, D.C.

DOE Order 5480.4, Change 4, 1993, Environmental Protection, Safety, and Health Protection Standards, U.S. Department of Energy, Washington, D.C.

DOE Order 5480.5, 1986, Safety of Nuclear Facilities, U.S. Department of Energy, Washington, D.C.

DOE Order 5482.1B, 1986, Environment, Safety, and Health Appraisal Program, U.S. Department of Energy, Washington, D.C.

DOE Order 5483.1A, 1983, Occupational Safety and Health Program for DOE Contractor Employees at Government-Owned Contractor-Operated Facilities, U.S. Department of Energy, Washington, D.C.

DOE Order 5632.2A, Change 1, 1989, Physical Protection of Special Nuclear Material and Vital Equipment, U.S. Department of Energy, Washington, D.C.

DOE Order 5632.5, Change 1, 1993, Physical Protection of Classified Matter, U.S. Department of Energy, Washington, D.C.

DOE Order 5632.11, 1992, Physical Protection of Unclassified Irradiated Reactor Fuel in Transit, U.S. Department of Energy, Washington, D.C.

DOE Order 5635.3, 1994, Hand-Carrying Classified Matter on Air Carriers, U.S. Deparment of Energy, Washington, D.C.

DOE Order 5820.2A, 1988, Radioactive Waste Management, U.S. Department of Energy, Washington, D.C.

DOE/RL-91-28, Revision 1, 1993, Hanford Facility Dangerous Waste Permit Application, General Information, U.S. Department of Energy, Richiand Operations, Richland, Washington.

RLID 5480.3, 1993, Safety Requirements for the Packaging and Transportation of Hazardous Materials, Hazardous Substances, and Hazardous Wastes, U.S. Department of Energy, Richland Operations, Richland, Washington.

RLID 5820.2A, 1988, Radioactive Waste Management, U.S. Department of Energy, Richland Operations, Richland, Washington.

IAEA, 1985, Safety Standards, Safety Series 6, Regulations for the Safe Transport of Radioactive Material, International Atomic Energy Agency, Vienna, Austria.

IAEA, 1986, Safety Series 6, Regulations for the Safe Transport of Radioactive Material, Supplement, International Atomic Energy Agency, Vienna, Austria.

RL Order 5480.1, Change I, 1982, Environment, Safety, and Heaith Program, U.S. Department of Energy, Richland Operations, Richland, Washington. 
RL Order 5480.1A, 1988, Environment, Safety, and Health Program for Department of Energy Operations for Richland Operations, U.S. Department of Energy, Richland Operations, Richland, Washington.

RL Order 5480.5, 1984, Safety of Nuclear Facilities, U.S. Department of Energy, Richland Operations, Richland, Washington.

U.S. Nuclear Regulatory Commission, 1975, Guide 7.4, Leakage Tests on Packages for Shipment of Radioactive Materials, U.S. Nuclear Regulatory Commission, Washington, D.C..

U.S. Nuclear Regulatory Commission, 1978, Guide 7.6, Design Criteria for the Structural Analysis of Shipping Cask Containment Vessels, U.S. Nuclear Regulatory Commission, Washington, D.C.

U.S. Nuclear Regulatory Commission, 1977, Guide 7.7, Administrative Guide for Verifying Compliance with Packaging Requirements for Shipments of Radioactive Materials, U.S. Nuclear Regulatory Commission, Washington, D.C.

U.S. Nuciear Regulatory Commission, 1989, Guide 7.8, Load Combinations for the Structural Analysis of Shipping Casks for Radioactive Material, U.S. Nuclear Regulatory Commission, Washington, D.C. 
Westinghouse Hanford Company (WHC)

Standards/Requirements Identification Document

14.0 Environmental Restoration
WHC-SD-MP-SRID-002 January 10, 1996

Rev. 0

\section{TABLE OF CONTENTS}

14.0 ENVIRONMENTAL RESTORATION $\ldots \ldots \ldots \ldots \ldots \ldots \ldots \ldots \ldots \ldots \ldots \ldots \ldots \ldots$ 
This page intentionaliy left blank. 
Westinghouse Hanford Company (WHC)

Standards/Requirements Identification Document

14.0 Environmental Restoration
WHC-SD-MP-SRID-002

January 10, 1996

Rev. 0

Page 1 of 2

\subsection{ENVIRONMENTAL RESTORATION}

\section{INTRODUCTION}

A Standards/Requirements Identification Document (S/RID) set forth the Environmental Safety and Health (ES\&H) standards/requirements. This S/RID is applicable to the appropriate life cycle phases of design, construction, operation, and decommissioning for each of the categories of facilities addressed in Revision 5 of the Department of Energy Implementation Plan for the Defense Nuclear Facilities Safety Board (DNFSB) Recommendation 90-2. This Recommendation calls for the strengthening of DOE weapons complex activities through the identification and application of relevant DOE Orders, regulations, industry codes/standards, industry guidance documents and, as appropriate, good industry practices. These standards/requirements are adequate to ensure protection of the health and safety of workers, the public, and the environment.

The Westinghouse Hanford Company S/RID, as defined in Revision 5 of the Department of Energy Implementation Plan for DNFSB Recommendation 90-2, contains standards/requirements applicable company-wide that are necessary for safe operation of the site and its associated facilities, and that are not the direct responsibility of a specific facility manager (e.g., a company-wide fire department). Facility S/RIDs contain standards/requirements applicable to a specific facility that are the direct responsibility of the facility manager.

\section{SCOPE}

The Westinghouse Hanford Company (WHC) S/RID contains standards/requirements applicable to WHC that are adequate to ensure protection of the health and safety of workers, the public, and the environment, and that are not the direct responsibility of a specific facility manager (e.g., a company fire department).

\section{JUSTIFICATION OF FUNCTIONAL AREA NONAPPLICABILITY}

The Functional Areas listed below have been determined to be nonapplicable, for purposes of Westinghouse Hanford Company S/RID development, for one or more of the following reasons:

1. The Functional Area is outside the Scope statement above in that the applicable requirements/standards are the direct responsibility of a specific facility manager and identified in facility level S/RIDs;

2. Responsibility for implementation of the Functional Area lies within an organization other than Westinghouse Hanford Company; or 
3. Applicable requirements/standards are appropriately identified within other WHC Functional Areas.

Maintenance

Management Systems

Configuration Management

Construction

Decontamination \& Decommissioning

Engineering Programs

Environmental Restoration

Nuclear Safety

Operations

Research \& Development

Waste Management 
Westinghouse Hanford Company (WHC)

Standards/Requirements Identification Document

15.0 Decontamination and Decommissioning
WHC-SD-MP-SRID-002

January 10, 1996

Rev. 0

Page $i$ of $i$

\section{TABLE OF CONTENTS}

15.0 DECONTAMINATION AND DECOMMISSIONING $\ldots \ldots \ldots \ldots \ldots \ldots \ldots \ldots \ldots \ldots$ 
This page intentionally left blank. 


\subsection{DECONTAMINATION AND DECOMMISSIONING}

\section{INTRODUCTION}

A Standards/Requirements Identification Document (S/RID) set forth the Environmental Safety and Health (ES\&H) standards/requirements. This S/RID is applicable to the appropriate life cycle phases of design, construction, operation, and decommissioning for each of the categories of facilities addressed in Revision 5 of the Department of Energy Implementation Plan for the Defense Nuclear Facilities Safety Board (DNFSB) Recommendation 90-2. This Recommendation calls for the strengthening of DOE weapons complex activities through the identification and application of relevant DOE Orders, regulations, industry codes/standards, industry guidance documents and, as appropriate, good industry practices. These standards/requirements are adequate to ensure protection of the health and safety of workers, the public, and the environment.

The Westinghouse Hanford Company S/RID, as defined in Revision 5 of the Department of Energy Implementation Plan for DNFSB Recommendation 90-2, contains standards/requirements applicable company-wide that are necessary for safe operation of the site and its associated facilities, and that are not the direct responsibility of a specific facility manager (e.g., a company-wide fire department). Facility S/RIDs contain standards/requirements applicable to a specific facility that are the direct responsibility of the facility manager.

\section{SCOPE}

The Westinghouse Hanford Company (WHC) S/RID contains standards/requirements applicable to WHC that are adequate to ensure protection of the health and safety of workers, the public, and the environment, and that are not the direct responsibility of a specific facility manager (e.g., a company fire department).

\section{JUSTIFICATION OF FUNCTIONAL AREA NONAPPLICABILITY}

The Functional Areas listed below have been determined to be nonapplicable, for purposes of Westinghouse Hanford Company S/RID development, for one or more of the following reasons:

1. The Functional Area is outside the Scope statement above in that the applicable requirements/standards are the direct responsibility of a specific facility manager and identified in facility level S/RIDs;

2. Responsibility for implementation of the Functional Area lies within an organization other than Westinghouse Hanford Company; or 
Westinghouse Hanford Company (WHC)

Standards/Requirements Identification Document

WHC-SD-MP-SRID-002

January 10, 1996

Rev. 0

15.0 Decontamination and Decommissioning

Page 2 of 2

3. Applicable requirements/standards are appropriately identified within other WHC Functional Areas.

Maintenance

Management Systems

Configuration Management

Construction

Decontamination \& Decommissioning

Engineering Programs

Environmental Restoration

Nuclear Safety

Operations

Research \& Development

Waste Management 
Westinghouse Fanford Company (WHC)

Standards/Requirements Identification Document

16.0 Waste Management
WHC-SD-MP-SRID-002

January 10, 1996

Rev. 0

Page i of $i$

\section{TABLE OF CONTENTS}

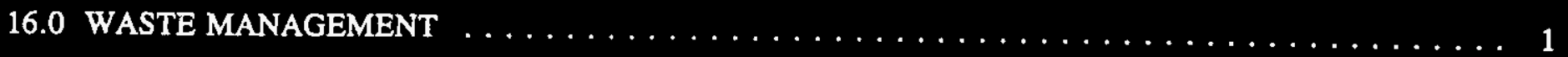


This page intentionally left blank. 
Westinghouse Hanford Company (WHC)

Standards/Requirements Identification Document

16.0 Waste Management
WHC-SD-MP-SRID-002

January 10, 1996

Rev. 0

Page 1 of 2

\subsection{WASTE MANAGEMENT}

\section{INTRODUCTION}

A Standards/Requirements Identification Document (S/RID) set forth the Environmental Safety and Health (ES\&H) standards/requirements. This S/RID is applicable to the appropriate life cycle phases of design, construction, operation, and decommissioning for each of the categories of facilities addressed in Revision 5 of the Department of Energy Implementation Plan for the Defense Nuclear Facilities Safety Board (DNFSB) Recommendation 90-2. This Recommendation calls for the strengthening of DOE weapons complex activities through the identification and application of relevant DOE Orders, regulations, industry codes/standards, industry guidance documents and, as appropriate, good industry practices. These standards/requirements are adequate to ensure protection of the health and safety of workers, the public, and the environment.

The Westinghouse Hanford Company S/RID, as defined in Revision 5 of the Department of Energy Implementation Plan for DNFSB Recommendation 90-2, contains standards/requirements applicable company-wide that are necessary for safe operation of the site and its associated facilities, and that are not the direct responsibility of a specific facility manager (e.g., a company-wide fire department). Facility S/RIDs contain standards/requirements applicable to a specific facility that are the direct responsibility of the facility manager.

\section{SCOPE}

The Westinghouse Hanford Company (WHC) S/RID contains standards/requirements applicable to WHC that are adequate to ensure protection of the health and safety of workers, the public, and the environment, and that are not the direct responsibility of a specific facility manager (e.g., a company fire department).

\section{JUSTIFICATION OF FUNCTIONAL AREA NONAPPLICABILITY}

The Functional Areas listed below have been determined to be nonapplicable, for purposes of Westinghouse Hanford Company S/RID development, for one or more of the following reasons:

1. The Functional Area is outside the Scope statement above in that the applicable requirements/standards are the direct responsibility of a specific facility manager and identified in facility level S/RIDs;

2. Responsibility for implementation of the Functional Area lies within an organization other than Westinghouse Hanford Company; or 
3. Applicable requirements/standards are appropriately identified within other WHC Functional Areas.

\section{Maintenance}

Management Systems

Configuration Management

Construction

Decontamination \& Decommissioning

Engineering Programs

Environmental Restoration

Nuclear Safety

Operations

Research \& Development

Waste Management 
Westinghouse Hanford Company (WHC)

WHC-SD-MP-SRID-002

Standards/Requirements Identification Document

January 10, 1996

Rev. 0

17.0 Research and Development and Experimental Activities

Page $i$ of $i$

TABLE OF CONTENTS

17.0 RESEARCH AND DEVELOPMENT AND EXPERIMENTAL ACTIVITIES $\ldots \ldots \ldots \ldots \ldots \ldots$ 
This page intentionally left blank. 


\subsection{RESEARCH AND DEVELOPMENT AND EXPERIMENTAL ACTIVITIES}

\section{INTRODUCTION}

A Standards/Requirements Identification Document (S/RID) set forth the Environmental Safety and Health (ES\&H) standards/requirements. This S/RID is applicable to the appropriate life cycle phases of design, construction, operation, and decommissioning for each of the categories of facilities addressed in Revision 5 of the Department of Energy Implementation Plan for the Defense Nuclear Facilities Safety Board (DNFSB) Recommendation 90-2. This Recommendation calls for the strengthening of DOE weapons complex activities through the identification and application of relevant DOE Orders, regulations, industry codes/standards, industry guidance documents and, as appropriate, good industry practices. These standards/requirements are adequate to ensure protection of the health and safety of workers, the public, and the environment.

The Westinghouse Hanford Company S/RID, as defined in Revision 5 of the Department of Energy Implementation Plan for DNFSB Recommendation 90-2, contains standards/requirements applicable company-wide that are necessary for safe operation of the site and its associated facilities, and that are not the direct responsibility of a specific facility manager (e.g., a company-wide fire department). Facility S/RIDs contain standards/requirements applicable to a specific facility that are the direct responsibility of the facility manager.

\section{SCOPE}

The Westinghouse Hanford Company (WHC) S/RID contains standards/requirements applicable to WHC that are adequate to ensure protection of the health and safety of workers, the public, and the environment, and that are not the direct responsibility of a specific facility manager (e.g., a company fire department).

\section{JUSTIFICATION OF FUNCTIONAL AREA NONAPPLICABILITY}

The Functional Areas listed below have been determined to be nonapplicable, for purposes of Westinghouse Hanford Company S/RID development, for one or more of the following reasons:

1. The Functional Area is outside the Scope statement above in that the applicable requirements/standards are the direct responsibility of a specific facility manager and identified in facility level S/RIDs;

2. Responsibility for implementation of the Functional Area lies within an organization other than Westinghouse Hanford Company; or 
Westinghouse Hanford Company (WHC)

WHC-SD-MP-SRID-002

Standards/Requirements Identification Document

January 10, 1996

Rev. 0

17.0 Research and Development and Experimental Activities

Page 2 of 2

3. Applicable requirements/standards are appropriately identified within other WHC Functional Areas.

Maintenance

Management Systems

Configuration Management

Construction

Decontamination \& Decommissioning

Engineering Programs

Environmental Restoration

Nuclear Safety

Operations

Research \& Development

Waste Management 
Westinghouse Fanford Company (WHC)

Standards/Requirements Identification Document

18.0 Nuclear Safety

WHC-SD-MP-SRID-002

January 10, 1996

Rev. 0 Page i of $\mathbf{i}$

\section{TABLE OF CONTENTS}

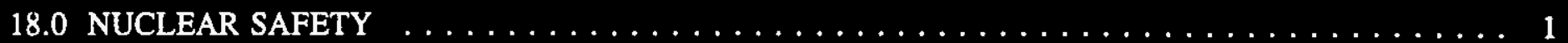


This page intentionally left blank. 


\subsection{NUCLEAR SAFETY}

\section{INTRODUCTION}

A Standards/Requirements Identification Document (S/RID) set forth the Environmental Safety arid Health (ES\&H) standards/requirements. This S/RID is applicable to the appropriate life cycle phases of design, construction, operation, and decommissioning for each of the categories of facilities addressed in Revision 5 of the Department of Energy Implementation Plan for the Defense Nuclear Facilities Safety Board (DNFSB) Recommendation 90-2. This Recommendation calls for the strengthening of DOE weapons complex activities through the identification and application of relevant DOE Orders, regulations, industry codes/standards, industry guidance documents and, as appropriate, good industry practices. These standards/requirements are adequate to ensure protection of the health and safety of workers, the public, and the environment.

The Westinghouse Hanford Company S/RID, as defined in Revision 5 of the Department of Energy Implementation Plan for DNFSB Recommendation 90-2, contains standards/requirements applicable company-wide that are necessary for safe operation of the site and its associated facilities, and that are not the direct responsibility of a specific facility manager (e.g., a company-wide fire department). Facility S/RIDs contain standards/requirements applicable to a specific facility that are the direct responsibility of the facility manager.

SCOPE

The Westinghouse Hanford Company (WHC) S/RID contains standards/requirements applicable to WHC that are adequate to ensure protection of the health and safety of workers, the public, and the environment, and that are not the direct responsibility of a specific facility manager (e.g., a company fire department).

A WHC level organization establishes the guidelines to meet the goals contained in SEN 35-91, but the implementation of these guidelines is at the facility level.

\section{JUSTIFICATION OF FUNCTIONAL AREA NONAPPLICABILITY}

The Functional Areas listed below have been determined to be nonapplicable, for purposes of Westinghouse Hanford Company S/RID development, for one or more of the following reasons:

1. The Functional Area is outside the Scope statement above in that the applicable requirements/standards are the direct responsibility of a specific facility manager and identified in facility level S/RIDs;

2. Applicable requirements/standards are appropriately identified within other WHC Functional Areas. 
This page intentionally left blank. 


\section{TABLE OF CONTENTS}

19.0 OCCUPATIONAL SAFETY AND HEALTH $\ldots \ldots \ldots \ldots \ldots \ldots \ldots \ldots \ldots$

19.1

19.1.1

19.1.2

19.1.3

19.2

19.2.1

19.2 .2

19.2 .3

19.2 .4

19.3

19.3.1

19.3.2

19.3.3

19.4

19.4 .1

19.4 .2

19.4 .3

19.4 .4

19.4 .5

19.4 .6

19.4 .7

19.4 .8

19.5

19.6

19.6.1

19.6 .2

19.7
MANAGEMENT AND ADMINISTRATION

Program Policy ..................... 2

Occupational Safety and Health Goals and Objectives ...... 3

Requests for Exemptions $/$ ariances . . . . . . . . . 3

\section{HAZARD ANTICIPATION, IDENTIFICATION AND}

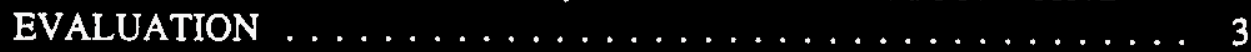

Hazard Assessment Program . . . . . . . . . . . . . 3

Hazards Reporting System . . . . . . . . . . . . 3

Investigation of Occurrences, Accidents, and Near Misses . . . 3

Injury and Illness Trend Analysis . . . . . . . . . . . 4

OS\&H HAZARD PREVENTION AND CONTROL . . . . . . . . . . 4

Hazard Monitoring, Sampling, and Surveillance . . . . . . . . 10

Hazard Controls . . . . . . . . . . . . . . . . . . . 10

Safety Inspection and Maintenance $\ldots \ldots \ldots \ldots \ldots$

OCCUPATIONAL HEALTH PROGRAM $\ldots \ldots \ldots \ldots$

Health Examinations $\ldots \ldots \ldots \ldots \ldots \ldots \ldots$

Health Maintenance and Preventive Medicine . . . . . . 11

Diagnosis and Treatment $\ldots \ldots \ldots \ldots \ldots \ldots \ldots$

Fitness for Duty . . . . . . . . . . . . . . . 11

Medical Facilities and Equipment . . . . . . . . . . . 11

Professional Development of Occupational Staff . . . . . . . . 11

Health Records and Reporting . . . . . . . . . . 11

Medical Staffing . . . . . . . . . . . . . . . 11

OCCUPATIONAL SAFETY AND HEALTH TRAINING . . . . . . 11

RECORDKEEPING AND REPORTING $\ldots \ldots \ldots \ldots \ldots$

Occupational Injury and Illness Reporting . . . . . . . . . 11

Occurrence Reporting $\ldots \ldots \ldots \ldots \ldots \ldots$

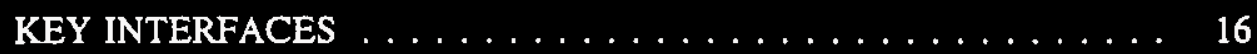

19.7.1

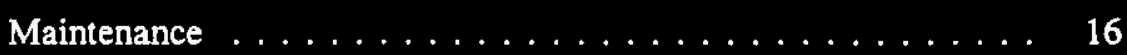

19.7 .2

19.7 .3

19.7 .4

19.7.5

19.7.6

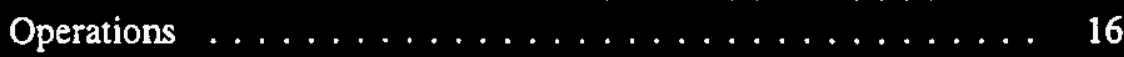

Radiation Protection $\ldots \ldots \ldots \ldots \ldots \ldots \ldots$

Training and Qualification $\ldots \ldots \ldots \ldots \ldots \ldots$

Construction Program $\ldots \ldots \ldots \ldots \ldots \ldots \ldots$

Fire Protection . . . . . . . . . . . . . . 17 
Westinghouse Hanford Company (WHC)

Standards/Requirements Identification Document

19.0 Occupational Safety and Health
WHC-SD-MP-SRID-002

January 10, 1996

Rev. 0

Page ii of ii

19.8

REFERENCES $\ldots \ldots \ldots \ldots \ldots \ldots \ldots \ldots \ldots \ldots \ldots$

19.8.1

Requirement Source Documents . . . . . . . . . . . . . . . 17

19.8 .2

Reviewed Documents Not Used as Requirement Sources

17 


\subsection{OCCUPATIONAL SAFETY AND HEALTH}

\section{INTRODUCTION}

A Standards/Requirements Identification Document (S/RID) sets forth the Environmental Safety and Health (ES\&H) standards/requirements. This S/RID is applicable to the appropriate life cycle phases of design, construction, operation, and decommissioning for each of the categories of facilities addressed in Revision 5 of the Department of Energy Implementation Plan for the Defense Nuclear Facilities Safety Board (DNFSB) Recommendation 90-2. This Recommendation calls for the strengthening of DOE weapons complex activities through the identification and application of relevant DOE Orders, regulations, industry codes/standards, industry guidance documents and, as appropriate, good industry practices. These standards/requirements are adequate to ensure protection of the health and safety of workers, the public, and the environment.

The Westinghouse Hanford Company S/RID, as defined in Revision 5 of the Department of Energy Implementation Plan for DNFSB Recommendation 90-2, contains standards/requirements applicable company-wide that are necessary for safe operation of the site and its associated facilities, and that are not the direct responsibility of a specific facility manager (e.g., a company-wide fire department). Facility S/RIDs contain standards/requirements applicable to a specific facility that are the direct responsibility of the facility manager.

This Standards/Requirements Identification Document (S/RID) defines the Westinghouse Hanford Company (WHC) Occupational Safety and Health program in place at Hanford. The Occupational Safety and Health program defined in this document is described in general accordance with the (ES\&H) Configuration Guide, Revision 0, dated July 30, 1993, and is presented in the form of program elements and subelements. The specific DOE Orders, regulations, industry codes/standards, guidance documents and good industry practices which serve as the basis for each element/subelement are identified and aligned with each subelement.

\section{SCOPE}

This document, in conjunction with DOE-RL and facility S/RIDs defines the Westinghouse Hanford Company Occupational Safety and Health Program. This functional area only contains those statutory requirements that apply to the company as a whole, and are required to be centrally implemented. Some requirements may be intentionally duplicated in facility S/RIDs. This was necessary to adequately capture requirement implementation responsibilities occurring at both the company and facility level.

This document deviates from the ES\&H Guidelines, because of the fact that a majority of the Occupational Safety and Health $(\mathrm{OH})$ Functional-Area requirements are implemented at the facility and therefore contained in the facility specific Standards/Requirements Identification Document (S/RID).

Multiple organizations support the facility line manager with compliance to these occupational health and safety requirements. 
Westinghouse Hanford Company (WHC)

Standards/Requirements Identification Document

WHC-SD-MP-SRID-002

January 10, 1996

Rev. 0

19.0 Occupational Safety and Health

Page 2 of 18

19.1

19.1 .1

\title{
MANAGEMINT AND ADMINISTRATION
}

\author{
Propram Policy
}

\section{REQUIREMENT SOURCE: 54FR3904 Part (a)(1)}

"Employers are advised and encouraged to institute and maintain in their establishments a program which provides systematic policies, procedures, and practices that are adequate to recognize and protect their employees from occupational safety and health hazards."

\section{REQUIREMENT SOURCE: 54FR3904 Part (a)(4)}

"The extent to which the program is described in writing is less important than how effective it is in practice. As the size of a worksite or the complexity of a hazardous operation increases, however, the need for written guidance increases to ensure clear communication of policies and priorities and consistent and fair application of rules."

\section{REQUIREMENT SOURCE: 54FR3904 Part (b)(1)}

"Management commitment and employee involvement are complementary. Management commitment provides the motivating force and the resources for organization. In an effective program, management regards worker safety and health as a fundamental value of the organization and applies its commitment to safety and health protection with as much vigor as to other organizational purposes. Employee involvement provides the means through which workers develop and/or express their own commitment to safety and health protection, for themselves and for their fellow workers."

\section{REQUREMENT SOURCE: 54FR3904 Part (c)(1)(i)}

"State clearly a worksite policy on safe and healthful work and working conditions, so that all personnel with responsibility at the site and personnel at other locations with responsibility for the site understand the priority of safety and health protection in relation to other organizational values."

\section{REQUIREMENT SOURCE: 54FR3904 Part (c)(1)(iii)}

"Provide visible top management involvement in implementing the program, so that all will understand that management's commitment is serious."

\section{REQUIREMINT SOURCE: 54FR3904 Part (c)(1)(iv)}

"Provide for and encourage employee involvement in the structure and operation of the program and in decisions that affect their safety and health, so that they will commit their insight and energy to achieving the safety and health program's goal and objectives."

\section{REQUIREMENT SOURCE: 54FR3904 Part (c)(1)(v)}

"Assign and communicate responsibility for all aspects of the program, so that managers, supervisors, and employees in all parts of the organization know what performance is expected of them." 
Westinghouse Hanford Company (WHC)

Standards/Requirements Identification Document

19.0 Occupational Safety and Health
WHC-SD-MP-SRID-002

January 10, 1996

Rev. 0

Page 3 of 18

\section{REQUTREMENT SOURCE: DOE5480.10 Section 9.d(1)}

"The staff responsible for the direction and operation of the industrial hygiene program must be professionally qualified, adequate in number, and have sufficient time and authority to design and implement the industrial hygiene program set forth in this Order."

19.1 .2

19.1 .3

19.2

$\underline{19.2 .1}$

$\underline{19.2 .2}$

19.2 .3

\section{Occupational Safety and Health Goals and Objectives}

\section{REQUIREMENT SOURCE: 54FR3904 Part (c)(1)(ii)}

"Establish and communicate a clear goal for the safety and health program and objectives for meeting that goal, so that all members of the organization understand the results desired and the measures planned for achieving them."

\section{Requests for Exemptions/Variances}

Author's Note: Requirements for this subelement can be found in the facility specific S/RID.

\section{HAZARD ANTICIPATION, IDENTIFICATION AND EVALUATION}

\section{Hazard Assessment Proqram}

\section{REQUTREMENT SOURCE: 54FR3904 Part (a)(2)}

"An effective program includes provisions for the systematic identification, evaluation, and prevention or control of general workplace hazards, specific job hazards, and potential hazards which may arise from foreseeable conditions."

\section{Hazards Reporting System}

\section{REQUTREMENT SOURCE: 54FR3904 Part (c)(2)(iii)}

"So that employee insight and experience in safety and health protection may be utilized and employee concerns may be addressed, provide a reliable system for employees, without fear of reprisal, to notify management personnel about conditions that appear hazardous and to receive timely and appropriate responses; and encourage employees to use the system."

\section{REQUIREMENT SOURCE: DOE5483.1A Chapter I, Section 5.a.(1)}

"All contractor employees shail be instructed by the contractor to:

(1) Observe the DOE-prescribed OSHA standards applicable to their work and report promptly to the contractor any condition which may lead to a violation of these standards."

\section{Investigation of Occurrences, Accidents, and Near Misses}

\section{REQUIREMENT SOURCE: 54FR3904 Part (c)(2)(iv)}

"Provide for investigation of accidents and "near miss" incidents, so that their causes and means for their prevention are identified." 


\section{REQULREMNT SOURCE: 54FR3904 Part $(c)(2)(v)$}

"Analyze injury and illness trends over time, so that patterns with common causes can be identified and prevented."

\section{OS\&H HAZARD PREVENTION AND CONTROL}

\section{REQUIREMENT SOURCE: 29CFR1910 Part 134(d)(1)}

"Air quality. Compressed air, compressed oxygen, liquid air, and liquid oxygen used for respiration shall be of high purity. Oxygen shall meet the requirements of the United States Pharmacopoeia for medical or breathing oxygen. Breathing air shall meet at least the requirements of the specification for Grade D breathing air as described in Compressed Gas Association Commodity Specification G-7.1-1966. Compressed oxygen shall not be used in supplied-air respirators or in open circuit self-contained breathing apparatus that have previously used compressed air. Oxygen must never be used with air line respirators."

\section{REQUIREMENT SOURCE: 29CFR1910 Part 134(d)(2)(i)}

Author's Note: Performed by the OH Program, Hanford Fire Department, and the facility.

"Cylinders shall be tested and maintained as prescribed in the Shipping Container Specification Regulations of the Department of Transportation (49 CFR part 178)."

\section{REQUIREMENT SOURCE: 29CFR1910 Part 134(e)(1)}

"Use of respirators. Standard procedures shall be developed for respirator use. These should include all information and guidance necessary for their proper selection, use, and care. Possible emergency and routine uses of respirators should be anticipated and planned for."

\section{REQUIREMENT SOURCE: 29CFR1910 Part 134(e)(4)}

Author's Note: This requirement performed in conjunction with the $Q A$ organization.

"Respiratory protection is no better than the respirator in use, even though it is worn conscientiously. Frequent random inspections shall be conducted by a qualified individual to assure that respirators are properly selected, used, cleaned, and maintained."

\section{REQUREMENT SOURCE: 29CFR1910 Part 134(0)(1)}

Author's Note: Performed in conjunction with the Hanford Fire Department and an outside vendor.

"Maintenance and care of respirators. A program for maintenance and care of respirators shall be adjusted to the type of plant working conditions, and hazards involved, and shall include the following basic services:

(j) Inspection for defects (including a leak check)

(ii) Cleaning and disinfecting

(iii) Repair 
(iv) Storage"

\section{REQUIREMENT SOURCE: 29CFR1910 Part 134(1)(2)(i)}

Author's Note: Performed by the OH Program, facility, and an outside vendor.

"All respirators shall be inspected routinely before and after each use. A respirator that is not routinely used but is kept ready for emergency use shall be inspected after each use and at least monthly to assure that it is in satisfactory working condition."

\section{REQUIREMENT SOURCE: 29CFR1910 Part 134(I)(2)(iii)}

Author's Note: Performed by the OH Program, facility, and an outside vendor.

"Respirator inspection shall include a check of the tightness of connections and the condition of the facepiece headbands, valves connecting tube, and canisters. Rubber or elastomer parts shall be inspected for pliability and signs of deterioration. Stretching and manipulating rubber or elastomer parts with a massaging action will keep them pliable and flexible and prevent them from taking a set during storage."

\section{REQUIREMENT SOURCE: 29CFR1910 Part 134(1)(3) Sentence 1}

Author's Note: Performed by the $O H$ Program and an outside vendor.

"Routinely used respirators shall be collected cleaned, and disinfected as frequently as necessary to insure that proper protection is provided for the wearer."

\section{REQUIREMENT SOURCE: 29CFR1910 Part 134(1)(4)}

Author's Note: Performed by the OH Program in conjunction with the Hanford Fire Department, and an outside vendor.

"Replacement or repairs shall be done only by experienced persons with parts designed for the respirator. No attempt shall be made to replace components or to make adjustment or repairs beyond the manufacturer's recommendations. Reducing or admission valves or regulators shall be returned to the manufacturer or to a trained technician for adjustment or repair."

\section{REQUTREMENT SOURCE: 29CFR1910 Part 134(f)(5)(i)}

Author's Note: Performed by the OH Program in conjunction with the facility, and an outside vendor.

"After inspection cleaning, and necessary repair, respirators shall be stored to protect against dust sunlight, heat extreme cold, excessive moisture, or damaging chemicals. Respirators placed at stations and work areas for emergency use should be quickly accessible at all times and should be stored in comparments built for the purpose. The compartments should be clearly marked. Routinely used respirators such as dust respirators may be placed in plastic bags. Respirators should not be stored in such places as lockers or tool boxes unless they are in carrying cases or cartons." 


\section{REQUIREMENT SOURCE: 29CFR1910 Part 134(1)(5)(ii)}

Author's Note: Performed by the OH Program in conjunction with the facility, and an outside vendor.

"Respirators should be packed or stored so that the facepiece and exhalation valve will rest in a normal position and function will not be impaired by the elastomer setting in an abnormal position."

\section{REQUIREMENT SOURCE: 29CFR1910 Part 134(g)(2)}

Author's Note: Performed by the OH Program in conjunction with the facility, and an outside vendor.

"All who issue or use gas masks falling within the scope of this section shall see that all gas mask canisters purchased or used by them are properly labeled and colored in accordance with these requirements before they are placed in service and that the labels and colors are properly maintained at all times thereafter until the canisters have completely served their purpose."

\section{REQUREMENT SOURCE: ANSI-Z88.2-1992 Section 10.1}

Author's Note: Performed by an outside vendor with $\mathrm{OH}$ acting as oversight.

"Cleaning and Sanitizing. Respirators issued to an individual shall be cleaned and sanitized regularly. Each respirator shall be cleaned and sanitized before being worn by different individuals. Respirators intended for emergency use shall be cleaned and sanitized after being used. (Clause A.4 in annex A provides a suggested procedure for cleaning and sanitizing.)"

\section{REQUIREMENT SOURCE: ANSI-Z88.2-1992 Section 10.2}

Author's Note: Performed by an outside vendor with $O H$ acting as oversight in conjunction with the facility.

"Inspection. The user shall inspect the respirator immediately prior to each use to ensure that it is in proper working condition. After cleaning and sanitizing, each respirator shall be inspected to determine if it is in proper working condition, if it needs replacement of parts or repairs, or if it should be discarded. Each respirator stored for emergency or rescue use shall be inspected at least monthly.

Respirator inspection shall include a check for tightness of connections; for the condition of the respiratory inlet covering, head harness, valves, connecting tubes, harness assemblies, hoses, filters, cartridges, canisters, end-of-service-life indicator, electrical components, and shelf-life date(s); and for the proper function of regulators, alarms, and other warning systems. Each rubber or other elastomeric part shall be inspected for pliability and signs of deterioration. Each air oxygen cylinder shall be inspected to ensure that it is fully charged according to the manufacturer's instructions.

A record of inspection dates shall be kept for each respirator maintained for emergency or rescue use. Respirators that do not meet applicable inspection criteria shall be immediately removed from service and repaired or replaced." 


\section{REQUIREMIENT SOURCE: ANSI-ZZ38.2-1992 Section 10.3}

Author's Note: Performed by the OH Program in conjunction with an outside vendor and the Hanford Fire Department.

"Parts Replacement and Repair. Replacement of parts or repairs shall be done only be persons trained in proper respirator maintenance and assembly. Replacement parts shall be only those designated for the specific respirator repaired. Reducing or admission valves, regulators, and alarms shall be adjusted or repaired by the respirator manufacturer or a technician trained by the manufacturer. Instrumentation for valve, regulator, and alarm adjustments and tests should be calibrated to a standard traceable to the National Institute of Standards and Technology (NIST), at a minimum of every 3 years."

\section{REQUIREMENT SOURCE: ANSI-Z88.2-1992 Section 10.4}

Author's Note: Performed by the OH Program in conjunction with an outside vendor and the facility.

"Storage. Respirators shall be stored in a manner that will protect them against physical and chemical agents such as vibration, shocks, sunlight, heat, extreme cold, excessive moisture, or damaging chemicals. Respirators shall be stored to prevent distortion of rubber or other elastomeric parts. Respirators shall not be stored in such places as lockers and tool boxes, unless they are protected from contamination, distortion, and damage. Emergency and rescue use of respirators that are placed in work areas shall be quickly accessible at all times, and the storage cabinet or container in which they are stored shall be clearly marked."

\section{REQUTRMENT SOURCE: ANSI-Z88.2-1992 Section 10.5.1}

"Air Quality. Compressed gaseous air, compressed gaseous oxygen, liquid air, and liquid oxygen used for respiration shall be of high purity. Compressed gaseous or liquid oxygen shall meet the requirements of the United States Pharmacopoeia for medical or breathing oxygen. Compressed gaseous air shall meet at least the requirements of the specification for Type I - Grade D breathing air, and liquid air shall meet at least the requirements for Type II Grade B breathing air as described in ANSI/CGA G-7.1-1989."

\section{REQUIREMENT SOURCE: ANSI-Z38.2-1992 Section 10.5.4.1}

Author's Note: Performed by the OH Program in conjunction with the facility and Hanford Fire Deparment.

"Cylinders shall be tested and maintained in accordance with applicable Department of Transportation specifications for shipping containers (Title 49, Code of Federal regulations, Part 173, and Part 178).5) Specific test recommendations for purchased breathing air are given in table 3."

\section{REQUREMENT SOURCE: ANSI-Z88.2-1992 Section 4.3.3}

"The employer shall be responsible for the establishment and maintenance of a respiratory protection program that shall include the requirements outlined in 4.5." 


\section{REQUIREMENT SOURCE: ANSI-Z88.2-1992 Section 4.3.5}

Author's Note: Performed by the OH Program in conjunction with the facility.

"Malfunctions of respiratory protective equipment shall be investigated by the employer to determine the cause and to assure corrective measures are taken. Suspected manufacturing defects should be reported to the manufacturer and the certifying agency."

\section{REQUIREMENT SOURCE: ANSI-Z88.2-1992 Section 4.5.1}

"Program Administration. The responsibility and authority for the respiratory program shall be assigned by the employer to a single person. The administrator shall have knowledge of respiratory protection sufficient to supervise the respirator program properly. The program administrator's responsibilities include the monitoring of the respiratory hazards, maintaining records, and conducting program evaluations (clause 5)."

\section{REQUIREMENT SOURCE: ANSI-Z88.2-1992 Section 4.5.2}

"Standard operating procedures. Written standard operating procedures covering the complete respirator program shall be established and implemented (clause 6)."

\section{REQUIREMENT SOURCE: ANSI-Z88.2-1992 Section 4.5.7}

"Maintenance, inspection, and storage. Maintenance shall be carried out according to the manufacturer's instructions and on a schedule that ensures that each respirator wearer is provided with a respirator that is clean, sanitary, and in good operating condition. Each respirator shall be inspected by the wearer prior to its use to ensure that it is in proper working condition. Respirators shall be stored in a convenient, clean, and sanitary location (clause 10)."

\section{REQUIREMENT SOURCE: ANSI-Z88.2-1992 Section 5.1}

\section{"Description}

An individual shall be assigned responsibility and authority for administration of each respirator program. It is preferable that the administrator be in the company's industrial hygiene, health physics, or safety engineering department. In plants or companies having no formal industrial hygiene, health physics, or safety engineering department, the respirator program shall be administered by a qualified person responsible to the facility manager."

\section{REQUIREMENT SOURCE: ANSI-Z88.2-1992 Section 5.2}

"Qualifications. Respirator program administrators, in order to exercise their responsibility, shall be knowledgeable in respiratory protection. Administrators shall keep abreast of current issues/advances and regulations." 


\section{REQUREMENT SOURCE: ANSI-Z88.2-1992 Section 5.3}

"Responsibilities

The administrator's responsibilities shall include

- measuring, estimating, or reviewing information on the concentration of an airborne contaminant in the work area prior to respirator selection and periodically during respirator use to ensure that the proper type of respirator is being used;

- maintaining records and written procedures in a manner that documents the respirator program and allows for the evaluation of the program's effectiveness.

The most comprehensive respiratory protection program is of little value if it is not maintained and implemented as designed. Therefore, in addition to ongoing surveillance, the program shall be periodically audited to ensure that (a) the program procedures reflect the requirements of current applicable regulations and industry accepted standards and (b) the program as implemented reflects the written procedures.

To aid objectivity, the audit should be conducted by a knowledgeable person not directly associated with the program, rather than the respiratory protection administrator. An audit checklist should be prepared and updated as necessary. The audit program should focus, as a minimum, on the following areas:

- program administration;

- training;

- medical evaluation;

- fit testing;

- air sampling/classification of hazard;

- selection and issuance;

- use;

- equipment cleaning, maintenance, and inspection;

- breathing air supplies;

- storage;

- emergency preparedness;

- special problems.

When applicable, medical surveillance, including bioassay shall be carried out periodically to determine if respirator wearers are adequately protected. An occupational health professional shall determine the requirements of the medical surveillance program.

Action shall be taken to correct any defects or shortcomings found during the audit. Findings shall be documented, including plans to correct problem areas and target dates for completion."

\section{REQUIREMENT SOURCE: ANSI-Z88.2-1992 Section 6.a}

"Operating procedures for routine use: Written standard operating procedures shall cover a complete respirator program and shall include information necessary for the proper use of respirators, including, as a minimum:

1) training of wearers;

2) fit tests; 
3) issuance;

4) cleaning, storage, and maintenance;

5) inspection;

6) monitoring use;

7) monitoring hazards;

8) selection;

9) company policies."

\section{REQUIREMENT SOURCE: DOE1324.2A Attachment V-1, Section 4.c}

"Records and investigations establishing the extent of employee exposure to toxic chemicals and materials. These records should be filed in the Health Hazard case file (item 6, below), wherever possible.

Destroy when 75 years old. NCI-430-76-9(5)"

\section{REQUIREMENT SOURCE: DOE1324.2A Attachment V-1, Section 4.d}

"Industrial hygiene logsheets recording surveys for industrial hazards other than radiation and contamination.

(1) Surveys indicating no industrial hazard. - Destroy when 75 years old. NCI-430-76-9(5)

(2) Surveys indicating a potential industrial hazard. - Until related facility is dismantied. NCI-430-76-9(5)"

$\underline{19.3 .1}$

$\underline{19.3 .2}$

$\underline{19.3 .3}$

19.4

\section{Hazard Monitoring, Sampling, and Surveillance}

Requirements for this subelement are contained in the facility specific S/RID.

\section{Hazard Controls}

Requirements for this subelement are contained in the facility specific S/RID.

\section{Safety Inspection and Maintenance}

\section{REQUIREMENT SOURCE: DOE5700.6C Section 9.b(2)(a)}

"Performance

Criterion 5 - Work Processes

Work shall be performed to established technical standards and administrative controls. Work shall be performed under controlled conditions using approved instructions, procedures, or other appropriate means. Items shall be identified and controlled to ensure their proper use. Items shall be maintained to prevent their damage, loss, or deterioration. Equipment used for process monitoring or data collection shall be calibrated and maintained."

\section{OCCUPATIONAL HEALTH PROGRAM}

The Hanford Environmental Health Foundation (HEHF) is a primary provider of medical services to the Hanford Site. Requirements applicable to medical activities are contained in HEHF specific documents. 
19.4 .1

$\underline{19.4 .2}$

$\underline{19.4 .3}$

19.4 .4

$\underline{19.4 .5}$

19.4 .6

$\underline{19.4 .7}$

$\underline{19.4 .8}$

19.5

19.6

$\underline{19.6 .1}$

\section{Health Examinations}

This subelement defines when WHC employees are required to have medical examinations. These requirements are located in the facility specific S/RID.

\section{Health Maintenance and Preventive Medicine}

This subelement addresses WHC employee immunization requirements. The Employee Assistance Program (EAP) is under the direction of HEHF.

\section{Diagnosis and Treatment}

Diagnosis and Treatment requirements are under the direction of HEHF.

Fitness for Duty

Fitness for duty requirements are under the direction of HEHF.

Medical Facilities and Equipment

This subelement does not apply to WHC.

Professional Development of Occupational Staff

This subelement does not apply - WHC doe not maintain the medical staff (HEHF).

Health Records and Reporting

Author's Note: All medical records are maintained by HEHF.

Medical Staffing

This subelement does not apply - WHC does not maintain the medical staff (HEHF).

OCCUPATIONAL SAFETY AND HEALTH TRAINING

RECORDKEEPING AND REPORTING

Occupational Iniury and Illness Reporting

Author's Note: Requirements for CFR 1910.20 and 1926.33 address employee exposure and medical records for both the construction and industrial hygiene program.

WHC Occupational Heaith and Safety Programs retains records per letter from Secretary of Energy dated March 26, 1990, placing a moratorium on all exposure records.

\section{REQUIREMENT SOURCE: 29CFR1904 Part 2}

"Log and summary of occupational injuries and illnesses.

(a) Each employer shall, except as provided in paragraph (b) of this section, (1) maintain in each establishment a log and summary of all recordable occupational injuries and illnesses for 
that establishment; and (2) enter each recordable injury and iliness on the log and summary as early as practicable but no later than 6 working days after receiving information that a recordable injury or illness has occurred."

\section{REQUIREMENT SOURCE: 29CFR1904 Part 3}

"Records shall be established on a calendar year basis."

\section{REQUIREMINT SOURCE: 29CFR1904 Part 5(a)}

"Each employer shall post an annual summary of occupational injuries and illnesses for each establishment. This summary shall consist of a copy of the year's totals from the form OSHA No. 200 and the following information from that form: Calendar year covered, company name establishment name, establishment address, certification signature, title, and date. A form OSHA No. 200 shall be used in presenting the summary. If no injuries or illnesses occurred in the year, zeros must be entered on the totals line, and the form must be posted."

\section{REQUIREMENT SOURCE: 29CFR1904 Part 6}

"Records provided for in $\$ \$ 1904.2,1904.4$, and $1904.5 \ldots$ shall be retained in each establishment for 5 years following the end of the year to which they relate."

\section{REQUIREMENT SOURCE: 29CFR1904 Part 7(b)(1)}

"The log and summary of all recordable occupational injuries and illnesses... provided for in $\$ 1904.2$ shall, upon request, be made available by the employer to any employee, former employee, and to their representatives for examination and copying in a reasonable manner and at reasonable times. The employee, former employee, and their representatives shall have access to the $\log$ for any establishment in which the employee is or has been employed."

\section{REQUTREMENT SOURCE: 29CFR1910 Part 20(d)(1)(ii)}

"Employee exposure records. Each employee exposure record shall be preserved and maintained for at least thirty (30) years, except that:

(A) Background data to environmental (workplace) monitoring or measuring, such as laboratory reports and worksheets, need only be retained for one (1) year as long as the sampling results, the collection methodology (sampling plan), a description of the analytical and mathematical methods used, and a summary of other background data relevant to interpretation of the results obtained, are retained for at least thirty (30) years; and

(B) Material safety data sheets and paragraph (c)(5)(iv) records concerning the identity of a substance or agent need not be retained for any specified period as long as some record of the identity (chemical name if known) of the substance or agent, where it was used, and when it was used is retained for at least thirty (30) years; and

(C) Biological monitoring results designated as exposure records by specific occupational safety and health standards shall be preserved and maintained as required by the specific standard." 


\section{REQUIRTMENT SOURCE: 29CFR1910 Part 20(d)(1)(iii)}

"Analyses using exposure or medical records. Each analysis using exposure or medical records shall be preserved and maintained for at least $(30)$ years."

\section{REQUIREMENT SOURCE: 29CFR1910 Part 20(e)(1)(i)}

"Access to records --

General.

Whenever an employee or designated representative requests access to a record, the employer shall assure that access is provided in a reasonable time, place, and manner. If the employer cannot reasonably provide access to the record within fifteen (15) working days, the employer shall within the fifteen (15) working days apprise the employee or designated representative requesting the record of the reason for the delay and the earliest date when the record can be made available."

\section{REQUIREMENT SOURCE: 29CFR1910 Part 20(e)(1)(ii)}

"The employer may require of the requester only such information as should be readily known to the requester and which may be necessary to locate or identify the records being requested (e.g., dates and locations where the employee worked during the time period in question)."

\section{REQUIREMENT SOURCE: 29CFR1910 Part 20(e)(1)(iii)}

"Whenever an employee or designated representative requests a copy of a record, the employer shall assure that either:

(A) Copy of the record is provided without cost to the employee or representative,

(B) The necessary mechanical copying facilities (e.g., photocopying) are made available without cost to the employee or representative for copying the record, or

(C) The record is loaned to the employee or representative for a reasonable time to enable a copy to be made."

\section{REQUIREMENT SOURCE: 29CFR1910 Part 20(e)(2)(i)A}

"Employee and designated representative access-Employee exposure records.

Except as limited by paragraph $(f)$ of this section each employer shall, upon request, assure the access to each employee and designated representative to employee exposure records relevant to the employee. For the purpose of this section an exposure record relevant to the employee consists of:"

\section{REQUTREMIENT SOURCE: 29CFR1910 Part 20(e)(2)(iii)A}

"Employee medical records. Each employer shall upon request assure the access of each employee to employee medical records of which the employee is the subject except as provided in paragraph $(e)(2)(i i)(D)$ of this section." 


\section{REQUIREMINT SOURCE: 29CFR1910 Part 20(e)(2)(iii)B}

"Whenever access is requested to an analysis which reports the contents of employee medical records by either direct identifier (name address, social security number, payroll number, etc.) or by information which could reasonably be used under the circumstances indirectly to identify specific employees (exact age height, weight race, sex, date of initial employment, job title, etc.), the employer shall assure that personal identifiers are removed before access is provided. If the employer can demonstrate that removal of personal identifiers from an analysis is not feasible access to the personally identifiable portions of the analysis need not be provided."

\section{REQUIREMENT SOURCE: 29CFR1910 Part 20(e)(3)(i)}

"OSHA access. Each employer shall upon request, and without derogation of any rights under the Constitution or the Occupational Safety and Health Act of 197029 U.S.C. 651 et seq. that the employer chooses to exercise, assure the prompt access of representatives of the Assistant Secretary of Labor for Occupational Safety and Health to employee exposure and medical records and to analyses using exposure or medical records. Rules of agency practice and procedure governing OSHA access to employee medical records are contained in 29 CFR 1913.10."

\section{REQUIREMENT SOURCE: 29CFR1910 Part 20(g)(1)}

"Employee information. Upon an employee's first entering into employment and at least annually thereafter, each employer shall inform current employees covered by this section of the following:

(i) The existence location, and availability of any records covered by this section;

(ii) The person responsible for maintaining and providing access to records; and

(iii) Each employee's rights of access to these records."

\section{REQUIREMENT SOURCE: 29CFR1910 Part 20(h)(1)}

"Transfer of records. Whenever an employer is ceasing to do business the employer shall transfer all records subject to this section to the successor employer. The successor employer shall receive and maintain these records."

\section{REQUIREMENT SOURCE: 29CFR1910 Part 134(b)(1) and (2)}

"Requirements for a minimal acceptable program.

(1) Written standard operating procedures governing the selection and use of respirators shall be established.

(2) Respirators shall be selected on the basis of hazards to which the worker is exposed."

\section{REQUIREMENT SOURCE: DOE5483.1A Chapter I, Section 5.d}

"All contractor employees shall be informed that the contractor is required to monitor the employee's workplace for radiation exposure and known toxic materials or harmful physical agents which are used or produced at the GOCO facility, and to maintain records of the data as required by Titie 29 CFR Part 1910.20, "Access to Employee Exposure and Medical Records. " Employees or their authorized representatives are to be provided with an 
opportunity to observe monitoring or measuring for toxic materials and harmful physical agents and to have access to the results thereof. Each employee or former employee or representative thereof, within 15 days of a written request, shall be provided access to or copies of any records of cumulative recorded occupational radiation dose or any monitoring or bioassay records relevant to potential exposure to toxic materials or harmful physical agents during employment. Employees will be notified of any information indicating that a radiation dose or an exposure to toxic materials or harmful physical agents may have exceeded the limits specified by the DOE-prescribed OSHA standards."

\section{REQUIREMENT SOURCE: DOE5483.1A Chapter III, Section 2}

Author's Note: c. applies to facilities not company.

\section{"RECORDKEEPING.}

a. Contractors subject to the provisions of DOE PR 9-50.704-2(a) shall be responsible for recording and reporting recordable occupational illnesses and injuries, as required by DOE 5484.1, ENVIRONMENTAL PROTECTION, SAFETY, AND HEALTH PROTECTION INFORMATION REPORTING REQUIREMENTS, of 2-24-81.

b. All contractors shall be responsible for maintaining records of employees exposures to toxic materials or harmful physical agents as appropriate. Such records shall be maintained in perpetuity.

c. A central file of all violations of DOE-prescribed OSHA standards noted during inspections (and abatement actions) shall be maintained by field organizations. A central file also shall be maintained by the field organizations of formal employee safety and health complaints and their disposition. Upon request, any of these safety and health violation or complaint-related records shall be made available for review by employees directly affected by such information, or by their authorized representatives. DOE 1324.1, RECORDS DISPOSITION, of 5-28-80, Attachment IV, DOE Records Schedule 25, paragraph $1 \mathrm{~b}$, specifies the retention period for these records.

d. DOE contractors subject to the provisions of DOE PR 9-50.704-2(a) shall respond to requests for injury/illness recordkeeping information from the U.S. Department of Labor, Bureau of Labor Statistics, or the Bureau's cooperating State agencies, as appropriate. The information shall be returned to the requestor on OSHA Form 200-S (included with the request) in accordance with the instructions accompanying the request, and a copy thereof shall be provided to the safety and health director of the field organization. The contractor shall include a statement on the OSHA Form 200-S which states: "With respect to work performed under contract with the DOE at (name of contractor and/or GOCO facility) this employer is not subject to the Occupational Safety and Health Act of 1970, under section $4(\mathrm{~b})(1)$ of that Act." "

\section{REQUIREMENT SOURCE: DOE5483.1A Chapter III, Section 3}

\section{"3. POSTING.}

a. Each DOE contractor shall post DOE Forms 5480.2 and 5480.3 or DOE Forms EV-632 and EV-632S, as appropriate, and include the information specified.

b. Each year, from 2-1 until 3-1, DOE contractors subject to the provisions of DOE PR 9-50.704-2(a) shall post a completed DOE Form EV-102A. 
$\underline{19.6 .2}$

19.7

19.7.1

19.7 .2

$\underline{19.7 .3}$

19.7 .4

$\underline{19.7 .5}$ c. The required forms shall be posted in a sufficient number of places to permit contractor employees working in or frequenting any portion of the GOCO facility to observe the information on the way to or from their place of employment."

\section{Occurrence Reporting}

These requirements are completely addressed with the Management Systems Functional Area.

\section{KEY INTERFACES}

Information relating to occupational injuries/illnesses, exposure data, accident investigations, etc. must be provided in support of this function.

\section{Maintenance}

The facility specific Maintenance functional area provides exposure records and/or accident/illness records to the WHC Occupational Safety and Health organization. The Maintenance Functional Area interfaces and complies with the Facility Specific Occupational Safety and Health Programs and requirements.

\section{Operations}

The Operations Organization depends on the controls outlined in the Facility Specific Health and Safety documents in order to operate safely. The facility specific operations functional area provides exposure records and/or accident/illness records to the WHC Occupational Safety and Health organization.

Workplace hazard identification and assessment is accomplished through walkdown inspections, surveys, monitoring and surveillance. Based upon the hazards identified the necessary controls are defined and implemented to ensure safe operations. The Operations Organization should work closely with the Occupational Safery and Health Program on all routine and non-routine operations.

\section{Radiation Protection}

Personnel working in radiological controlled areas must adhere to all ALARA policies and OSHA controls. The Radiation Protection Functional Area must coordinate all routine and non-routine activities with the OSH Program.

\section{Training and Qualification}

The training organization shall properly document all health and safety training provided and maintain all such documentation in accordance with established procedures.

\section{Construction Program}

Information relating to facility occupational safety and health injuries/iliness, exposure data, accident investigations, etc. must be provided in support of this function. 
Westinghouse Hanford Company (WHC)

Standards/Requirements Identification Document

WHC-SD-MP-SRID-002

January 10, 1996

Rev. 0

19.0 Occupational Safety and Health

Page 17 of 18

$\underline{19.7 .6}$

19.8

$\underline{19.8 .1}$

19.8 .2
Eire Protection

The Hanford Fire Department provides SCBA maintenance and testing for the Occupational Safety and Health organization as well as the site.

\section{REFERENCES}

\section{Requirement Source Documents}

Documents reviewed and incorporated for Regulatory Requirements and Industry Accepted Good Practices:

29 CFR 1904, Recording and Reporting of Occupational Injury and Illness, 07/01/94

29 CFR 1910, Occupational Safety and Health Standards, 07/01/93

Federal Register, Vol. 54 No. 16, Thursday, January 26, 1989/Notices, Department of Labor, Occupational Safety and Health Administration, Issuance of Voluntary Guidelines

WAC 296-45, Safety Standards - Electrical Workers, 6/30/89

DOE Order 5480.10 Subject: Contractor Industrial Hygiene Program, 06/26/85

DOE Order 5483.1A Subject: Occupational Safety and Health Program for DOE Contractor Employees at Government-Owned Contractor-Operated Facilities, 06/22/83

ANSI-Z88.2-1992, American National Standard for Respiratory Protection, 08/06/92

DOE Order 1324.2A, Records Disposition, 04/09/92

DOE Order 5700.6C, Quality Assurance, 08/21/91

\section{Reviewed Documents Not Used as Requirement Sources}

The following documents were reviewed as requirement sources but were not used in the development of this Standards/Requirements Identification Document:

29 CFR 1926, Locking and Tagging of Circuits, 07/01/94

DOE Order 5480.9 Subject: Construction Safety and Health Program, 04/13/94

DOE Order 5480.8A Subject: Contractor Occupational Medical Program, 06/26/92

DOE Order 5480.20A Subject: Personnel Selection, Qualification, Training, and Staffing Requirements at DOE Reactor and Non-Reactor Nuclear Facilities, 11/15/94

DOE Order 5484.1 Subject: Environmental Protection, Safety and Health Protection Information Reporting Requirements, 02/24/81

DOE-RL-92-36, Hanford Site Hoisting and Rigging Manual, 01/93

DOE/EH 0135, Criteria for Technical Safety Appraisals, 06/90 
WAC Washington Administrative Code, Industrial Safety and Health Standards, 06/93

RLID 5480.29, Employee Concerns Management Systems, 12/12/93

RLIP 5480.4C, Environmental Protection, Safety, and Health Protection Standards for RL, $11 / 06 / 92$

DOE-STD-92, Guide to Good Practices for Lockouts and Tagouts, United States Department of Energy, 11/92

ANSI Z244.1-1982, American National Standards Institute, American National Standard for personnel protection, lockout/tagout of energy sources, minimum safety requirements, approved 03/08/82

Edison Electric Institute Guide to Effective Drug and Alcohol/Fitness for Duty Policy Development, 08/85 


\section{TABLE OF CONTENTS}

20.0 ENVIRONMENTAL PROTECTION $\ldots \ldots \ldots \ldots \ldots \ldots \ldots \ldots \ldots \ldots \ldots \ldots \ldots \ldots$

20.1

20.2

20.2.1

20.2.2

20.2.3

20.2.4

20.3

20.3.1

20.4

20.5

20.6

20.6.1

20.6.2

20.7

20.7.1

20.7 .2

20.7 .3

20.8

20.8.1

20.8.2
ENVIRONMENTAL POLICY MANAGEMENT $\ldots \ldots \ldots \ldots \ldots \ldots$

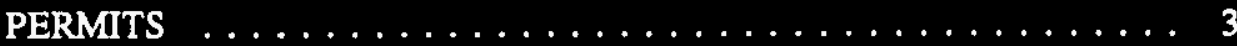

National Pollution Discharge Elimination System . . . . . . . 3

Stormwater Discharge . . . . . . . . . . . . . . 4

Clean Air Permits . . . . . . . . . . . . . . . . . . 4

RCRA TSD Facility Permits $\ldots \ldots \ldots \ldots \ldots \ldots \ldots$

ENVIRONMENTAL MONITORING, SURVEILLANCE AND

INSPECTIONS $\ldots \ldots \ldots \ldots \ldots \ldots \ldots \ldots \ldots$

Groundwater Monitoring $\ldots \ldots \ldots \ldots \ldots$

ENVIRONMENTAL CONTROL STANDARDS . . . . . . . . . 10

POLLUTION PREVENTION $\ldots \ldots \ldots \ldots \ldots \ldots$

RECORDKEEPING, REPORTS AND NOTIFICATIONS . . . . . . . 14

Incident Investigation and Reporting $\ldots \ldots \ldots \ldots \ldots \ldots$

Reporting Requirements . . . . ............ 15

KEY INTERFACES $\ldots \ldots \ldots \ldots \ldots \ldots \ldots \ldots \ldots \ldots$

Waste Management . . . . . . . . . . . . . . . 18

Emergency Management $\ldots \ldots \ldots \ldots \ldots \ldots \ldots \ldots$

Radiation Protection . . . . . . . . . . . . .... 19

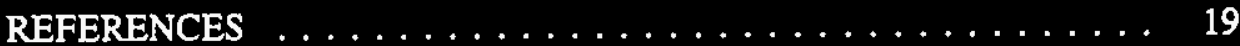

Requirement Source Documents . . . . . . . . . . . . . . . 19

Reviewed Documents Not Used as Requirement Sources . . . . 20 
This pege intentionally left blenk. 


\subsection{ENVIRONMENTAL PROTECTION}

\section{NTRODUCTION}

A Standards/Requirements Identification Document (S/RID) sets forth the Environmental Safety and Health (ES\&H) standards/requirements. This S/RID is applicable to the appropriate life cycle phases of design, construction, operation, and decommissioning for each of the categories of facilities addressed in Revision 5 of the Department of Energy Implementation Plan for the Defense Nuclear Facilities Safety Board (DNFSB) Recommendation 90-2. This Recommendation calls for the strengthening of DOE weapons complex activities through the identification and application of relevant DOE Orders, regulations, industry codes/standards, industry guidance documents and, as appropriate, good industry practices. These standards/requirements are adequate to ensure protection of the health and safety of workers, the public, and the environment.

The Westinghouse Hanford Company S/RID, as defined in Revision 5 of the Department of Energy Implementation Plan for DNFSB Recommendation 90-2, contains standards/requirements applicable company-wide that are necessary for safe operation of the site and its associated facilities, and that are not the direct responsibility of a specific facility manager (e.g., a company-wide fire department). Facility S/RIDs contain standards/requirements applicable to a specific facility that are the direct responsibility of the facility manager.

This S/RID defines the Westinghouse Hanford Company (WHC) Environmental Protection (EP) program in place at Hanford. The EP program defined in this document is described in general accordance with the Environmental, Safety, and Health (ES\&H) Configuration Guide, Revision 0, dated July 30,1993 , and is presented in the form of program elements and subelements. The specific DOE Orders, regulations, industry codes/standards, guidance documents and good industry practices which serve as the basis for each element/subelement are identified and aligned with each subelement.

\section{SCOPE}

The scope of the EP Functional Area encompasses those requirements necessary to ensure compliance with applicable environmental laws and regulations. It also includes additional requirements which further prevent, reduce, or control, to the extent practicable, environmental impact by DOE operations. The EP Functional Area includes the requirements to protect environmental media, biota, and cultural and natural resources. By preventing, reducing, and controlling environmental impacts, hazardous exposures to personnel and the public are also prevented, reduced or controlled.

This Functional Area is divided into elements to aid in identifying and categorizing applicable environmental requirements in accordance with the structure outlined in the ES\&H Configuration Guide. The elements described are not necessarily environmental protection programs--they provide categories of identified requirements from which environmental protection activities are implemented. The contents of this company S/RID are representative of WHC Environmental Services functional charter which includes supporting the following activities:

- Site-Wide Air Operating Permit

- Hanford Facility Permit (RCRA Part B) 
- Site-Wide Reporting

- Interpretations of EP Policy, Regulations, DOE Orders, etc.

Additionally, requirements have been identified and included which involve interface with the Pollution Prevention and Hanford Technical Services organizations. These requirements are recognized here as responsibilities beyond the functional charter of the WHC Environmental Services organization, but within the scope of the WHC EP S/RID. Some requirements contained in this document may be intentionally duplicated in facility S/RIDs. This was necessary to capture implementation responsibilities occurring at both the company and facility level. 
Author's Note: No requirements for which WHC has direct responsibility for implementation, were identified relative to this element.

\section{2 .1}

\section{PERMITS}

\section{National Pollution Discharge Dlimination System}

Author's Note: Specific conditions can be found in "Authorization to Discharge under the National Pollutant Discharge Elimination System", Permit NO. WA000374-3.

The EPA has not delegated authority to Washington State to issue NPDES permits to federal facilities. Therefore, the EPA is the permitting authority for the Hanford Site and the federal NPDES regulations are applicable.

\section{REQUIREMENT SOURCE: 40CFR122 Part 21(a)}

"Application for a permit (applicable to State programs, see $\$ 123.25$ ). Duty to apply. Any person who discharges or proposes to discharge pollutants or who owns or operates a "sludge-only facility" and who does not bave an effective permit, except persons covered by general permits under $\S 122.28$, excluded under $\$ 122.3$, or a user of a privately owned treatment works unjess the Director requires otherwise under $\$ 122.44(\mathrm{~m})$, shall submit a complete application (which shall include a BMP program if necessary under 40 CFR 125.102) to the Director in accordance with this section and part 124."

\section{REQUIREMENT SOURCE: 40CFR122 Part 21(d)(3)(i)}

"All applicants for EPA-issued permits, other than POTWs, new sources, and "sludge-only facilities," must complete Forms 1 and either $2 \mathrm{~b}$ or $2 \mathrm{c}$ of the consolidated permit application forms to apply under $\S 122.21$ and paragraphs $(f)$, $(g)$, and $(\mathrm{h})$ of this section."

\section{REQUIREMENT SOURCE: 40CFR122 Part 26(a)(6)}

"Non-municipal separate storm sewers. For storm water discharges associated with industrial activity from point sources which discharge through a non-municipal or non-publicly owned separate storm sewer system the Director, in his discretion, may issue: a single NPDES permit with each discharger a co-permittee to a permit issued to the operator of the portion of the system that discharges into waters of the United States; or individual permits to each discharger of storm water associated with industrial activity through the non-municipal conveyance system.

(i) All storm water discharges associated with industrial activity that discharge through a storm water discharge system that is not a municipal separate storm sewer must be covered by an individual permit or a permit issued to the operator of the portion of the system that discharges to waters of the United States with each discharger to the non-municipal conveyance a co-permittee to that permit.

(ii) Where there is more than one operator of a single system of such conveyances all operators of storm water discharges associated with industrial activity must submit applications. 
(iii) Any permit covering more than one operator shall identify the effluent limitations or other permit conditions, if any, that apply to each operator."

\section{REQUIREMENT SOURCE: 40CFR122 Part 26(a)(7)}

"Combined sewer systems. Conveyances that discharge storm water runoff combined with municipal sewage are point sources that must obtain NPDES permits in accordance with the procedures of $\mathbf{1 2 2 . 2 1}$ and are not subject to the provisions of this section."

\section{REQUIREMIENT SOURCE: 40CFR122 Part 26(a)(8)}

"Whether a discharge from a municipal separate storm sewer is or is not subject to regulation under this section shall have no bearing on whether the owner or operator of the discharge is eligible for funding under title II title III or title VI of the Clean Water Act. See 40 CFR part 35 subpart I, appendix $A(b) H .2 . j$."

\section{REQULREMENT SOURCE: 40CFR122 Part 41(a) Introduction}

"Duty to comply. The permittee must comply with all conditions of this permit. Any permit noncompliance constitutes a violation of this permit. Any permit noncompliance constitutes a violation of the Clean Water Act and is grounds for enforcement action; for permit termination, revocation and reissuance, or modification; or denial of a permit renewal application."

\section{REQUTREMENT SOURCE: 40CFR122 Part 41(a)(1)}

"The permittee shall comply with effluent standards or prohibitions established under section 307(a) of the Clean Water Act for toxic pollutants and with standards for sewage sludge use or disposal established under section 405(d) of the CWA within the time provided in the regulations that establish these standards or prohibitions or standards for sewage sludge use or disposal, even if the permit has not yet been modified to incorporate the requirement."

\section{Stormwater Discharge}

Author's Note: Specific conditions can be found in "Authorization to Discharge under the National Pollutant Discharge Elimination System for Stormwater Discharges Associated with Construction Activities", Permit NO. WAR-00-000F, September 9, 1992, and "Authorization to Discharge under the National Pollutant Discharge Elimination System for Stormwater Discharges Associated with Industrial Activity", Permit NO. WAR-10-000F, September 9, 1992.

\section{Clean Air Permits}

Author's Note: DOE/RL-95-07, "Hanford Site Air Operating Permit Application," dated May 25,1995 , has been filed with DOH/ECOLOGY. This permit application imposes commitments WHC, and other contractors on the Hanford Site also included in the application, intend to perform. The contents of this application may be revised during the permitting process. Therefore, individual requirements are not listed until final issuance of the permit (anticipated end of FY97). 


\section{REQUIREMENT SOURCE: WAC-173-401 Section 500(3)}

"Duty to apply. For each chapter 401 source, the owner or operator shall submit a timely and complete permit application in accordance with this section. Whenever practicable, the applicant shall utilize methods provided by the permitting authority for electronic transmission of the completed application.

(a) Existing chapter 401 sources. Chapter 401 sources in existence on the date of EPA approval of the state permit program shall submit permit applications no later than one hundred eighty days after EPA approval of the state permitting program.

(b) Existing sources becoming chapter 401 sources due to future regulations. An existing source may become subject to the operating permit program as a result of regulations promulgated after EPA approval of the state permit program. For those sources, a complete application must be submitted within twelve months from the time that the source becomes subject to the permit program.

(c) New or modified sources. New or modified chapter 401 sources which commence operation after EPA approval of the state operating program shall file a complete application to obtain the chapter 401 permit or permit revision within twelve months after commencing operation. Where an existing chapter 401 permit would prohibit such construction or change in operation, the source must obtain a permit revision before commencing operation. The applicant may elect to integrate procedures for new source review and operating permit issuance as described in subsection (10) of this section.

(d) Permit renewal. For purposes of permit renewal, a timely application is one that is submitted at the time specified in WAC 173-401-710.

(e) Applications for initial phase II acid rain permits shall be submitted to the permitting authority by January 1, 1996, for sulfur dioxide, and by January 1, 1998, for nitrogen oxides."

\section{REQUIREMENT SOURCE: WAC-173-401 Section 605(1)}

"Emission standards and limitations. General. Each permit shall contain emission limitations and standards, including those operational requirements and limitations that assure compliance with all applicable requirements at the time of permit issuance."

\section{REQUTREMENT SOURCE: WAC-173-401 Section 605(2)}

"Alternative emission limits. If the Washington state implementation plan allows a determination of an alternative emission limit at a chapter 401 source, equivalent to that contained in the plan, to be made in the permit issuance, renewal, or significant modification process, the permitting authority may elect to use such process. Any permit containing such equivalency determination shall contain provisions to ensure that any resulting emissions limit has been demonstrated to be quantifiable, accountable, enforceable, and based on replicable procedures."

\section{REQUIREMENT SOURCE: WAC-173-401 Section 722(1)(a)}

"General. A chapter 401 source is authorized to make the changes described in this section without a permit revision, providing the following conditions are met:

(i) The proposed changes are not Title I modifications; 
(ii) The proposed changes do not result in emissions which exceed those allowable under the permit, whether expressed as a rate of emissions, or in total emissions;

(iii) The proposed changes do not alter permit terms that are necessary to enforce limitations on emissions from units covered by the permit; and

(iv) The facility provides the administrator and the permitting authority with written notification at least seven days prior to making the proposed changes except that written notification of a change made in response to an emergency shall be provided as soon as possible after the event."

\section{REQUIREMENT SOURCE: WAC-173-401 Section 722(2)}

"Section 502 (b)(10) changes. Pursuant to the conditions in subsection (1) of this section, a chapter 401 source is authorized to make section 502 (b)(10) changes (as defined in WAC $173-401-200(28)$ ) without a permit revision.

(a) For each such change, the written notification required under subsection (1)(a)(iv) of this section shail include a brief description of the change within the permitted facility, the date on which the change will occur, any change in emissions, and any permit term or condition that is no longer applicable as a result of the change.

(b) The permit shield authorized under WAC 173-401-640 shall not apply to any change made pursuant to this paragraph."

\section{REQUIREMENT SOURCE: WAC-173-401 Section 724(1)}

"Off-permit changes. The source shall be allowed to make changes not specifically addressed or prohibited by the permit terms and conditions without requiring a permit revision, provided that the proposed changes do not weaken the enforceability of existing permit conditions. Any change that is a Title I modification or is a change subject to the acid rain requirements under Title IV of the FCAA must be submitted as a permit revision."

\section{REQUIREMENT SOURCE: WAC-173-401 Section 725(2)(f)}

"Source's ability to make change. The source may make the change proposed in its minor permit modification application immediately after it files such application provided that those changes requiring the submissions of a notice of construction application have been reviewed and approved by the permitting authority. After the source makes the change allowed by the preceding sentence, and until the permitting authority takes any of the actions specified in (d) of this subsection, the source must comply with both the applicable requirements governing the change and the proposed permit terms and conditions. During this time period, the source need not comply with the existing permit terms and conditions it seeks to modify. However, if the source fails to comply with its proposed permit terms and conditions during this time period, the existing permit terms and conditions it seeks to modify may be enforced against it."

\section{REQUREMENT SOURCE: WAC-173-401 Section 725(4)(a)}

"Significant modification procedures. Criteria. Significant modification procedures shall be used for applications requesting permit modifications that do not qualify as minor permit modifications or as administrative permit amendments. Every significant change in existing monitoring permit terms or conditions and every relaxation of reporting or recordkeeping permit terms or conditions shall be considered significant. Nothing herein shall be construed 
to preclude the permittee from making changes consistent with this chapter that would render existing permit compliance terms and conditions irrelevant."

\section{REQUREMENT SOURCE: WAC-173-401 Section 725(4)(b)}

"Significant permit modifications shall meet all requirements of this chapter, including those for applications, public participation, review by affected states, and review by EPA, as they apply to permit issuance and permit renewal. The permitting authority shall complete review on the majority of significant permit modifications within nine months after receipt of a complete application."

\section{REQUIREMENT SOURCE: WAC-246-247(940131) Section 060(7)}

"Each federal facility that comes under the authority of this chapter shall hold one license for each site, base, or installation. When applicable, the license shall be part of the facility's air operating permit."

\section{REQUIREMENT SOURCE: WAC-246-247(940131) Section 060(8)}

"Facilities may request a single categorical license which identifies limits and conditions of operation for similar multipurpose temporary and/or portable emission units. When applicable, the license shall be part of the facility's air operating permit."

\section{REQUTREMENT SOURCE: WAC-246-247(940131) Section 060(9)}

"All facilities with licensed emission units, except for radioactive materials licensees, shall submit a request to the department for renewal of their radioactive air emissions license at least sixty days prior to expiration of the license or as required by the air operating permit. All renewal requests shall include a summary of the operational status of all emission units, the status of facility compliance with the standards of WAC 246-247-040, and the status of any corrective actions necessary to achieve compliance with the requirements of this chapter. Facilities with licensed emission units that also hold a radioactive materials license issued by the department shall submit this information along with their radioactive material license renewal submittal. If the department is unable to renew a radioactive air emissions license before its expiration date, the existing license, with all of its requirements and limitations, remains in force until the department either renews or revokes the license."

Author's Note: The Hanford Facility Permit (the Permit) dictates all requirements for final starus TSD units. All operating TSD units that have not yet been incorporated into the Permit must operate pursuant to the interim status standards of WAC 173-303-400 until final status permitting is achieved. In addition, Ecology intends to incorporate closure plans for all TSD units into the Permit, even those for which final status is not sought. Therefore, although the requirements or WAC 173-303-610 are applicable to all TSD units, all closure and postclosure plan(s) that are developed must be approved by Ecology and incorporated into the Permit. Such plans must be followed as a condition of the Permit.

\section{REQUTREMENT SOURCE: TPA Attachment 2, Section 6.3, Paragraphs 1 and 2}

\section{"TREATMENT, STORAGE, AND DISPOSAL CLOSURE PROCESS}

The DOE will follow applicable Federal and State statutes, regulations and guidance documents, and written policy determinations that pertain to the closure process for TSD groups/units. 
The TSD units containing mixed waste will normally be closed with consideration of all hazardous substances, which includes radioactive constituents. Hazardous substances not addressed as part of the TSD closure may be addressed under CERCLA past-practice (CPP) authority in accordance with the process defined in Section 7.0."

\section{REQURRMINT SOURCE: WAC-173-303(940523) Section 400(2)(b)}

"Interim status facilities must meet the interim status standards by November 19, 1980, except that:

(i) Interim status facilities which handle only state designated wastes (i.e., not designated by 40 CFR Part 261) must meet the interim status standards by August 9, 1982; and

(ii) Interim status facilities must comply with the additional state interim status requirements specified in subsection (3)(c)(ii), (iii) and (v), of this section, by August 9, 1982."

REQUIREMENT SOURCE: WAC-173-303(940523) Section 610(2) and (2)(a)

"(2) Closure performance standard. The owner or operator must close the facility in a manner that:

(a)(i) Minimizes the need for further maintenance;

(ii) Controls, minimizes or eliminates to the extent necessary to protect human health and the environment, postclosure escape of dangerous waste, dangerous constituents, leachate, contaminated run-off, or dangerous waste decomposition products to the ground, surface water, ground water, or the atmosphere; and

(iii) Returns the land to the appearance and use of surrounding land areas to the degree possible given the narure of the previous dangerous waste activity."

\section{REQULREMENT SOURCE: WAC-173-303(940523) Section 610(2)(b)}

"Where the closure requirements of this section, or of WAC 173-303-630 (10), 173-303-640 (8), 173-303-650 (6), 173-303-655 (8), 173-303-660 (9), 173-303-670 (8), or 173-303-680 (2) through (4) call for the removal or decontamination of dangerous wastes, waste residues, or equipment, bases, liners, soils or other materials containing or contaminated with dangerous wastes or waste residue, then such removal or decontamination must assure that the levels of dangerous waste or dangerous waste constituents or residues do not exceed:

(i) For soils, ground water, surface water, and air, the numeric cleanup levels calculated using residential exposure assumptions according to the Model Toxics Control Act Regulations, chapter 173-340 WAC as now or hereafter amended. Primarily, these will be numeric cleanup levels calculated according to MTCA Method B, although MTCA Method A may be used as appropriate, see WAC 173-340-700 through 173-340-760, excluding WAC 173-340-745; and

(ii) For all structures, equipment, bases, liners, etc., clean closure standards shall be set by the department on a case-by-case basis in accordance with the closure performance standards of WAC 173-303-610 (2)(a)(ii) and in a manner that minimizes or eliminates post-closure escape of dangerous waste constituents." 


\section{REQUIREMENT SOURCE: WAC-173-303(944523) Section 610(7)(a)}

"Postclosure care for each dangerous waste management unit subject to postclosure requirements must begin after completion of closure of the unit and continue for thirty years after that date and must consist of at least the following:

(i) Ground water monitoring and reporting as applicable; and

(ii) Maintenance and monitoring of waste containment systems as applicable."

\section{ENVIRONMENTAL MONTTORNG, SURVEILLANCE AND INSPECTIONS}

This element addresses monitoring, surveillance, and inspection activities.

\section{REQUIREMIENT SOURCE: DOE5400.1 Chapter IV, Section 4}

"Environmental Monitoring Plans. A written environmental monitoring plan shall be prepared for each site, facility, or process that uses, generates, releases, or manages significant pollutants or hazardous materials. The plan shall contain the rationale and design criteria for the monitoring program, extent and frequency of monitoring and measurements, procedures for laboratory analyses, quality assurance requirements, program implementation procedures, and direction for the preparation and disposition of reports. The plan shall be approved by the appropriate Head of Field Organization, or his or her designee. The plan shall be reviewed annually and updated as needed. The plan shall identify and discuss two major activities: (a) effluent monitoring, and (b) environmental surveillance. The plan shall reflect the importance of monitoring as a critical element of an effective environmental protection program. The plan shall be reviewed annually and updated every 3 years."

\section{$\underline{20.3 .1}$}

\section{Groundwater Monitoring}

Groundwater Monitoring requirements for TSD interim status units are those of 40 CFR 265 , Subpart F as referenced (with changes) by WAC 173-303-400(3). Groundwater Monitoring requirements for final status units are those requirements incorporated into the Hanford Facility Permit (WA 7890008967) based upon the standards of WAC 173-303-645.

In addition, an agreement was reached in December 1991 to include all miscellaneous waste streams and/or any new waste streams discharged to the ground under the State of Washington waste discharge permit program (WAC 173-216). Some of the "216 State Waste Discharge Permit" sites also require groundwater monitoring.

\section{REQUIREMENT SOURCE: DOE5400.1 Chapter IV, Section 9}

"Groundwater Monitoring Program. Groundwater that is or could be affected by DOE activities shall be monitored to determine and document the effects of operations on groundwater quality and quantity and to demonstrate compliance with DOE requirements and applicable Federal, State, and local laws and regulations."

\section{REQUIREMENT SOURCE: DOE5400.1 Chapter IV, Section 9.a}

"Groundwater Monitoring Plans. A groundwater monitoring plan shall be developed as a specific element of all environmental monitoring plans and the Groundwater Protection Management Program required in page III-2, subparagraph 4.a. The plan shall ideatify all DOE requirements and regulations applicable to groundwater protection and include monitoring strategy. The elements of the groundwater monitoring program shall be specified (sampling 
plan, sampling, analysis, and data management), as shall the rationale or purpose for selecting these elements."

\section{REQUIREMENT SOURCE: DOE5400.1 Chapter IV, Section 9.b}

"General Requirements - Groundwater monitoring programs shall be conducted on-site and in the vicinity of DOE facilities to:

(1) Obtain data for the purpose of determining baseline conditions of groundwater quality and quantity;

(2) Demonstrate compliance with and implementation of all applicable regulations and DOE Orders;

(3) Provide data to permit the early detection of groundwater pollution or contamination;

(4) Provide a reporting mechanism for detected groundwater pollution or contamination;

(5) Identify existing and potential groundwater contamination sources and to maintain surveillance of these sources;

(6) Provide data upon which decisions can be made concerning land disposal practices and the management and protection of groundwater resources."

REQUIREMENT SOURCE: WAC-173-304 Section 490(1)

"Applicability. These requirements apply to owners and operators of landfills, piles, landspreading disposal facilities, and surface impoundments that are required to perform ground water monitoring under WAC 173-304-400."

\section{ENVIRONMINNAL CONTROL STANDARDS}

Based on the description of this element in the ES\&H Configuration Guide and current charter responsibilities, the company-level environmental control standards were combined under element 20.2, "Permits". Remaining standards are managed at the facility level.

\section{POLLUTION PREVENTION}

The requirements for implementing an Affirmative Procurement Program are cited from Executive Order 12873, "Federal Acquisition, Recycling, and Waste Prevention," in lieu of 40 CFR 248 - 250, 40 CFR 252, and 40 CFR 253.

\section{REQUTREMENT SOURCE: 40CFR262 Appendix, Item 16, Paragraph 3}

"In signing the waste minimization certification statement those generators who have not been exempted by statute or regulation from the duty to make a waste minimization certification under section 3002(b) of RCRA are also certifying that they have complied with the waste minimization requirements." 


\title{
REQUIREMENT SOURCE: 40CFR264 Part 75
}

\author{
Author's Note: Items (c) through (g) do not apply.
}

"The owner or operator must prepare and submit a single copy of a biennial report to the Regional Administrator by March 1 of each even numbered year. The biennial report must be submitted on EPA for 8700-13B. The report must cover facility activities during the previous calendar year and must include:

(a) The EPA identification number, name, and address of the facility;

(b) The calendar year covered by the report;

(c) For off-site facilities, the EPA identification number of each hazardous waste generator from which the facility received a hazardous waste during the year; for imported shipments, the report must give the name and address of the foreign generator;

(d) A description and the quantity of each hazardous waste the facility received during the year. For off-site facilities, this information must be listed by EPA identification number of each generator;

(e) The method of treatment, storage, or disposal for each hazardous waste;

(f) (Reserved)

(g) The most recent closure cost estimate under Sec. 264.142 , and, for disposal facilities, the most recent post-closure cost estimate under Sec. 264.144; and

(h) For generators who treat, store, or dispose of hazardous waste on-site, a description of the efforts undertaken during the year to reduce the volume and toxicity of waste actually achieved during the year in comparison to previous years to the extent such information is available for the years prior to 1984 .

(j) The certification signed by the owner or operator of the facility or his authorized representative."

\section{REQUIREMENT SOURCE: 42USC13101 Section 6602(b)}

"Policy. The Congress hereby declares it to be the national policy of the United States that pollution should be prevented or reduced at the source whenever feasible; pollution that cannot be prevented should be recycled in an environmentally safe manner, whenever feasible; pollution that cannot be prevented or recycled should be treated in an environmentally safe manner whenever feasible; and disposal or other release into the environment should be employed only as a last resort and should be conducted in an environmentally safe manner."

\section{REQUIREMIENT SOURCE: DO25400.1 Chapter III, Section 4.b}

"A Waste Minimization Program that will contain goals for minimizing the volume and toxicity of all wastes that are generated, with annual reductions if programmatic requirements allow. Changes in waste quantity, volume and toxicity that are achieved shall be compared with quantities generated in the previous year. The proposed methods of treatment, storage, and disposal that accomplish waste minimization that are technically and economically practicable shall be reported as appropriate. Waste minimization plans required by specific 
legislation, such as RCRA, shall be included as a part of this program plan. This plan shall be completed no later than 18 months after the effective date of this Order. The plan shall be reviewed annually and updated every 3 years."

\section{REQUIRTMINT SOURCE: DON5400.1 Chapter III, Section 4.c}

"A Pollution Prevention Awareness Program that shall be specifically identified in his or her environmental protection statement. All mission statements and project plans shall recognize a requirement for pollution prevention, where appropriate. The documented program, including elements for employee awareness through specific training, special awareness campaigns, and incentives and award programs shall be implemented. This plan shall be completed no later than 12 months after the effective date of this Order. The plan shall be reviewed annually and updated every 3 years."

\section{REQURRMENT SOURCE: EO12873 Section 402(b)}

"For the currently designated EPA guideline items, which are:

(i) concrete and cement containing fly ash;

(ii) recycled paper products;

(iii) re-refined lubricating oil;

(iv) retread tires; and

(v) insulation containing recovered materials; and for all future guideline items, agencies shall ensure that their affirmative procurement programs require that 100 percent of their purchases of products meet or exceed the EPA guideline standards unless written justification is provided that a product is not available competitively within a reasonable time frame, does not meet appropriate performance standards, or is only available at an unreasonable price."

\section{REQUIREMENT SOURCE: EO12873 Section 701}

"Contractor Operated Facilities. Contracts that provide for contractor operation of a government-owned or leased facility, awarded after the effective date of this order, shall include provisions that obligate the contractor to comply with the requirements of this order within the scope of its operations. In addition, to the extent permitted by law and where economically feasible, existing contracts should be modified."

\section{REQUIREMIENT SOURCE: E012873 Section 705}

"Recycling Programs. Each Executive agency that has not already done so shall initiate a program to promote cost effective waste prevention and recycling of reusable materials in all of its facilities. The recycling programs implemented pursuant to this section must be compatible with applicable State and local recycling requirements. Federal agencies shall also consider cooperative ventures with State and local governments to promote recycling and waste reduction in the community."

\section{REQUREMENT SOURCE: WAC-173-303(940523) Section 180}

"Before transporting dangerous waste or offering dangerous waste for transport off the site of generation, the generator shall prepare a manifest and shall follow all applicable procedures described in this section." 


\section{REQUIREMENT SOURCE: WAC-173-303(940523) Section 180(1)}

"This subsection describes the form and contents of dangerous waste manifests. 40 CFR Part 262 Appendix - Uniform Hazardous Waste Manifest and Instructions (EPA Forms 8700-22 and 8700-22A and Their Instructions) is adopted by reference. The manifest shall be EPA Form 8700-22 and, if necessary, EPA Form 8700-22A. The manifest must be prepared in accordance with the instructions for these forms, as described in the uniform manifest Appendix of 40 CFR Part 262, and in addition must contain the following information in the specified shaded items of the uniform manifest:

(a) Item D - The first transporter's telephone number must be provided in this space;

(b) Item F - If a second transporter is used, then the second transporter's telephone number must be provided in this space;

(c) Item $\mathrm{H}$ - The designated receiving facility's telephone number must be provided in this space;

(d) Item I, and R if the continuation sheet $8700-22 \mathrm{~A}$ is used - The dangerous waste number (e.g., F001, D006, WT02, P102) must be provided in this space for each corresponding waste entered and described under Item 11 , and 28 if the continuation sheet $8700-22 \mathrm{~A}$ is used. As discussed in subsection (5) of this section, dangerous waste numbers WLO1 or WL02 may be used in this space for labpacks;

(e) Item $\mathrm{O}$, (on the continuation sheet 8700-22A) - If a third transporter is used, then the third transporter's telephone number must be provided in this space; and

(f) Item $Q$, (on the continuation sheet 8700-22A) - If a fourth transporter is used, then the fourth transporter's telephone number must be provided in this space."

\section{REQUIREMIENT SOURCE: WAC-173-307 Section 030 WAC Plans Part (1)}

"(a) A written policy articulating management and corporate support for the plan and a commitment to implement planned activities and achieve established goals.

(b) The plan scope and objectives.

(c) A description of the facility type, a description of product(s) made and/or services provided, and a statement or listing of the current level(s) of production or service activity in units of measure appropriate to the industry or activity;

(d) A general overview of the processes used in production or service activities (a schematic drawing may be included);

(e) A statement providing, for the last calendar year, the total pounds of extremely hazardous waste and total pounds of dangerous waste reported on Form 4, Generator Annual Dangerous Waste Report, and, if applicable, the total pounds of toxic releases reported on Form $R$ under SARA Title III, Section 313; and

(f) A description of current reduction, recycling, and treatment activities and documentation of hazardous substance use reduction and hazardous waste reduction efforts completed prior to the first plan due date specified in WAC 173-307-050. Clearly separate the explanations of reduction activities from recycling and other management activities." 
Author's Note: Specific conditions can be found in "Authorization to Discharge under the National Pollutant Discharge Elimination System for Stormwater Discharges Associated with Construction Activity", Permit NO. WAR-00-000F, September 9, 1992, and "Authorization for Discharge under the National Pollutant Discharge Elimination System for Stormwater Discharges Associated with Industrial Activity", Permit NO. WAR-10-000F, September 9, 1992.

\section{REQUREMENT SOURCE: 40CFR302 Part 6(a)}

"Notification requirements. Any person in charge of a vessel or an offshore or an onshore facility shall, as soon as he has knowledge of any release (other than a federally permitted release or application of a pesticide) of a hazardous substance from such vessel or facility in a quantity equal to or exceeding the reportable quantity determined by this part in any 24-hour period, immediately notify the National Response Center (800) 424-8802; in Washington, D.C. (202) 426-2675."

\section{REQUIREMENT SOURCE: WAC-173-303(940523) Section 145(2)}

"Notification. Any person who is responsible for a spill or nonpermitted discharge shall immediately notify the individuals and authorities described for the following situations:

(a) For spills or discharges onto the ground or into groundwater or surface water, notify all local authorities in accordance with the local emergency plan. If necessary, check with the local emergency service coordinator and the fire department to determine all notification responsibilities under the local emergency plan. Also, notify the appropriate regional office of the department of ecology;

(b) For spills or discharges which result in emissions to the air, notify all local authorities in accordance with the local emergency plan. If necessary, check with the local emergency service coordinator and the fire department to determine all notification responsibilities under the local emergency plan. Also, in western Washington notify the local air pollution control authority, or in eastem Washington notify the appropriate regional office of the department of ecology."

\section{REQUREMENT SOURCE: WAC-173-400(930920) Section 105 Introduction}

"The owner or operator of a source shall upon notification by the director of ecology, maintain records on the type and quantity of emissions from the source and other information deemed necessary to determine whether the source is in compliance with applicable emission limitations and control measures."

\section{REQUIREMENT SOURCE: WAC-173-400(930920) Section 105(1)}

"Emission inventory. The owner(s) or operator(s) of any air contaminant source shall submit an inventory of emissions from the source each year. The inventory may include stack and fugitive emissions of particulate matter, PM10, sulfur dioxide, carbon monoxide, total reduced sulfur compounds (TRS), fluorides, lead, VOCs, and other contaminants, and shall be submitted (when required) no later than one hundred five days after the end of the calendar year. The owner(s) or operator(s) shall maintain records of information necessary to 
substantiate any reported emissions, consistent with the averaging times for the applicable standards."

\section{REQUIREMENT SOURCE: WAC-246-247(940131) Section 080(5)}

"The facility shall notify the department within twenty-four hours of any shutdown, or of any transient abnormal condition lasting more than four hours or other change in facility operations which, if allowed to persist, would result in emissions of radioactive material in excess of applicable standards or license requirements. If requested by the department, the facility shall submit a written report within ten days including known causes, corrective actions taken, and any preventive measures taken or planned to minimize or eliminate the chance of recurrence."

\section{REQUIREMENT SOURCE: WAC-246-247(940131) Section 080(11)}

"The facility shall respond in writing in a timely manner, or within a time limit set by the department. The inspection results which require the facility to implement corrective actions or any other actions so directed by the department."

\section{Reporting Requirements}

Author's Note: As used in this requirement, the term "facility" includes all buildings, structures, plants, processes, and operations on the contiguous Hanford Site under the control of the DOE.

\section{REQUIREMENT SOURCE: 40CFR370 Part 21}

Author's Note: This report is prepared for submission by RL as owner of the Hanford Site, and includes information on hazardous chemicals stored on site by all contractors under the control of $R L$. Its preparation is contingent on the availability of timely inventory information from all WHC organizations and other independent $R L$ contractors.

The State of Washington Department of Ecology prefers the submittal of a chemical list in lieu of an MSDS for each hazardous chemical, pursuant to section 370.21 (b).

"MSDS reporting.

(a) Basic requirement. The owner or operator of a facility subject to this Subpart shall submit an MSDS for each hazardous chemical present at the facility according to the minimum threshold schedule provided in paragraph (b) of 370.20 to the committee, the commission, and the fire department with jurisdiction over the facility.

(b) Alternative reporting. In lieu of the submission of an MSDS for each hazardous chemical under paragraph (a) of this section, the owner or operator may submit the following:

(1) A list of the hazardous chemicals for which the MSDS is required, grouped by hazard category as defined under $\mathbf{3 7 0 . 2}$ of this Part;

(2) The chemical or common name of each hazardous chemical as provided on the MSDS; and

(3) Except for reporting of mixtures under 370.28(a)(2), any hazardous component of each hazardous chemical as provided on the MSDS.

(c) Supplemental reporting. 
(1) The owner or operator of a facility that has submitted an MSDS under this section shall provide a revised MSDS to the committee, the commission, and the fire department with jurisdiction over the facility within three months after discovery of significant new information concerning the hazardous chemical for which the MSDS was submitted.

(2) After October 17, 1987, the owner or operator of a facility subject to this section shall . submit an MSDS for a hazardous chemical pursuant to paragraph (a) of this section or a list pursuant to paragraph (b) of this section within three months after the owner or operator is first required to prepare or have available the MSDS or after a hazardous chemical requiring an MSDS becomes present in an amount exceeding the threshold established in $370.20(\mathrm{~b})$.

(d) Submission of MSDS upon request. The owner or operator of a facility that has not submitted the MSDS for a hazardous chemical present at the facility shall submit the MSDS for any such hazardous chemical to the committee upon its request. The MSDS shall be submitted within 30 days of the receipt of such request."

\section{REQUIREMENT SOURCE: 40CFR370 Part 25(a and b)}

Author's Note: This report is prepared for submission by $R L$ as owner of the Hanford Site, and includes information on hazardous chemicals stored on site by all contractors under the control of $R L$. Its preparation is contingent on the availability of timely inventory information from all WHC organizations and other independent RL contractors.

The State of Washington Department of Ecology requires the submittal of a Tier II inventory form in lieu of the Tier I information, pursuant to section 370.25(b).

"(a) Basic requirement. The owner or operator of a facility subject to this Subpart shall submit an inventory form to the commission, the committee, and the fire department with jurisdiction over the facility. The inventory form containing Tier I information on hazardous chemicals present at the facility during the preceding calendar year above the threshold levels established in 370.20 (b) shall be submitted on or before March 1 of each year, beginning in 1988.

(b) Alternative reporting. With respect to any specific hazardous chemical at the facility, the owner or operator may submit a Tier II form in lieu of the Tier I information."

\section{REQUIREMENT SOURCE: 40CFR372 Part 30(a)}

"Reporting requirements and schedule for reporting. For each toxic chemical known by the owner or operator to be manufactured (including imported), processed, or otherwise used in excess of an applicable threshold quantity in 372.25 at its covered facility described in 372.22 for a calendar year, the owner or operator must submit to EPA and to the State in which the facility is located a completed EPA Form R (EPA Form 9350-1) in accordance with the instructions referred to in subpart $E$ of this part."

\section{REQUIREMENT SOURCE: 40CFR61 Part 94(a)}

"Compliance and Reporting

(a) Compliance with this standard shall be determined by calculating the highest effective dose equivalent to any member of the public at any off-site point where there is a residence, school, business or office. The owners or operators of each facility shall submit an annual report to both EPA headquarters and the appropriate regional office by June 30 which includes the 
results of the monitoring as recorded in DOE's Effluent Information System and the dose calculations required by 61.93 (a) for the previous calendar year."

\section{REQURREMENT SOURCE: EO12856 Section 3-304(b)}

Author's Note: This report is prepared for submission by $R L$ as owner of the Hanford Site. Compliance determinations are based on the use of toxic chemicals and required reports include all releases, transfers, and waste generation from the activities of all contractors under the control of RL. Its preparation is contingent on the availability of timely information from all WHC organizations and other independent $R L$ contractors.

"The head of each Federal agency shall comply with these provisions without regard to the Standard Industrial Classification (SIC) delineations that apply to the Federal agency's facilities, and such reports shall be for all releases, transfers, and wastes at such Federal agency's facility without regard to the SIC code of the activity leading to the release, transfer, or waste. All other existing statutory or regulatory limitations or exemptions on the application of EPCRA section 313 shall apply to the reporting requirements set forth in section 3-304(a) of this order."

\section{REQUIREMENT SOURCE: WAC-173-303(940523) Section 390(2)}

"Annual reports. The owner or operator of a facility that holds an active EPA/state identification number shall prepare and submit a single copy of an annual report to the department by March 1 of each year. The report form and instructions in the TSD Facility Annual Dangerous Waste Report - Form 5 (which may be obtained from the department) must be used for this report. In addition, any facility which ships dangerous waste off-site must comply with the annual reporting requirements of WAC 173-303-220. The annual report must cover facility activities during the previous calendar year and must include, but is not limited to the following information:

(a) The EPA/state identification number, name, and address of the facility;

(b) The calendar year covered by the report;

(c) For off-site facilities, the EPA/state identification number of each dangerous waste generator from which the facility received a dangerous waste during the year. For imported shipments, the report must give the name and address of the foreign generator;

(d) A description and the quantity of each dangerous waste the facility received during the year. For off-site facilities, this information must be listed by EPA/state identification number of each generator;

(e) The method of treatment, storage, or disposal for each dangerous waste;

(f) The most recent closure cost estimate under WAC 173-303-620 (3) (or 40 CFR 265.142 for interim status facilities), and for disposal facilities, the most recent post-closure cost estimate under WAC 173-303-620 (5) (or 40 CFR 265.144 for interim status facilities); and

(g) The certification signed in accordance with the requirements of WAC 173-303-810 (12)." 
Westinghouse Hanford Company (WHC)

Standards/Requirements Identification Document

20.0 Environmental Protection
WHC-SD-MP-SRID-002

January 10, 1996

Rev. 0

Page 18 of 23

\section{REQUIREMENT SOURCE: WAC-246-247(940131) Section 080(3)}

"The facility shall annually submit to the deparment the information requirements adopted in subsection (2) of the section, as applicable, along with the following additional information, as applicable:

(a) The results of emission measurements for those emission units subject only to periodic confirmatory measurements;

(b) Wind rose or joint frequency table;

(c) Annual average ambient temperature;

(d) Annual average emission unit gas temperature, if available; (e) Annual total rainfall;

(f) Annual average emission unit flow rate and total volume of air released during the calendar year.

If this additional information is available in another annual report, the facility may instead provide a copy of that report along with the information requirements in this subsection. Annual reports are due by June 30 for the previous calendar years's operations."

\section{REQUIREMENT SOURCE: WAC-246-247(940131) Section 080(6)}

"The facility shall file a report of closure with the department whenever operations producing emissions of radioactive material are permanently ceased at any emission chapter. The closure report shall indicate whether, despite cessation of operations, there is still a potential for radioactive air emissions and a need for an active or passive ventilation system with emission control and/or monitoring devices. If decommissioning is planned and will constitute a modification, a NOC is required, as applicable, in accordance with WAC 246-247-060."

20.7

20.7.1

$\underline{20.7 .2}$

\section{KEY INTERFACES}

This element describes key functional area interfaces including waste management, emergency management, and radiological protection. These interfaces represent areas where there is the potential for overlap of requirements, and the need for review of more than one functional area to appreciate the total program in any one functional area.

\section{Waste Management}

The EP Functional Area provides for the development and implementation of programs for protection of the environment. This program provides oversight to the Waste Management Functional Area which focuses more narrowly on the identification, characterization, and management of radioactive, mixed, and dangerous wastes.

\section{Emergency Management}

The Emergency Management Functional Area defines the emergency planning, preparedness, and response activities which are required by the various permits and plans included in the EP Functional Area. The Emergency Management Functional Area focuses on the preparation for and response to off-normal events. 


\section{Radiation Protection}

The Radiation Protection Functional Area provides the control standards with which the EP programs must comply to provide protection to human health and the environment.

\section{RTFERENCES}

\section{Bequirement Source Documents}

The following documents were used in the creation of this S/RID:

40 CFR 61, National Emission Standards for Hazardous Air Pollutants, U.S. Environmental Protection Agency, amendments as of 06/25/93

40 CFR 122, National Pollutant Discharge Elimination System Permits, U.S. Environmental Protection Agency, amendments as of 12/22/93

40 CFR 264, Standards for Owners and Operators of Hazardous Waste Treatment, Storage, and Disposal Facilities, U.S. Environmental Protection Agency, amendments effective through $12 / 06 / 95$

40 CFR 265, Interim Status Standards for Owners and Operators of Hazardous Waste Treatment, Storage, and Disposal Facilities, U.S. Environmental Protection Agency, amendments as of $09 / 19 / 94$

40 CFR 302, Designation, Reportable Quantities, and Notification Requirements for Hazardous Substances under CERCLA, U.S. Environmental Protection Agency, amendments as of 06/30/93

40 CFR 370, Hazardous Chemical Reporting: Community Right-To-Know, U.S. Environmental Protection Agency, amendments as of 12/01/95

40 CFR 372, Toxic Chemical Release Reporting: Community Right-To-Know, U.S. Environmental Protection Agency, amendments as of 12/01/95

42 USC 13101, Pollution Prevention Act of 1990, U.S. Congress, 11/05/90

DOE 5400.1, General Environmental Protection Program, DOE Order 5400.1, U.S. Department of Energy, 11/09/88

Executive Order 12856, Federal Compliance with Right-To-Know Laws and Pollution Prevention Requirements, Presidential Office; 08/03/93

Executive Order 12873, Federal Acquisition, Recycling, and Waste Prevention, Presidential Office, $58 \mathrm{FR} 54911,10 / 22 / 93$

TPA, Hanford Federal Facilities Agreement and Consent Order (Tri-Party Agreement), U.S. Department of Energy, U.S. Environmental Protection Agency, 03/01/94

WAC 173-303, Dangerous Waste Regulations, Washington Department of Ecology, 06/23/94 WAC 173-304, Minimum Functional Standards for Solid Waste Handling, amendments as of $10 / 04 / 88$ 
WAC 173-307, Plans, Washington Department of Ecology, 11/01/91

WAC 173-401, Operating Permit Regulations, Washington Department of Ecology, effective amendments as of 05/17/94

WAC 246-247, Radioactive Air Emissions, Washington State Department of Health, 01/31/94

\section{Reviewed Documents Not Used as Requirement Sources}

The following were reviewed but not used in this S/RID:

10 CFR 1021, Compliance with the National Environmental Policy Act, U.S. Department of Energy, amendments as of 04/24/92

10 CFR 1022, Compliance with Floodplain/Wetlands Environmental Review Requirements, U.S. Department of Energy, amendments as of 07/01/92

33 CFR 323, Permits for Discharges of Dredged or Fill Material into Waters of the United States, U.S. Department of the Army, 11/13/86

36 CFR 63, Determination of Eligibility for Inclusion in the National Historic Register of Historic Places, National Park Service, amendments as of 04/30/80

36 CFR 800, Protection of Historic and Cultural Properties, National Park Service, amendments as of $09 / 02 / 86$

40 CFR 6, Implementation of Procedures on the National Environmental Policy Act, U.S. Environmental Protection Agency, amendments as of 11/30/93

40 CFR 124, Procedures for Decisionmaking, U.S. Environmental Protection Agency, amendments as of $07 / 01 / 93$

40 CFR 5281, Approval of State Underground Storage Tank Programs, U.S. Environmental Protection Agency, 06/25/93

40 CFR 355, Emergency Planning and Notification, U.S. Environmental Protection Agency, 06/30/93

43 CFR 8351, Designated National Areas, U.S. Bureau of Land Management, 09/12/78

40 CFR 8352, Established Areas, U.S. Bureau of Land Management, 08/04/80

100 CFR 605, Public Law 100-605, U.S. Congress, 11/04/88

40 CFR 129, Toxic Pollutant Efiluent Standards, U.S. Environmental Protection Agency, amendments as of $07 / 01 / 92$

40 CFR 1500, National Environmental Policy Act Procedures, U.S. Environmental Protection Agency, amendments as of $07 / 01 / 91$

40 CFR 1501, National Environmental Policy Act and Agency Planning, U.S. Environmental Protection Agency, amendments as of 05/24/77 
40 CFR 1502, Environmental Impact Statement, U.S. Environmental Protection Agency, amendments as of $11 / 29 / 78$

40 CFR 1506, Other Requirements of National Environmental Policy Act, U.S. Environmental Protection Agency, 07/30/79

40 CFR 1507, Agency Compliance, U.S. Environmental Protection Agency, amendments as of $05 / 24 / 77$

16 USC 1271, Wild and Scenic Rivers Act, U.S. Congress, 10/02/68

16 USC 661-I, The Fish and Wildlife Coordination Act, U.S. Congress, 12/12/58

16 USC 1531, The Endangered Species Act of 1973, U.S. Congress, 10/13/82

16 USC 1536, Conservation Interagency Cooperation, U.S. Congress, 10/13/82

16 USC 4701, The National Historic Preservation Act of 1966, U.S. Congress, 12/20/80

33 USC 1251, The Federal Disaster Pollution Control Act, U.S. Congress, 12/27/77

42 USC 1996, The American Indian Religious Freedom Act, U.S. Congress, 08/11/78

42 USC 4321, The National Environmental Policy Act of 1969, U.S. Congress, 01/01/70

42 USC 7112, Congressional Declaration of Purpose, 08/04/77

42 USC 7671, Clean Air Act, U.S. Congress, 11/15/90

42 USC 13106, Pollution Prevention Act of 1990, U.S. Congress, 11/05/90

DOE 5400.4, Comprehensive Environmental Response Compensation and Liability Act Requirements, DOE Order 5400.4, U.S. Department of Energy, 10/06/89

DOE 5400.5, Radiation Protection of the Public and Environment, DOE Order 5400.5, U.S. Department of Energy, 02/08/90

DOE 5484.1, Environmental Protection, Safety, and Health Protection Information Reporting Requirements, DOE Order 5484.1, U.S. Department of Energy, 02/24/81

DOE 5820.2A, Radioactive Waste Management, DOE Order 5820.2A, U.S. Department of Energy, 09/26/88

DOE 5400.3, Hazardous and Radioactive Mixed Waste Program, 02/22/89

DOE 5440.1E, National Environmental Policy Act Compliance Program, DOE Order 5440.1E, U.S. Department of Energy, 11/10/92

DOE 5480.1B, Environmental Safety and Health Protection Programs for DOE Operations, DOE Order 5480.1B, U.S. Department of Energy, 09/23/86

DOE-RL-91-28, Hanford Facility Dangerous Waste Permit Application General Information, Revision 1, U.S. Department of Energy - Richland, 05/93 
Westinghouse Hanford Company (WHC)

Standards/Requirements Identification Document

20.0 Environmental Protection
WHC-SD-MP-SRID-CO2

January 10, 1996

Rev. 0

Page 22 of 23

DOE/EH-0173T, Environmental Regulatory Guide for Radiological Effluent Monitoring amid Environmental Surveillance, DOE/EH-0173T, U.S. Department of Energy, 01/91

DE 91 NM-177, Liquid Effuent Consent Order, Washington Department of Ecology, $10 / 27 / 93$

FF-01, Permit for Radioactive Airborne Emission Sources (FF-01), Washington State Department of Health, 11/19/93

WA000374, Authorization to Discharge Under the National Pollutant Discharge Elimination System, Permit No. WA000374-3, U.S. Environmental Protection Agency, 12/07/81

WAR-00-000F, Authorization to Discharge Under the National Pollutant Discharge Elimimmion System for Stormwater Discharges Associated with Construction Activity, WA-00-000F, U.S. Environmental Protection Agency, 09/09/92

WAR-10-000F, Authorization to Discharge Under the National Pollutant Discharge Elimin ion System for Stormwater Discharges Associated with Industrial Activity, WA-R-00-000F, U.S. Environmental Protection Agency, 09/09/92

FCCA-2/7/94, NESHAPS Federal Facilities Compliance Agreement, U.S. Environmental Protection Agency, 02/07/94

FFCS, Federal Facility Compliance Agreement for Radionuclide NESHAP (FFCA-2/7/94). Washington State Department of Health, 02/07/94

PSD-Z80-14, Point Source Discharge Permit No. PSD-X80-14, U.S. Environmental Protection Agency, 09/30/80

WA7890008967-HSWA, Hazardous Waste Portion of the RCRA Permit for the Treatment, Storage, and Disposal of Hazardous Waste, WA 7890008967 (RCRA-B), U.S. Environmentw Protection Agency, 08/29/94

WAC 173-8, Environmental Coordination Procedures Act of 1973, Washington Department of Ecology, 05/01/74

WAC 173-220, National Pollutant Discharge Elimination System Permit Program

WAC 173-221A, Wastewater Discharge Standards and Effluent Limitations

WAC 173-225, Federal Water Pollution Control Act - Establishment of Implementation Procedures of Application for Certification, Washington Department of Ecology, effective $12 / 16 / 73$

WAC 173-470, Washington Air Pollution Control Regulations - Ambient Air Quality Standerds for Particulate Matter, Washington Department of Ecology, 02/04/89

WAC 246-3, State Environmental Policy Act Guidelines, Washington State Department of Health, 01/01/90

WAC 246-272, On-Site Sewage System, Washington State Department of Health, 06/03/83

WAC 246-290, Public Water Supplies, Washington State Department of Health, 09/08/83 
WAC 332-41, State Environmental Policy Act Policies and Procedures, Washington State Department of Natural Resources, 12/21/92

E011593, Protection and Enhancement of the Cultural Environment, Presidential Office, $05 / 13 / 71$

EO12088, Federal Compliance with Pollution Control Standards, Presidential Office, 10/13/78

EO12114, Environmental Effects Abroad of Major Federal Actions, Presidential Office, $01 / 04 / 79$

RCRA-B(DW), Dangerous Waste Portion of the RCRA Permit for the Treatment, Storage, and Disposal of Dangerous Waste (RCRA-B), WA7890008967, Washington Department of Ecology, 08/29/95

RCW Title 15.58, Washington Pesticide Control Act, Washington State Congress, 03/01/73

RCW Title 43.21, State Environmental Policy, Washington State Congress, 07/01/70

WAC 173-160, Minimum Standards for Construction and Maintenance of Wells, Washington Department of Ecology, amendments through 04/06/88

WAC 173-200, Water Quality Standards for Ground Waters of the State of Washington, Washington Department of Ecology, effective 12/01/90

WAC 173-218, Underground Injection Control Program, Washington Department of Ecology, $03 / 30 / 84$

WAC 173-240, Submission of Plans and Reports for Construction of Wastewater Facilities, Washington Department of Ecology, 03/30/84

WAC 173-340, Cleanup Process, Washington Department of Ecology, 11/29/91

WAC 173-400, General Regulations for Air Pollution Sources, Washington Department of Ecology, amendments as of 09/15/94

WAC 173-460, Controls for New Sources of Toxic Air Pollutants, Washington Department of Ecology, effective 02/14/94

WAC 197-11, Washington State Environmental Policy Act Rules, Department of Ecology, effective 05/01/86 
This page intentionally left blank. 


\section{DISTRIBUTION SHEET}

\begin{tabular}{|c|c|c|c|c|c|}
\hline \multirow{2}{*}{$\begin{array}{l}\text { To } \\
\text { Distribution }\end{array}$} & \multirow{2}{*}{\multicolumn{3}{|c|}{$\begin{array}{l}\text { From } \\
\text { Codes and Standards Compliance }\end{array}$}} & \multicolumn{2}{|c|}{ Page 1 of 1} \\
\hline & & & & \multicolumn{2}{|c|}{ Date $3 / 13 / 96$} \\
\hline \multirow{2}{*}{\multicolumn{4}{|c|}{$\begin{array}{l}\text { Project Title/Work Order } \\
\text { Westinghouse Hanford Company (WHC) Standards Requirements } \\
\text { Identification Document (S/RID) Release }\end{array}$}} & \multicolumn{2}{|c|}{ EDT No. 614650} \\
\hline & & & & \multicolumn{2}{|c|}{ ECN No. N/A } \\
\hline \multicolumn{2}{|l|}{ Name } & $\begin{array}{c}\text { Text } \\
\text { With } \\
\text { All } \\
\text { Attac } \\
\text { h. }\end{array}$ & $\begin{array}{l}\text { Text } \\
\text { Only }\end{array}$ & $\begin{array}{l}\text { Attach. } \\
\text { / } \\
\text { Append } \\
\text { ix } \\
\text { Only }\end{array}$ & $\begin{array}{l}\text { EDT/E } \\
\text { CN } \\
\text { Only }\end{array}$ \\
\hline $\begin{array}{l}\text { J. Garcia Jr. } \\
\text { J. Jackson } \\
\text { J. M. Roberts } \\
\text { G. L. Bennett }\end{array}$ & \multicolumn{2}{|l|}{$\begin{array}{l}\text { A5-55 } \\
\text { B1-14 } \\
\text { B1-13 } \\
\text { B1-14 }\end{array}$} & $\begin{array}{l}x \\
x \\
x \\
x\end{array}$ & & \\
\hline
\end{tabular}


THIS PAGE INTENHONATKY

LEFT BLANK 